\title{
Optimization of mixing in a Chinese dome digester for tropical regions
}

\author{
Abiodun O. Jegede
}

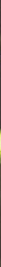




\section{Propositions}

1. Improved mixing in a conventional Chinese dome digester is needed, but addition of moveable or mechanical parts must and can be avoided. (this thesis).

2. The self-agitating mechanism in the baffled Chinese dome digester enables a substantial reduction in reactor volume.

(this thesis)

3. The sun is not only the safest nuclear reactor, but also the primary source of solar and biomass energies.

4. Intelligence and brilliance are not sufficient to meet the current thirst for innovation in science, creativity must take the driver's seat.

5. Nature has the best "factories".

6. A cent spend on prevention saves a euro on treatment.

Propositions belonging to the thesis entitled

"Optimization of mixing in a Chinese dome digester for tropical regions"

Abiodun Jegede

Wageningen, 15 October 2018 


\section{Optimization of mixing in a Chinese dome digester for tropical regions}

Abiodun O. Jegede 


\section{Thesis committee}

\section{Promotor}

Prof. Dr Grietje Zeeman

Personal chair at the sub-Department of Environmental Technology

Wageningen University \& Research

\section{Co-promotor}

Dr Harry Bruning

Assistant Professor at the sub-Department of Environmental Technology

Wageningen University \& Research

\section{Other members}

Prof. Dr K.J. Keesman, Wageningen University \& Research

Prof. Dr P.W.G. Groot Koerkamp, Wageningen University \& Research

Prof. Dr M.K. de Kreuk, Delft University of Technology

Dr. H.M. El-Mashad, Mansoura University, Egypt and University of California Davis, USA

This research was conducted under the auspices of the Graduate School for Socio-Economic and Natural Sciences of the Environment (SENSE). 


\title{
Optimization of mixing in a Chinese dome digester for tropical regions
}

\author{
Abiodun O. Jegede
}

\section{Thesis}

submitted in fulfilment of the requirements for the degree of doctor

at Wageningen University

by the authority of the Rector Magnificus,

Prof. Dr A.P.J. Mol,

in the presence of the

Thesis Committee appointed by the Academic Board

to be defended in public

on Monday 15 October 2018

at $11 \mathrm{am}$ in the Aula. 
Abiodun O. Jegede

Optimization of mixing in a Chinese dome digester for tropical regions, 158 pages.

PhD Thesis, Wageningen University, Wageningen, the Netherlands (2018)

With references and summaries in English

ISBN: https://doi.org/10.18174/458539

DOI: 978-94-6343-345-7 


\section{Table of contents}

$\begin{array}{lll}\text { Chapter } 1 & \text { General introduction } & 7\end{array}$

Chapter 2 Mixing in anaerobic digesters with a specific emphasis on 13 household digesters: A Review

Chapter 3 Effect of mixing regime on anaerobic digestion of cow manure: comparing mechanically mixed, unmixed and Chinese dome digesters

Chapter 4 Evaluation of liquid and solid phase mixing in Chinese dome digesters using Residence Time Distribution (RTD) technique

Chapter 5 Location of inlets and outlets of Chinese dome digesters to mitigate biogas emission

Chapter 6 Development of an improved Chinese dome digester enables smaller reactor volumes; pilot scale performance

Chapter 7 Simulation of the hydraulic characteristics of an improved high loaded Chinese dome digester using COMSOL Multiphysics 



\section{Chapter 1}

General introduction 


\subsection{Household energy in rural regions and household digesters}

The number of people worldwide, especially in the tropical regions that do not have access to electricity is approximately 1.5 billion, and about 2.5 billion people globally depend on traditional biomass as their main source of energy for heating and cooking (Yumkella \& Srivastava, 2010; Mungwe et al., 2016). The use of firewood as cooking fuel has several environmental and social negative effects. The collection of firewood is usually done by women and children and this activity can take many hours a day, which indirectly affects employment, education, and recreation. The use of firewood and other biomass for cooking produces hazardous particles in the smoke (Gautam et al., 2009) and is a major factor causing deforestation, erosion and climate change. The conversion of biomass to clean sources of energy in the developing nations could raise the standard of living, health, local environment and mitigate climate change (Bajgain et al., 2005).

The production and use of biogas is one of the ways to solve the problems of energy access in the rural areas of developing countries. With the use of commonly available biomass, such as dung, farm wastes, and other biodegradable waste from agricultural activities, households and communities can become more self-sufficient in energy. Biogas can be used as cooking fuel, without air pollution or used for heating and electricity production (Bajgain et al., 2005). Smallscale household biogas plants for the treatment of organic wastes are most popular in Asia. More than forty million low-cost household digesters have been built across China and India (Chanakya et al., 2005; Lansing et al., 2010; Chen et al., 2012; Rupf et al., 2015), with an estimated potential of one hundred and forty million biogas systems in the agricultural regions of China alone (Khan \& Martin, 2016). The major types of low-cost household digesters are Chinese fixed dome, Indian floating drum, Plug Flow, and the recently developed Puxin Digester (a prefabricated digester), which is a modification of the Chinese fixed dome digester (Arthur et al., 2011; Cheng et al., 2013). These are regarded as unstirred and unheated systems that are easy to maintain, making them well suitable for people living in rural areas. Their application and the type of household digester will depend on location, socio-economic context, and weather conditions (Kanwar and Guleri, 1994; Singh et al., 1997; Rupf et al., 2016).

\subsection{Chinese dome digester}

The Chinese fixed dome biogas plant is the most popular in developing countries in terms of number (Fulford, 1988; Chen et al 2010; Ghimire, 2013; Ferrer et al., 2013). It is supported by The Netherlands Development Organization (SNV) as a design of choice for most of their programs in rural areas of developing countries because of their reliability, low maintenance, and long lifespan (Ghimire, 2013). The size of domestic household biogas plants (Chinese dome digester, CDD) varies and is usually between $6-10 \mathrm{~m}^{3}$ (Adeoti 1993; Akinbami et al., 2001; Ferrer et al., 2013). Approximately 1-3 $\mathrm{m}^{3}$ of biogas per day can be generated to satisfy the cooking need of a household of about nine persons (Akinbami et al., 2001). The applied cow manure influent (approx. $50 \mathrm{~kg} /$ day) concentration is usually $7 \%$ TS or lower while the hydraulic retention time (HRT) of a mesophilic CDD is generally between 40 and 90 days (An \& Preston, 1999; Kalia, 1998; Ferrer et al., 2011;). 


\subsection{Mixing in anaerobic digesters}

Anaerobic digestion depends on mixing for the spread of fresh feed, nutrients and microorganisms; homogenization of reactor content; removal of metabolic waste, and for equal distribution of temperature inside the digester. Forced mixed reactors are mixed by different methods, viz. mechanical mixing, pneumatic mixing, and slurry and gas recirculation. Aside from mixing method and intensity, intermittent mixing modes can be applied to further control the anaerobic digestion process (Lindmark et al., 2014). The Chinese dome digester could be considered as a naturally mixed reactor as no moving parts are used. The CDD is mixed by the variation of the slurry level in reactor tank and the expansion chamber due to gas accumulation and use (shown in Chapter 5 , Figs. 5.1 \& 5.2) Considerable effort has gone into studying and improving mixing in forced mixed reactors (Kim et al., 2002; Gerardi, 2003; Gomez et al., 2006; Concklin et al., 2008; Ward et al., 2008; Ike et al., 2010; Halalsheh et al., 2011; Bridgeman, 2012). Karim et al., (2005), but little or no effort has gone into studying and optimizing mixing in the CDD.

\subsection{Scope of the thesis}

In this thesis, a bottom up approach was used to optimize mixing in the CDD with the intention to keep the system simple, easy to maintain, and reduce the size and cost when possible. Starting with a critical review on mixing in anaerobic digesters, with specific emphasis on household digesters, it was questioned why Chinese dome digesters are generally operated at high dilution and long retention time. Chapter 2 reviews mixing in various household and forced mixed reactors. The review compares thirty-three experiments in forced mixed reactors with twenty-four in-household digesters. The comparison was based on impact of organic loading rate and hydraulic retention time on mixing. It became clear, that household digesters, particularly the Chinese dome digesters are operated at long retention time and with high-water dilution because of mixing limitations. The review also suggests approaches to optimizing mixing in the CDD at high loading rate to achieve lower water requirement and subsequently reduction in reactor volume. Chapters 3 and 4 describe the first approach to optimize mixing in the Chinese dome digester at laboratory scale. Two consecutive laboratory experiments were designed to study the impact of lower water dilution on mixing in forced mixed reactors, CDDs, and unmixed reactors. Chapter 3 describes the impact of increased volumetric biogas production $\left(\mathrm{m}^{3} /\right.$ $\mathrm{m}^{3} / \mathrm{d}$ ) on mixing in three digesters with different modes of mixing, including the CDD. Chapter 4 evaluates the impact of increased volumetric biogas production on hydraulic characteristics of the three different digesters. In addition, the percentage of dead zones was estimated. The results of Chapters $\mathbf{3}$ and $\mathbf{4}$ indicate that high volumetric gas production, achieved via application of a high loading rate in the CDD, does not improve mixing and a considerable dead zone was detected using the residence time distribution technique.

Chapters 5 and 7 describe models applied to mitigate $\mathrm{CH}_{4}$ emission and to improve and evaluate mixing in the Chinese dome digester. Chapter 5 describes the set of equations developed, to estimate the length of one of the baffles necessary for the optimization of mixing, to mitigate biogas emission from the CDD. First, the model, helped to prevent biogas emission from the inlet and outlet, which 
was described as a treat to cancel the benefits of the application of the digester. Second, a pressurebased self-mixing mechanism was proposed as a cheap alternative to improve mixing in the digester. The model was used to estimate the length of the upper baffle applied in the optimization strategy and to determine the depth of the inlet and outlet in the reactor. Chapter 7 describes the multiphase computational fluid dynamic model used to evaluate the hydraulic characteristics of the baffled Chinese dome digester. The results of the hydraulic characterisation were consistent with the results of the pilot scale experiments in Chapter 6.

Chapter 6 describes the pilot experiments using an improved Chinese dome digester in comparison with a conventional CDD, with highly concentrated (15\% TS) cow manure as a feedstock and at reduced hydraulic retention times of successively 40 and 30 days. The improved or baffled CDD exhibited superior digestion efficiency and stability compared to the conventional CDD at both HRTs.

Chapter 8 provides a general discussion of this thesis. In this chapter, all results are summarized and discussed. The consequences of the pilot experimental results on reactor size and cost are presented and discussed. Recommendations for future studies, using the optimized system in different tropical regions, are made. A complete overview of the thesis is given in Fig.1.1.

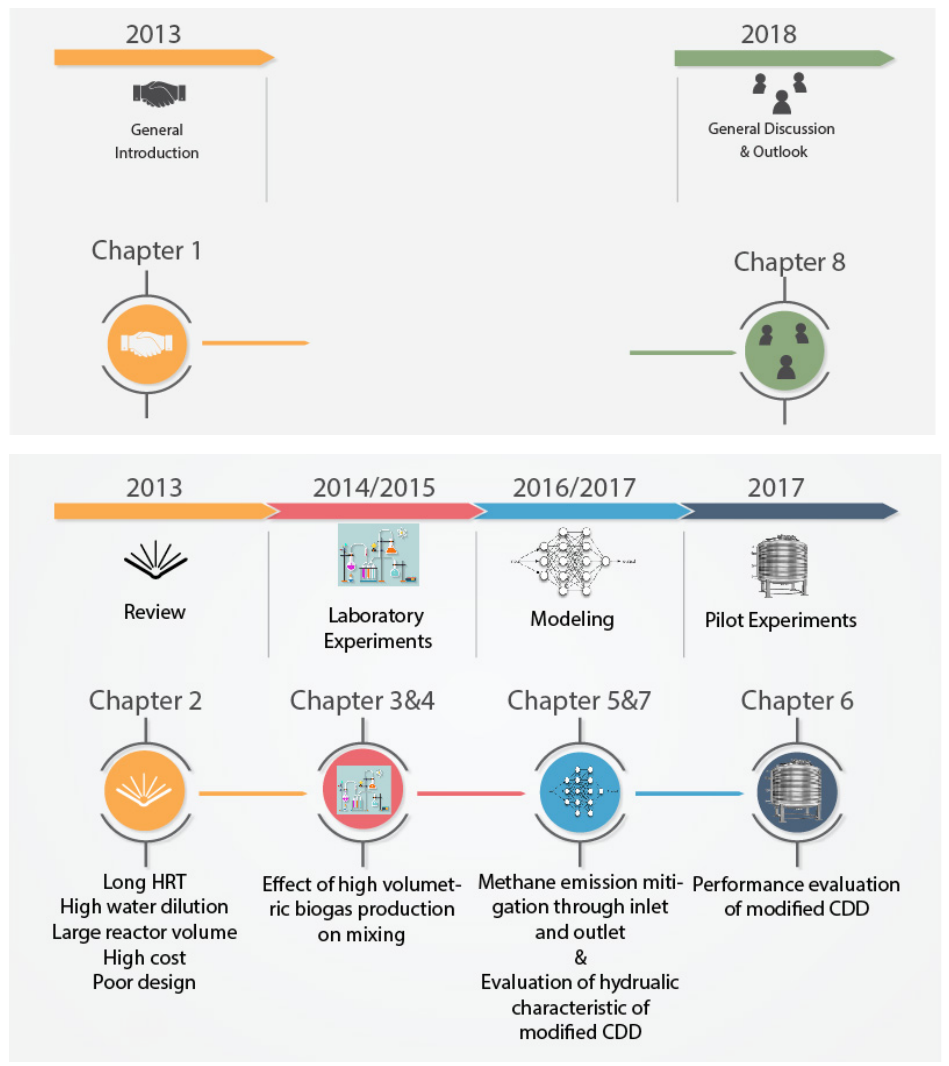

Figure 1.1 | Overview of the thesis. 


\section{References}

Adeoti O. (1998). Engineering economy studies of biogas as renewable energy source at household level in Nigeria. M.Sc. Thesis in Technology Management, Technology Planning and Development, Unit, Faculty of Technology, Obafemi Awolowo University, Ile-Ife, Nigeria.

Akinbami J.F.K., Ilori M. O., Oyebisi T.O., Akinwunmi I.O., Adeoti O. (2001). Biogas energy use in Nigeria: current status, future prospects and policy implications. Renewable and sustainable Energy Reviews 5(1): 97 -112.

An B.X., Preston T.R. (1999). Gas production from pig manure fed at different loading rates to polyethylene tubular biodigesters. Livest. Res. Rural Dev., 11(1) Available at (http://www.lrrd.org/lrrd11/1/an111.htm) (Accessed 02.06.15).

Arthur R., Baidoo M. F., Brew-Hammond A. (2011). Biogas generation from sewage in four public universities in Ghana: A solution to potential health risk. Biomass and Bioenergy, 35: 3086 -3093.

Bajgain S, Shakya I, Mendis M S. (2005). The Nepal Biogas Support Program: a successful model of public private partnership for rural household energy supply. Report prepared by Biogas Support Program Nepal. Kathmandu, Nepal: Vision Press P. Ltd.

Bridgeman J., (2012). Computational fluid dynamics modeling of sewage sludge mixing in an anaerobic digester. Advances in Engineering Software. 44:54-62.

Chen Y., Yang G., Sweeney S., Feng Y. (2010). Household biogas use in rural China: a study of opportunities and constraints. Renewable and Sustainable Energy Reviews 14 (1): 545-549.

Cheng S., Li Z., Mang H. P., Huba E. M. (2013). A review of prefabricated biogas digesters in China. Renewable and Sustainable Energy Reviews 28:738 -748.

Chen L., Zhao L., Ren C., Wang F. (2012). The progress and prospects of rural biogas production in China. Energy Policy, 51:58-6.

Chanakya H N., Bhogle S., Arun RS. (2005). Field experience with leaf litter-based biogas plants. Energy Sustain Dev. 9:49-62.

Conklin A.S., Chapman T., Zahller J.D., Stensel H.D., Ferguson J.F. (2008). Monitoring the role of aceticlasts in anaerobic digestion: activity and capacity. Water Research. 42:4895-4904.

Ferrer I., Garfí M., Uggetti E., Ferrer-Martí L., Calderon A., Velo E. (2011). Biogas production in low-cost household digesters at the Peruvian Andes. Biomass and Bioenergy, 35: 1668-1674.

Ferrer I., Cadena E., Perez B. Garfi M. (2013). Technical, economic and environmental assessment of household biogas digesters in developing countries. Proceedings of 13th World Congress on Anaerobic Digestion, Sandiago de Compostela, Spain.

Fulford, D. (1988). Running a Biogas Programme: A Handbook. London, Intermediate Technology Publications.

Gautam, R, Baral S, Herat S. (2009). Biogas as a sustainable energy source in Nepal: present status and future challenges. Renew Sustain Energy Rev; 13: 248-52.

Gerardi, M., (2003). The Microbiology of Anaerobic Digesters. John Wiley and Sons, Inc., Pennsylvania.

Ghimire, P. C. (2013). SNV Supported domestic biogas programmes in Asia and Africa. Renewable Energy 49: 90-94.

Gomez X., Cuetos M.J., Cara J., Moran A., Garcia A., (2006). Anaerobic co-digestion of primary sludge and the fruit and vegetable fraction of the municipal solid wastes-conditions for mixing and evaluation of the organic loading rate. Renew. Energy 31: 2017-2024.

Halalsheh M., Kassab G., Yazajeen H., Qumsieh S., Field, J., (2011). Effect of increasing the surface area of primary sludge on anaerobic digestion at low temperature. Bioresour. Technol. 102:748-752.

Ike M., Inoue, D., Miyano, T., Liu, T.T., Sei, K., Soda, S., Kadoshin, S., 2010. Microbial population dynamics during startup of a full-scale anaerobic digester treating industrial food waste in Kyoto eco-energy project. Bioresour. Technol. 101:3952-3957.

Kalia A. K. (1988). Development and evaluation of a fixed dome plug flow anaerobic digester. Biomass, 16:225-235.

Kanwar S.S., Guleri R.L. (1994). Performance evaluation of a family-size, rubber-balloon biogas plant under hilly conditions. Bioresour. Technol. 50:119-121.

Karim K., Hoffmann R., Klasson K. T., Al-Dahhan M. H. (2005). Anaerobic digestion of animal waste: effect of mode of mixing. Water Research 39; 3597-3606.

Khan E U, Martin A R, (2016). Review of biogas technology in rural Bangladesh Renewable and sustainable energy reviews. 62: 247- 259.

Kim M., Ahn, Y.H., Speece, R.E., (2002). Comparative process stability and efficiency of anaerobic digestion: mesophilic vs. thermophilic. Water Res. 36:4369-4385. 
Lansing S., Martin J.F., Botero R.B., da Silva T.N., da Silv E.D. (2010). Methane production in low-cost, unheated, plugflow digesters treating swine manure and used cooking grease. Bioresource Technology10 (12): 4362-4370.

Lindmark J., Thorin E., Fdhila R. B., Dahlquist E. (2014). Effect of mixing on the result of anaerobic digestion: Review. Renewable and Sustainable Energy Review (40):1030 -1047.

Mungwe J N. Colombo E. Adani F., Schievano A. (2016). The fixed dome digester: An appropriate design for the context of sub-Sahara Africa? Biomass and Bioenergy 95: 35-44.

Rupf G V., Bahri P A., de Boer., McHenry M P. (2015). Barriers and opportunities of biogas dissemination in Sub-Saharan Africa and lessons learned from Rwanda, Tanzania, China, India, and Nepal. Renewable and Sustainable energy reviews, 52: 468:476.

Rupf G V, Bahri P A., de Boer., McHenry M P. (2016). Broadening the potential of biogas in Sub-Saharan Africa: An assessment of feasible technologies and feedstocks. Renewable and Sustainable energy reviews 61:556-571.

Singh S.P., Vatsa D.K., Verma, H.N. (1997). Problems with biogas plants in Himachal Pradesh. Bioresource Technology 59: 69-71.

Ward A.J., Hobbs, P.J., Holliman, P.J., Jones, D.L. (2008). Optimisation of the anaerobic digestion of agricultural resources. Bioresour. Technol. 99, 7928-7940.

Yumkella K. K., Srivastava L. (2010). Energy for all. Making it. April 2, 2010 Issue pp. 22 -29.

Zabranska, J., Dohanyos, M., Jenicek, P., Zalpatilkova, P., Kutil, J., (2002). The contribution of thermophilic anaerobic digestion to the stable operation of wastewater sludge treatment. Water Sci. Technol. 46: 447-453. 


\title{
Chapter
}

\section{Mixing in anaerobic digesters with a specific emphasis on household digesters: A review}

\author{
Abiodun O. Jegede ${ }^{* 1}$, Grietje Zeeman *, Harry Bruning* \\ * Sub-Department of Environmental Technology, Wageningen University, \\ Wageningen, The Netherlands. \\ ${ }^{1}$ Centre for Energy Research and Development, \\ Obafemi Awolowo University, Ile-ife, Nigeria.
}

This chapter is based on:

Jegede A.O, Zeeman G., Bruning H. (2018). Mixing in anaerobic digesters with a specific emphasis on household digesters: A review. Under review in Critical Reviews in Environmental Science and Technology. 


\begin{abstract}
Mixing is an important parameter in the anaerobic digestion process. Mixing in household digesters is usually intermittent and achieved during feeding and effluent removal. The Chinese Dome digester is a type of household digester mixed via pressure variation during gas use and feeding. The Chinese dome digester is the most popular and applied household digester type in Asia and Africa, and has formed the basis for contemporary developments in the household digester sector in the world. Mixing intensities have effect on biogas production rate and reactor start-up and little or no efforts have been put to review mixing in household digesters. This review analyses and presents the various types of domestic biogas plants and how they are mixed. Experimental results of household biogas plants, stirred lab reactors with different mixing modes, and intensities have been reviewed and compared. The mixing conditions in household digesters are difficult to quantify due to poor reporting in literature. Intermittent or low intensity mixing gives similar biogas production as continuously mixed digesters and is beneficial to digesters' startup. Household digesters could be regarded as intermittently mixed reactors via substrate feeding, removal and gas use, however, they are operated at a longer hydraulic retention time (HRT) compared to other intermittently mixed reactors mixed via mechanical, biogas circulation, and slurry recirculation. To optimize household digesters without the use of external energy, further research should focus on quantifying the natural input energy for mixing and improving the intermittently mixing processes via substrate addition (using different concentrations), gas use, gas storage, and effluent removal.
\end{abstract}




\subsection{Introduction}

One important way to solve the problem of energy shortage in rural areas of developing countries is the use of biogas produced in domestic biogas plants. The use of traditionally available biomass, such as animal dung and other biodegradable waste from the farm, can make single households and even communities become self-sufficient in energy (Bond \& Templeton, 2011). Biogas can be used as cooking fuel, without air pollution, and can be used for heating, lighting, and electricity production (Bajgain et al., 2005). Domestic biogas plants, also called household digesters, are small-scale (maximum -10 m³) anaerobic digesters (Shian et al., 1979; Hamad et al., 1982; Akinbami et al., 2001; Arthur et al., 2011; Rajendran et al., 2012; Jihen et al., 2010), which are usually constructed very close to individual houses mostly in rural areas to provide biogas for household use. The digestate from the plant is applied on farm land as organic manure. The major types of domestic biogas plants are the Chinese fixed dome, Indian floating drum, Plug flow, and the recently developed Puxin Digesters (Arthur et al., 2011). They have no mechanical mixers and are unheated systems, which make them inexpensive and well suitable for farmers and people living in rural areas (Kanwar and Guleri, 1994; Singh et al., 1997).

The history of domestic biogas plants dates as far back as the 10th century BC in Assyria where heating of bath water was done with the use of biogas. In ancient China (13th century), anaerobic digestion was applied to solid waste (He, 2010). The commercial use of biogas in China has been attributed to Guorui Luo, in 1921, who built an $8 \mathrm{~m}^{3}$ anaerobic digester using household waste as feedstock (He, 2010). The high oil prices in the 1970s made biogas technology popular, especially in Asian, African and Latin American countries (Ni and Nyns, 1996). More than 7 million biogas plants were installed in China during this period because of the encouragement and policies from the Chinese Government for biogas use in every rural household (He, 2010). The number of household biogas plants increased since the turn of this century, with over 40 million systems installed in China (Song et al., 2014) because of various subsidies from the government. In Africa and Latin America, the situation is mixed and most plants were built in the 80s and 90s. In subSahara Africa, domestic biogas plants had little success compared to Asia (Akinbami et al., 2001; SNV, 2014).

About forty million domestic biogas plants (DBPs) have been installed worldwide, mainly in Asia, however the total world technical potential has been put at 155 million (SNV, 2010; Jiang et al., 2011). This estimation was based on the amount of animal manure that could be generated from the livestock as the potential of domestic household digesters is still far from being achieved especially in developing countries such as Latin America and most sub-Sahara Africa countries (Akinbami et al., 2001; Bond \& Templeton, 2011).

Methane emission in 2010 was about $10 \mathrm{GtCO}_{2}$ - equivalent and about $16 \%$ of the total anthropogenic greenhouse gas (GHG) emission in 2014 (IPCC, 2014). The large volume of household digesters in operation in the world and the above-mentioned technical potential of 155 million (SNV,2010) suggest that anaerobic digestion technology may mitigate GHG substantially through methane recovery from organic waste (Kobayashi \& Li, 2011). 
Out of all the household digesters, the Chinese dome digester (CDD) is the most popular digester and most implemented due to its reliability, low maintenance, and long lifespan (Ghimire, 2012; Cheng et al., 2013). The CDD has become a basis for the development of twenty-first century household digester design, such as the Puxin digester an example of a prefabricated digester (Cheng et al., 2013). The most important issues related to household digesters reported in literature are mentioned and discussed later in this paper.

A few reviews (Rajendran et al., 2012; Cheng et al., 2013; Perez et al., 2014) exist on domestic biogas plants. These reviews do not evaluate the effect of mixing in domestic biogas plants and/ or compare this with completely mixed systems. This paper therefore aims to review mixing in domestic biogas plants and completely mixed systems with varying speeds. The major types of household digesters, their features, mode of mixing, advantages, and disadvantages are reviewed in the present paper. In addition, the effect of substrate dilution and organic loading rate (OLR) on mixing in household digesters, and the effect of mixing intensities in various completely mixed biogas plants and domestic biogas plants on HRT and digestion efficiency are discussed. An overall discussion is presented on the potential improvement of performance and with volume reduction of household digesters by improving mixing conditions.

\subsection{Types of household biogas plants and challenges}

The various types of household digesters are discussed in this section.

\subsubsection{Overview of various household digesters}

Table 1.1 gives an overview of the household digesters discussed in this section comparing them on the basis of mixing method, HRT, OLR, size, and reported advantages and disadvantages. All different types of household digesters have similar applied loading rate, HRT, and volume/size. The Chinese dome, Deenbandhu, Floating dome and Prefabricated digesters are all mixed in the same way via the influent flow and variation of gas pressure due to storage and use, while the plug flow is mixed by the flow of the feed from the inlet to the outlet of the digester and gas production. The plug flow digester would be regarded as least durable if the material used were polyethylene because of the short life span of the material, while the most reliable are the prefabricated digesters because of the quality control that can be achieved during factory production among other advantages (Cheng et al., 2013). Long hydraulic retention time is a common disadvantage of most household digesters.

\subsubsection{The Chinese dome digester}

This type is usually constructed underground with a concrete hemispherical dome top as shown in Figure 1.1 The upper chamber is the gasholder and gas pressure is maintained through the height of the effluent in the displacement chamber (Gunnerson and Stuckey, 1986) and is usually between 0 and $90 \mathrm{~cm}$ water column (Khoiyangbam et al., 2004). The size of the domestic Chinese fixed dome varies usually between $6-10 \mathrm{~m}^{3}$ (Shian et al., 1979; Hamad et al., 1982; Adeoti 1993; 
Akinbami et al., 2001; Jihen et al 2010; Ferrer et al., 2013) and generates approximately $3 \mathrm{~m}^{3}$ of biogas per day to satisfy the cooking need of a household of an average size of nine persons (GTZ, 1999; Akinbami et al., 2001;). The reactor is operated in a semi-continuous mode i.e. feeding is done once a day. To meet this daily biogas requirement using cow manure as the feedstock, the organic loading rate requirement is around $1.5 \mathrm{~kg} \mathrm{VS} / \mathrm{m}^{3}$ day, with a HRT of 40 - 90 days and at mesophilic condition (Kalia, 1998; An \& Preston, 1999; Ferrer et al., 2011). Mixing is achieved in the digester via hydraulic variation during feeding, effluent discharge, and gas use (Tamkin et al., 2014).

The biogas plant is fed through the influent pipe until the level of the influent reaches the base of the expansion chamber. The biogas produced accumulates and is stored in the upper part of the digester above the slurry. The stored gas results in a pressure build up and presses part of the slurry into the effluent chamber. During gas use, the effluent flows back into the biogas plant therefore creating a mixing regime.

The reactor has no moving parts and is well insulated because it is usually constructed with bricks and cement below the ground. One major drawback is high technical skills required to ensure good gas tightness, which are difficult to construct in bedrock (Balasubramaiyam et al., 2008), and lot of structural strength required for construction.

The Chinese fixed dome biogas plant is most popular in developing countries in terms of number (Fulford, 1988; Chen et al., 2010; Ghimire, 2013; Ferrer et al., 2013) and largely supported by SNV.It is the design of choice for most of their programmes in rural areas in developing countries because of their reliability, low maintenance, and long lifespan (Ghimire,2013).Appendix 1.1 shows the details of the national biogas programmes supported by SNV, a Dutch Non-Governmental Organization (NGO) in Asia, Africa, and South America.

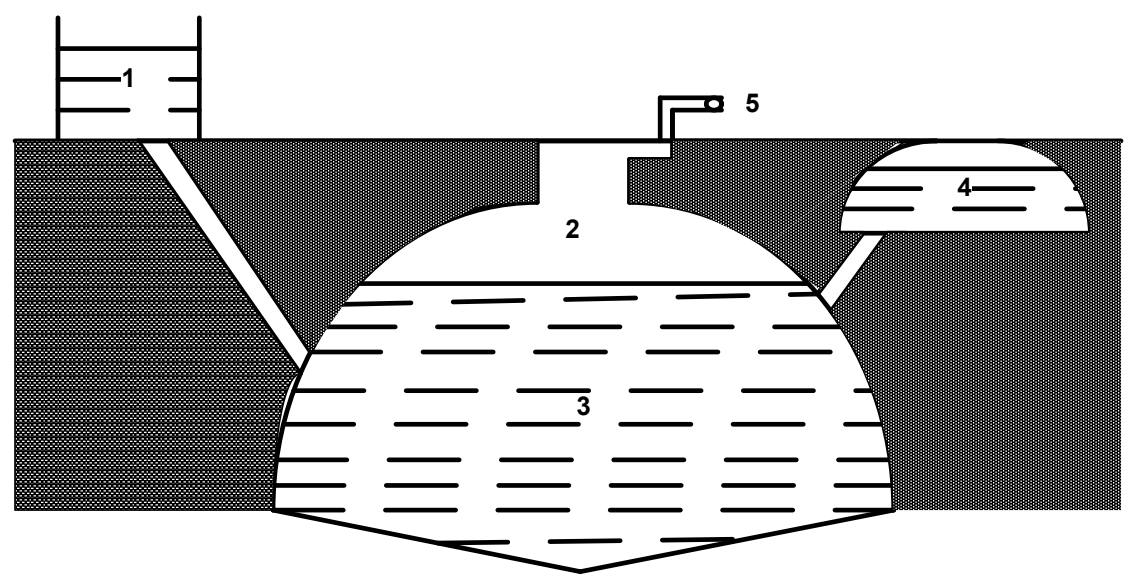

Figure 2.1 | Fixed Chinese dome digester. 1. Mixing tank with inlet pipe: 2. Gasholder: 3. Digester: 4. Expansion tank and outlet: 5. Gas pipe (Based on Arthur, 2011). 


\subsubsection{The Deenbandhu digester}

The Deenbandhu digester, also constructed with bricks and cement, was developed to create a system less susceptible to gas leakage than the Chinese Fixed dome digester. The Deenbandhu Digester is reported to be more resistant to gas leakages because both the gasholder and the digester base have a dome shape (CEM, 2005) as shown in Figure 1.2. The dome-like structure of the whole digester body, unlike the Chinese digester with only top dome shape, can hold very high structural forces because the pressure from the produced biogas is spread over a large surface (Buysman, 2009). The Deenbandhu Digester is operated like the Chinese fixed dome and mixing is also achieved via hydraulic variation.

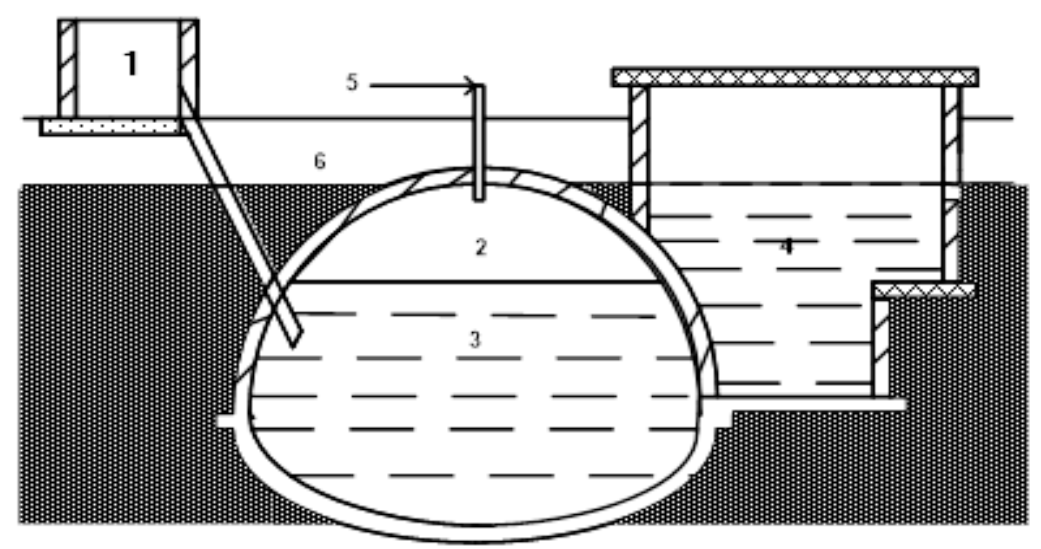

Figure 2.2 | The Deenbandhu Digester. Mixing tank with inlet pipe. 2. Gasholder: 3. Digester: 4. Expansion chamber and outlet: 5. Gas pipe: 6. Ground level (Based on CEM, 2005).

\subsubsection{The Indian floating dome digester}

The Indian floating dome digester has an inverted movable steel tank/drum as the gas holder, which is inserted into the digester as shown in Figure 1.3. This biogas system was developed by Khadi and Village Industry Commission (KVIC) (Singh \& Sooch, 2004). The digester is operated in a semi-continuous mode and has a similar substrate feeding and effluent removal pattern like the Chinese dome digester. The digester has a high depth width ratio, and a wall is constructed at the middle of the digester to prevent short-circuiting (Gunnerson and Stuckey, 1986). Mixing is achieved when substrates in the digester move over this wall mostly during feeding. The digester is easy to operate and has constant gas pressure because of the weight of the floating drum. However, the drawback for this system is the cost associated with the steel drum and the corrosion of the drum (Balasubramaniyam et al., 2008). 


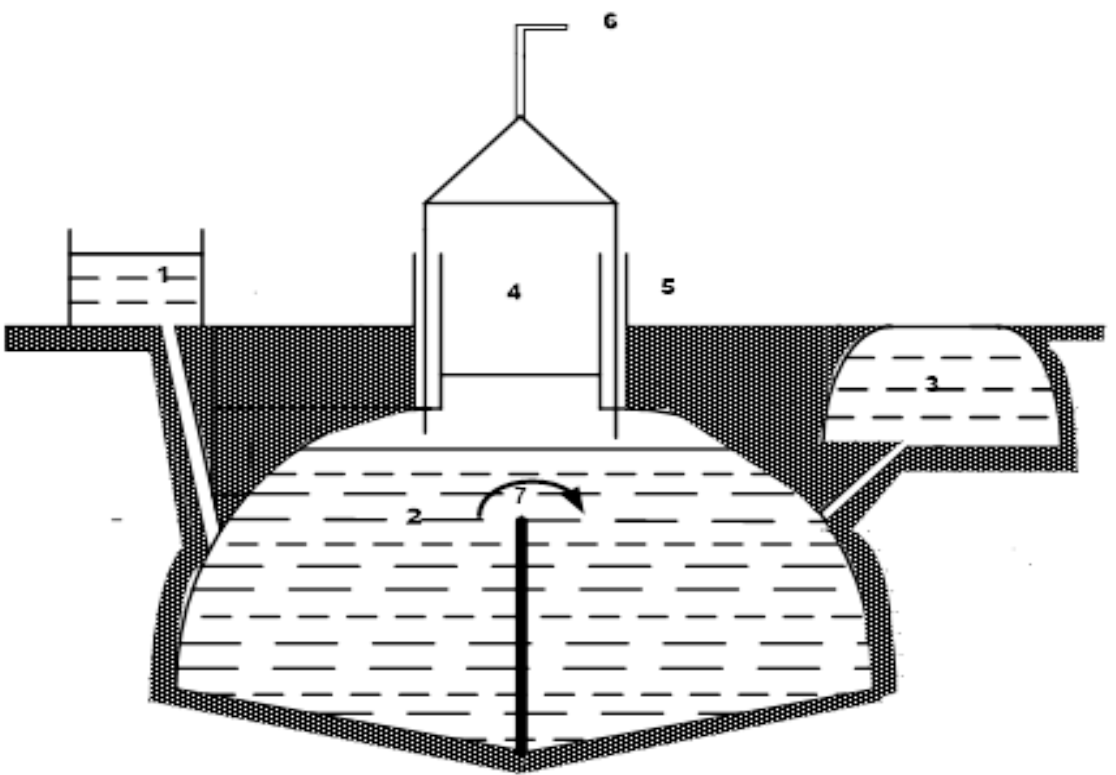

Figure 2.3 | Floating drum digester. Mixing tank with inlet pipe: 2. Digester: 3. Compensation tank 4. Gasholder: 5. Water jacket: 6. Gas pipe: 7. Wall (Based on Arthur et al., 2011).

\subsubsection{The Taiwanese bag digester}

The Taiwanese bag digester is a plug flow digester usually made from flexible plastics. It was developed in the 1960s, and this type of digester is popular in Central and South America. It is usually made from flexible plastic (e.g. tarpaulin) and Polyvinyl Chloride (PVC) (Gunnerson \& Stuckey, 1986; Herrero, 2008). The biogas plant is a long cylindrical bag supported on the ground with concrete or compacted sand (Gunnerson \& Stuckey, 1986) as shown below in Figure 1.4. Solar radiation is absorbed better in this digester than in the dome digesters because of the thin covering of the biogas plant, hence a higher temperature is achieved in the digester. On the other hand, because of the thin layer of the digester material, heat loss is also high (Daxiong et al., 1990) during the night and winter. The digester is a plug flow reactor with no mixing, but convective transport in horizontal direction as feed passes from the inlet to the outlet and concentration therefore reduces from left to right (Balasubramaiyam et al., 2008).

The design is simple, the cost of material is relatively low, and cleaning or maintenance is not complicated. However, the major drawbacks for this type of digester are the low life span, usually around two years because of the nature of the reactor material, difficulty to repair, and susceptibility to physical damage by humans (Daxiong et al., 1990; GTZ, 1999). 


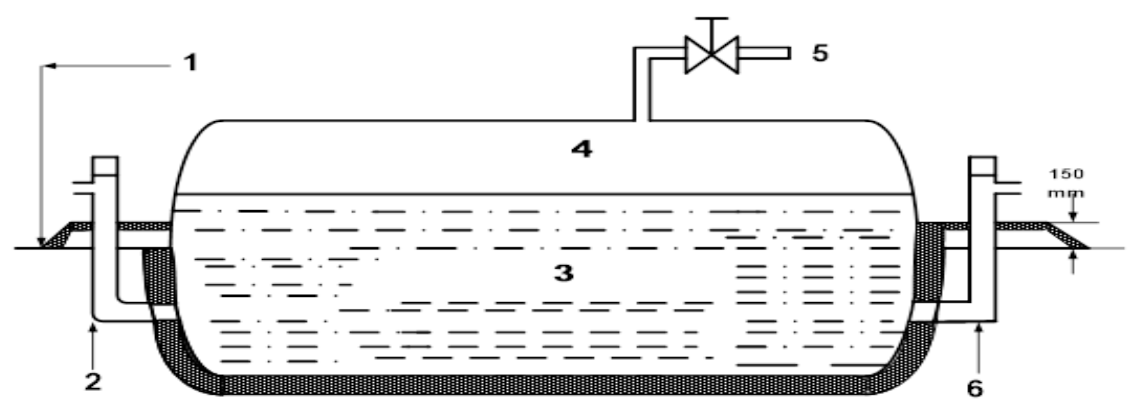

Figure 2.4 | Taiwanese flexible bag digester. 1. Levelled surface with concrete or compact sand (black): 2. Inlet: 3 Slurry inside digester: 4. Gas: 5 Gas pipe: 6. Outlet. (Based on Gunnerson and Stuckey,1986).

\subsubsection{Prefabricated biogas digesters}

Prefabricated biogas digesters (PBDs) are classified into fibre reinforced plastic (FRP), plastic soft (PS) and plastic hard (PH) digesters. Most PBDs designs are based on the Chinese dome digester. FRP digesters are made from unsaturated polyester resin and glass fibre cloth. Plastic soft (PS) digesters are made from polyvinyl chloride (PVC), red mud, polypropylene, poly-methyl methacrylate. The plastic hard (PH) digesters are made from hard PVC, Polypropylene (PP), linear low-density polyethylene and high-density polyethylene (HDPE). On the other hand, some digesters such as the Puxin digesters are still being constructed with some parts from blocks/ concretes and reinforced plastics, usually the gas holders; that is, the combination of prefabricated parts and parts that could be constructed locally though the standardization schemes are incomplete and not robust. The PBDs can have several advantages over other types of household digesters, viz. quality control at the factory during production, high mechanical strength, gas tightness and longlife span. Also, they provide good insulation because they are installed underground to maintain stable internal temperature, and they are light and can therefore be easily transported (Cheng et al., 2013), they can be easily installed and maintained. See Figures 1.5 and 1.6.

The Puxin Digester is one of the brands of prefabricated digesters and is a modification of the Chinese fixed dome digester (Arthur et al., 2011; Cheng et al., 2013). Their applications and designs depend on location, available local substrates, socio-economic context, and weather conditions (Kanwar and Guleri, 1994; Singh et al., 1997). 


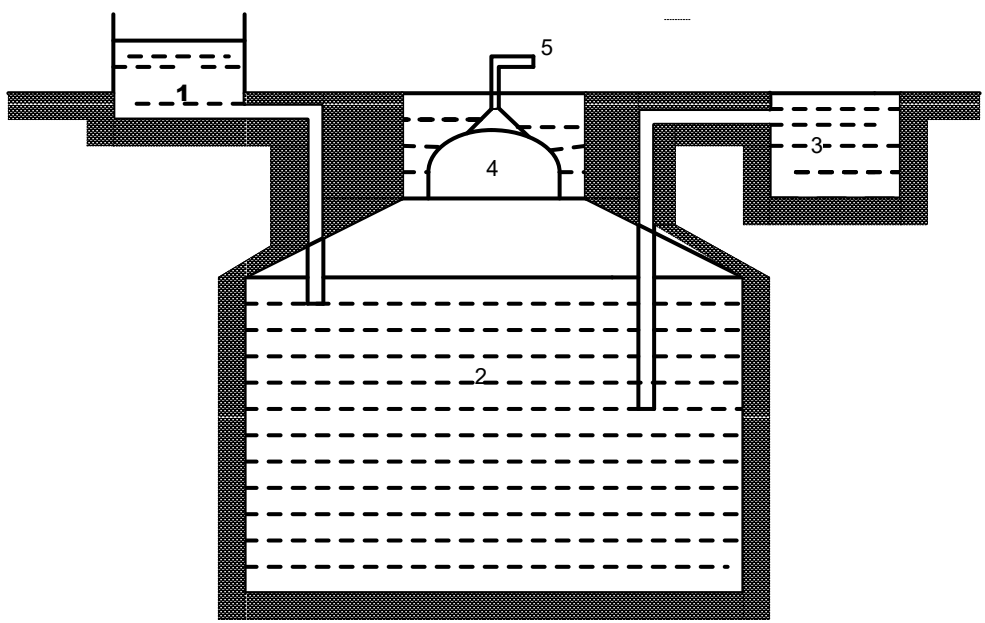

Figure 2.5 | Puxin digester, top-half PBD .1. Mixing tank with inlet pipe: 2. Digester (concrete): 3.Expansion chamber: 4. Gasholder (reinforced fibre plastic): 5. Gas pipe. (Based on Arthur et al., 2011).

(a)

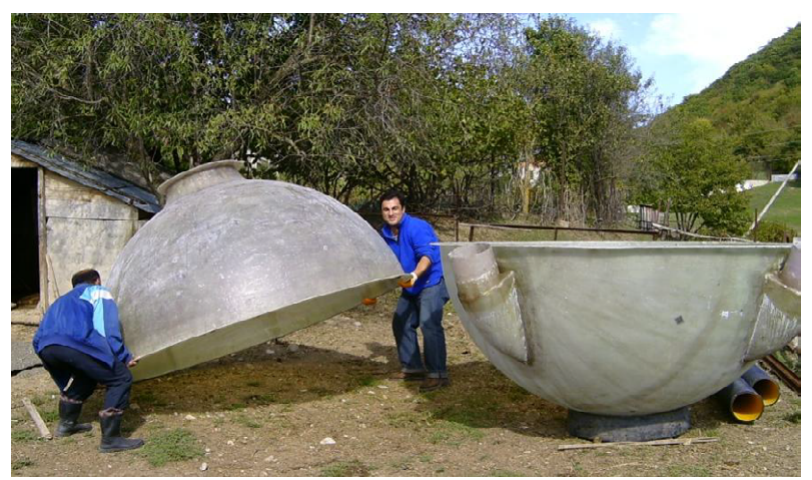

(b)

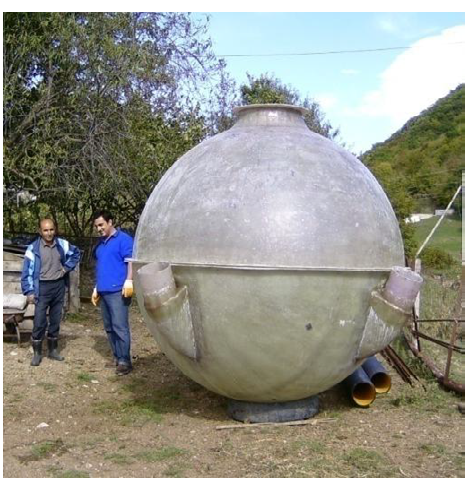

Figure 2.6 a \& b | The components of a complete glass fibre light weight digester (Buysman, 2009).

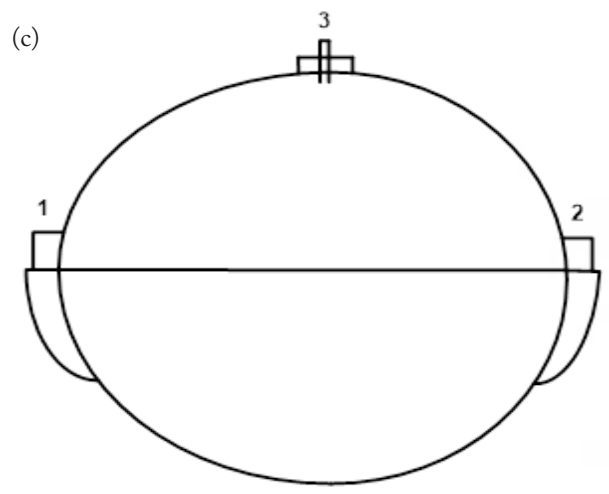

Figure 2.6c $\mid$ Schematic of the Glass Fibre Light Weight Digester 1. Inlet: 2. Outlet: 3. Gas outlet (based on Buysman, 2009). 


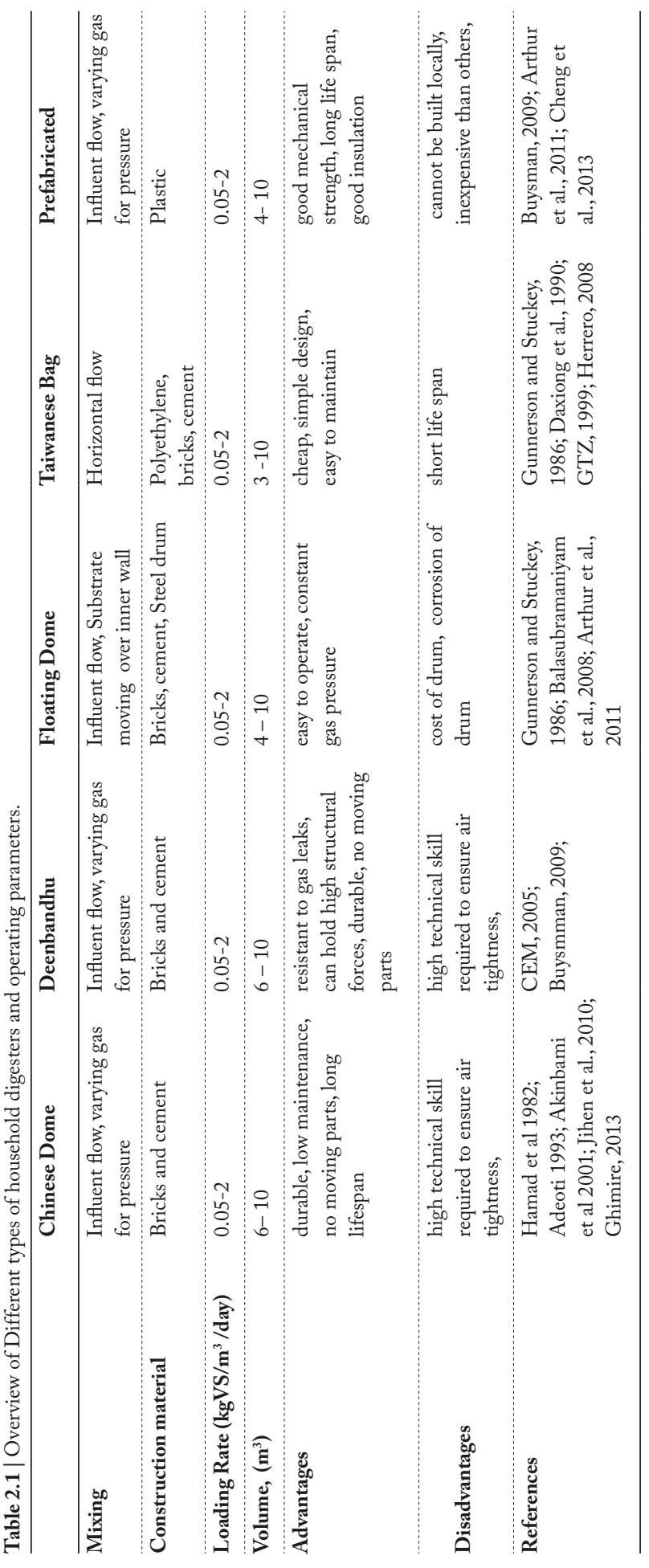




\subsection{Organic loading rate and substrate dilution in household digesters}

The total solid concentration of the influent applied in domestic household biogas plants varies between 5\% -7\% (Xavier \&Nand, 1990; Mohammad, 1991; Shyam \& Sharma, 1994; Bouallagui et al., 2003; Bond \& Templeton, 2011). The influent generally consists of manure diluted with water, which is the normal practice, without any scientific reason, when feeding the digester. According to Shyam \& Sharma, (1994), the input concentration could be increased by reducing dilution to indirectly reduce the digester volume (Ferrer et al., 2011) and to achieve higher volumetric biogas production $\left(\mathrm{m}^{3} / \mathrm{m}^{3} \mathrm{~d}\right)$. Biogas production would be negatively affected if the total solid concentration were increased above $19 \%$ according to experimental results of Shyam \& Sharma, (1994) because of settling of fed substrates (both organic and inorganic fractions) due to the absence of forced mixing. The loading rate usually applied in household digesters is between 0.7-2 $\mathrm{kg} \mathrm{VS} / \mathrm{m}^{3} /$ day for mesophilic temperature conditions (Rajendran et al., 2012). The usual practice of excessive substrate dilution (substrate: water, 1:4) and long HRT used in household biogas plants often result in low OLR i.e. $0.75 \mathrm{~kg} \mathrm{VS} / \mathrm{m}^{3} /$ day and low volumetric biogas generation, thus large reactor volumes have to be applied (Kalia \& Kanwar 1998; Ferrer et al., 2011; Ciotola et al., 2013; Tamkin et al., 2014). When higher loading rates are applied because of higher input concentration, the increased volumetric biogas production may positively affect the mixing of the reactor content. No information is available on the relation between volumetric gas production and mixing in the household digesters, especially the Chinese dome digester. Moreover, further studies should be carried out at higher input concentration (10 -15\% TS) at several HRTs to reduce the applied reactor volume and eventually reactor cost.

Kalia, (1988), attempted to decrease the volume of household anaerobic digesters by comparing two fixed domes domestic biogas plants with volume $9.2 \mathrm{~m}^{3}$ and $8.1 \mathrm{~m}^{3}$ operated at HRT 79 days and 70 days respectively. They were fed with an influent concentration between $9-10 \%$ TS and dilution ratio was $1: 1$. The average specific biogas production for the first digester was 0.63 - $0.65 \mathrm{~m}^{3} / \mathrm{kg}$ VS, but the second digester was higher in the range of $0.67-0.68 \mathrm{~m}^{3} / \mathrm{kg} \mathrm{VS}$ and comparable to the results of Hills \& Mehlschau, (1984); Kalia \& Kanwar, (1998); Jihen et al., (2010), with similar operating parameters and substrates. The volumetric gas production $\left(\mathrm{m}^{3} / \mathrm{m}^{3}\right.$ d) was as expected, higher when applying a shorter HRT as compared to that of the digester with a longer HRT at same loading rate. However, there is no significant difference in the specific gas production because the difference in the applied HRTs is limited.

Ferrer et al., (2011) conducted pilot studies on household plug flow digesters at a temperature between $20-25^{\circ} \mathrm{C}$ at two different dilutions, and on different HTRs to study the effect of different organic loading rates (OLRs) and HRTs on reactor performance. 
Table 2.2 | Functional parameters of low cost household digesters based on Ferrer et al., (2011).

\begin{tabular}{|c|c|c|}
\hline Parameter & 1: 4 dilution & 1: 2 dilution \\
\hline Substrate dilution (substrate: water) & Cow manure (1:4) & Cow manure $(1: 2)$ \\
\hline Total Solids (\%) & 13.42 & 17.56 \\
\hline Volatile Solids (\%) & 61.72 & 88.24 \\
\hline Hydraulic residence time (day) & 90 & 60 \\
\hline Digester volume $\left(\mathrm{m}^{3}\right)$ & 7.5 & 2.4 \\
\hline OLR ( $\mathrm{kg} \mathrm{VS} / \mathrm{m}^{3} /$ day) & 0.22 & 1.3 \\
\hline Volumetric biogas production rate $\left(\mathrm{m}^{3} / \mathrm{m}^{3} /\right.$ day $)$ & $0.07 \pm 0.02$ & $0.42 \pm 0.01$ \\
\hline Specific biogas production $\left(\mathrm{m}^{3} / \mathrm{kg} \mathrm{VS}\right)$ & $0.32 \pm 0.09$ & $0.36 \pm 0.01$ \\
\hline Methane content $\mathrm{CH}_{4}(\%)$ & $63-67$ & $63-67$ \\
\hline
\end{tabular}

Their results show a higher volumetric biogas production and specific biogas production of 0.42 $\mathrm{m}^{3} / \mathrm{m}^{3} /$ day and $0.36 \mathrm{~m}^{3} / \mathrm{kg}$ VS respectively for dilution ratio of $1: 2$, HRT of 60 days compared to $0.07 \mathrm{~m}^{3} / \mathrm{m}^{3} /$ day and $0.32 \mathrm{~m}^{3} / \mathrm{kg}$ VS with dilution ratio of $1: 4$ and HRT of 90 days as shown in Table 1.2. From the results, a lower dilution of substrate and reduced HRT are feasible without affecting the specific biogas production. However, increasing organic loading rates by reduction of dilution in household digester may lead to the accumulation of solids in digesters when forced mixing is not applied such as in the plug flow and Chinese dome. At high loading rates, unstirred systems such as the plug flow reactors have problems because of accumulation of solids, organic acids, and $\mathrm{pH}$ reduction in the front part of the system (Barber and Stuckey, 1999).

\subsection{Effect of temperature on household digesters}

Temperature and HRT are important parameters in the anaerobic digestion process and challenging in household digesters because they are operated without heating. The growth rate of methanogens and the first hydrolysis constant of organic suspended solids are temperature dependent and very low at low temperature $\left(<20^{\circ} \mathrm{C}\right.$ ) (Steven and Schilte, 1979; Singh et al., 1995; Rebac et al., 1999; Collin et al., 2005; Ferrer et al., 2009). The climatic conditions in most developing countries are favourable for the anaerobic digestion process, throughout the year with ambient temperature in the range 20 $-25{ }^{\circ} \mathrm{C}$ (Buysman, 2009). On the other hand, some regions have highlands or have warm summers but cold winters. The lower temperature during the winter is not favourable for biogas production (Sodha et al., 1987; Gupta et al., 1988; GTZ, 1999), unlike very long HRTs are applied.

To solve the problem of low biogas production in winter, different methods have been developed to keep the temperature in household digesters at a certain minimum, i.e. $15^{\circ} \mathrm{C}$, also in winter. Solar radiation is the most popular method which could be applied to raise the temperature of domestic digesters (Shian et al., 1979; Tiwari, 1986; Tiwari et al., 1989, El-Massah, 2004; Herrero, 2008). The main solar energy applications in domestic digesters are hot charging (heating of substrate and water with solar radiation), covering of digester by applying a greenhouse, and indirect utilization of solar energy such as solar thermal collector (Buysman, 2009). Sodha et al., (1987) investigated the 
concept of a greenhouse coupled with an $8 \mathrm{~m}^{3}$ digester to increase biogas production during winter in Masoodpur Village, New Delhi, India. A year study revealed almost a 100\% increase in biogas yield when applying a digester inside a greenhouse. The comparative study with a conventional digester without a greenhouse shows that the digester mean temperature could be increased from $20^{\circ} \mathrm{C}$ to almost $35^{\circ} \mathrm{C}$.

Furthermore, in cold hilly regions, different types of Taiwanese plug flow digesters have been used (Herrero, 2008; Kumar \& Bai, 2008). Plug flow digesters have been successful at low temperatures because of the low cost and solar canopy that retain the captured radiation (Buysman, 2009), even in winter, compared to other types of household digesters (Anjan, 1988) Coating the top of a domestic digester with charcoal was proposed by Singh and Anand, (1993). They reported an increase in temperature by $3{ }^{\circ} \mathrm{C}$ and biogas production by $7-15 \%$, but the digester has to be coated almost every two months. Singh et al., (1985) concluded that in winter, biogas production could be maintained by insulating the inner surface of biogas holders.

Hot charging of substrate may not be a very practical solution for domestic biogas plant operating at long HRT, i.e. 60 days and above (Buysman, 2009), because the incoming high temperature (60 ${ }^{\circ} \mathrm{C}$ ) of substrate would affect the microbial community negatively, which may have acclimatized to a psychrophilic temperature range. Nevertheless, domestic digesters could be insulated to prevent heat loss, which might make hot charging viable if the overall digester heat transfer coefficient $(\mathrm{K})$ is below $1 \mathrm{~W} / \mathrm{m}^{2} \mathrm{~K}$ and the proper mixing of incoming substrate with digester content (Anand and Singh, 1993, Buysman, 2009). Indirect utilization of solar radiation in domestic biogas plant has been proposed by different authors (Gupta et al., 1 988; Tivari et al., 1989; El-Mashad et al., 2004), as a good approach to increasing temperature of digestion if implemented. For example, Buysman, (2009) performed a solar energy simulation on a $3.5 \mathrm{~m}^{3}$ Janata household digester for four countries; Georgia, Romania, Kyrgyztan and Bolivia. The goal was to assess the heating requirement using solar collectors for a digester operating at a minimum temperature and 55 days HRT. The total heat and collector area required for each country are 44. $6 \mathrm{MJ}$ and $12.69 \mathrm{~m}^{2}, 45.2 \mathrm{MJ}$ and $5.74 \mathrm{~m}^{2}, 47.3 \mathrm{MJ}$ and $5.50 \mathrm{~m}^{2}$, 26.6 MJ and $5.11 \mathrm{~m}^{2}$ for Romania, Kyrgyztan, Bolivia and Georgia respectively. The analysis showed that it is possible to maintain the digester temperature to at least $15{ }^{\circ} \mathrm{C}$, but the collector area need is large especially for Romania. In addition, El-Mashad, (2003), modelled a 10 $\mathrm{m}^{3}$ digester with a solar collector to achieve $44.5^{\circ} \mathrm{C}$ in summer and $47.6^{\circ} \mathrm{C}$ in winter in Egypt. The results showed high-energy demand to operate the digester at thermophilic condition. The input heat energy required are $3560 \mathrm{MJ}$ and $1560 \mathrm{MJ}$ for summer and winter respectively. These systems have not been implemented majorly because of high cost and limited experience worldwide.

The common approaches such as hot charging, digester insulation, and solar green house could increase digesters temperature to $10-15^{\circ} \mathrm{C}$ in situations where the temperature is below $5^{\circ} \mathrm{C}$. Other approaches such as indirect solar utilization are necessary. The concept of Herrero, (2008) which supports the combination of hot charging, sand wall, and solar greenhouse looks promising, but further studies are required to study the performances of the systems (Buysman, 2009).

Therefore, at lower operating temperatures $\left(<20^{\circ} \mathrm{C}\right)$, household digester would be operated at a long HRT > 60 day, which implies low OLRs, lower substrate inflow, and effluent withdrawal. Low OLR rates would result in low volumetric biogas production rates and this may result in poor mixing. Also, 
poor mixing would be achieved during feeding and effluent withdrawal, since household digester are also mixed via these two processes because only limited volume of influent and effluent could be added and removed respectively.

\subsection{Mixing in anaerobic digestion}

The effect of mixing in anaerobic digesters has been studied by different authors. The need for digesters to be adequately and sufficiently mixed has been supported by many scientists (Gerardi, 2003; Concklin et al., 2008; Halalsheh et al., 2011; Bridgema, 2012) and challenged by many others (Kim et al., 2002; Gomez et al., 2006; Ward et al., 2008; Ike et al., 2010). Karim et al., (2005) noticed in their study of effect of mode of mixing on anaerobic digestion that disruption in mixing causes hydraulic dead zones, leading to reduction of effective hydraulic retention time and could result to poor digester performance. Conversely, the studies of Kim et al., (2002) showed high performance in an unstirred continuously fed lab-scale biogas reactor digesting primary sludge when compared with continuously fed stirred biogas plants. The absence of mixing reduced and stabilized the start-up stage of the biogas digester, but afterwards, reduced biogas production when compared with mixed digesters (Karim et al., 2005). In addition, higher biogas production was reported by Kaparaju et al., (2008) for minimal and intermittent mixing when compared to the performance of a continuously mixed system, i.e. a better performance for a gently mixed system compared with vigorously mixed systems. Zeeman, (1991) reported a negative effect of mixing during the start-up of anaerobic treatment of cow manure at $15{ }^{\circ} \mathrm{C}$ using Accumulating System (AC). She attributed the negative effect to the destruction of adjacent structure between the hydrogen consuming and the propionic acid oxidising microflora, which resulted in the increase of hydrogen in the propionic acid oxidising bacteria region. Also, the study of Stroot et al., (2001), under minimal and continuous mixing of mesophilic co-digestion of sludge and organic fraction of municipal solid waste (OFMS), concluded that mixing increases the distance between syntrophic microbes and therefore destroys their association. In fact, Ward et al., (2008) attributed the accumulation of propionate in unstable biogas plants to the increase of diffusion distance between synthrophs. These studies were executed at lab scale.

Ghanimeh et al., (2012) evaluated the effect of mixing and organic loading rate (OLR) on the performance of the anaerobic digestion process of source-separated organic fraction of municipal solid waste (SS-OFMSW) during start-up and without an acclimated seed in two different continuously fed reactors operated with similar starting conditions but different mixing schemes for 235 days. The first reactor was continuously and slowly mixed at $100 \mathrm{rpm}$, while the second was not mixed except for a few minutes before feeding and wasting. The first reactor exhibited superior digestion efficiency when compared to the second digester and was more stable in relation to lower propionate level, reduced VFA, and lower VFA-to-alkalinity ratio. In this regard, slow mixing (100 rpm) enhanced the system stability, digesters' capacity, and digestion efficiency. They attributed this to the insufficient hydrogenotrophic diversity in the non-acclimated seed, therefore requiring the need of mixing to avoid hydrogen accumulation. 
Furthermore, Hoffmann et al., (2007) studied the effect of various mixing intensities on the methanogenic population dynamics, performance, and comparing syntrophic microbes in a biogas plant digesting cow manure. Four 4.5 L CSTR biogas plants were used and operated at different speeds of $1500,500,250$, and $50 \mathrm{rpm}$ at $34^{\circ} \mathrm{C}$ for a total period of 260 days. The OLR was increased between 0.6 and $3.5 \mathrm{~g} \mathrm{VS} / \mathrm{L}$ day. The shear level was quantified using computer automated radioactive particle tracking together with Computational Fluid Dynamics (CFD). The mean specific biogas production was $0.241 \pm 0.007 \mathrm{~m}^{3} / \mathrm{kg} \mathrm{VS}$, and the various mixing magnitude had no effect on biogas production under steady state conditions, but the reactor performance at $1500 \mathrm{rpm}$ was negatively affected at start up with higher effluent volatile fatty acid (VFA) concentrations. The acetoclastic methanogenic populations varied for the low and high intensity mixing, with Methanosaeta concilii and Methanosarcina spp as predominant methane producing microbes respectively.

\subsection{Mixing in household digesters}

The overview of different studies on domestic anaerobic biogas plants, mainly Chinese fixed dome and Plug flow digesters, is presented in Appendix 2. The overview provides information on the substrate type, inoculum, digester type, volume, organic loading rate, dilution ratio, HRT, temperature, biogas production rate, specific biogas production, and percentage of volatile solids degraded. Chinese dome digesters are mixed via pressure variation during gas use and feeding. There is no really mixing in Plug flow digesters, but convective transport longitudinal as feed passes through the digester in a horizontal direction from left to right i.e. inlet to outlet. Mixing in Chinese dome and plug flow digesters might depend on the feeding regime, the volumetric gas production $\left(\mathrm{m}^{3} / \mathrm{m}^{3} / \mathrm{d}\right)$, and therefore the organic loading rate, the gas use frequency and quantity, and the viscosity or rheological properties of the substrate and reactor content. The effect of mixing, mixing frequency, and intensity in household digesters are to the best of our knowledge not measured or quantified for studies presented in Appendix 1.2. Various operating parameters are presented in the table to find a link with mixing in household biogas plants.

Jihen et al., (2010) reported a high VS removal and high volumetric biogas production rate. $80 \%$ and $0.79 \mathrm{~m}^{3} / \mathrm{m}^{3} / \mathrm{d}$ respectively in a Chinese dome digester operated at an HRT of 23 days compared to other reported studies (Hamad et al., 1983; Polprasert et al., 1986; Kalia, 1988; Xavier and Nand 1990; Cuzin et al., 1992; Singh \& Anand 1993; Kanwar \& Guleri 1994; Singh et al., 1994; Kalia \& Singh 1997; Xuan \& Preston 1999; Lansing et al., 2010; Ferrer et al., 2011; Tamkin et al., 2014) reviewed in Appendix 1.2. The high VS removal and biogas production can be attributed to the concentration and nature of substrates applied in the digester. Dairy manufacture effluent (DME), the co-substrate applied by Jihen et al., (2010), is a highly biodegradable waste providing a balanced $\mathrm{C}: \mathrm{N}$ ration of 25 . The results show that a Chinese dome digester can provide a high volumetric gas production. However, household digesters generally have only access to more complex waste like animal manure and other agricultural wastes. Though, efficiencies could be increased, it is not yet clear to which extent. 
Cuzin et al., (1992), reported a volumetric biogas production of $2.4 \mathrm{~m}^{3} / \mathrm{m}^{3} /$ day at 45 days HRT in a plug flow digester. The high biogas production rate can be associated with the nature of the substrate (cassava) applied and the high OLR, $3.6 \mathrm{~kg} \mathrm{VS} / \mathrm{m}^{3} /$ day. However, Kalia and Sigh, (1997) also reported a similar high OLR rate $3.44-4.45 \mathrm{~kg} \mathrm{VS} / \mathrm{m}^{3} /$ day but lower biogas production rate, $0.52 \mathrm{~m}^{3} / \mathrm{m}^{3}$ /day applying cow manure as a substrate. The difference can be attributed to the high biodegradability of the cassava peel compared to cow manure and also probably the resulted degree of mixing in both digesters. The four times higher volumetric gas production in the plug flow system might also have affected the mixing in comparison to the Chinese dome digester. For all systems (Appendix 1.2), volumetric biogas production fluctuates greatly, depending on the loading rate and type of substrate applied.

\subsection{Forced mixed reactors}

Forced mixed reactors are mixed by different methods and equipment. The major types of forced mixing are hydraulic mixing, mechanical mixing, and pneumatic mixing. Hydraulic mixing is achieved by pumps, which recirculate digester content. In mechanical mixing, agitators and propellers are used to even out digester content. Pneumatic mixing makes use of the gas produced, which is injected into the reactor from the bottom to the surface of the digester content (Deublein and Steinhauster, 2008). The content of the digester can be continuously mixed, intermittently mixed, or not mixed. An intermittent mixing regime means mixing is switched on and off for a planned time interval ranging from just a few seconds to almost constant mixing (Lindmark et al., 2014).

To evaluate, the effect of mixing results of different laboratory mixing experiments reported in literature have been reviewed and presented in Appendix 1.3, which also reports the substrate type, inoculum, digester type, volume, organic loading rate, dilution ratio, HRT, temperature, biogas production rate, specific biogas production and percentage of volatile solids degraded. The table shows an overview of results from studies that have been conducted to evaluate the effect of mixing on biogas production, hydraulic retention time, organic loading rate, and VS reduction. They were conducted in lab-scale set-ups with different mixing modes. The mixing was executed either continuously, semi-continuously or intermittently, while applying biogas circulation, slurry recirculation, or mechanically mixing with sometimes unmixed conditions as a Blanco. The Appendix (1.3) focuses on comparing different continuous mixing modes to unmixed reactors. The parameters and results presented reveal that intermittent mixing modes aid anaerobic digestion when compared to continuously mixed digesters.

The highest specific biogas production reviewed in this study for mixed lab biogas plants is 0.71 $\mathrm{m}^{3} / \mathrm{kg}$ VS at $3 \mathrm{~kg}$ VS/day OLR, 6\% TS. The second and third highest specific biogas production are $0.70 \mathrm{~m}^{3} / \mathrm{kg} \mathrm{VS}$, at OLR $2 \mathrm{~kg} \mathrm{VS} / \mathrm{m}^{3} /$ day, $4 \% \mathrm{TS}$, and $0.64 \mathrm{~m}^{3} / \mathrm{kg} \mathrm{VS}$, at OLR $3.9 \mathrm{~kg} \mathrm{VS} / \mathrm{m}^{3} /$ day, $8 \%$ TS, respectively at 20 days HRT in a semi-continuously mixed plug flow digester treating fruit and vegetable waste (Bouallagui et al.,2003). The high specific biogas production in this study may be attributed to three factors; the high biodegradability of the applied substrate; the semicontinuous or intermittent mixing pattern; and the ability of the reactor to separate acidogenesis and methanogenesis, while horizontally allowing the plant to act like a two-phase system. 
Karim et al., (2005) at laboratory scale, evaluated the effect of various types of mixing (biogas circulation, impeller mixing, slurry recirculation, and unmixed) on specific biogas production, OLR, and digester start-up, using the recommended EPA (EPA, 1979) power input of $8 \mathrm{~W} / \mathrm{m}^{3}$ for all the digesters. The applied substrate is cow manure, OLR between $2-3.24 \mathrm{~kg}$ VS/day, 16.2 days $\mathrm{HRT}$ at $35^{\circ} \mathrm{C}$ for all the digesters. The highest specific biogas production reviewed is $0.51 \mathrm{~m}^{3} / \mathrm{kg}$ $\mathrm{VS}$ at an OLR of $3.24 \mathrm{~kg} \mathrm{VS} / \mathrm{m}^{3}$ day using biogas circulation as the mode of mixing. The authors concluded that there was no effect of mixing on digesters performance when applying an influent TS concentration less than 5\%. In contrast, the effect of mixing, speed, and the mode of mixing became important when TS concentration was between $10 \%$ and $15 \%$ because the rheological and viscosity properties of the substrate were changing at these concentrations. Gomez et al., (2006) and Rico et al., (2011) resolved from their results that the most important gain of changing mixing from continuous to semi-continuous (or intermittent) mixing mode is that almost the same gas production could be attained while using lower energy input, therefore making the anaerobic digestion process more energy efficient. Also, Ong et al., (2002) obtained the same biogas production from continuous and semi-continuous mixing experiments. When comparing the different types of mixing, it seemed that there was no disadvantage for semi-continuous (or intermittent) keeping of the mixing duration short. Intermittent or semi-continuous mixing seems enough for the digestion process operating at lower TS influent concentration. However, the mode of mixing becomes crucial when higher TS concentrations are applied (Karim et al., 2005). Reactors mixing during start-up (before the biogas production rate becomes stable) was not beneficial (Karim et al., 2005; Hoffmann et al., 2008) to almost all digesters but was, during steady state (Karim et al.,2005). Mixed digesters during steady state produced more biogas than unmixed digesters. These results are similar to Vesvikar, (2006). Hoffmann et al., (2008) recorded at steady state, the same specific biogas production of $0.38 \mathrm{~m}^{3} / \mathrm{kg}$ VS at same, OLR, substrate, temperature, and HRT at different mixing speeds, viz. 50 - $1500 \mathrm{rpm}$. But for digestion experiment at 1500 $\mathrm{rpm}$, there was negative effect on digester performance at reactor start-up.

United States Environmental Protection Agency (EPA) recommends a power input anaerobic digester of $8 \mathrm{~W} / \mathrm{m}^{3}$, resembling $275 \mathrm{rpm}$. Karim et al., (2005) and Hoffmann et al., (2008) showed similar digestion performance at a mixing rate between 50 and $275 \mathrm{rpm}$, indicating that a power input could be reduced to $1.2 \mathrm{w} / \mathrm{m}^{3}$.

Therefore, applying semi-continuous or intermittent mixing mode could be applied in anaerobic digesters to achieve similar biogas production, while consuming less energy, making the anaerobic digestion process energy efficient (Gomez et al., 2006).

\subsection{General discussion: mixing in household vs. forced mixed reactors}

It has been shown in this review that mixing is an important parameter in anaerobic digesters. Mixing in domestic biogas digesters is difficult to quantify and poorly reported. Intermittent or semi-continuous mixing in comparison to continuous mixing is beneficial for anaerobic digestion during start-up, and in enhancing interaction between microorganisms. Lower mixing during reactor start-up allows for a more stable $\mathrm{AD}$ process and permits the microbial community to 
develop faster. Semi-continuous mixing during digester start-up permits for a more stable digestion process probably due to non-disturbed interaction among different microbial groups (Zeeman, 1991; Stroot et al., 2001). During start-up, strong mixing intensity in digesters may cause an unstable process and continuous mixing contributed to low biogas production in the reviewed articles. However, this does not imply that continuous mixing will have a negative effect on the performance of the biogas plant on the long term.

Unequal mixing as occurring in unmixed digesters or intermittently mixed digesters can produce protective pockets of stagnant regions that can act as inoculation zones for methane producing bacteria and offer protection for the methanogens during acidification. When unmixed and household biogas plants perform well, the performance could be attributed to natural mixing caused by feeding, long hydraulic retention time, decantation, and volumetric biogas production rate at lower organic loading rates or higher dilution.

In household digesters, quantifying energy input for mixing is difficult and therefore challenging to optimize. According to Hoffman et al., (2008), high mixing intensity did not have much effect on biogas production during steady state and mixing intensity between 50-100 rpm is sufficient for biogas production. It can be argued that semi-continuous or intermittent mixing may be more advantageous than continuous mixing if energy is of interest. Semi-continuous mixing mode can therefore produce similar amount of biogas in continuously stirred systems.

Chinese dome digesters are not mechanically mixed or mixed by gas or liquid recirculation. They are mixed as a result of natural occurring processes, viz. substrate feeding, volumetric gas production, pressure difference, and effluent removal. Therefore, they could be regarded as intermittently mixed digesters. Moreover, for the Fixed dome digester, the degree of mixing will depend on the reactor geometry, type of feed, OLR, and frequency of gas use. When considering the optimization of low cost household digesters without input of energy for forced mixing, the challenge would be to quantify the natural mixing in relation to the above-mentioned parameters and optimize the digester performance accordingly. The interest of optimizing domestic biogas plants is of course to generate as much biogas as possible while applying lowest cost or input. In mixing household digester, there are no cost to be considered on mixing equipment and operation. It has been established earlier in this review that, it can be inferred that a semi-continuous/or an intermittent mixing mode at $1.5 \mathrm{~W} / \mathrm{m}^{3}$ or $50 \mathrm{rpm}$ aid anaerobic digestion and is sufficient for biogas production compared to continuous mixing. This means the natural mixing parameters such as substrate feeding, volumetric gas production, pressure difference, and effluent removal in household digesters need to be quantified and translated to the required input energy so that mixing optimization could be achievable.

Furthermore, comparing the results of the studies presented in Appendix 1.3 and Appendix 1.2 is difficult because the mixing in the household digesters presented in Appendix 1.2 is not quantified in any study. The organic loading rate and HRT vary significantly between the household reactors reported in literature and the anaerobic digestion systems applying forced mixing, presented in Appendix 3. The performance results of the anaerobic digestion systems applying forced mixing implies that optimization of the household digesters, depending on natural mixing, is possible. The application of higher input concentration by lower dilution of substrate at the same HRT will 
not only result in smaller reactor volume but also in higher volumetric gas productions. Together with the gas use frequency, the latter is a promising parameter to influence mixing conditions and therefore process performance of household digesters. The potential for improvement is large. HRTs and OLRs applied in reactors with forced mixing as reported in this study vary between 10 and 20 days at 0.6 and $6.9 \mathrm{~kg} \mathrm{VS} / \mathrm{m}^{3} /$ day respectively while these vary between $23-170$ days at $0.04-4.45 \mathrm{~kg} \mathrm{VS} / \mathrm{m}^{3}$ day respectively for household digesters. The average biogas production rate of $1.3 \mathrm{~m}^{3} / \mathrm{m}^{3}$ day in reactors with forced mixing is higher compared to the average of $0.5 \mathrm{~m}^{3} /$ $\mathrm{m}^{3}$ day in household digesters. Similarly, the average specific biogas production is $30 \%$ higher in forced mixed reactors compared to household systems.

In an attempt to improve natural mixing in small scale biogas systems without mechanical mixing Kobayashi \& Li, (2011) and Qi et al., (2013) have reported a self-agitating biogas reactor suitable for application at small scale. Their preliminary results showed that the self-agitated system could be compared in digestion performance to the combination of Completely Stirred Tank Reactor (CSTR) and plug flow reactor in series. Mixing in the self-agitating biogas reactor is achieved periodically by the biogas generated. Mixing is done by the blast from the generated biogas and sudden change of the flow pattern in the liquid levels in the reactor. The applied substrate for the simulation is water with Newtonian properties (Qi et al., 2013).

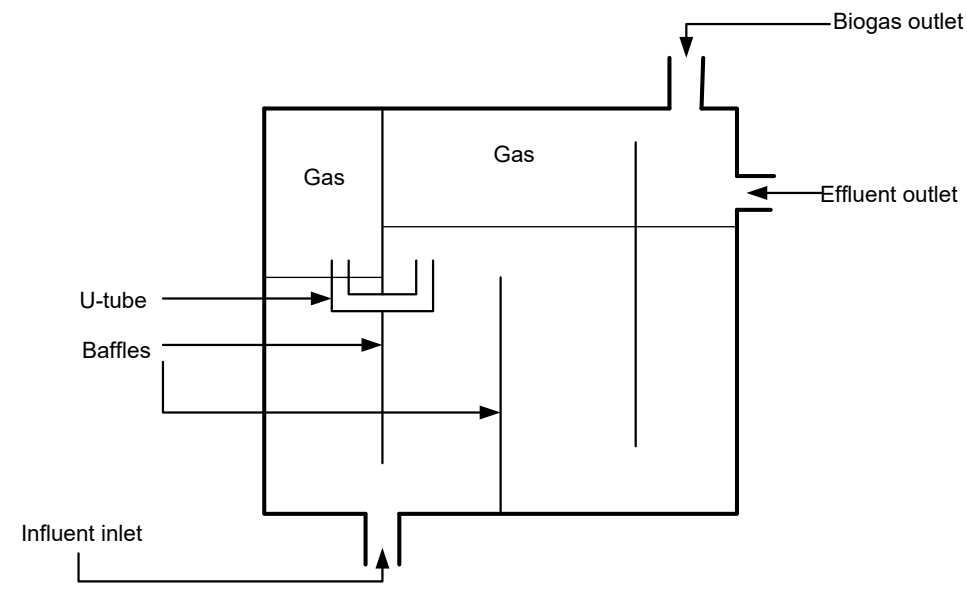

Figure 2.7 | Schematic diagram of the self-agitation anaerobic baffled reactor based on Qi et al., (2013).

One major difference between the self-agitating and the Chinese dome digester is that the selfagitating digester has two chambers for the gas phase that are linked together with a u-tube, and the liquid phase is divided into four with the use of baffles as shown in Figure 1.7. The way mixing is achieved in the system is similar to the commercial biogas induced mixing arrangement (BIMA) large scale digesters designed by Entec Biogas gmbh (Entec-Biogas, 2016). Moreover, this design needs testing and validation with higher organic loading rates and substrates such as cow manure or pig manure usually applied in household digesters. Future research in household digester should also focus on studying the prevention of sedimentation and flotation which occur 
in household digesters, because there is high tendency to mistakenly decant effluent with lower TS concentration during wasting (or effluent withdrawal) and indirectly increasing the retention time of the settled reactor content.

\subsection{Conclusion}

Most applied household digesters are the Chinese dome and the Plug flow digesters. Mixing in these digesters is not quantified and established via pressure build up and flow of influent from inlet to outlet. Household digesters are generally operated at a low organic rate between 0.05-2 $\mathrm{kg} \mathrm{VS} / \mathrm{m}^{3} /$ day established via a long HRT and dilution of the substrate (generally manure) at < $7 \%$ TS.

Mixing in forced mixed reactors or completely stirred tank reactors (CSTRs) is established by impeller mixing, effluent recirculation, and biogas circulation. Research on the effect of mixing in forced mixed reactors was generally applied at lab scale and focuses on type of mixing at fixed energy input, different influent TS concentrations, and continuous mixing versus intermittent mixing during start-up and at steady state conditions. Results show that during reactor start-up, intermittent or no mixing is preferred because continuous mixing generally decreased digester stability. During steady state, no difference was observed in digestion performance between continuous mixing and intermittent mixing, and mixing intensity was not positively affecting digestion performance between $50 \mathrm{rpm}$ and $1500 \mathrm{rpm}$ at < 10\% TS. At higher TS concentration > $10 \%$, a higher mixing intensity is required to achieve similar performance.

Household digesters could be regarded as an intermittently mixed reactor, and mixing in Chinese dome digester could be positively affected by higher volumetric gas production and increased frequency of gas use. The latter could be achieved by increased loading rate, and by applying less dilution of the influent and/or shorter HRT, both leading to smaller reactor volumes. Future research should focus on quantifying energy input and optimizing mixing in the household digester at higher influent TS concentration and/or shorter HRT.

\section{Acknowledgements}

This work was funded by the Netherlands Fellowship Programme (NFP), the Netherlands. 


\section{Appendices}

Appendix 1.1 | Number of biogas plants installed through SNV supported programme. Source: SNV (2014).

\begin{tabular}{|c|c|c|c|c|}
\hline Country & $\begin{array}{l}\text { Programme } \\
\text { took off in }\end{array}$ & $\begin{array}{r}\text { No. of biogas plants } \\
\text { installed in } 2012\end{array}$ & $\begin{array}{r}\text { Cumulative } \\
\text { up to } 2012\end{array}$ & $\begin{array}{l}\text { Cumulative up } \\
\text { to } 1^{\text {st }} \text { half of } 2013\end{array}$ \\
\hline \multicolumn{5}{|l|}{ Asia } \\
\hline Nepal & 1992 & 18,383 & 268,444 & 290,508 \\
\hline Vietnam & 2003 & 28,717 & 152,431 & 158,602 \\
\hline Bangladesh & 2006 & 5,555 & 26,311 & 28,901 \\
\hline Cambodia & 2006 & 4,201 & 19,173 & 19,682 \\
\hline Lao PDR & 2007 & 483 & 2,888 & 2,888 \\
\hline Pakistan & 2009 & 915 & 2,354 & 2,814 \\
\hline Indonesia & 2009 & 3,368 & 7,981 & 9,375 \\
\hline Bhutan & 2011 & 265 & 305 & 905 \\
\hline
\end{tabular}

\begin{tabular}{|c|c|c|c|c|}
\hline \multicolumn{5}{|l|}{ Africa } \\
\hline Kenya & 2009 & 3,510 & 6,749 & 9,046 \\
\hline Tanzania & 2008 & 2,409 & 4,980 & 6,906 \\
\hline Ethiopia & 2008 & 2511 & 5,011 & 6,393 \\
\hline Uganda & 2009 & 1,181 & 3,083 & 4,087 \\
\hline Rwanda & 2007 & 773 & 2,519 & 3,030 \\
\hline Burkina Faso & 2009 & 1,292 & 2,013 & 2,944 \\
\hline Senegal & 2010 & 95 & 334 & 334 \\
\hline Cameroon & 2009 & 54 & 159 & 172 \\
\hline Benin & 2010 & 12 & 54 & 72 \\
\hline Total & & 73,724 & 504,889 & 546,659 \\
\hline
\end{tabular}


Appendix 1.2 | Review of Studies on household biogas plant, "unstirred" systems.

\begin{tabular}{|c|c|c|c|c|c|c|}
\hline No. & $\begin{array}{l}\text { Substrate } \\
\text { inoculum }\end{array}$ & $\begin{array}{l}\text { Design } \\
\text { Operating mode }\end{array}$ & $\begin{array}{l}\text { Volume } \\
\mathbf{m}^{3}\end{array}$ & $\begin{array}{l}\text { OLR } \\
\mathrm{kg} \mathrm{VS} / \mathrm{m}^{3} / \mathrm{d}\end{array}$ & $\begin{array}{l}\text { Loading } \\
\text { rate/day }\end{array}$ & $\begin{array}{l}\text { TS } \\
\%\end{array}$ \\
\hline 1 & Dairy manure & Chinese dome & 1.14 & $0.04-0.18$ & & \\
\hline 2 & Buffalo dung & Chinese dome & 5 & $1.79-2.4^{*}$ & & 9- 11 \\
\hline 3 & Dairy effluent, biological waste & Chinese dome & 5 & 1.64 & & \\
\hline 4 & Cattle dung & $\begin{array}{l}\text { Fixed dome, Deebandhu } \\
\text { Semicontinous }\end{array}$ & 2 & & $80 \mathrm{~L}$ & 9 \\
\hline 5 & cattle + Horse dung & $\begin{array}{l}\text { Fixed dome, Deebandhu } \\
\text { Semicontinous }\end{array}$ & 1 & $1.72-2.23^{*}$ & & $8-10$ \\
\hline 6 & cattle dung & $\begin{array}{l}\text { Fixed dome, Deebandhu } \\
\text { Semicontinous }\end{array}$ & 2 & $3.44-4.45^{*}$ & & $8-10$ \\
\hline 7 & $\begin{array}{l}\text { Night Soil, water hyacinth rice straw } \\
\text { wastewater sludge }\end{array}$ & $\begin{array}{l}\text { Fixed dome, with mechanical } \\
\text { mixer }\end{array}$ & 3.5 & 1.2 & & \\
\hline 8 & $\begin{array}{l}\text { Night Soil, water hyacinth rice straw } \\
\text { wastewater sludge }\end{array}$ & Fixed dome & 3.5 & 0.75 & & \\
\hline 9 & $\begin{array}{l}\text { Night Soil, water hyacinth, rice straw } \\
\text { wastewater sludge }\end{array}$ & Fixed dome & 3.5 & 0.53 & & \\
\hline 10 & Cow dung & Fixed dome plug flow & 9.2 & $1.1^{*}$ & & \\
\hline 11 & Cow dung & Fixed dome plug flow & 8.1 & $1.1^{*}$ & & \\
\hline 12 & $\begin{array}{l}\text { Cassava peel } \\
\text { cassava peel, straw }\end{array}$ & $\begin{array}{l}\text { plug flow } \\
\text { semicontinous }\end{array}$ & 0.128 & 3.6 & & $25-35$ \\
\hline 13 & Pig manure, Cooking grease pig manure & Plug Flow & 0.25 & & $5 \mathrm{~L}$ & \\
\hline 14 & Pig manure, Cooking grease pig manure & Plug Flow & 0.25 & & $5 \mathrm{~L}$ & \\
\hline 15 & Pig manure, Cooking grease pig manure & Plug Flow & 0.25 & & $5 \mathrm{~L}$ & \\
\hline 16 & Pig manure & Plug flow, semicontinous & 1.5 & 0.34 & & \\
\hline 17 & Pig manure & Plug flow semiconitnous & 1.5 & 1.4 & & \\
\hline 18 & Cattle dung & Plug flow, semicontinous & 2 & & $80 \mathrm{~L}$ & 9 \\
\hline 19 & Cow manure & Plug flow, semicontinous & 7.5 & 0.22 & & $15-20$ \\
\hline 20 & Cow manure & Plug flow, semicontinous & 2.4 & 1.3 & & $15-20$ \\
\hline 21 & Night soil residue (Agaratum and Lantana) & Floating dome, semi continuous & 0.025 & & & \\
\hline 22 & Cattle waste & KVIC Floating dome & 2.5 & 2.2 & $40 \mathrm{~kg}$ & $\sim 17$ \\
\hline 23 & Buffalo dung & Floating dome & 7 & $2.2^{*}$ & & 9.- 11 \\
\hline 24 & Cow dung cow slurry fruit and Vegetable & Fixed bed, semi continuous & 0.06 & 1.1 & & 8 \\
\hline 25 & Cattle waste & $\begin{array}{l}\text { Solid State Digester Cylindrical } \\
\text { vertical }\end{array}$ & 2.5 & 2.2 & $40 \mathrm{~kg}$ & $\sim 17$ \\
\hline
\end{tabular}

* Calculated. Inoculum in italics 


\begin{tabular}{|c|c|c|c|c|c|c|c|}
\hline Dilution & HRT & Days of & Temp. & Biogas prod. & Specific bio & VS removal & References \\
\hline s:w & day & Operation & ${ }^{\circ} \mathrm{C}$ & $\mathbf{m}^{3} / \mathbf{m}^{3} / \mathbf{d}$ & $\mathrm{m}^{3} / \mathrm{kg} \mathrm{VS}$ & $\%$ & \\
\hline $1: 1$ & $170-695$ & & $2-33$ & $0.004-0.10$ & $0.10-0.57^{*}$ & & Tamkin et al., (2014) \\
\hline $1: 1$ & 35 & & 20 & $0.13-0.23$ & $0.07-0.09^{*}$ & $\sim 27$ & Hamad et al., (1983) \\
\hline & 23 & 120 & 55 & 0.79 & 0.48 & 80 & Jihen et al., (2010) \\
\hline & 55 & 365 & $13-24$ & 0.62 & & 44.3 & Kanwar \& Guleri, (1994) \\
\hline $1: 1$ & 55 & 365 & $10-25$ & $0.56^{*}$ & $0.25-0.33^{*}$ & $11.6-12.3^{*}$ & Kalia \& Singh, (1997) \\
\hline $1: 1$ & 55 & 365 & $10-26$ & $0.52^{*}$ & $0.12-0.15^{*}$ & $7-7.9$ & Kalia \& Singh, (1997) \\
\hline $1: 10$ & 30 & 95 & $20-32$ & $0.336^{*}$ & $\sim 0.278$ & & Polprasert et al., (1986) \\
\hline $1: 10$ & 50 & 95 & $20-32$ & $0.24^{*}$ & $\sim 0.321$ & & Polprasert et al., (1986) \\
\hline $1: 10$ & 70 & 95 & $20-32$ & $0.133^{*}$ & $\sim 0.249$ & & Polprasert et al., (1986) \\
\hline $1: 1$ & 79 & 365 & $21-25$ & $0.74-0.75^{*}$ & $0.63-0.65$ & & Kalia A K. (1988) \\
\hline $1: 1$ & 70 & 365 & $22-25$ & $0.66-0.69^{*}$ & $0.67-0.68$ & & Kalia A K. (1988) \\
\hline & 45 & 600 & $35-39$ & $2.4^{*}$ & 0.661 & & Cuzin et al., (1992) \\
\hline $4: 1$ & 40 & 270 & $22-26$ & & 0.443 & & Lansing et al., (2010) \\
\hline $4: 1$ & 40 & 270 & $22-26$ & & 0.273 & & Lansing et al., (2010) \\
\hline $4: 1$ & 40 & 270 & $22-26$ & & 0.189 & & Lansing et al., (2010) \\
\hline & 30 & 56 & $25-27$ & $0.082^{*}$ & 0.24 & & Xuan \& Preston, (1999) \\
\hline & 30 & 56 & $25-27$ & $0.42^{*}$ & 0.3 & & Xuan \& Preston, (1999) \\
\hline & 55 & 365 & $13-24$ & $0.46^{*}$ & & 37.5 & Kanwar \& Guleri, (1994) \\
\hline $1: 4$ & 90 & 365 & $20-25$ & 0.07 & 0.32 & & Ferrer et al., (2011) \\
\hline $1: 2$ & 60 & 365 & $20-25$ & 0.42 & 0.36 & & Ferrer et al., (2011) \\
\hline & 25 & 365 & 10 & & 0.06972 & & Singh et al., (1994) \\
\hline $1: 1$ & 30 & 365 & $25-38$ & 0.48 & 0.223 & 36.4 & Singh \& Anand, (1993) \\
\hline $1: 1$ & 57 & & 27.5 & 0.31 & 0.14 & 47 & Hamad et al., (1983) \\
\hline & 30 & 60 & 30 & $0.11-0.40^{*}$ & $0.11-0.36$ & & Xavier \& Nand, (1990) \\
\hline $1: 1$ & 60 & 365 & $25-38$ & 0.33 & 0.15 & 24 & Singh \& Anand, (1993) \\
\hline
\end{tabular}


Appendix 1.3 | Studies of effect of degree of mixing on biogas production.

\begin{tabular}{|c|c|c|c|c|c|c|c|}
\hline \multicolumn{2}{|c|}{ No. Substrate inoculum } & \multirow{2}{*}{$\begin{array}{l}\text { Mixing Mode } \\
\text { semicontinous tubular }\end{array}$} & \multirow{2}{*}{$\begin{array}{l}\begin{array}{l}\text { Volume } \\
\text { L }\end{array} \\
18\end{array}$} & \multirow{2}{*}{$\begin{array}{l}\begin{array}{l}\text { OLR } \\
\mathrm{kgVS} / \mathrm{m}^{3} \mathrm{~d}\end{array} \\
2\end{array}$} & \multirow{2}{*}{$\begin{array}{l}\begin{array}{l}\text { Loading } \\
\text { rate/day }\end{array} \\
1 \mathrm{~kg}\end{array}$} & \multirow{2}{*}{$\begin{array}{l}\text { TS } \\
\% \\
4\end{array}$} & \multirow{2}{*}{\begin{tabular}{|l|}
$\begin{array}{l}\text { HRT } \\
\text { day }\end{array}$ \\
20
\end{tabular}} \\
\hline 1 & $\begin{array}{l}\text { Fruit, Vegetable waste Olive oil } \\
\text { waste water, cow dung slurry }\end{array}$ & & & & & & \\
\hline 2 & $\begin{array}{l}\text { Fruit, Vegetable waste Olive oil } \\
\text { waste water, cow dung slurry }\end{array}$ & Semicontinous tubular & 18 & 3 & $1 \mathrm{~kg}$ & 6 & 20 \\
\hline 3 & $\begin{array}{l}\text { Fruit, Vegetable waste, Olive oil } \\
\text { waste water, cow dung slurry }\end{array}$ & Semicontinous tubular & 18 & 3.9 & $1 \mathrm{~kg}$ & 8 & 20 \\
\hline 4 & Cow manure cow manure & $\begin{array}{l}\text { Continuous } \\
100 \mathrm{rpm}\end{array}$ & 10 & 6.8 & & 8 & 10 \\
\hline 5 & Cow Manure cow manure & $\begin{array}{l}\text { Semi continuous } 160 \mathrm{rpm} 4 \mathrm{x} \\
30 \mathrm{~min} / \mathrm{day}\end{array}$ & 10 & 6.8 & & 8 & 10 \\
\hline 6 & Cow Manure cow manure & $\begin{array}{l}\text { continuous } \\
100 \mathrm{rpm}\end{array}$ & 10 & 6.8 & & 8 & 10 \\
\hline 7 & Cow Manure cow manure & $\begin{array}{l}\text { continuous } \\
200 \mathrm{rpm}\end{array}$ & 10 & 6.8 & & 8 & 10 \\
\hline 8 & Cow manure & biogas circulation & 3.73 & 2 & & 5 & 16.2 \\
\hline 9 & Cow manure & impeller & 3.73 & 2 & & 5 & 16.2 \\
\hline 10 & Cow manure & slurry recirculation & 3.73 & 2 & & 5 & 16.2 \\
\hline 11 & Cow manure & unmixed & 3.73 & 3.24 & & 10 & 16.2 \\
\hline 12 & Cow manure & biogas circulation & 3.73 & 3.24 & & 10 & 16.2 \\
\hline 13 & Cow manure & impeller & 3.73 & 3.24 & & 10 & 16.2 \\
\hline 14 & Cow manure & slurry recirculation & 3.73 & 3.24 & & 10 & 16.2 \\
\hline 15 & Cow manure & unmixed & 3.73 & 3.24 & & 10 & 16.2 \\
\hline 16 & Cow manure & biogas circulation & 3.73 & 3.24 & & 10 & 16.2 \\
\hline 17 & Cow manure & impeller & 3.73 & 3.24 & & 10 & 16.2 \\
\hline 18 & Cow manure & unmixed & 3.78 & & $0.46 \mathrm{~L}$ & & 16.2 \\
\hline 19 & Cow manure & biogas circulation & 3.78 & & $0.46 \mathrm{~L}$ & & 16.2 \\
\hline 20 & Cow manure & impeller & 3.78 & & $0.46 \mathrm{~L}$ & & 16.2 \\
\hline 21 & Cow manure & slurry & 3.78 & & $0.46 \mathrm{~L}$ & & 16.2 \\
\hline & & recirculation & & & & & \\
\hline 22 & Cow manure & unmixed & 97 & & $12 \mathrm{~L}$ & & 16.2 \\
\hline 23 & Cow manure & biogas circulation & 97 & & $12 \mathrm{~L}$ & & 16.2 \\
\hline 24 & Cow manure primary sludge & $1500 \mathrm{rpm}$ & 4.5 & $0.6-3.5$ & & & $15-83$ \\
\hline 25 & Cow manure primary sludge & $500 \mathrm{rpm}$ & 4.5 & $0.6-3.5$ & & & $15-83$ \\
\hline 26 & Cow manure primary sludge & $250 \mathrm{rpm}$ & 4.5 & $0.6-3.5$ & & & $15-83$ \\
\hline 27 & Cow manure primary sludge & $50 \mathrm{rpm}$ & 4.5 & $0.6-3.5$ & & & $15-83$ \\
\hline 28 & $\begin{array}{l}\text { Screened diary manure screened } \\
\text { diary manure }\end{array}$ & continuous slurry recirculation & 1500 & 2.3 & & 6.1 & 20 \\
\hline 29 & $\begin{array}{l}\text { Screened diary manure screened } \\
\text { diary manure }\end{array}$ & $\begin{array}{l}\text { semi-continuous slurry } \\
\text { recirculation } 30 \mathrm{~min} 10 \mathrm{x} / \mathrm{d}\end{array}$ & 1500 & 2.3 & & 6.1 & 20 \\
\hline 30 & $\begin{array}{l}\text { Screened diary manure screened } \\
\text { diary manure }\end{array}$ & $\begin{array}{l}\text { semi-continuous slurry } \\
\text { recirculation for heating } 2.5 \mathrm{~h} / \mathrm{d}\end{array}$ & 1500 & 2.3 & & 6.1 & 20 \\
\hline 31 & $\begin{array}{l}\text { Screened diary manure screened } \\
\text { diary manure }\end{array}$ & continuous slurry recirculation & 1500 & 4.5 & & 6.1 & 10 \\
\hline 32 & $\begin{array}{l}\text { Screened diary manure screened } \\
\text { diary manure }\end{array}$ & $\begin{array}{l}\text { semi-continuous slurry } \\
\text { recirculation } 30 \mathrm{~min} 10 \mathrm{x} / \mathrm{d}\end{array}$ & 1500 & 4.5 & & 6.1 & 10 \\
\hline 33 & $\begin{array}{l}\text { Screened diary manure screened } \\
\text { diary manure }\end{array}$ & $\begin{array}{l}\text { semi-continuous slurry } \\
\text { recirculation for heating } 2.5 \mathrm{~h} / \mathrm{d}\end{array}$ & 1500 & 4.5 & & 6.1 & 10 \\
\hline
\end{tabular}

\footnotetext{
* Calculated
} 


\begin{tabular}{|c|c|c|c|c|c|c|}
\hline $\begin{array}{l}\text { Duration } \\
\text { day }\end{array}$ & $\begin{array}{l}\text { Temp. } \\
{ }^{\circ} \mathrm{C}\end{array}$ & $\begin{array}{l}\text { Biogas prod. } \\
\mathbf{m}^{3} / \mathbf{m}^{3} / \mathrm{d}\end{array}$ & $\begin{array}{l}\text { Specific bioga } \\
\mathrm{m}^{3} / \mathrm{kg} \text { VS }\end{array}$ & $\begin{array}{l}\text { sVS removal } \\
\%\end{array}$ & Effect of mixing & Reference \\
\hline 50 & 35 & $1.4^{*}$ & 0.7 & 74.4 & & Bouallagui et al., (2002) \\
\hline 50 & 35 & $2.13^{*}$ & 0.71 & 75.91 & & Bouallagui et al., (2002) \\
\hline 50 & 35 & $2.5^{*}$ & 0.64 & 64.58 & & Bouallagui et al., (2002) \\
\hline 70 & 35 & $1.39^{*}$ & 0.2 & & $\begin{array}{l}\text { biogas production same as semi } \\
\text { continuous (intermittent) }\end{array}$ & Ong et al., (2002) \\
\hline 70 & 35 & $1.36^{*}$ & 0.2 & & $\begin{array}{l}\text { biogas production same as } \\
\text { continuous mixing }\end{array}$ & Ong et al., (2002) \\
\hline 70 & 35 & $1.62^{*}$ & 0.23 & & $\begin{array}{l}\text { biogas production same as semi } \\
\text { continuous (intermittent) }\end{array}$ & Ong et al., (2002) \\
\hline 70 & 35 & $1.30^{*}$ & 0.18 & & $\begin{array}{l}\text { biogas production same as semi } \\
\text { continuous (intermittent) }\end{array}$ & Ong et al., (2002) \\
\hline 80 & 35 & $0.94^{*}$ & 0.47 & & more biogas not beneficial at start-up & Karim et al., (2005) \\
\hline 80 & 35 & $0.88^{*}$ & 0.44 & & more biogas not beneficial at start-up & Karim et al., (2005) \\
\hline 80 & 35 & $0.86^{*}$ & 0.43 & & more biogas not beneficial at start-up & Karim et al., (2005) \\
\hline 80 & 35 & $0.91^{*}$ & 0.28 & & & Karim et al., (2005) \\
\hline 80 & 35 & $1.1^{*}$ & 0.33 & & more biogas not beneficial at start-up & Karim et al., (2005) \\
\hline 80 & 35 & $1.13^{*}$ & 0.35 & & more biogas not beneficial at start-up & Karim et al., (2005) \\
\hline 80 & 35 & $1.2^{*}$ & 0.37 & & more biogas not beneficial at start-up & Karim et al., (2005) \\
\hline 80 & 35 & $1.1^{*}$ & 0.34 & & & Karim et al., (2005) \\
\hline 80 & 35 & $1.7^{*}$ & 0.51 & & more biogas not beneficial at start-up & Karim et al., (2005) \\
\hline 80 & 35 & $1.2^{*}$ & 0.38 & & more biogas not beneficial at start-up & Karim et al., (2005) \\
\hline 90 & $25-40$ & & 0.35 & 35 & & Vesvikar, (2006) \\
\hline 90 & $25-40$ & & 0.39 & 39 & & Vesvikar, (2006) \\
\hline 90 & $25-40$ & & 0.41 & 41 & & Vesvikar, (2006) \\
\hline 90 & $25-40$ & & 0.35 & 35 & & Vesvikar, (2006) \\
\hline 90 & 35 & & 0.1 & & $\begin{array}{l}\text { biogas production: degree of } \\
\text { mixing depends on reactor size }\end{array}$ & Vesvikar, (2006) \\
\hline 90 & 35 & & 0.2 & & $\begin{array}{l}\text { biogas production: degree of } \\
\text { mixing depends on reactor size }\end{array}$ & Vesvikar, (2006) \\
\hline 260 & 34 & $0.23-1.33$ & $0.36^{*}$ & & $\begin{array}{l}\text { same biogas production as } \\
\text { others, negative effect at start-up. } \\
\text { thanogens competition }\end{array}$ & Hoffmann et al.,(2008) \\
\hline 260 & 34 & $0.23-1.33$ & $0.36^{*}$ & & $\begin{array}{l}\text { same biogas production asothers. } \\
\text { Methanogens competition }\end{array}$ & Hoffmann et al., (2008) \\
\hline 260 & 34 & $0.23-1.33$ & $0.36^{*}$ & & same biogas production as others. & Hoffmann et al., (2008) \\
\hline 260 & 34 & $0.23-1.33$ & $0.36^{*}$ & & same biogas production as others. & Hoffmann et al., (2008) \\
\hline$\sim 185$ & 37 & 0.71 & $0.31^{*}$ & & $\begin{array}{l}\text { continuous recirculation did not } \\
\text { affect reactor performance. }\end{array}$ & Rico et al., (2011) \\
\hline$\sim 185$ & 37 & 0.70 & $0.30^{*}$ & & $\begin{array}{l}\text { continuous recirculation did not } \\
\text { affect reactor performance }\end{array}$ & Rico et al., (2011) \\
\hline$\sim 185$ & 37 & 0.71 & $0.31^{*}$ & & $\begin{array}{l}\text { continuous recirculation did not } \\
\text { affect reactor performance. }\end{array}$ & Rico et al., (2011) \\
\hline$\sim 185$ & 37 & 1.30 & $0.29^{*}$ & & $\begin{array}{l}\text { continuous recirculation did not } \\
\text { improve reactor performance }\end{array}$ & Rico et al., (2011) \\
\hline$\sim 185$ & 37 & 1.34 & $0.30^{*}$ & & $\begin{array}{l}\text { continuous recirculation did not } \\
\text { improve reactor performance }\end{array}$ & Rico et al., (2011) \\
\hline$\sim 185$ & 37 & 1.26 & $0.28^{*}$ & & $\begin{array}{l}\text { continuous recirculation did not } \\
\text { improve reactor performance }\end{array}$ & Rico et al., (2011) \\
\hline
\end{tabular}




\section{References}

Adeoti O. (1998). Engineering economy studies of biogas as renewable energy source at household level in Nigeria. M.Sc. Thesis in Technology Management, Technology Planning and Development, Unit, Faculty of Technology, Obafemi Awolowo University, Ile-Ife, Nigeria.

Akinbami J.F.K., Ilori M. O., Oyebisi T.O., Akinwunmi I.O., Adeoti O. (2001). "Biogas Energy Use in Nigeria: Current Status, Future Prospects and Policy Implications.” Renewable and Sustainable Energy Reviews 5(1): 97 -112.

An B.X., Preston, T.R. (1999). Gas production from pig manure fed at different loading rates to polyethylene tubular biodigesters." Livest. Res. Rural Dev., 11. (1) http://www.cipav.org.co/lrrd/lrrd11/1/an111.htm

Anand R.C., Singh, R. (1993). A simple technique, charcoal coating around the digester, improves biogas production in winter." Bioresour. Technol., 45, 151-152.

Anjan K.K. (1988). Development and evaluation of a fixed dome plug flow anaerobic digester. Biomass, 16: 225-235.

Arthur R., Baidoo M. F., Brew-Hammond A. (2011). Biogas generation from sewage in four public universities in Ghana: A solution to potential health risk. Biomass and Bioenergy, 35: 3086 -3093.

Arthur R, Baidoo MF, Antwi E. (2011). Biogas as a potential renewable energy source. A Ghanaian case study. Renew Energ, 36(5):1510-6.

Axaopoulos P., Panagakis P. (2003). Energy and economic analysis of biogas heated livestock buildings. Biomass and Bioenergy, 24: 239-248.

Bajgain S, Shakya I, Mendis M S. (2005). The Nepal Biogas Support Program: a successful model of public private partnership for rural household energy supply. Report prepared by Biogas Support Program Nepal. Kathmandu, Nepal: Vision Press P. Ltd.

Balasubramaniyam U., Zisengwe L. S., Meriggi N., Buysman E, (2008). Biogas production in climates with long cold winters. WECF.

Barber W. P., Stuckey D. C. (1999). The use of the anaerobic baffled reactor (ABR) for wastewater treatment: A review. Water Research 33(7) 1559-1578.

Bond T., Templeton M.R. (2011). History and future of domestic biogas plants in the developing world. Energy Sustain. Dev., 15: 347-354.

Bouallagui H., Ben Cheikh R., Marouani L., Hamdi M. (2003). Mesophilic biogas production from fruit and vegetable waste in a tubular digester. Bioresour. Technol., 86:85-89

Bridgeman J., (2012). Computational fluid dynamics modeling of sewage sludge mixing in an anaerobic digester. Advances in Engineering Software. 44: 54-62.

Buysman E, (2009). Anaerobic Digestion for Developing Countries with Cold Climates. M.Sc. Thesis. Wageningen University, Netherlands.

Cheng S., Li Z., Mang H. P., Huba E. M., (2013). A review of prefabricated biogas digesters in China. Renewable and Sustainable Energy Reviews 28, $738-748$.

Chen Y, Yang G, Sweeney S, Feng Y. (2010). Household biogas use in rural China: a study of opportunities and constraints. Renewable and Sustainable Energy Reviews 14 (1):545-9.

China National Development and Reform Commission (NDRC) (2007). China's medium to long-term renewable energy development plan. (http://www.chinaenvironmentallaw.com/wp-content/uploads/2008/04/mediumand- long-termdevelopment-plan-for-renewable-energy.pdf)

Ciotola R.J., Martin J.F., Castańo J.M., Lee J., Michel F. (2013). Microbial community response to seasonal temperature variation in a small-scale anaerobic digester. Energies, 6:5182-5199.

Collins G, Malony T., O’Flaherty V. (2006). Stability and reproducibility of low-temperature anaerobic biological waste water treatment, FEMS, Microbiol Ecol 55: $449-458$

Conklin A.S., ChapmanT., Zahller J.D., Stensel H.D., Ferguson J.F., (2008). Monitoring the role of aceticlasts in anaerobic digestion: activity and capacity. Water Research. 42, 4895-4904.

Consulting Engineers Mekong (CEM) (2005). Evaluation Study for biogas plant design - Final. Phnom Penh, NBP and SNV.

Deublein D, Steinhauser A. (2008). Biogas from waste and renewable resources. Weinheim, Germany: Wiley-VCH Verlag GmbH\& Co. KGaA.

Daxiong Q., Shuhua G., Baofen L., Gehua W. (1990). Diffusion and innovation in the Chinese biogas program. World Dev. 18:555563.

El-Mashad H. M., van Loon W. K-P., Zeeman G., Bot G. P. A, Lettinga G. 2(004). Design of a solar thermophilic anaerobic reactor for small farms. Biosystem Engineering 87 (3): 345-353

El-Mashad H. M. (2003). Solar Thermophilic Anaerobic Reactor (STAR) for Renewable Energy Production. PhD Thesis. Wageningen University, The Netherlands.

Entec- Biogas (2016). http://www.entec-biogas.com/en/services/technology-system-bima.php. Accessed February 6, 2016.

Ferrer I., Gamiz M., Almeida M., Ruiz A. (2009). Pilot project of biogas production from pig manure and urine mixture at ambient temperature in Ventanilla (Lima, Peru). Waste Manag. (Oxf.) 29, 168-173.

Ferrer I., Garfí M., Uggetti E., Ferrer-Martí L., Calderon A., Velo, E. (2011). Biogas production in low-cost household digesters at the Peruvian Andes. Biomass Bioenergy, 35:1668-1674. 
Ferrer I., Cadena E., Perez B., Garfi M. (2013). Technical, economic and environmental assessment of household biogas digesters in developing countries. Proceedings of 13th World Congress on Anaerobic Digestion, Sandiago de Compostela, Spain.

Fulford D. (1988). Running a Biogas Programme: A handbook. London, Intermediate Technology Publications.

Garfí M., Gelman, P., Comas, J., Carrasco, W., Ferrer I. (2012). Agricultural reuse of the digestate from low-cost tubular digesters in rural Andean communities. Waste Manag. (Oxf.) 31: 2584-2589.

Gerardi M. (2003). The Microbiology of Anaerobic Digesters. John Wiley and Sons, Inc., Pennsylvania.

Ghanimeh S., Fadel M. E., Saikaly P., (2012). Mixing effect on thermophilic anaerobic digestion of source-sorted organic fraction of municipal solid waste. Bioresource Technology 117: 63-71

Gomez X., Cuetos M.J., Cara, J., Moran, A., Garcia, A. (2006). Anaerobic co-digestion of primary sludge and the fruit and vegetable fraction of the municipal solid wastes- conditions for mixing and evaluation of the organic loading rate. Renew. Energy 31:2017-2024.

Ghimire P. C. (2013). SNV Supported domestic biogas programmes in Asia and Africa. Renewable Energy 49:90-94.

GTZ, (1999). Biogas Digest Volume II Biogas - Application and Product Development.

Gunnerson C., G. and D. Stuckey, C. (1986). Anaerobic Digestion - Principles and Practices for Biogas systems. Washington DC, The World Bank \& UNDP: 178.

Gupta R. A., Rai S. N., Tiwari G. N. (1988). “An improved solar assisted biogas plant (fixed dome type): A transient analysis.” Energy Conversion and Management 28(1): 53-57.

Halalsheh M., Kassab G., Yazajeen H., Qumsieh, S., Field, J. (2011). Effect of increasing the surface area of primary sludge on anaerobic digestion at low temperature. Bioresour. Technol. 102:748-752.

Hamad M.A.; Abdel Dayem A.M., El Halwagi M.M. (1983). Evaluation of the performance of two rural biogas units of Indian and Chinese design. Energy Agric.1:235-250.

He P.J. (2010). Anaerobic digestion: An intriguing long history in China. Waste Manag. (Oxf.) 30, 549-550.

Herrero M. J., (2008). Biodigestores Familiaires - Guia de Diseno y manual de instalacion. La Paz, GTZ - Energia.

Hills D. J., Mehlschau, J.J. (1984). Plug flow digestion of dairy manure at different solid concentrations. Transaction of the American Society of Agricultural Engineers 27(3) 889.

Hoffmann R. A, Garcia M. L., Veskivar M, Karim K, Al-Dahhan M, Angenent L. T. (2008). Effect of Shear on Performance and Microbial Ecology of Continuously Stirred Anaerobic Digesters Treating Animal Manure. Biotechnology and Bioengineering 100: 38- 48

Ike M., Inoue D., Miyano T., Liu T.T., Sei K., Soda S., Kadoshin S. (2010). Microbial population dynamics during start-up of a full-scale anaerobic digester treating industrial food waste in Kyoto eco-energy project. Bioresour. Technol. 101: 3952-3957.

IPCC, 2014: Climate Change (2014). Synthesis Report. Contribution of Working Groups I, II and III to the Fifth Assessment Report of the Intergovernmental Panel on Climate Change [Core Writing Team, R.K. Pachauri and L.A. Meyer (eds.)]. IPCC, Geneva, Switzerland, pp. 15.

Jiang X., Sommer S.G., Christensen K.V. (2011). A review of the biogas industry in China. Energy Policy, 39: 6073-6081.

Jihen T., Hassib B., Moktar H., Said N. (2010). Improvement of dairy manufacture effluent anaerobic digestion with biological waste addition using a Chinese dome digester. Bioresource Technology 101:3743-3746.

Kalia A. K. (1988). Development and evaluation of a fixed dome plug flow anaerobic digester. Biomass, 16:225-235.

Kalia A.K., Kanwar S.S. (1998). Long-term evaluation of a fixed dome Janata biogas plant in hilly conditions. Bioresour. Technol. 65:61-63.

Kalia A.K., Singh S.P. (1998). Horse dung as a partial substitute for cattle dung for operating family-size biogas plants in a hilly region. Bioresour. Technol., 64: 63-66.

Kanwar S.S., Guleri R. L. (1994). Performance evaluation of a family-size, rubber-balloon biogas plant under hilly conditions. Bioresour. Technol. 50:119-121.

Karim K., Hoffmann R., Klasson K. T., Al-Dahhan M. H. (2005). Anaerobic digestion of animal waste: effect of mode of mixing. Water Research 39: 3597-3606.

Khoiyangbam R.S., Kumar S., Jain M.C., Gupta N., Kumar A., Kumar V. (2004). Methane emission from fixed dome biogas plants in hilly and plain regions of northern India. Bioresour. Technol. 95:35-39.

Kim M., Ahn Y.H., Speece R.E. (2002). Comparative process stability and efficiency of anaerobic digestion: mesophilic vs. thermophilic. Water Res. 36:4369-4385.

Kobayashi T., Li Y.-Y. (2011). Performance and Characterization of a newly developed self-agitated anaerobic reactor with biological desulfurization. Bioresource Technology 102 (10):5580 -5588

Kumar V. K., Bai R. K., (2008). Solar greenhouse assisted biogas plant in hilly region - A field study. Solar Energy 82(10): 911-917.

Lansing S., Martin J.F., Botero R.B., da Silva T.N., da Silva E.D. (2010). Methane production in low-cost, unheated, plug-flow digesters treating swine manure and used cooking grease. Bioresource Technology10 (12): 4362-4370.

Lindmark J., Thorin E., Fdhila R. B., Dahlquist E. (2014). Effect of mixing on the result of anaerobic digestion: Review. Renewable and Sustainable Energy Review (40): $1030-1047$

Misra U., Singh S., Singh A., Pandey G.N. (1992). A new temperature-controlled digester for anaerobic digestion for biogas production. Energy Convers. Manag. 33:983-986.

Modi V., McDade S., Lallement D, Saghir J. (2005). Energy services for millennium development goals, achieving MGDs. Millennium project, UNDP, World Bank and ESMAP.

Mohammad N. (1991). Biogas plants construction technology for rural areas. Bioresour. Technol., 35: 283-289. 
Myles M. R. (1986). A practical guide to Janta Biogas plant Technology. Action for food Production (AFPRO), New Delhi, India.

Ni J Q, Nyns E J. (1996). New concept for the evaluation of rural biogas management in developing countries. Energy Conversion and Management, 37(10):1525-34.

Ong H. K., Greenfield P.F., Pullammanappallil P. C. (2002). Effect of mixing on biomethanation of cattle manure slurry. Environ. Technol, 23:1081-90.

Perez I, Garfí M, Cadena E., Ferrer I. (2014). Technical, economic and environmental assessment of household biogas digesters for rural communities. Renewable Energy 62: 313- 318

Perrigault T., Weatherford V., Herrero J. M., Poggio D. (2012). Towards thermal design optimization of tubular digesters in cold climates: A heat transfer model. Bioresource Technology 124; 259-268.

Polprasert C., Edwards, P., Rajput V.S., Pacharaprakiti C. (1986). Integrated biogas technology in the tropics. Performance of smallscale digesters. Waste Manag. Res. 4, 197-213.

Rajendran k., Aslanzadeh S., TaherzadehM. J. (2012). Household Biogas Digester- A review. Energies. 5: 2911 -2942.

Rebac S., van Lier J., Lens P., Stams A.J.M., Dekkers F., Swinkels K.T.H.M. \& Lettinga G. (1999). Psychrophilic anaerobic treatment of low strength wastewaters. Water Science and Technology 39: 203-211.

Rico C, RicoJ L, Muñoz N, Gómez B, Tejero I. (2011). Effect of mixing on biogas production during mesophilic anaerobic digestion of screened dairy manure in a pilot plant. Eng. Life Sci.11:476-81.

Shian S.-T., Chang M.-C., Ye Y.-T., Chang W. (1979). The construction of simple biogas digesters in the province of Szechwan, China. Agric. Wastes, 1: 247-258.

Shyam M., Sharma P.K. (1994). Solid-state anaerobic digestion of cattle dung and agro-residues in small-capacity field digesters. Bioresour. Technol., 48: 203-207.

Singh D., Singh K.K., Bansal N.K. (1985). Heat loss reduction from the gas holder/fixed gas dome of a community-size biogas plant. Int. J. Energy Res. 9:417-430.

Singh R., Anand R.C. (1994). Comparative performances of Indian small solid-state and conventional anaerobic digesters. Bioresour. Technol. 47:235-238.

Singh L., Maurya, M.S., Ramana K.V., Alam S.I. (1995) Production of biogas from night soil at psychrophilic temperature. Bioresour. Technol. 53:147-149.

Singh S.P., Vatsa D.K., Verma, H.N. (1997). Problems with biogas plants in Himachal Pradesh. Bioresource Technology 59, 69-71.

Singh K. J., Sooch S. S. (2004). Comparative study of economics of different models of family size biogas plants for state of Punjab, India. Energy Conversion and Management 45(9-10): 1329-1341.

SNV (2010). Domestic Anaerobic Digesters in Developing Countries. How to improve Biochemical Practices? $12^{\text {th }}$ World Congress on Anaerobic Digestion, Guadalajara, Mexico, November.

SNV (2014). www.snvworld.org. Accessed November 3, 2014.

Sodha M. S., Ram S., Bansal N.K., Bansal P.K., (1987). Effect of PVC greenhouse in increasing the biogas production in temperate cold climatic conditions. Energy Conversion and Management 27(1): 83-90.

Song Z. L., Zhang C., Yang G.H., Feng Y.Z., Ren G.X., Han X. H. (2014). Comparison of biogas development from households and medium and large-scale biogas plants in rural China. Renew Sust Energ Rev. 33:204-13.

Stafford D. A. (1982). The effects of Mixing and Volatile Fatty Acid concentrations on anaerobic digester performance. Biomass 2: $43-55$

Stevens M.A., Schulte D.D. (1979). Low temperature anaerobic digestion of swine manure. J. Environ. Eng. Div. 105:33-42.

Stroot P.G., McMahon K.D., Mackie R.I., Raskin L. (2001). Anaerobic co-digestion of municipal solid waste and biosolids under various mixing conditions: digester performance. Water Res. 35, 1804-1816.

Tamkin A., Martin J., Castano J., Ciotola R., Rosenblum J., Bisesi M. (2014). Impact of organic loading rates on the performance of variable temperature biodigesters. Ecological Engineering. 78:87-94.

Tiwari G. N. (1986). "Enhancement in daily production of biogas system." Energy Conversion and Management 26(3-4): 379-382.

Tiwari G., Chandra, A., Singh, K., Sucheta, S., Yadav, Y., (1989). Studies of KVIC biogas system coupled with flat plate collector. Energy conversion and management 29(4): 253-257.

Qi W-K, Toshimasa H., Li Yu-You. (2013). Hydraulic Characteristics of an innovative self-agitation anaerobic baffled reactor (SAABR). Bioreource Tech 136:94-101.

US EPA. (1979). Process design manual for sludge treatment and disposal. EPA 625/1-79-011, Cincinnati:OH.

Vesvikar M. (2006). Understanding the Hydrodynamics and performance of Anaerobic Digesters. PhD Thesis. Washington University in St Louis, M O.

Ward A.J., Hobbs, P.J., Holliman, P.J., Jones, D.L. (2008). Optimisation of the anaerobic digestion of agricultural resources. Bioresour. Technol. 99:7928-7940.

Xavier S., Nand, K. (1990). A preliminary study on biogas production from cow dung using fixed-bed digesters. Biol. Wastes. 34:161165.

Yumkella K. K., Srivastava L. (2010). Energy for all. Making it; April 2, 2010 Issue pp. 22 -29.

Zeeman G. (1991). Mesophilic and psychrophilic digestion of liquid cow manure. PhD thesis. Sub-Department of Environmental Technology. Wageningen University, Wageningen. 


\title{
Chapter
}

\section{Effect of mixing regime on anaerobic digestion of cow manure: comparing mechanically mixed, unmixed and Chinese dome digesters}

\author{
Abiodun O. Jegede ${ }^{* 1}$, Grietje Zeeman *, Harry Bruning* \\ * Sub-Department of Environmental Technology, Wageningen University, \\ Wageningen, The Netherlands. \\ ${ }^{1}$ Centre for Energy Research and Development, \\ Obafemi Awolowo University, Ile-ife, Nigeria.
}

This chapter is based on:

Jegede A.O., Zeeman G., Bruning H. (2018). Effect of mixing regime in anaerobic digestion of cow manure: comparing mechanically mixed, unmixed and Chinese dome digester. Under review in Sustainable Energy Technologies and Assessments. 


\begin{abstract}
This article examines the effect of mixing on the performance of anaerobic digestion of cow manure in Chinese dome digesters (CDD) at ambient temperature (27-32 $\mathrm{C}$ ) in comparison with mechanically mixed and unmixed digesters at laboratory scale. Six digesters (two of each type) were operated at two different influent total solids (TS) concentration ranges, viz. 3-7.3\% and 6-15\%, at a hydraulic retention time (HRT) of 30 days for 319 days. The impeller mixed reactors were mixed at $55 \mathrm{rpm}, 10 \mathrm{mins} /$ hour, the unmixed digesters were not mixed and the Chinese dome digesters were mixed once a day releasing the build-up gas pressure. The reactors exhibited different specific biogas production and treatment efficiency at steady state conditions (day 150-318). The mechanically mixed digester fed with $3-7.3 \%$ TS cow manure exhibited the highest methane $\left(\mathrm{CH}_{4}\right)$ production and treatment efficiency (VS reduction), viz. $0.16 \mathrm{~L} / \mathrm{g} \mathrm{VS}$ and $65.74 \pm 4.7 \%$ respectively at a loading rate of $1.38 \mathrm{~g} \mathrm{VS} / \mathrm{Ld}$. The mechanically mixed reactor operated at the higher loading rate performed second best. The CDDs performed better (10\% more methane) than the unmixed digesters but less (approx.8\%) compared to the mechanically mixed reactors.
\end{abstract}




\subsection{Introduction}

About 2.5 billion people globally depend on traditional biomass as their main source of energy for heating and cooking (Yumkella \& Srivastava,2010). The use of firewood as cooking fuel has several negative effects on the environment, health and social life. The collection of firewood is usually done by women and children, and this activity can take many hours a day, which indirectly affects their productive periods, education and leisure time. The use of firewood and other biomass for cooking produces hazardous particles from the smoke (Gautam et al., 2009), which are dangerous to human health. The use of firewood for cooking is a major factor that causes deforestation, erosion, reduction of water resources, and indirectly contributes to climate change (Tumwesige et al., 2014).

About 1.4 billion people worldwide will possible be left without access to a modern source of cooking energy such as gas and clean stove, if sustainable energy sources are not made available (Modi et al., 2005). The conversion of biomass to clean sources of energy such as biogas via anaerobic digestion could help to solve part of this energy problem in the rural areas of developing countries and improve the standards of living, health and the local environment, and mitigate climate change (Bajgain et al., 2005).

Small-scale household biogas plants for the treatment of organic wastes such as cow manure, are mostly popular in Asia. More than forty million household low-cost anaerobic digesters have been built across China and India (Chanakya et al., 2005; Lansing et al., 2010; Chen et al., 2012) with an estimated potential of about one hundred and forty million household biogas systems in the agricultural regions in China (China NDRC, 2007). The most popular low-cost household digesters are the Chinese dome (Fulford, 1988; Chen et al., 2010; Ghimire, 2013; Ferrer et al., 2013), Indian floating drum, plug flow and Puxin digester (a modification of the Chinese dome digester (Arthur et al., 2011).

These digesters are relatively inexpensive, unheated and have non-forced mixed systems, making them well suitable for farmers and people living in rural areas. However, the application and specific design of these digesters still depend on location, socio-economic context, and weather conditions of the particular location (Kanwar and Guleri, 1994; Singh et al., 1997).

The anaerobic digestion process depends on mixing for distribution of the inoculum during startup, improving contact between nutrients substrate and microorganisms, temperature equalization, removal of intermediate products and prevention of settling and floating layers (Deublein and Steinhauser, 2008). The Chinese dome digester (CDD), which is the most frequently applied household digester is usually constructed underground with a hemispherical dome top, which serves as gas storage. Gas pressure is created as a result of biogas production, while collection in a closed environment and slurry level difference in the reactor is a result of the pressure buildup. The stored biogas pushes part of the slurry into the effluent (expansion) chamber, because water or the slurry is an incompressible liquid. During gas use, the effluent flows back into the main digester chamber creating a mixing regime. Mixing in the Chinese dome digester (CDD) depends on the hydraulic variation in the digester during digester use and could be regarded as intermittent natural mixing. The mixing depends on the feeding regime, the gas production rate, 
gas use frequency, and slurry viscosity. Significant efforts have been made to evaluate the effect of mixing in mechanically mixed reactors viz. impeller mixing, slurry recirculation, biogas injection in comparison to non-mixed reactors (Kim et al., 2002; Gerardi, 2003; Karim et al., 2005; Gomez et al., 2006; Concklin et al., 2008; Ward et al., 2008; Kaparaju et al., 2008; Halalsheh et al., 2011; Ike et al., 2010; Bridgema, 2012), but little research was done in mixing of naturally mixed systems. Most of these studies focus on the effects of mixing modes and intensities on biogas yields in relation to retention time and organic loading rate. The optimum mixing mode is still subject of debate, but most researchers found that intermittent mixing aids anaerobic digestion. Most household digesters are operated at total solid (TS) influent concentrations $<7 \%$ and long hydraulic retentions times (HRT) ( > 40 days) (Hamad et al., 1983; Polprasert et al., 1986; Anjan, 1988; Xavier \& Nand, 1990; Singh and Anand, 1994; Kanwar and Guleri, 1994; Singh et al., 1995; Kalia and Singh, 1997; An and Preston, 1999; Ferrer et al., 2011; Tamkin et al., 2014), as compared to mechanically mixed systems, which are generally operated at an HRT $\leq 20$ days at mesophilic conditions (Hoshimoto et al., 1982; Stroot et al., 2001; Kim et al., 2002; Bouallagui et al., 2002; Ong et al., 2002; Karim et al., 2005; Vesvikar, 2006; Sulaiman et al., 2009; Rico et al., 2011; Chen et al., 2011).

In CDDs, improved mixing might reduce applicable HRTs and therewith reactor volume and investment costs. Moreover, increasing the influent TS concentration by reduced dilution, at the same HRT, will result in an additional reduction of the reactor volume and might increase the mixing conditions, due to a higher volumetric gas production. Therefore, the objective of this study was to study the performance of three types of digesters with different mixing i.e. the Chinese dome digester or hydraulic digester, mechanically mixed digester, and unmixed digester using cow manure at two different total solids (TS) concentrations at the same HRT of 30 days.

\subsection{Materials and methods}

\subsubsection{Reactor design and setup}

The study was performed in six laboratory-scale digesters consisting of two impeller mixed reactors, two unmixed reactors, and two Chinese dome digesters. The working volume of the impeller mixed, and the unmixed reactors is $39 \mathrm{~L}$, while the Chinese dome digesters (CDDs) have a working volume of $39 \mathrm{~L}$ and an additional $10 \mathrm{~L}$ for the extension chamber, which is not regarded as part of the working volume of the reactors. A scheme of the three types of reactors is shown in fig. 1: a, b \& c. All digesters were constructed from polyvinyl chloride (PVC). Generated biogas was collected in plastic gas bags. Biogas produced in the impeller mixed reactors and unmixed reactors was directly collected into the gas bags while the biogas produced in the Chinese dome lab scale reactors was stored in the reactor headspace thereby creating pressure to displace some of the reactor content to the extension chamber. Pressure was released once a day before feeding and the biogas was collected in gas bags. In addition, in the CDDs, effluents were removed from the reactors through the extension chambers. In the mechanically and non-mixed reactors, influents were added from the top and effluents withdrawn from the bottom as shown in Fig. $3.1 \mathrm{a} \& \mathrm{~b}$. Biogas was collected and measured with a wet gas meter before feeding was done in all reactors daily. The two impeller mixed reactors were mixed with $18 \mathrm{~cm}$ impeller at $55 \mathrm{rpm}$ for $10 \mathrm{mins} /$ 
hour throughout the study period based on Karim et al., (2005) and Hoffmann et al., (2008). A reasonable level of intermittent mixing was achieved during reactor feeding and effluent removal from all the reactors based on the reactors geometry. The reactors set-up and arrangement are given in Table 3.1.

(a)

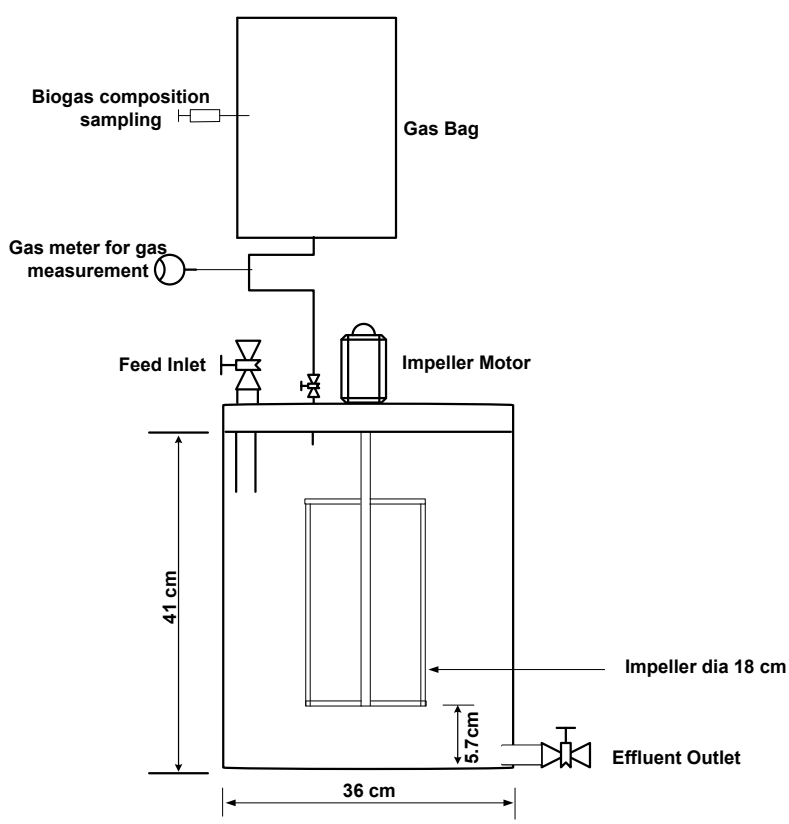

(b)

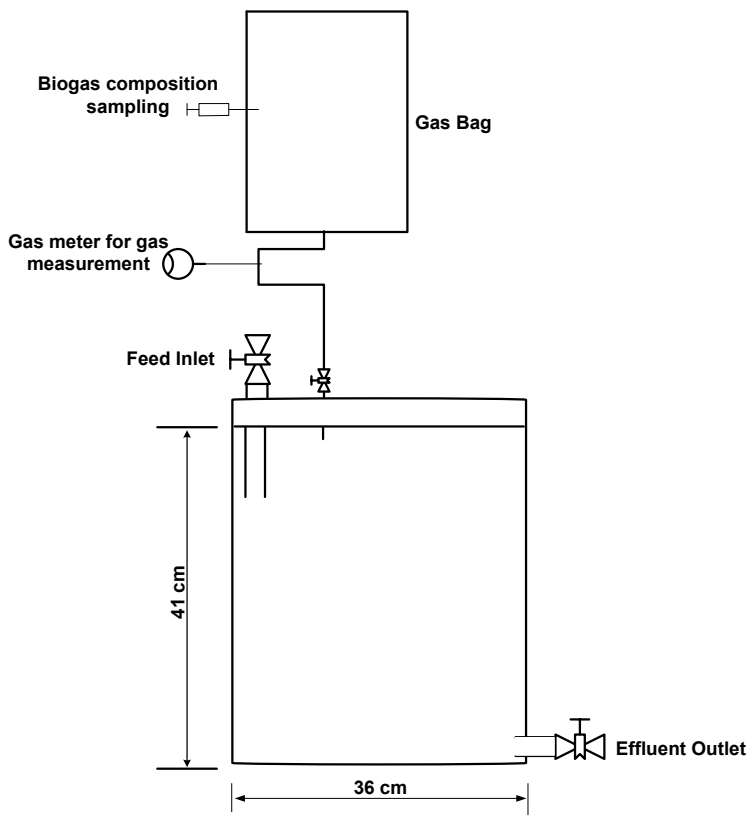


(c)

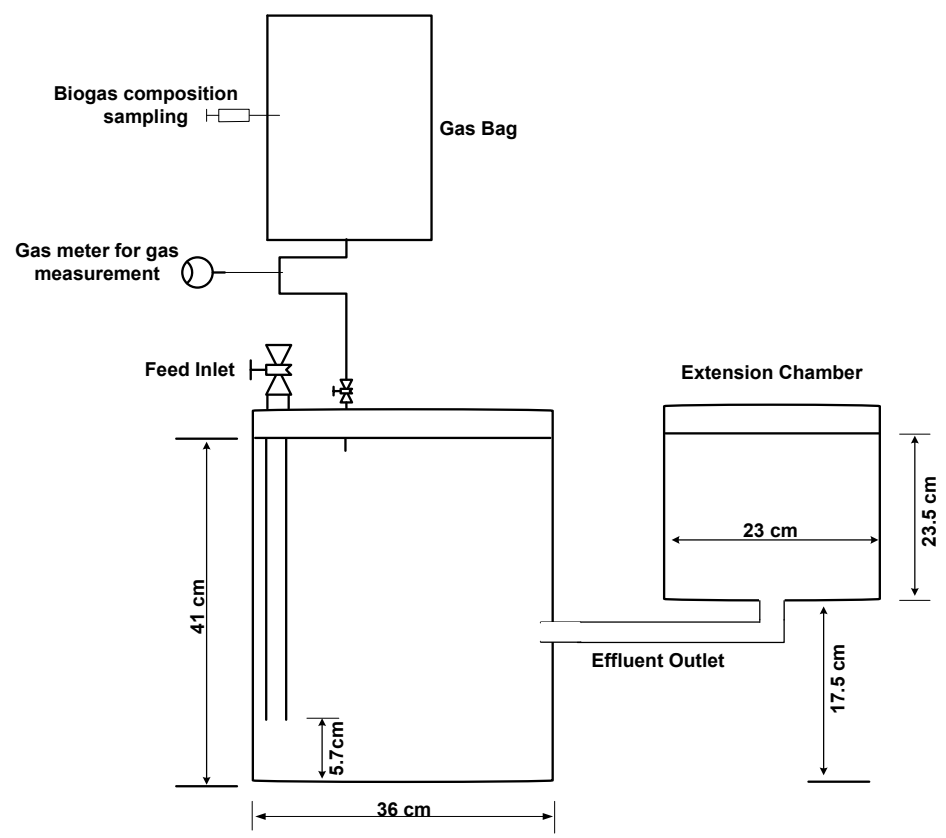

Figure 3.1 | (a) impeller mixed. (b) unmixed. (c) hydraulic mixed (Chinese dome) digesters.

Table 3.1 | Reactors set-up.

\begin{tabular}{lll}
\hline Number & Reactor Design & \% TS \\
\hline 1 & Impeller mixed, $55 \mathrm{rpm}$ for $10 \mathrm{~min} / \mathrm{hour}$ & $3-7.3$ \\
\hline 2 & Impeller mixed, $55 \mathrm{rpm}$ for $10 \mathrm{~min} / \mathrm{hour}$ & $6-15$ \\
\hline 3 & Unmixed & $3-7.3$ \\
\hline 4 & Unmixed & $6-15$ \\
\hline 5 & Chinese dome, hydraulically mixed & $3-7.3$ \\
\hline 6 & Chinese dome, hydraulically mixed & $6-15$ \\
\hline
\end{tabular}

\subsubsection{Manure collection and preparation}

The inoculum used for the reactors start-up was collected from a small-scale biogas plant treating cow manure at the Agricultural Engineering Department, Obafemi Awolowo University, Nigeria, at an average ambient temperature of $32{ }^{\circ} \mathrm{C}$ and operated with an average influent concentration of $5.5 \% \mathrm{TS}$. The inoculum was collected on the same day the reactors were started and occupied $23 \%$ volume of each reactor during start-up. The cow manure used for feeding the reactors was collected freshly at the Obafemi Awolowo University farm. Each batch was stored in a refrigerator at $3{ }^{\circ} \mathrm{C}$ prior to use. The manure was prepared by manual screening for stones, blending, and water dilution into two total solid concentrations. The blending of the substrates was done in a household blender at about 8,000 rpm for 2 mins to break large pieces of manure. The characteristics of the prepared substrate feed including the biomethane potential (BMP) before dilution are given in Table 3.2. The BMP was done in triplicate as described by ABAI, (2006). The applied organic loading rates and period of operation for each of the reactors are given in Table 3.3. 
Table 3.2 | Applied feed characteristics before dilution for the feeding periods.

\begin{tabular}{|c|c|c|c|c|c|}
\hline $\begin{array}{l}\text { Feed } \\
\text { Manure }\end{array}$ & $\begin{array}{l}\text { Initial TS } \\
(\mathrm{g} / \mathrm{L})\end{array}$ & $\begin{array}{l}\text { Initial VS } \\
(\mathrm{g} / \mathrm{L})\end{array}$ & $\begin{array}{l}\text { BMP (Biogas) } \\
\text { L/g VS }\end{array}$ & $\begin{array}{l}\mathrm{BMP}\left(\mathrm{CH}_{4}\right) \\
\mathrm{L} / \mathrm{g} \mathrm{VS}\end{array}$ & $\begin{array}{l}\mathrm{NH}_{4}{ }^{+}-\mathrm{N} \\
(\mathrm{g} / \mathrm{L})\end{array}$ \\
\hline 1 & $284 \pm 16$ & $229 \pm 14$ & 0.25 & 0.17 & 2.2 \\
\hline 2 & $262 \pm 12$ & $152 \pm 2$ & 0.23 & 0.15 & 2.1 \\
\hline 3 & $316 \pm 5$ & $250 \pm 1$ & 0.22 & 0.15 & 2.3 \\
\hline 4 & $339 \pm 4$ & $287 \pm 7$ & 0.24 & 0.16 & 1.9 \\
\hline 5 & $200 \pm 14$ & $137 \pm 2$ & 0.23 & 0.15 & 2 \\
\hline 6 & $257 \pm 1$ & $167 \pm 2$ & 0.25 & 0.16 & 1.8 \\
\hline 7 & $296 \pm 13$ & $168 \pm 3$ & 0.25 & 0.16 & 2.2 \\
\hline 8 & $383 \pm 13$ & $195 \pm 13$ & 0.28 & 0.18 & 2.1 \\
\hline
\end{tabular}

Table 3.3 Influent concentrations and applied loading rates for the impeller mixed $1 \& 2$, unstirred $3 \& 4$, and Chinese dome reactor $5 \& 6$.

\begin{tabular}{|c|c|c|c|c|c|c|c|}
\hline \multirow[t]{2}{*}{$\begin{array}{l}\text { Feed } \\
\text { Manure }\end{array}$} & \multirow[t]{2}{*}{ Day } & \multicolumn{2}{|l|}{$\begin{array}{l}\text { TS } \\
(\mathrm{g} / \mathrm{L})\end{array}$} & \multicolumn{2}{|l|}{$\begin{array}{l}\text { VS } \\
(g / L)\end{array}$} & \multicolumn{2}{|c|}{$\begin{array}{l}\text { OLR } \\
\text { gVS/L/d }\end{array}$} \\
\hline & & $1,3,5$ & $2,4,6$ & $1,3,5$ & $2,4,6$ & $1,3,5$ & $2,4,6$ \\
\hline 1 & $1-35$ & 43 & 86 & 35 & 70 & 1.16 & 2.33 \\
\hline 2 & $36-59$ & 40 & 80 & 23 & 46 & 0.77 & 1.54 \\
\hline 3 & $60-78$ & 47 & 94 & 37 & 74 & 1.22 & 2.44 \\
\hline \multirow[t]{2}{*}{4} & $79-93$ & 52 & 105 & 44 & 88 & 1.47 & 2.94 \\
\hline & $94-125$ & \multicolumn{6}{|c|}{ Recirculation } \\
\hline 4 & $126-133$ & 52 & 105 & 44 & 88 & 1.47 & 2.94 \\
\hline 5 & $134-169$ & 30 & 60 & 20 & 41 & 0.68 & 1.36 \\
\hline 6 & $170-198$ & 40 & 80 & 26 & 52 & 0.86 & 1.72 \\
\hline 7 & $199-259$ & 44 & 88 & 25 & 50 & 0.83 & 1.67 \\
\hline 8 & 260-319 & 73 & 147 & 42 & 84 & 1.39 & 2.79 \\
\hline
\end{tabular}

\subsubsection{Operation}

All reactors were operated at a hydraulic retention time (HRT) of 30 days throughout the study. About 1.3L of effluents were daily removed from the outlet port of reactors $1-4$ and from the extension chambers of reactors $5 \& 6$, after which the same quantity of freshly prepared manure was added. Reactors were considered to operate in steady state when the change in biogas production was within $15 \%$ (Karim et al., 2004). All reactors were operated at laboratory ambient temperatures between $27^{\circ} \mathrm{C}-32^{\circ} \mathrm{C}$. All the digesters were started under similar operational conditions but different mixing schemes and loading rates. Digesters 1 and 2 were mixed at $55 \mathrm{rpm}, 10 \mathrm{mins} /$ hour, the Reynolds number $(\mathrm{Re})$ and power were calculated using equations 1 and 2. Digesters 5 and 6 were mixed by hydraulic variation and the energy created and utilized consumption was calculated in form of potential energy created as a result of slurry displacement in the extension chamber. Digesters 3 and 4 were not mixed, however all digesters could be assumed to be "mixed" intermittently once a day during effluent withdrawal and feeding. The reactors were fed and effluents removed daily from day 1 to day 319 , except for day 94 to 125 when recirculation was applied for all digesters as overloading was observed. During the recirculation period, there was no addition of new feed into the reactors but feeding of effluent. 
Energy consumption for reactors 1 and 2 was calculated from equation (3.2).

$R_{e}=\frac{N \rho D^{2}}{K \gamma^{n-1}}$

$P=N p^{*} \rho^{*} N^{3 *} D^{5}$

where $P$ is the Power consumption (W), $\rho$ is the density of manure influent $\left(\mathrm{kg} / \mathrm{m}^{3}\right), N$ is impeller speed in $\mathrm{S}^{-1}, D$ is impeller diameter in $\mathrm{m}, K$ is the consistency coefficient $\left(\mathrm{P}_{\mathrm{a}} \cdot \mathrm{S}^{\mathrm{n}}\right), \gamma$ is shear $\left(\mathrm{S}^{-1}\right)$ and $n$ is power-law index.

The values of parameters, mentioned in the text are given in Table 3.4 according to $\mathrm{Wu},(2014)$. The power number was determined from the Np vs. Re. chart (Liu et al., 2015).

Table 3.4 | Manure physical characteristic for energy calculation.

\begin{tabular}{llllll}
\hline Digester & $\mathbf{K}\left(\mathrm{P}_{\mathrm{a}} \cdot \mathrm{S}^{\mathrm{n}}\right)$ & $\mathbf{n}$ & $\boldsymbol{\gamma}\left(\mathrm{S}^{-1}\right)$ & $\boldsymbol{\rho}\left(\mathrm{kg} / \mathrm{m}^{3}\right)$ & Reference \\
\hline 1 & 0.525 & 0.533 & 11 & 1000 & $\mathrm{Wu},(2014)$ \\
\hdashline 2 & 31.3 & 0.3 & 11 & $\sim 1000$ & $\mathrm{Wu},(2014)$ \\
\hline
\end{tabular}

The energy created and consumed for mixing was estimated in form of potential energy and kinetic energy using equations 3.3 and 3.4 respectively,

$P . E=m g h$

$K . E=0.5 m v^{2}$

where P.E is the potential energy (J),K.E is the kinetic energy also, in J, $m$ is the mass $(\mathrm{kg})$ of the maximum volume of manure displaced during gas production (as a result of pressure build-up due to gas production) each day, $g$ is $9.8 \mathrm{~m} / \mathrm{s}^{2}, h(\mathrm{~m})$ is the height of the extension chamber and $v$ is the velocity $(\mathrm{m} / \mathrm{s})$. The velocity is the distance divided by time. The distance is the height of extension from the base of the reactor and time is the duration it takes for the displaced slurry to flow back in the digester. These were experimentally determined as $7 \mathrm{~s}$ and $6 \mathrm{~s}$ for the digester 5 and 6 respectively. The volume of the displaced slurry in the extension chambers were calculated from the displacement to be 0.0025 and $0.0042 \mathrm{~m}^{3}$ for CDD5 and CDD6 respectively. The mass of the displaced slurry was estimated from the volume and density.

The gas space of the reactors was filled with nitrogen after inoculation and gas produced in the first three days was purged and not recorded. Biomethane potential of each substrate batch was measured in triplicate according to ABAI, (2006). 


\subsubsection{Monitoring and analytical methods}

The laboratory temperature was monitored using an EL- USB digital temperature logger. $\mathrm{pH}$ of feeds and effluents were measured using a table top $\mathrm{pH}$ meter with a probe, WTW InoLab Level 1 model. The feed and effluents samples were analysed for TS, VS, volatile fatty acids (VFA) (acetate, propionate and butyrate), and ammonium nitrogen $\left(\mathrm{NH}_{4}{ }^{+} \mathrm{N}\right)$. Generated biogas was collected in gas bags, five days a week (Monday to Friday) and measured daily using a Schlumberger Lab wet gas meter. Biogas composition was determined in terms of carbon dioxide $\left(\mathrm{CO}_{2}\right)$ and methane $\left(\mathrm{CH}_{4}\right)$ content. The $\mathrm{CH}_{4}$ content was indirectly measured by measuring the concentration of $\mathrm{CO}_{2}$ viz. $\mathrm{CO}_{2}$ absorption using $\mathrm{NaOH}$ in the gas bag once a week. TS, $\mathrm{VS}$, and $\mathrm{NH}_{4}{ }^{+} \mathrm{N}$ were analysed according to standard procedures (APHA, 2006). Specific biogas and methane yields were expressed as daily methane produced, divided by the amount of VS daily fed to the digester, and used to monitor the digestion efficiency of the digesters

Concentration of volatile fatty acids (VFA) in effluent samples were determined in triplicate using a $7890 \mathrm{~B}$ gas chromatograph (Agilent Technologies) equipped with an HP-5 column (30 m $\times$ $0.32 \mathrm{~mm} \times 0.25 \mu \mathrm{m}$, Agilent Technologies) and a flame ionization detector (FID). The carrier gas was nitrogen with a flow rate of $6.5 \mathrm{ml} / \mathrm{min}$. The operating conditions were as follows: injector temperature, $120^{\circ} \mathrm{C}$ (split-splitless); detector temperature, $250{ }^{\circ} \mathrm{C}$; and an oven temperature program initiating at $40{ }^{\circ} \mathrm{C}$, followed by three sequenced temperature increases (i) at a rate of $60 \mathrm{~K} \cdot \mathrm{min}$ up to $100{ }^{\circ} \mathrm{C}$, (ii) at a rate of $50 \mathrm{~K} \cdot \mathrm{min}$ up to $150{ }^{\circ} \mathrm{C}$, and finally, (iii) at a rate of $90 \mathrm{~K} \cdot \mathrm{min}$ until $240{ }^{\circ} \mathrm{C}$ was reached. Calibration stock solution and sample preparation were done according to Standard Methods for the examination of Water and Wastewater (APHA, 2005).

Average steady-state biogas production data and the standard deviation over the period between 150-319 days of observations are presented in this paper. The specific methane yield, which was calculated as daily methane produced divided by the amount of VS fed to the digester, was used to monitor the efficiency of the digesters as stated earlier.

\subsubsection{Statistical analysis}

The statistical significance of the experimental data at steady state condition for all the digesters was performed using a one-way analysis of variance (ANOVA) statistical program (Microsoft Excel 2016). 


\subsection{Results and discussion}

The digester performance was evaluated based on the effect of loading rate on methane production to volumetric gas production, volatile fatty acid concentration (VFA), treatment efficiency, and energy consumption.

\subsubsection{Effect of loading rate, volumetric biogas production, VFA concentration and treatment efficiency}

The digesters exhibited different volumetric gas production and peaked at the highest organic loading rates. The highest volumetric biogas production rates for the steady state period are 0.34 , $0.67,0.23,0.43,0.29$, and $0.53 \mathrm{~L} / \mathrm{L} / \mathrm{d}$ for respectively digesters $1,2,3,4,5$, and 6 at OLRs of 1.39 $\mathrm{g} \mathrm{VS/L/d} \mathrm{for} \mathrm{digesters} \mathrm{1,} \mathrm{3,} \mathrm{and} \mathrm{5;} \mathrm{and} 2.79 \mathrm{~g} \mathrm{VS} / \mathrm{L} / \mathrm{d}$ for digesters 2, 4, and 6 as shown in Table 3.4. The higher the loading rate the higher the observed volumetric biogas production. The specific methane production for the same type of digesters are comparable but different for different types of digesters. The maximum specific methane production is $0.17 \pm 0.003 \mathrm{~L} / \mathrm{g}$ VS at a OLR of 1.39 $\mathrm{g} \mathrm{VS} / \mathrm{L} / \mathrm{d}$ for digester $1,0.16 \pm 0.003 \mathrm{~L} / \mathrm{g} \mathrm{VS}$ at $2.79 \mathrm{~g} \mathrm{VS} / \mathrm{L} / \mathrm{d}$ for digester 2, $0.107 \pm 0.003 \mathrm{~L} / \mathrm{g}$ $\mathrm{VS}$ at $1.39 \mathrm{~g} \mathrm{VS} / \mathrm{L} / \mathrm{d}$ for digester 3, $0.095 \pm 0.002 \mathrm{~L} / \mathrm{g} \mathrm{VS}$ at $2.79 \mathrm{~g} \mathrm{VS} / \mathrm{L} / \mathrm{d}$ for digester 4, 0.135 $\pm 0.003 \mathrm{~L} / \mathrm{g} \mathrm{VS}$ at $1.39 \mathrm{~g} \mathrm{VS} / \mathrm{L} / \mathrm{d}$ for digester 5 , and $0.126 \pm 0.003 \mathrm{~L} / \mathrm{g} \mathrm{VS}$ at $2.79 \mathrm{~g} \mathrm{VS} / \mathrm{L} / \mathrm{d}$ for digester 6 . The methane production in all digesters increased slightly from day 260 till the end of the experiment, which is in tandem with the BMP of the applied substrate. The eighth substrate batch had the highest BMP of $0.18 \mathrm{LCH}_{4} / \mathrm{gVS}$ compared to earlier applied substrate. As a consequence, the maximally recorded specific methane production in all the digesters was achieved during the application of the eighth substrate. The average specific methane production from highest to lowest is $0.16,0.15,0.13,0.12,0.10$, and $0.09 \mathrm{~L} / \mathrm{g} \mathrm{VS}$ in respectively digester 1 , $2,5,6,3$, and 4 .

At 'steady state' periods, there were differences in the biogas production and methane content depending on the applied OLRs and the type of digester. The volumetric methane production increased with increasing organic loading rates (OLRs) in all digesters (Table 3.5). The biogas production and methane composition observed during this experiment are summarized in Table 3.5. The higher biogas production in the stirred reactors compared to the hydraulic and unstirred reactors is attributed to the impeller mixing at $55 \mathrm{rpm}$ for $10 \mathrm{mins} /$ hour, which might have minimized stratification in the reactors. Biogas release in the liquid phase during intermittently mixed reactors has been reported to increase up to $70 \%$ during when applying forced in comparison to non-mixing regimes (Mills, 1979; Sung and Dague, 1995; Ong et al., 2002). This means gas release may be hindered in unmixed digesters, and mixing increases the chances of mass transfer from liquid phase to gas phase. This is consistent with results of Lin and Pearce, (1981) and Karim et al., (2005) with conclusion that there is impact on methane production between intermittent mixing mode and unmixed systems. In addition, Stafford, (1982) showed that there was a gradual release of biogas from liquid phase to gas phase during the first minute of mixing for various intermittent mixing periods (140 -1000 rpm). The Chinese dome digesters produced more methane than the unmixed digesters as seen in Table 3.5. The digesters also have 
slightly higher methane concentration compared to the unmixed digesters. Vavlin and Angelidaki, (2005) reported that uneven mixing in digesters can lead to the creation of initiation zones in the anaerobic digesters, where methane producing bacteria can grow and flourish and could seed the rest of the digester from these zones.

The volumetric biogas production rate increases with increasing VS influent concentration, but the specific methane production from digesters $(2,4$, and 6$)$, where a double loading rate, was applied were lower compared to that of digester 1,3, and 5. Similar observations were reported by Linke, (1997) and Karim et al., (2005). For the naturally mixed reactors, a higher volumetric methane production rate as a result of increased loading rate did not improve mixing in the digesters and specific methane production. For example, as seen in digester 5 and 6 (CDDs), digester 5 has a slightly higher specific methane production than digester 6 despite the fact that it was operated at a double TS concentration and exhibited higher volumetric biogas rate. This is understandable because manure is a non-Newtonian material and behaves like real plastic material. The higher the solid content, the higher the apparent viscosity (El-Massad et al., 2004), and more force is required for mixing.

The range of specific methane production $(0.10-0.16 \mathrm{~L} / \mathrm{g} \mathrm{VS})$ in this study for all the three mixing modes is in agreement with the BMP of the applied feeds and with specific methane gas productions measured by (Zeeman, 1991), but lower compared to many studies reported (Stroot et al., 2005; Karim et al., 2005; Kaparaju et al., 2008) with slightly different mixing modes and intensities and lower HRT< 20 days. However, the results from this present study is higher than results $(0.08-0.10 \mathrm{~L} / \mathrm{g}$ VS) of Ong et al., (2002) for continuous and intermittent mixing modes. The lower specific biogas production of Ong et al., (2002), could be attributed to high OLR 7.2 $\mathrm{g}$ VS/L d at 10 days HRT. Lastly, difference in gas production between the CDDs and the nonmixed digesters is in agreement with the review of Lindmark et al., (2014), showing that unmixed digesters will produce $10-20 \%$ lower biogas production than intermittently or mixed digesters.

The VFA during the steady state period are $0.82 \pm 0.21,0.98 \pm 0.2,2.21 \pm 0.5,2.66 \pm 0.55,1.4075$ $\pm 0.25,1.61 \pm 0.26 \mathrm{~g} / \mathrm{L}$ in respectively digester 1 through 6 . The observed VFA concentration in the stirred reactors $(1 \& 2)$ during this period are lower compared to that in the unstirred ( $3 \& 4)$ and CDD (5\&6) reactors. The average VFA concentration in the stirred reactors are lesser or equal to $1 \mathrm{~g} / \mathrm{L}$, and they could be regarded as well-balanced digesters according to Hill et al., (1987). The average of VFA concentration in digester 2 is slightly higher but not significant ( $p>0.05)$ than digester 1 because digester 2 has higher OLRs. The higher VFA concentration in the UST and $\mathrm{CDD}$ reactors could be attributed to reduction of the real HRT caused by limited mixing. The limited mixing in these reactors might have created dead zones and lowered the actually working volume of the reactors. The higher levels of VFA in the unstirred reactors (3\&4) probably did not inhibit biogas production or biodegradation. This is coherent with the results of authors Banks et al., (2008), Angelidaki et al., (2006) and Ghanimeh et al., (2012) who stated that inhibition of biogas production may not occur at high VFA (max. $4 \mathrm{~g} / \mathrm{L})$ if $\mathrm{pH}$ stays between $(6.8-7.7)$, which is in agreement with the $\mathrm{pH}$ range (6.7- 7.2) in this study. 
Table 3.5 | Mean volumetric and specific methane production and effluent VFA concentration, VS reductions at different OLRs for 6 differently operated digesters at steady state. HRT $=30$ days.

\begin{tabular}{|c|c|c|c|c|c|c|}
\hline Day & $\begin{array}{l}\text { OLR } \\
\text { gVS/L d }\end{array}$ & $\begin{array}{l}\mathrm{CH}_{4} \\
\mathrm{~L} / \mathrm{L} / \text { day }\end{array}$ & $\begin{array}{l}\mathrm{CH}_{4} \\
\mathrm{~L} / \mathrm{g} \mathrm{VS}\end{array}$ & $\begin{array}{l}\mathrm{CH}_{4} \\
\% \\
\end{array}$ & $\begin{array}{l}\text { VFA } \\
(\mathrm{g} / \mathrm{L})\end{array}$ & $\begin{array}{l}\text { VS red. } \\
(\%)\end{array}$ \\
\hline \multicolumn{7}{|c|}{ Digester 1 (Stirred 1) } \\
\hline $149-169$ & 0.68 & $0.09 \pm 0.002$ & $0.13 \pm 0.002(a)$ & 67 & $0.83 \pm 0.14$ & $57.17 \pm 0.8$ \\
\hline $170-198$ & 0.86 & $0.12 \pm 0.002$ & $0.14 \pm 0.002(b)$ & 68 & $0.97 \pm 0.13$ & $63.98 \pm 1$ \\
\hline $199-259$ & 0.83 & $0.12 \pm 0.01$ & $0.14 \pm 0.01(\mathrm{c})$ & 68 & $0.80 \pm 0.18$ & $64.24 \pm 1.7$ \\
\hline $260-319$ & 1.39 & $0.23 \pm 0.005$ & $0.16 \pm 0.003(\mathrm{~d})$ & 68 & $0.86 \pm 0.20$ & $70.87 \pm 1.5$ \\
\hline
\end{tabular}

Digester 2 (Stirred 2)

\begin{tabular}{|c|c|c|c|c|c|c|}
\hline $149-169$ & 1.36 & $0.17 \pm 0.007$ & $0.12 \pm 0.004\left(\mathrm{a}_{2}\right)$ & 66 & $1.0 \pm 0.03$ & $55.47 \pm 1.6$ \\
\hline $170-198$ & 1.72 & $0.22 \pm 0.005$ & $0.13 \pm 0.006\left(b_{2}\right)$ & 66 & $1.2 \pm 0.24$ & $58.76 \pm 48$ \\
\hline $199-259$ & 1.67 & $0.22 \pm 0.02$ & $0.13 \pm 0.01\left(c_{2}\right)$ & 66 & $0.95 \pm 0.10$ & $62.07 \pm 1.6$ \\
\hline $260-319$ & 2.79 & $0.43 \pm 0.01$ & $0.15 \pm 0.003\left(\mathrm{~d}_{2}\right)$ & 66 & $1.03 \pm 0.17$ & $68.76 \pm 1.6$ \\
\hline
\end{tabular}

\section{Digester 3 (UST 1)}

\begin{tabular}{lllllll}
$149-169$ & 0.68 & $0.06 \pm 0.001$ & $0.08 \pm 0.02(\mathrm{e})$ & 63 & $2.4 \pm 0.24$ & $38.35 \pm 0.5$ \\
\hdashline $170-198$ & 0.86 & $0.08 \pm 0.003$ & $0.09 \pm 0.003(\mathrm{f})$ & 63 & $2.7 \pm 0.25$ & $40.59 \pm 1.5$ \\
\hdashline $199-259$ & 0.83 & $0.09 \pm 0.004$ & $0.09 \pm 0.002(\mathrm{f})$ & 63 & $2.2 \pm 0.15$ & $41.74 \pm 2$ \\
\hline $260-319$ & 1.39 & $0.13 \pm 0.007$ & $0.10 \pm 0.003(\mathrm{~g})$ & 63 & $2.3 \pm 0.28$ & $46.80 \pm 3.8$ \\
\hline
\end{tabular}

\section{Digester 4 (UST 2)}

\begin{tabular}{lllllll}
$149-169$ & 1.36 & $0.12 \pm 0.002$ & $0.09 \pm 0.001\left(\mathrm{e}_{2}^{*}\right)$ & 61 & $2.5 \pm 0.19$ & $41.40 \pm 0.4$ \\
\hdashline $170-198$ & 1.72 & $0.14 \pm 0.001$ & $0.08 \pm 0.004\left(\mathrm{f}_{2}\right)$ & 61 & $3.0 \pm 0.04$ & $40.51 \pm 4.3$ \\
\hdashline $199-259$ & 1.67 & $0.13 \pm 0.004$ & $0.08 \pm 0.002\left(\mathrm{f}_{2}\right)$ & 61 & $2.8 \pm 0.18$ & $39.34 \pm 1.7$ \\
\hdashline $260-319$ & 2.79 & $0.25 \pm 0.008$ & $0.09 \pm 0.002\left(\mathrm{~g}_{2}\right)$ & 61 & $2.81 \pm 0.19$ & $43.48 \pm 1.3$ \\
\hline
\end{tabular}

\section{Digester 5 (CDD 1)}

\begin{tabular}{lllllll}
$149-169$ & 0.68 & $0.07 \pm 0.003$ & $0.09 \pm 0.003(\mathrm{~h})$ & 65 & $1.6 \pm 0.18$ & $43.97 \pm 1.1$ \\
\hdashline $170-198$ & 0.86 & $0.09 \pm 0.004$ & $0.10 \pm 0.003(\mathrm{i})$ & 65 & $1.5 \pm 0.12$ & $47.58 \pm 1.5$ \\
\hline $199-259$ & 0.83 & $0.10 \pm 0.003$ & $0.11 \pm 0.003(\mathrm{j})$ & 65 & $1.4 \pm 0.13$ & $52.70 \pm 1.9$ \\
\hline $260-319$ & 1.39 & $0.18 \pm 0.005$ & $0.13 \pm 0.003(\mathrm{k})$ & 65 & $1.44 \pm 0.10$ & $58.76 \pm 1$ \\
\hline
\end{tabular}

\section{Digester 6 (CDD 2)}

\begin{tabular}{lllllll}
$149-169$ & 1.36 & $0.13 \pm 0.003$ & $0.10 \pm 0.002\left(\mathrm{~h}_{2}^{*}\right)$ & 64 & $1.58 \pm 0.05$ & $44.23 \pm 2.8$ \\
\hdashline $170-198$ & 1.72 & $0.17 \pm 0.002$ & $0.10 \pm 0.006(\mathrm{i})$ & 64 & $1.7 \pm 0.11$ & $44.82 \pm 1.9$ \\
\hdashline $199-259$ & 1.67 & $0.18 \pm 0.004$ & $0.12 \pm 0.003\left(\mathrm{j}_{2}^{*}\right)$ & 64 & $1.65 \pm 0.01$ & $50.49 \pm 1.7$ \\
\hline $260-319$ & 2.79 & $0.33 \pm 0.008$ & $0.12 \pm 0.003\left(\mathrm{~K}_{2}\right)$ & 64 & $1.7 \pm 0.13$ & $54.84 \pm 1.2$ \\
\hline
\end{tabular}

* Letters in parentheses indicate significant difference between each type of digester at each $O L R,(P<0.05)$ for specific methane production a to $\mathrm{k} ; \mathrm{a}_{2}$ to $\mathrm{k}_{2}$. Values with the same alphabet means no significant difference.

Alphabets with $\left(^{*}\right)$ mean value is higher and not lower.

The VFA concentration differ in the reactors and are significantly higher in the unmixed and Chinese dome digesters compared to the stirred reactors. The stability exhibited by the reactors especially the unmixed digesters ( 3 and 4 ) could be attributed to the reactor geometry in which the outlet is located at the bottom of the reactor and relatively long HRT of 30 days. The effluent withdrawal from the bottom could have prevented strong accumulation of solids, which may have resulted in large dead zones and indirectly VFA in the reactor beyond the tolerance level. The long HRT of 30 days applied 
throughout the experiments might have prevented washout of microbes. In addition, the "intermittent" mixing in the unmixed digesters (viz. feeding and effluent withdrawal) and Chinese dome digesters (viz. feeding, effluent withdrawal and hydraulic variation during gas collection) could have slowed down fermentation processes at higher OLR to allow large percentage of intermediates products to be consumed by methanogens and synthrophs without VFA accumulation and toxicity effects (Stroot et al., 2001).

In completely stirred tank reactors (CSTR), the removal of volatile solids (VS) should be equivalent to the methane production. Since no reactor was stirred continuously in this study, it was expected that the VS removal may not fit completely to the methane recovery. The percentage of VS removal in the reactors during the steady state period (day 150 - 318) are in Table 3.5 for reactors 1 to 6 . Volatile solids (VS) reductions in all the reactors are different but not significant, and digester 1 exhibited the highest VS removal, followed by digesters $2,5,6,3$, and 4 . This trend corresponds to the specific methane production of the reactors. Both digesters 1 and 2 exhibited better VS reduction and higher methane production because they were impeller mixed. This improved homogeneity and reduced dead zones in the digesters. Digester 1 exhibited higher VS removal compared to digester 2, despite the fact that, D2 was fed with doubled TS content and produced double volumetric gas production. Consequently, this affirms the earlier statement that higher volumetric gas production does not improve mixing at higher OLRs, and hence specific methane production. The lower VS removal in the unmixed digester and CDDs could be attributed to limited mixing compared to the digesters 1 and 2, because interrupted mixing or intermittent mixing has been reported to create hydraulic dead zones, which can reduce hydraulic retention time and cause effects on reaction kinetics (Karim et al., 2005; Elnekave et al., 2006). Indeed, in this study, unmixed digesters exhibited a lower VS reduction compared to the hydraulic mixed digesters (CDD) for both TS concentrations because the absence of 'sufficient intermittent' mixing could have reduced the effective volume of the unstirred digesters and lead to poor VS degradation Zabranska et al., (2002). In addition, the impeller mixed digester has lesser VS reduction variation compared to others; the unmixed and Chinese dome (hydraulic mixed) digesters. The VS reduction for the steady period are also shown in Table 3.5 for all the reactors.

The analysis of variance (ANOVA) using Microsoft Excel programme (2016) at level 5\% was performed on the specific methane production and VFA for the digesters in two different batches representing the two influent TS loading rates, the single (3-7.3\% TS) and the double (6-15\% TS). Digesters 1, 3 and 5, for the single and Digesters 2, 4 and 6, for the double concentrations represent the three types of mixing, impeller stirred, unmixed, and the hydraulic mixed (Chinese dome digester) investigated in this study. The digesters were compared based on OLR (single and double feeding), and the results show that the differences between each type of digester is significant for both specific methane production and VFA. Specifically, for the specific methane production, the significant differences are represented by $\left(a-d, a_{2}-d_{2}\right)$ for impeller mixed digesters, $\left(e-g, e_{2}-g_{2}\right)$ for unmixed digesters $\left(h-k, h_{2}-k_{2}\right)$ for CDD, shown in Table 3.5. This analysis implies, the reactors fed with single TS performed better than double fed digesters in terms of methane recovery, with the exception of unmixed and CDD digesters at OLR $1.36 \mathrm{~g} \mathrm{VS} / \mathrm{L} / \mathrm{d}$ (day 149-169) and CDD at OLR $1.67 \mathrm{~g}$ VS/L/d (day 199-159). Furthermore, digesters were compared and summarized in table 6. Comparison of these values show that the difference between impeller and unmixed, impeller and CDD, and unmixed and CDD at both TS are significant also $(\mathrm{p}<0.05)$. 
Table 3.6 | Methane production at steady state for single and double influent TS concentration $\mathrm{P}=$ differences in specific methane production.

\begin{tabular}{lllll}
\hline \% TS & impeller and unmixed & impeller and CDD & unmixed and CDD & All reactors \\
\hline Single & $\mathrm{P}<0.01$ & $\mathrm{P}<0.01$ & $\mathrm{P}<0.01$ & $\mathrm{P}<0.0001$ \\
\hline Doubled & $\mathrm{P}<0.01$ & $\mathrm{P}<0.01$ & $\mathrm{P}<0.01$ & $\mathrm{P}<0.0001$ \\
\hline
\end{tabular}

\subsubsection{Digesters performance and energy consumption}

The energy consumption for mixing in the stirred were estimated based on equation 2, while the natural potential energy created by Chinese dome digesters (CDD) was estimated using equation 3 , but no power requirement or consumption for the non-mixed reactors was calculated because in the non-mixed reactors, no external or internal energy was applied. In the CDDs it was possible to estimate the mixing energy created as a result of slurry displacement, which would later be utilized as kinetic energy when slurry flows back into the digester. The energy requirement for the impeller mixed reactors 1 and 2 are 10.5 and $42 \mathrm{~kJ} /$ day, while the P.E created in the CDD are 0.74 and 1.2 $\mathrm{J} /$ day for reactors 5 and 6 respectively in a day. Reactors 1 and 2 have far higher power requirement because of the mechanically mixing using an electric motor. The applied shear would be higher in reactor 2 because of the higher TS concentration. It has been shown by El-Mashad et al., (2004) and Karim et al., (2005) that shear rates increase with total solid concentration. Manure behaves like a non-Newtonian and real plastic material and the higher the TS concentration the higher the viscosity. In the Chinese dome digester, the energy consumed is very low because, the energy is naturally created initially, and it is in the form of gravitational potential achieved by the hydraulic variation as a result of pressure build up in the reactor. The pressure increases as a result of gas production at the headspace (gas phase) and pushes some volume of the slurry, which is nonNewtonian and non-compressible material from the reactor into the extension chamber creates potential energy. The volume of slurry displaced will depend on the amount of gas produced and location of extension chamber with the reactor. The potential and kinetic energy will depend on the viscosity or the percentage of the TS concentration of the applied feed. As discussed earlier, higher volumetric gas production does not improve mixing at higher OLR, because slurry at higher viscosity (higher \% TS) has lower velocity compared to slurry with lower \% TS concentration. The mixing intensity in the stirred reactors is higher than the CDDs because the spatial coverage of mixing and duration is more than the hydraulic mixing in the CDDs. The hydraulic variation in the CDDs occurred once a day in the present research. In fully operational household digesters, the hydraulic mixing occurs between two to three times a day depending on the frequency of cooking. Biogas production is higher in the stirred reactors; however, the difference in biogas production is not much compared to the huge power utilization difference. Both types of reactors were intermittently mixed but applying different types of mixing. The duration between each cycle in the stirred reactor is about 50 minutes while for the CDD this is 24 hours. 


\subsection{Conclusion}

Significant differences were observed among the three types of digesters at both influent TS concentrations applied in this study. The impeller mixed digesters exhibited better biogas production and treatment efficiency, followed by the Chinese dome digester (hydraulic mixed) and the unmixed digesters. The stirred reactor operated between 3-7.3 \% TS concentration produced $20 \%$ more methane than the Chinese dome and 37\% more methane than the unstirred digesters respectively at steady state conditions. At applying double influent TS concentrations, the reactors showed lower specific biogas production and higher VFA concentrations with few exceptions. The VFA accumulation was more pronounced in the unstirred digesters and Chinese dome digesters.

It could also be seen from the results that double TS concentration does not necessarily produce better reactor performance (based on specific methane production and VFA concentration) in the CDDs despite higher volumetric biogas production rate. This indicates that the natural mixing induced by biogas production did not yield sufficient mixing. In addition, the hydraulic variation or mixing cycle in Chinese dome digesters may not suffice for the treatment of cow manure at $10 \%$ TS concentration and more.

\section{Acknowledgements}

This work was funded by the Netherlands Fellowship Programme (NFP), the Netherlands. Special thanks to the analytic/lab support team at Environmental Technology department, Wageningen University, The Netherlands. Special appreciations to the management and support staff of Biochemical Engineering Laboratory, Centre for Energy Research and Development, Obafemi Awolowo University, Ile-ife Nigeria for their support. 


\section{References}

An B.X., Preston, T.R. (1999). Gas production from pig manure fed at different loading rates to polyethylene tubular biodigesters." Livest. Res. Rural Dev., 11. (1) http://www.cipav.org.co/lrrd/lrrd11/1/an111.htm

Anaerobic Biodegradation, Activity and Inhibition (ABAI). Task Group Meeting 9-10 October 2006, Prague.

Angelidaki I., Chen X., Cui J., Kaparaju P., Ellegaard L., (2006). Thermophilic anaerobic digestion of source-sorted organic fraction of household municipal solid waste: start-up procedure for continuously stirred tank reactor."Water Res. 40, 2621-2628.

Anjan K.K. (1988). Development and evaluation of a fixed dome plug flow anaerobic digester. Biomass, 16, $225-235$.

Arthur R., Baidoo M. F., Antwi E. (2011). "Biogas as a potential renewable energy source. A Ghanaian case study. Renew Energ. 36 (5):1510-6.

Banks C. J., Chesshire M., Stringfellow A., (2008). A pilot-scale comparison of mesophilic and thermophilic digestion of source segregated domestic food waste. Water Sci. Technol. 58: 1475-1481.

Bajgain S., Shakya I., Mendis M. S. (2005). The Nepal Biogas Support Program: a successful model of public private partnership for rural household energy supply. Report prepared by Biogas Support Program Nepal. Kathmandu, Nepal: Vision Press P. Ltd.

Bouallagui H., Ben Cheikh, R., Marouani L., Hamdi M. (2003). Mesophilic biogas production from fruit and vegetable waste in a tubular digester. Bioresour. Technol., 86: 85-89.

Chanakya H. N., Bhogle S., Arun R. S. (2005). Field experience with leaf litter-based biogas plants. Energy Sustain Dev. 9:49-62.

Chen, J., Li X., Liu Y., Zhu B.,Yuan H., Pang Y. (2011). Effect of mixing rates on anaerobic digestion performance of rice straw. Nongye Gongcheng Xuebao/Trans Chin Soc Agric Eng. 27:144-8.

Chen L., Zhao L., Ren C., Wang F. (2012). The progress and prospects of rural biogas production in China. Energy Policy. 51:58-6.

Chen Y., Yang G., Sweeney S., Feng Y. (2010). Household biogas use in rural China: a study of opportunities and constraints. Renew Sustain Energy.14: 545-9.

China, National Development and Reform Commission (NDRC) (2007). China's medium to long-term renewable energy development plan."http:/www.chinaenvironmentallaw.com/wp-content/uploads/2008/04/mediumand-long-termdevelopment-plan-for-renewable-energy.pdf, (accessed March 14, 2016).

Conklin A.S., Chapman T., Zahller J. D., Stensel H. D., Ferguson, J. F. (2008). Monitoring the role of aceticlasts in anaerobic digestion: activity and capacity. Water Research. 42: 4895-4904.

El-Mashad H. M., van Loon W. K-P., Zeeman G., Bot G. P. A, Lettinga G. (2004). Design of a solar thermophilic anaerobic reactor for small farms. Biosystem Engineering 87 (3): 345-353.

Deublein D., Steinhauser A. (2008). Biogas from waste and renewable resources. Weinheim, Germany: Wiley-VCH Verlag $\mathrm{GmbH} \&$ Co. KGaA.

Elnekave M., Tufekcj N., Kimchie S., Shelef G., (2006). Tracing the mixing efficiency of a primary meshophilic anaerobic digester in a municipal wastewater treatment plant. Fresenius Environ. Bull. 15:1098-1105.

Ferrer, I., Garfí, M., Uggetti E., Ferrer-Martí L., Calderon, A.; Velo, E. (2011). "Biogas production in low-cost household digesters at the Peruvian Andes.” Biomass and Bioenergy, 35: 1668-1674.

Ferrer I., Cadena E., Perez B., Garfi M. (2013). Technical, economic and environmental assessment of household biogas digesters in developing countries. Proceedings of 13th World Congress on Anaerobic Digestion, 25-28 June, 2013, Sandiago de Compostela, Spain.

Fulford, D. (1988). Running a Biogas Programme: A Handbook. London, Intermediate Technology Publications.

Gautam R., Baral S., Herat S. (2009). Biogas as a sustainable energy source in Nepal: present status and future challenges.” Renew Sustain Energy Rev;13: 248-52.

Gerardi M., (2003). The Microbiology of Anaerobic Digesters. John Wiley and Sons, Inc., Pennsylvania.

Gomez X., Cuetos M. J., Cara J., Moran A., Garcia A., (2006). Anaerobic co-digestion of primary sludge and the fruit and vegetable fraction of the municipal solid wastes-conditions for mixing and evaluation of the organic loading rate." Renew. Energy 31:2017-2024.

Ghanimeh S., Fadel M. E., Saikaly P., (2012). Mixing effect on thermophilic anaerobic digestion of source-sorted organic fraction of municipal solid waste. Bioresource Technology 117: 63-7.

Ghimire P. C. (2013). SNV Supported domestic biogas programmes in Asia and Africa. Renewable Energy 49: 90-94.

Halalsheh M., Kassab G., Yazajeen H., Qumsieh S., Field J. (2011). Effect of increasing the surface area of primary sludge on anaerobic digestion at low temperature. Bioresour. Technol. 102: 748-752. 
Hamad M.A., Abdel Dayem, A. M. El Halwagi M. M. (1983). Evaluation of the performance of two rural biogas units of Indian and Chinese design. Energy Agric.1: 235-250.

Hill D.T., Cobb S.A., Bolte J.P (1987). Using volatile fatty acid relationships to predict anaerobic digester failure. T. Asabe. 30:496-501.

Hoffmann R.A., Garcia M.L., Veskivar M., Karim K.,Al-Dahhan M.,Angenent L.T.(2008). Effect of Shear on Performance and Microbial Ecology of Continuously Stirred Anaerobic Digesters Treating Animal Manure. Biotechnology and Bioengineering 100: 38- 48.

Ike, M., Inoue D., Miyano T., Liu T. T., Sei K., Soda S., Kadoshin S., (2010). Microbial population dynamics during startup of a full-scale anaerobic digester treating industrial food waste in Kyoto eco-energy project. Bioresour. Technol. 101: 3952-3957.

Kalia A. K. (1988). Development and evaluation of a fixed dome plug flow anaerobic digester. Biomass, 16:225-235.

Kanwar S.S., Guleri, R.L. (1994). Performance evaluation of a family-size, rubber-balloon biogas plant under hilly conditions. Bioresour. Technol. 50:119-121.

Kaparaju P., Buendia I., Ellegaard L., Angelidakia I. (2008). Effects of mixing on methane production during thermophilic anaerobic digestion of manure: lab-scale and pilot-scale studies. Bioresour Technol. 99:4919-28.

Karim K., Hoffmann R., Klasson K. T., Al-Dahhan M. H. (2005). Anaerobic digestion of animal waste: effect of mode of mixing. Water Research 39:3597-3606.

Kim M., Ahn Y. H., Speece R. E. (2002). Comparative process stability and efficiency of anaerobic digestion: mesophilic vs. thermophilic. Water Res. 36: 4369-4385.

Lansing S., Martin J. F., Botero R. B., da Silva T. N., da Silva E. D., (2010). Methane production in low-cost, unheated, plugflow digesters treating swine manure and used cooking grease. Bioresource Technology10 (12): 4362-4370.

Lindmark J., Thorin E., Fdhila R. B., Dahlquist E. (2014). Effect of mixing on the result of anaerobic digestion: Review. Renewable and Sustainable Energy Review (40): 1030 -1047.

Lin K. C., Pearce M. E. J. (1991). Effect of mixing on anaerobic treatment of potato-processing wastewater." Can J Civ. Eng. 18:504 -14.

Linke B., (1997). A model for anaerobic digestion of animal waste slurries." Environ. Technol. 18: 849-854.

Liu B., Zhag Y., Chen M., Li P., Jin Z. (2015). Power consumption and flow field characteristics of a coaxial mixer with a double inner impeller. Chinese journal of Chemical Engineering 23:1-6.

Modi V., McDade S., Lallement D., Saghir J. (2005). Energy services for millennium development goals, achieving MGDs. Millennium project, UNDP, World Bank and ESMAP

Ong H. K., Greenfield P. F., Pullammanappallil P. C. (2002). Effect of mixing on biometha-nation of cattle-manure slurry. Environ Technol; 23:1081-90.

Polprasert C., Edwards P., Rajput, V. S., Pacharaprakiti C. (1986). Integrated biogas technology in the tropics 1. Performance of small-scale digesters. Waste Manag. Res. 4: 197-213.

Rico C., Rico J. L., Muñoz N., Gómez B., Tejero I. (2011). Effect of mixing on biogas production during mesophilic anaerobic digestion of screened dairy manure in a pilot plant. Eng Life Sci; 11:476-81.

Singh, R., Anand, R. C. (1994). Comparative performances of Indian small solid-state and conventional anaerobic digesters." Bioresour. Technol. 47:235-238.

Singh L., Maurya M. S., Ramana K. V., Alam S. I. (1995). Production of biogas from night soil at psychrophilic temperature.” Bioresour. Technol. 53:147-149.

Singh S. P., Vatsa D. K., Verma H. N. (1997). Problems with biogas plants in Himachal Pradesh. Bioresource Technology 59: 69-71.

Stafford D. A. (1982). The effects of Mixing and Volatile Fatty Acid Concentrations on Anaerobic Digester Performance. Biomass 2: $43-55$.

Stroot P. G., McMahon, K. D., Mackie R. I., Raskin L. (2001). Anaerobic codigestion of municipal solid waste and biosolids under various mixing conditions I: digester performance. Water Res. 35:1804-1816.

Sulaiman A., Hassan M. A., Shirai Y., Abd-Aziz S., Tabatabaei M., Busu Z. (2009). The effect of mixing on methane production in a semi-commercial closed digester tank treating palm oil mill effluent. Aust J Basic Appl. 3:1577-83.

Sung S., Dague R. R. (1995). Laboratory studies on the anaerobic sequencing batch reactor. Water Environ Res. 67:294-301.

Tamkin A., Martin J., Castano J., Ciotola R., Rosenblum J., Bisesi M. (2014). Impact of organic loading rates on the performance of variable temperature biodigesters. Ecological Engineering 78: 87-94.

Tumwesige V., Fulford D., Davidson G. C. (2014). Biogas appliances in Sub-Sahara Africa. Biomass and Bioenergy 70, 40 -50 .

Vesvikar M. (2006). Understanding the Hydrodynamics and performance of Anaerobic Digesters. Ph.D Thesis. Washington University in St Louis, MO. 
Ward A. J., Hobbs P. J., Holliman, P. J., Jones D. L. (2008). Optimisation of the anaerobic digestion of agricultural resources. Bioresour. Technol. 99, 7928-7940.

Xavier S., Nand K. (1990). A preliminary study on biogas production from cow dung using fixed-bed digesters. Biol. Wastes. 34, 161-165.

Yumkella K. K., Srivastava L. (2010). Energy for all. Making it;. 2, April 2010 Issue pp 22 -29.

Zabranska J., Dohanyos M., Jenicek P., Zalpatilkova P., Kutil J., (2002). The contribution of thermophilic anaerobic digestion to the stable operation of wastewater sludge treatment. Water Sci. Technol. 46:447-453.

Zeeman G. (1991). Mesophilic and psychrophilic digestion of liquid cow manure. PhD thesis. Sub-Department of Environmental Technology. Wageningen University, Wageningen, The Netherlands. 


\title{
Chapter
}

\section{Evaluation of liquid and solid phase mixing in Chinese dome digesters using Residence Time Distribution (RTD) technique}

\author{
Abiodun O. Jegede ${ }^{* 1}$, Grietje Zeeman *, Harry Bruning* \\ * Sub-Department of Environmental Technology, Wageningen University, \\ Wageningen, The Netherlands. \\ ${ }^{1}$ Centre for Energy Research and Development, \\ Obafemi Awolowo University, Ile-ife, Nigeria.
}

This chapter is based on:

Jegede A.O., Zeeman G., Bruning H. (2018). Evaluation of liquid and solid phase mixing in Chinese dome digester using Residence Time Distribution (RTD) technique. Under review in Renewable Energy. 


\begin{abstract}
The Residence Time Distribution (RTD) technique was applied to evaluate mixing of liquid and solid phases in laboratory scale Chinese dome digesters mixed via hydraulic variation. To achieve this purpose, six laboratory scales digesters with different mixing modes and two total solids (TS) concentrations using appropriate tracers were studied over a theoretical hydraulic retention time (HRT) of 30 days. The three different mixing modes were impeller, unmixed and hydraulic mixing, each at influent concentration of ca. 7.5 and $15 \%$ TS concentrations. The mode of mixing strongly affected the effective or actual residence time $\left(t_{\mathrm{a}}\right)$ and directly influenced the percentage of dead zones. The Chinese dome digesters had more dead volumes than the impeller mixed reactors and less than the unmixed reactors. This implied that mixing was more efficient in the impeller mixed reactors followed by the hydraulic mixed reactors and then the unmixed reactors, irrespective of the TS concentration. There was a clear relation between the RTD results and anaerobic digestion performance viz. methane production. There is need to optimize the hydraulic variation in the Chinese dome digester to reduce dead zones while also optimizing the effective residence time $\left(t_{\mathrm{a}}\right)$.
\end{abstract}




\subsection{Introduction}

Energy shortage in poor rural households in the developing world leads to challenges such as inadequate fuel for cooking and lighting. This shortage frequently leads to sickness and a low standard of living, thereby making it difficult for students to do their schoolwork (Austin and Blignaut, 2008). However, if rural dwellers in developing countries could access a renewable and clean source of energy for their cooking and lighting needs, poverty could be reduced and standards of living improved (Tumwesige et al., 2014). Anaerobic digestion, producing biogas for cooking and biofertilizer as end products from organic wastes, is an attractive technology for rural areas. Domestic (household) biogas technology is well suited for rural households because of availability of organic matter as feedstock, energy recovery, and economic benefits.

The Chinese dome digester (CDD) is the most popular domestic digester in developing countries in terms of number (Fulford, 1988; Chen et al., 2010; Ghimire, 2013; Ferrer et al., 2013). It is the design of choice for the Netherlands Development Organisation (SNV) biogas programmes because of the digester's reliability, low maintenance, and long lifespan (Ghimire, 2013). CDD is usually constructed underground with a concrete or reinforced plastic hemispherical dome top. The digester is operated in a semi-continuous mode at a relatively low total solid (TS) concentration (TS < 7\%) and a long hydraulic retention time (HRT), viz. between 40 - 90 days (Kalia, 1998; An \& Preston, 1999; Ferrer et al., 2011) at ambient temperature. Mixing in a CDD is achieved via hydraulic variation during gas use and reactor feeding. Biogas is produced and stored at the upper part of the digester displacing some digester content into the extension chamber. During gas use for cooking, gas pressure decreases and as a result, the displaced content in the extension chamber flows back into the main digester. The applied long HRT and low TS concentration make household digesters unnecessarily big. The application of a high solid anaerobic digestion process $(\mathrm{TS}>7 \%)$ in Chinese dome digesters may present a better alternative to the present norm because dilution with water could be substantially reduced without affecting the digestion efficiency (Jha et al., 2011; Li et al., 2011; Karthikeyan and Visvanathan, 2012). The advantage of applying this method would be a higher organic loading rate (OLRs), and then a smaller reactor volume would be applied. In high solid anaerobic digesters, the biological (microbial kinetics) and physical (mass transfer) processes are interlinked (Benbelkacem et al., 2013). It has been shown that the rheological properties of digestate from anaerobic digesters are affected by the percentage of total solids (Battistoni, 1997; Battistoni et al., 1993; El-Mashad et al., 2004). Digestate from high-solid (>7\% TS) digesters has been reported to be visco-elastic with high shear stress and obeys the power law $\tau=\mathrm{k} \gamma^{\mathrm{n}}$, where $\tau$ - shear stress $(\mathrm{Pa}) ; \gamma$ - rate of shear $\left(\mathrm{s}^{-1}\right) ; \mathrm{k}$ - consistency coefficient $\left(\mathrm{Pa} . \mathrm{s}^{\mathrm{n}}\right) ; n$ - flow behaviour index (El-Mashad et al., 2004; Garcia-Bernet et al., 2011; Benbelkacem et al., 2013). Consequently, achieving adequate mixing based on these characteristics at TS > 7\% could be challenging (Terashima et al., 2009; Wu, 2012; Banbelkachem et al., 2013) and indeed could be more difficult to achieve in Chinese dome digesters, which are only mixed intermittently about three times a day via hydraulic variation during gas use. Mixing is an important parameter in the anaerobic digestion process to disperse substrate, nutrients, and microorganisms; and achieve equal temperature distribution in the digester (Deublein and Stienhauser, 2008). In addition, mixing equipment, mixing mode, and reactor geometry can make results of mixing vary significantly (Lindmark et al., 2014). 
To the best of our knowledge, high solids (TS > 7\%) in Chinese dome digesters have never been evaluated for liquid and solid macro-mixing in either laboratory or pilot scale experiments. Therefore, this study evaluated, as our objective, the hydrodynamic behaviour in relation to reactor efficiency at two different influent TS concentrations, viz. 7 and $15 \%$ in a Chinese dome reactor using the residence time distribution (RTD) method. RTD experiments are frequently used to study the hydrodynamic behaviour of reactors with single liquid phase (Levenspiel, 1972; Martin, 2000; Escudie et al., 2005; Banbelkachem et al., 2013) and both liquid and solid phases (Hamad et al., 1983; Banbelkachem et al., 2013). RTD techniques make use of tracers to investigate the hydrodynamic behaviour of reactors within food, bioprocess, and environmental technology and many more. Several authors (Grobicki and Stuckey, 1992; Gravilescu and Tudose, 1996; Skiadas and Lyberatos, 1998; Liu et al., 2007; Banbelkachem et al., 2013) have applied RTD techniques to investigate mixing in anaerobic digesters, but most of the studies focused on Anaerobic Baffled Reactors (ABR); studies on Chinese dome digesters are scarce (Hamad et al., 1983).

In this study, appropriate tracers were applied to follow the liquid and solid phase of laboratory scale Chinese dome digesters to investigate the effect of influent TS content on macro-mixing of the reactors. To achieve this, the hydrodynamic behaviour of laboratory scale CDDs was compared with that of laboratory stirred and unstirred anaerobic digesters at two different TS influent concentrations, using RTD. The hydrodynamic behaviour was evaluated by determining the percentage of dead zone via estimation of the actual residence time in the three types of digesters i.e. the Chinese dome, stirred, and unstirred digesters. Lastly, the RTD results were linked with the results of biogas production in the digesters.

\subsection{Materials and methods}

\subsubsection{Reactor design}

The experiments were conducted in six laboratory digesters consisting of two mechanical (impeller) mixed reactors, two unmixed reactors, and two Chinese dome digesters (CDD), and mixed via hydraulic variation during gas production and collection. A scheme of the CDD is given in Fig. 4.1. A schematic diagram of the other two reactors is given in Jegede et al., (2018). The working volume of each digester is $39 \mathrm{~L}$. The CDDs have an additional $10 \mathrm{~L}$ extension chamber. The extension chamber is directly connected to the reactor, serves to accommodate the hydraulic variation (displacement of reactor content, gas production and collection), and acts as an outlet for the reactor. The extension chamber is not considered as part of the working volume of the Chinese domes digesters. The digesters were constructed from PVC. Each type of the digester was fed with cow manure at 7.5 and $~ 15 \%$ total solids (TS) concentrations. The two mechanically mixed reactors were mixed intermittently at $55 \mathrm{rpm}$ for $10 \mathrm{mins} /$ hour. Biogas produced in the impeller mixed reactors and unmixed reactors was directly collected in gas bags while the biogas produced in the CDDs was stored in the headspace creating pressure to displace some of the reactor content to the extension chamber. Biogas was collected in a gas bag once a day before feeding. Consequently, some of the digestate in the extension chamber did flow back to the main reactor. In the CDDs, effluents were extracted from the extension chamber (Jegede et al., 2018). 


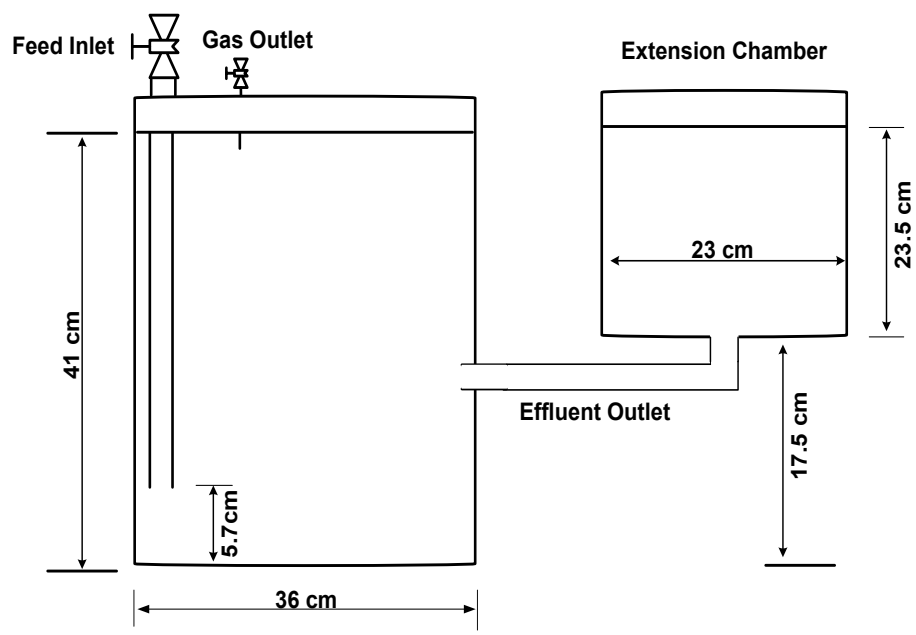

Figure 4.1 | Chinese dome digesters (Jegede et al., 2018).

\subsubsection{Substrate characteristics}

Cow manure was used for all experiments was collected at Obafemi Awolowo University farm, Ife, Osun Nigeria. The manure was prepared by screening, blending to reduce particle size variation, and water dilution into two total solids concentrations 7.5\% TS and $15 \% \mathrm{TS}$, and applied in each type of reactor as shown in Table 4.1.

Table 4.1 | Total solid concentrations in reactors.

\begin{tabular}{lll}
\hline & Reactor Design & Total solids (TS) \% \\
\hline 1 & Impeller mixed & 7.5 \\
\hline 2 & Impeller mixed & 15 \\
\hline 3 & Unmixed & 7.5 \\
\hline 4 & Unmixed & 15 \\
\hline 5 & Chinese dome (hydraulic) & 7.5 \\
\hline 6 & Chinese dome(hydraulic) & 15 \\
\hline
\end{tabular}

\subsubsection{Residence time distribution (RTD) technique}

Liquid and solid phase macro mixing were experimentally investigated by using the residence time distribution (RTD) method. In this study, a stimulus response technique was applied to investigate the mixing in the liquid and solid phase. A pulse input signal method was applied in all reactors at time $t=0$, by injecting a known number of tracers to the influent. The tracer amount was then measured daily in the reactor outlet during effluent withdrawal. Benbelkacem et al., (2013) described the selection of tracers for biochemical reactors as critical and the tracer should fulfil the following criteria: 
-The tracers should not impact the biochemical reaction process and convert to another phase;

-The tracer must possess similar physical characteristics as the phase being studied;

-The tracers should be easily and accurately detectable and measurable.

In this study, Fluorescein was selected as a tracer for the liquid phase. Fluorescein is a dye soluble in water with a chemical formula $\mathrm{C}_{20} \mathrm{H}_{12} \mathrm{O}_{5}$ that is frequently used in biochemical research (Noga and Udomkusonsri, 2002; Arsnow et al., 2010) both to trace blood stain in serology and in dye tracing. The fluorescein concentration was measured in the effluents using an ultraviolet (UV) spectrophotometer, Helious Omega $479 \mathrm{Mb}$, Thermo Scientific at $488 \mathrm{~nm}$. The effluents were centrifuged at 10,000 rpm for 20 minutes, filtered using $0.45 \mu \mathrm{m}$ membrane filter and diluted before measurement using UV.

Polystyrene (PS) was selected as the tracer for the solid phase. Polystyrene with a density of 1.04 $\mathrm{kg} / \mathrm{l}$ was selected. Polystyrene has a similar density as Bioflow $9^{\circledR}$, a solid plastic tracer applied by Benbelkacem et al., (2013), for evaluating the macro mixing in the solid phase. 300 pieces of the PS tracer, with diameter $0.7 \mathrm{~cm}$, were injected into each of the six reactors via influent addition. The PS traces were detected and counted manually by separating them from the digester effluent during effluent withdrawal or wasting.

The liquid and solid tracers were injected into the digesters after achieving steady-state conditions in all the reactors, and the duration of the RTD experiments were 2.2 times the theoretical hydraulic retention time, $t$ in days, defined by Equation (4.1).

$t=\frac{V}{Q}$

The concentration of the fluorescein $C_{i}$ for the liquid phase was measured from the effluent daily.

\subsubsection{Liquid phase modelling}

Many authors have worked on the interpretation of RTD curves (Levenspiel, 1972; Martin, 2000; Sanchez et al.,2005; Benbelkacem et al.,2013). The liquid phase macro mixing was modelled using a simplified model assuming continuous operation, continuous mixing and simplified geometry. The model applied in the study is schematically shown in Fig. 4.2. Each of the digesters investigated was represented by tanks in series from 1 to $\mathrm{n}$. Each tank or stage had three compartments. The top compartment was ideally mixed, and materials entering the top stage was exchanged with the second compartment. The second compartment could be interpreted as either a semi-dead volume that had limited exchange with the bulk; or solid matter to which the tracer adsorbed and desorbed. The third compartment was the complete dead zone, without exchange of materials with the other compartments. 


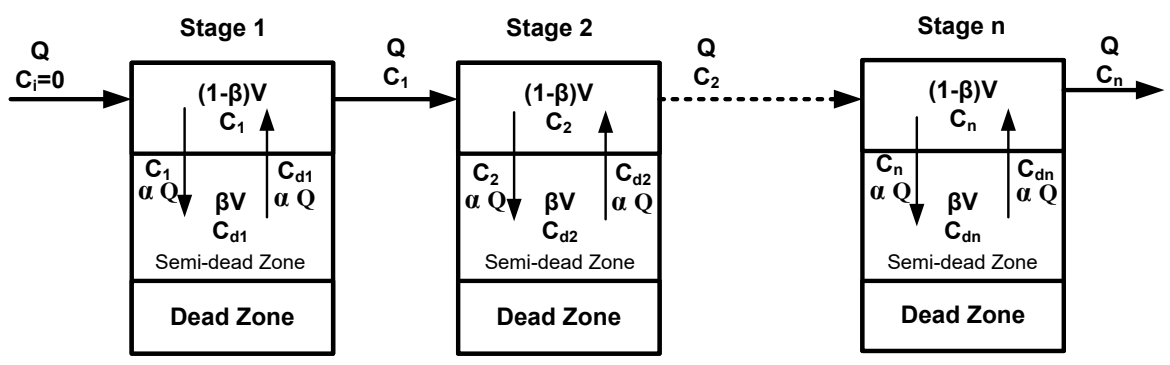

Figure 4.2 | Schematic diagram of the non-ideal model applied for the liquid phase.

The dynamic mass balance for the top compartment is given by

$$
(1-\beta) V \frac{d C_{i}}{d t}=Q\left(C_{i-1}-C_{i}\right)+\alpha Q\left(C_{d i}-C_{i}\right)
$$

where:

(1- $\beta$ ) $V \quad$ Volume of the top compartment

$t \quad$ Time (d)

Q Flow rate through the system $(\mathrm{L} / \mathrm{d})$

$C \quad$ Tracer concentration in the top compartment $\left(\mathrm{C}_{1}, \mathrm{C}_{2}, \mathrm{C}_{\mathrm{n}}\right)(\mathrm{mg} / \mathrm{L})$

$C_{i} \quad$ Ingoing tracer concentration, either from the inlet or the previous stage $(\mathrm{mg} / \mathrm{L})$

$C_{d} \quad$ Tracer concentration in the second compartment (semi-dead zone) (mg/L)

$\alpha \quad$ Dimensionless exchange rate, relative to the flow rate $\mathrm{Q}$, between top and second compartment. A value of $\alpha=0$ means a true dead zone, a large value of $\alpha$ means no semi dead zone at all.

$\mathrm{n} \quad$ Number of tanks in series

The dynamic mass balance for the second compartment is given by

$$
\beta V \frac{C_{d i}}{d t}=-\alpha Q\left(C_{d i}-C_{i}\right)
$$

where:

$\beta V \quad$ Volume of the second compartment (L)

$$
\beta=0 \text { means no semi dead zone at all, similar to a large value of } \alpha
$$


In the implementation of the model, $\mathrm{V}$ and $\mathrm{Q}$ are grouped as one parameter $\mathrm{V} / \mathrm{Q}$ - the one stage HRT. The Runge-Kutta midpoint method was used for the integration and fitting of the model to the experimental data applying the least square method.

\begin{tabular}{lcc} 
Table 4.2 & Residence time distribution & RTD) \\
\hline TS \% & 7.5 & 15 \\
\hline $\mathrm{Q}(\mathrm{L} / \mathrm{d})$ & 1.3 & 1.3 \\
$\mathrm{~V}(\mathrm{~L})$ & 39 & 39 \\
\hdashline $\mathrm{C}_{\mathrm{o}}(\mathrm{mg} / \mathrm{L})$ & 50 & 50 \\
\hline
\end{tabular}

where, $\mathrm{Q}=$ flow rate $(\mathrm{L} / \mathrm{d}), \mathrm{V}=$ Volume of reactor $(\mathrm{L}), \mathrm{C}_{\mathrm{o}}=$ initial concentration of tracer $(\mathrm{mg} / \mathrm{L})$. The exit time distribution for the pulse-input methods represented external RTD, $E(t)$ and could be defined by Equation (4.4).

$$
E(t)=\frac{t_{a \cdot} C_{f i t}}{\sum C_{f i t} \Delta t}
$$

The actual mean residence time $\left(t_{a}\right)$, unit $(d)$ was determined from Equation (4.5).

$t_{a}=\frac{\sum t C_{f i t} \Delta t}{\sum C_{f i t} \Delta t}$

Where, $C_{f i t}$ is the concentration of the best fit.

The percentage of dead zone was estimated using Equation 4.6

Dead Volume $(\%)=\frac{t_{a}}{V / Q}$

\subsubsection{Solid phase modelling: Sedimentation}

For the sedimentation evaluation, the standard analysis method used for the liquid phase could not be applied because the number of solid particles was only 300 pieces. This implies that the amount of tracer collected from each reactor was small and the quantities in a sampling volume each day were not as explicit as the concentration of the soluble tracers and not statistically applicable (Benbelkacem et al., 2013). On the other hand, it was possible to determine accurately the quantity of the Polystyrene (PS) coming out the reactor by just separating them from the digestate and counting at a given time using Equation (4.7).

$$
N(t)=\sum_{i=0}^{t} N_{i}
$$

where: $N_{\mathrm{i}}$ is the number of PS tracers counted in the effluent volume at time $t_{i}$ 
The fraction of PS tracers staying in the digesters shorter than the retention time $t$ was determined by Equation (4.8)

$$
F_{P S}(t)=\frac{N(t)}{N_{\text {total }}}
$$

Where, $N_{\text {total }}$ is the total number of PS tracers added

The F-function was determined by fitting the cumulative $F_{P S}(t)$, data using Equations $4.9 \& 4.10$.

$F(t)=1-\left(1+t^{*} p(t)\right) * e^{-a^{*} t}$

$p(t)=a_{0}+a_{1}{ }^{*} t+a_{2}{ }^{*} t^{2}$

The E-curves were calculated from the F-function using Equation 4.11

$$
E(t)=\frac{d F}{d t}
$$

Excel solver was used to determine the best fits for the cumulative $F_{P S}(t)$ data, thereby finding the best values for $\mathrm{a}, \mathrm{a}_{\mathrm{o}}, \mathrm{a}_{1}$, and $\mathrm{a}_{2}$.

The actual mean residence time $t_{a}(\mathrm{~d})$, was then calculated using Equation 4.12,

$$
t_{a}=\int_{0}^{1} t d F=\frac{a^{3}+a^{2} * a 0+2 * a * a 1+6 * a 2}{a^{4}}
$$

\subsection{Results and discussion}

The results of the macro mixing of both the liquid and solid phases of the six different anaerobic digesters are presented in this section.

\subsubsection{Mixing characterization of the liquid phase}

The mixing of the liquid phase was investigated for six reactors with three different mixing modes and two total solids (TS) influent concentrations were applied. For all six reactors, the actual (experimental) mean or average residence times $\left(t_{a}\right)$ were lower than the theoretical residence time (HRT). The actual mean residence times $\left(t_{a}\right)$ were 27.05, 25.12, 23.57, 20.31, 25.47, and 23.20 days for reactors 1 to 6 as shown in Table 4.3, meaning the active volume of the reactors were lower compared to the reactors volume.

Best fits were obtained by two tanks in series for the mixed digesters and three tanks in series for the unmixed and Chinese dome digesters as seen in Table 4.3. The mixed digesters and the CDDs had semi-dead zones. In the mixed digesters, there was no semi-dead volume at the 
first stage, but there was at the second stage for both digesters. In the CDDs, there were dead volumes in both digesters at stages 2 and 3. The dimensionless exchange rate relative to flow rate $(\alpha)$ between the second (semi-dead zone) and top compartments are also shown in Table 4.3. The $\alpha$ values imply that there were exchanges between the top and second compartments (semi-dead volume) in the mixed reactors at stage 2 , and the Chinese dome digester at both stages 2 and 3. However, in the unmixed digesters there was no semi-dead zone but main and large dead volumes.

The percentage of semi-dead and dead zones in the reactors depended on the mode of mixing and applied TS concentrations. The dead zones were estimated from the actual mean residence time as shown in Figures 4.3 and 4.4. It was observed that the impeller mixed reactors had the lowest dead zones, $9.83 \%$ and $16.28 \%$ for reactors 1 and 2 respectively. This, to some extent, could be due to the accumulation of digester content. Reactor 2 had a higher dead volume than reactor 1 because reactor 2 was fed with higher TS content (15\%), but same mixing intensities were applied to both reactors. The unmixed reactors had the highest dead zones mainly because no forced mixing was applied and biogas production in the reactors was not sufficient to establish mixing in the digesters at the operated TS concentrations $(7.5 \& 15$ $\%)$. The Chinese dome reactors (hydraulic mixed) had a lower dead volume compared to the unmixed digesters but higher than the impeller mixed digesters as shown in Table 4.3. The hydraulic variation achieved in the Chinese dome digesters during gas collection improved mixing, compared to the unmixed digesters but not enough to achieve similar results as in the impeller mixed reactors.

Table 4.3 | Results parameters for the non-ideal model.

\begin{tabular}{|c|c|c|c|c|c|c|c|}
\hline & Reactor & $\alpha$ & $\beta$ & $\mathbf{n}$ & $\begin{array}{l}t_{a} \\
\text { (day) }\end{array}$ & $\begin{array}{l}\text { Dead volume } \\
(\%)\end{array}$ & $\begin{array}{l}\text { Volume } \\
(\%) / \text { stage }\end{array}$ \\
\hline \multirow[t]{2}{*}{1} & Mixed 7.5 & 0 & - & & 27.0 & & 50 \\
\hline & & 0.43 & 0.53 & 2 & & 9.8 & 50 \\
\hline \multirow[t]{2}{*}{2} & Mixed 15 & 0 & - & & 25.1 & & 50 \\
\hline & & 0.27 & 0.47 & 2 & & 16.3 & 50 \\
\hline \multirow[t]{3}{*}{3} & Unmixed 7.5 & 0 & - & & 23.6 & & 33.3 \\
\hline & & 0 & - & & & & 33.3 \\
\hline & & 0 & - & 3 & & 21.4 & 33.3 \\
\hline \multirow[t]{3}{*}{$\begin{array}{l}4 \\
\ldots\end{array}$} & Unmixed 15 & 0 & - & & 20.3 & & 33.3 \\
\hline & & 0 & - & & & & 33.3 \\
\hline & & 0 & - & 3 & & 32.3 & 33.3 \\
\hline \multirow[t]{3}{*}{5} & CDD 7.5 & 0 & - & & 25.5 & & 9.66 \\
\hline & & 0.60 & 0.86 & & & & 45.2 \\
\hline & & 0.60 & 0.86 & 3 & & 15.1 & 45.2 \\
\hline \multirow[t]{3}{*}{6} & CDD 15 & 0 & - & & 23.2 & & 3.35 \\
\hline & & 0.73 & 0.94 & & & & 48.3 \\
\hline & & 0.73 & 0.94 & 3 & & 22.7 & 48.3 \\
\hline
\end{tabular}

N.B. stage also means number (n) of tank, if $\alpha=0, \beta$ has no meaning 
The dimensionless retention time distribution (RTD) graphs (E curves) are presented in Fig.4.3. The E curves for each digester type are similar but differ in magnitude, based on TS concentrations. This implies that the type of digester in relation to mode of mixing plays an important role in the established RTD curves. Digesters 1 and 2 produced similar E curves but different magnitudes, with early peaks and then a gradual exponential decay. Digester 3 and 5, having the same TS concentrations, produced broader peaks and quick decays while 4 and 6 produced higher peaks. The impeller mixed reactors have the sharpest peaks followed by the Chinese dome digesters and then the unmixed reactors. The peaks trend relates to the actual residence time $\left(t_{a}\right)$ of the reactors. None of the digesters produced symmetrical curves or peaks close to mean residence time $(\theta=1)$. All peaks appeared between $\theta=0.5-1$. The peaks clearly show that a certain amount of tracer was removed from the reactors before the mean residence time of the reactors. Mixed reactors and CDDs reactors have $\mathrm{E}$ curves with long tails which is consistent with the results in Table 4.3. The size of the tails varies, which is an indication of the fraction of the semi-dead zone and an exchange of particles occurring between the semi-dead zone and the active volume.

The applied model described was also used to investigate the mixing of the liquid phase with respect to the number of tanks (or stages) connected in series. The number of reactors (n) in series (Table 4.3) was adjusted to fit the experimental data. The best fit curves were determined for all the reactors and shown in Appendix 4.1. All the models were in a good agreement with the experimental data and the coefficient of determination $\left(\mathrm{R}^{2}\right)$ are $0.90,0.86,0.96,0.95,0.93$, and 0.85 for reactors $1-6$. The number of reactors $(n)$ applied in the models differs based on the mode of mixing and reactor type. For the impeller mixed reactors, $n=2$ for both TS concentration. In the models of the unmixed and Chinese dome digesters $n=3$ for both 7.5 and $15 \%$ TS. The dimensionless exchange rate relative to flow rate between bottom and the semi-dead zone compartment $(\alpha)$ for the reactors $1-6$ are $0.43,0.27,0,0,0.6$, and 0.7 . This together with the percentage dead zone, the unstirred reactors have true or higher dead zones compared to the stirred and Chinese dome digesters. Consequently, based on the number of reactors applied in the model and shape of the $\mathrm{E}$ (curves), the liquid phase macromixing in the impeller mixed reactors is close to two Continuously Stirred Reactors (CSTRs) at both TS contents with semi-dead volumes. The unmixed reactors modelled with 3 CSTRs with no semi-dead volume, but large dead zone approached a plug flow reactor. The CDDs at both influent TS concentrations were modelled with three tanks with a very small first stage according to values of V/Q, and no semi-dead volume shown in Table 4.3 are close to three CSTRs in series. This implies for the CDDs inlet mixing is prominent in these reactors. 

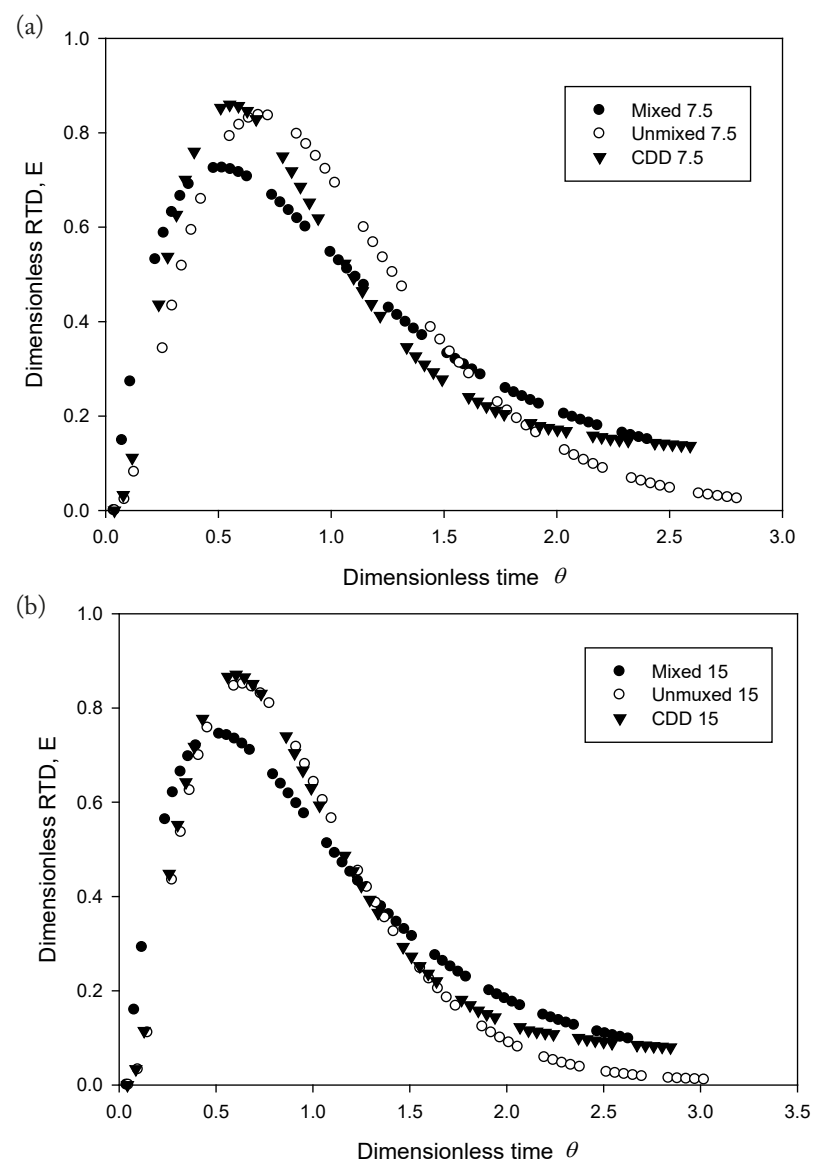

Figure 4.3 The dimensionless retention time distribution (RTD) E, plotted against the dimensionless $(\theta)$ time, for the liquid phase of digesters (a) 1,3 and 5 (b) 2, 4, and 6.

\subsubsection{Mixing characterization of the solid phase}

Fig. 4.5 and Table 4.4 present the fraction of the extracted solid tracer particles, for the six reactors against time (F functions). The model data fits well to the experimental data as can be seen in Appendix 4.2. It can be seen that the F-curves have the same trend in all the reactors because the type of applied tracer material polystyrene (PS) is the same in all reactors and have the same densities. This is consistent with the findings of Benbelkacem et al., (2013) on solid sedimentation of four different tracers' materials having different densities: $0.95,1,1.14$, and $2.5 \mathrm{~kg} / \mathrm{L}$. Their results showed that the tracers segregated according to their densities. However, the total number of particles extracted from the reactors at the end of the experiments differed according to the mixing mode and geometry of the reactors. As shown in Fig. 4.4 after two hydraulic retentions times $(\theta=2)$, the stirred reactors $(1 \& 2)$ have the highest percentages of tracers extracted ( 75 and $71 \%$ ), followed by the Chinese dome reactors, 5 (68\%) and 6 (66\%). The unstirred digesters have the lowest numbers of tracers extracted 64 and $63 \%$ for reactor 3 and 4 respectively. 
The dimensionless residence time, $\mathrm{E}$, was estimated by differentiating the $\mathrm{F}$ functions over time, Appendix 4.3 being similar to the E-curves of the liquid phase. All peaks appeared before the first HRT. However, the mixed reactors have broader peaks while the unmixed, and CDDs have sharp peaks.

The actual or effective retention times calculated from the fitted model for all the reactors differ according to their mode of mixing. After two hydraulic retention times $(\theta)$, the effective mean residence time $\left(t_{d}\right)$ are: $49.98,54.34,64.61,53.26,54.38$, and 58.40 days for reactors $1-6$. On the average, the mixed reactors have the lowest retention time followed by the Chinese dome, and lastly the unmixed. $t_{a}$, the fraction of particles extracted in relation to the mean residence time is an indication of degree of sedimentation or segregation of solid particles in the reactors. In the unmixed digesters, the fraction of particles extracted is lowest compared to other reactors. These results corroborate the results of the liquid phase modelling where the unmixed digesters have the largest dead volume with no semi-dead volume. This therefore implies the fraction of particles trapped or extracted is directly proportional to the percentage of the dead zone in the reactors.
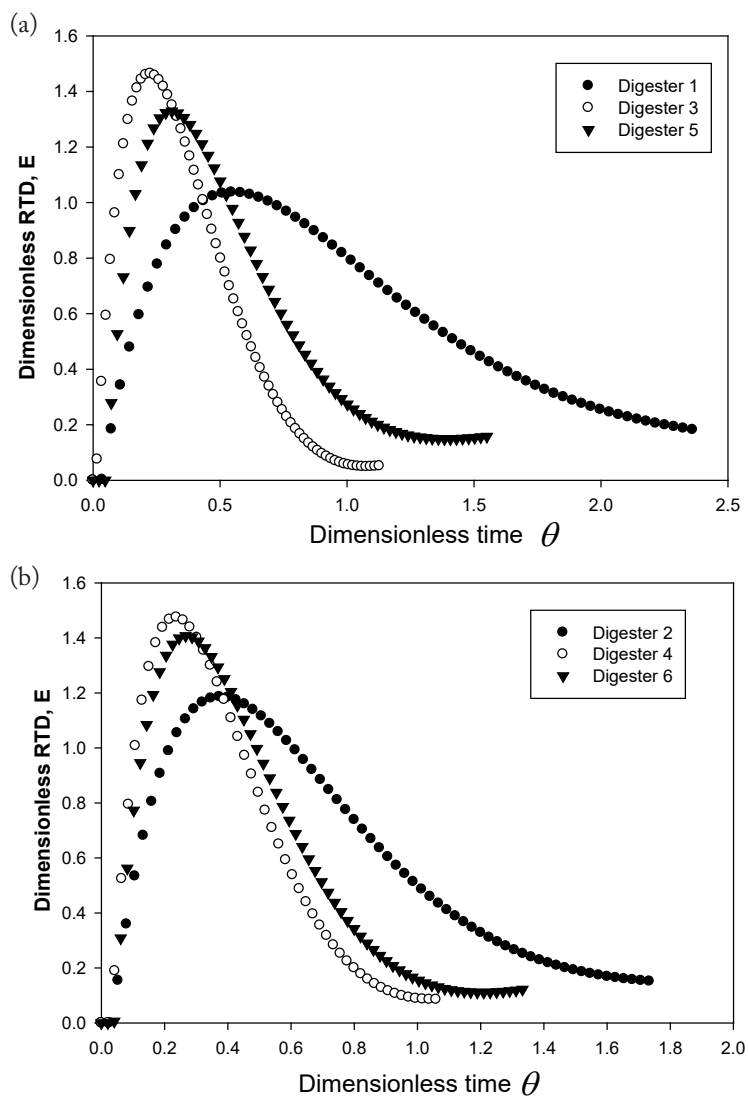

Figure 4.4 The dimensionless retention time distribution (RTD) E, plotted against the dimensionless $(\theta)$ time, for the solid phase of digesters (a) 1,3 and 5 (b) 2, 4, and 6 . 


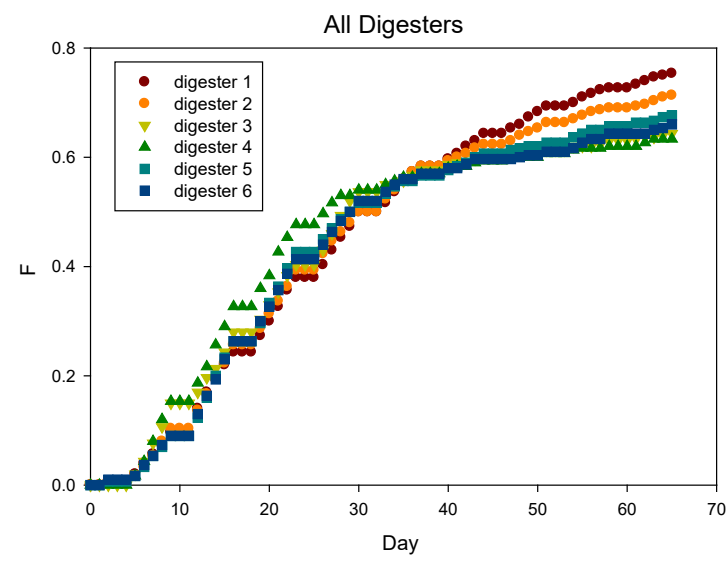

Figure 4.5 | Fraction of the extracted particles, (F) function for the solid phase.

\subsubsection{Reactors and biogas production}

The Chinese dome digesters which were mixed by hydraulic variation, exhibited a considerable percentage of dead zones and a high solid retention, which in fact affected the reactor performance and digestion efficiency. The fraction of the digester volume occupied by the dead zone is a proof of digester performance. The semi-dead and dead zones are regions in the reactor where flow velocities during mixing are very low, and fluid is delayed in these zones. These zones will reduce the actual reactor volume or create zones of non-uniform concentrations and temperature. Dead zones are results of poor mixing or absence of mixing. However, there is a debate about the role and extent of mixing in anaerobic digesters. The need for biogas reactors to be adequately mixed has been supported by many authors (Gerardi, 2003; Concklin et al., 2008; Halalsheh et al., 2011; Bridgeman, 2012), while challenged by others (Gomez et al., 2006; Kim et al., 2002; Ward et al., 2008; Ike et al., 2010). From the liquid phase mixing results presented earlier, it can be seen that mixing is important compared to non-mixing but an optimal mixing point to achieve optimal reactor performance is yet to be established.

The mode of mixing and geometry of the bioreactor play an important role in the RTD. The RTD results of the macromixing of the liquid and solid phases in the study show that the impeller mixed reactors performed best, followed by the Chinese dome digesters and then the unmixed digesters. Similarly, the results of methane production at steady state reported elsewhere (Jegede et al., 2018) are consistent with this trend.

Table 4.4 shows the average methane production from all the reactors. The high methane production in the impeller mixed reactors compared to the CDD and unmixed reactors is attributed to the forced mixing via impeller, which minimizes stratification in the reactors. This is consistent with the calculated dead zone in the RTD study where the impeller mixed reactors exhibited the lowest dead regions. Biogas release in the liquid phase in intermittently mixed reactors has been reported to increase during mixing regimes as compared to non-mixed periods (Sung and Dague, 1995; Ong et al., 2002). This means gas release may be hindered in unmixed digesters and mixing 
increases the chances of mass transfer liquid phase to gas phase. The Chinese digesters produced more methane than the unmixed digesters as reported. They also have slightly higher methane content compared to the unmixed digesters. This could be attributed the differences in the HRT viz. the uneven mixing created during the hydraulic variation during gas collection or gas "use". Volumetric biogas production rates increased with increase in TS concentration, nevertheless, specific methane production and methane content in the 'double fed digesters' (impeller 2, unmixed 4, and CDD 6) were lower compared to impeller 1, unmixed 3, and CDD 5. This might imply that higher volumetric biogas production in the double fed digesters does not improve mixing compared to single fed digesters (Jegede et al., 2018). One major reason for this is that the rheological properties, especially viscosity of manure, increases at higher TS. The viscous property of the reactor content coupled with the reactor type and mode of mixing did not improve specific methane production. This also means that at higher total solid concentration (TS) loading, the organic fraction could not be optimally utilized at the operated HRT and mesophilic temperature range applied in this study.

Table 4.4 | Fraction extracted after two HRT and actual residence time $\mathrm{t}_{\mathrm{a}}$ of solid particles and specific methane production.

\begin{tabular}{|c|c|c|c|}
\hline Digester & $\begin{array}{l}\text { Extracted particles } \\
(\%)\end{array}$ & $\begin{array}{l}\mathbf{t}_{\mathrm{a}} \\
\text { (day) }\end{array}$ & $\begin{array}{l}\mathrm{CH}_{4} \\
\mathrm{~L} / \mathrm{g} \mathrm{VS} \text { (Jegede et al., 2018) }\end{array}$ \\
\hline 1 & 75 & 49.98 & 0.16 \\
\hline 2 & 71 & 54.34 & 0.15 \\
\hline 3 & 64 & 64.61 & 0.1 \\
\hline 4 & 63 & 53.26 & 0.09 \\
\hline 5 & 68 & 54.38 & 0.13 \\
\hline 6 & 66 & 58.4 & 0.12 \\
\hline
\end{tabular}

\subsubsection{Mixing in the Chinese dome digesters}

The Chinese dome digesters can be described as three CSTRs in a series based on the RTD results of the liquid phase. The Chinese dome complex geometry i.e. the addition of the extension chamber, which helps to provide the natural hydraulic variation and also serves as the outlet of the reactor is the reason for these RTD outcomes. The mixing in the CDD reactors has been poorly investigated in literature with little or no information available about the reactor hydrodynamics. The suspected dead zones and sedimentation in the reactors are primarily at the bottom of the reactors, which is the region below the effluent pipe that connects the main reactor to the extension chamber. During the hydraulic variation, there are possibilities that these regions are poorly mixed because only low velocities would be achieved by the downward movements and flow of the reactor contents during these hydraulic variations.

Future research should focus on how to reduce the dead zones and large sedimentation at the bottom of the reactor. One of the possible methods is increasing the number of naturally occurring hydraulic variations in the reactor. To achieve this, special approaches are required to increase the mixing circles naturally, such as using the pressure created by the biogas produced in the reactor without the use of any internal mechanical or electrical devices. This is required because any addition or inclusion of any of these devices will increase the installation and maintenance cost of 
the Chinese dome digester (CDD). It is worthwhile to note that the Chinese dome digesters are primarily used by poor people mostly in developing countries with little or no access to electricity and limited access to skilled technicians for maintenance. To this end, an innovative approach that will require the use of advanced modelling methods such as computational fluid dynamics to study and to optimize the velocity flow fields in the reactor should be investigated to optimize the reactor performance via improving the mixing frequency and subsequently reduce dead zones and sedimentation.

\subsection{Conclusion}

The residence time distribution (RTD) technique was applied to study the hydrodynamic behaviour of three types of reactors: impeller mixed, unmixed, and the hydraulic mixed reactors at two different TS concentrations (7.5 and $15 \%$ ). The main focus was to investigate the hydraulic reactor (Chinese dome digester). The impeller mixed reactors have the lowest dead zones followed by the hydraulic reactors and lastly the unmixed. The reactor performance in terms of methane production is consistent with the evaluation of the RTD results. The reactor type and mixing modes have direct impact on reactor hydrodynamics and eventually reactor performance. At both TS concentrations, the hydraulic reactor has considerable dead zones or low velocity zone because the mixing viz. hydraulic variation is inadequate. The CDD (hydraulic) digester therefore needs to be optimized for improved hydraulic variation to achieve optimized mixing cycles without use of external energy.

\section{Acknowledgements}

This work was funded by the Netherlands Fellowship Programme (NFP), the Netherlands. Special thanks to the analytic/lab support team at Environmental Technology department, Wageningen University, The Netherlands. Special appreciations to the management and support staff of Biochemical Engineering laboratory, Centre for Energy Research and Development, Obafemi Awolowo University, Ile-ife Nigeria for their support. 


\section{Appendices}
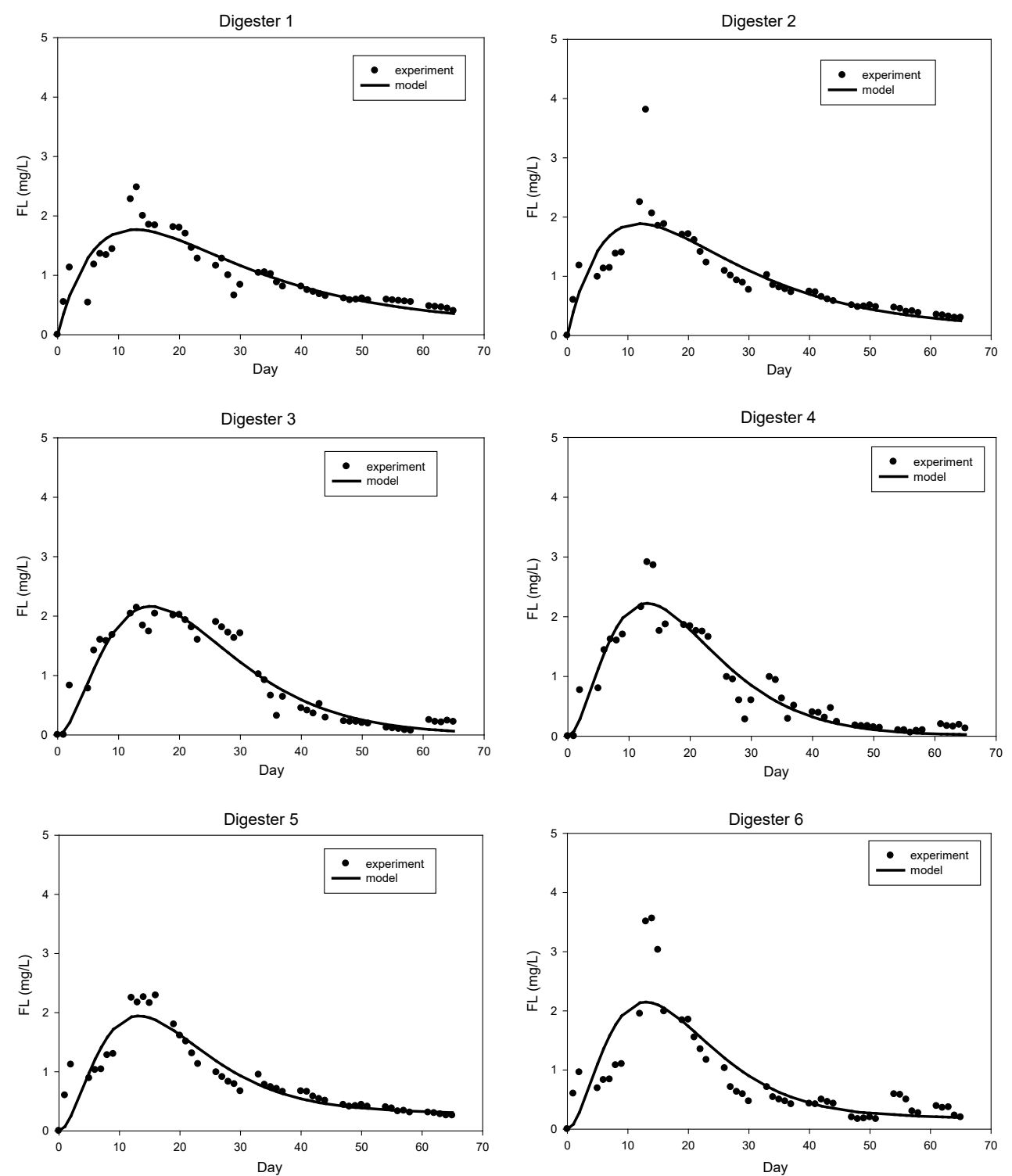

Appendix 4.1. Concentration of tracer FL (mg/L) against time (days) for all digesters, experimental and model for the liquid phase. 

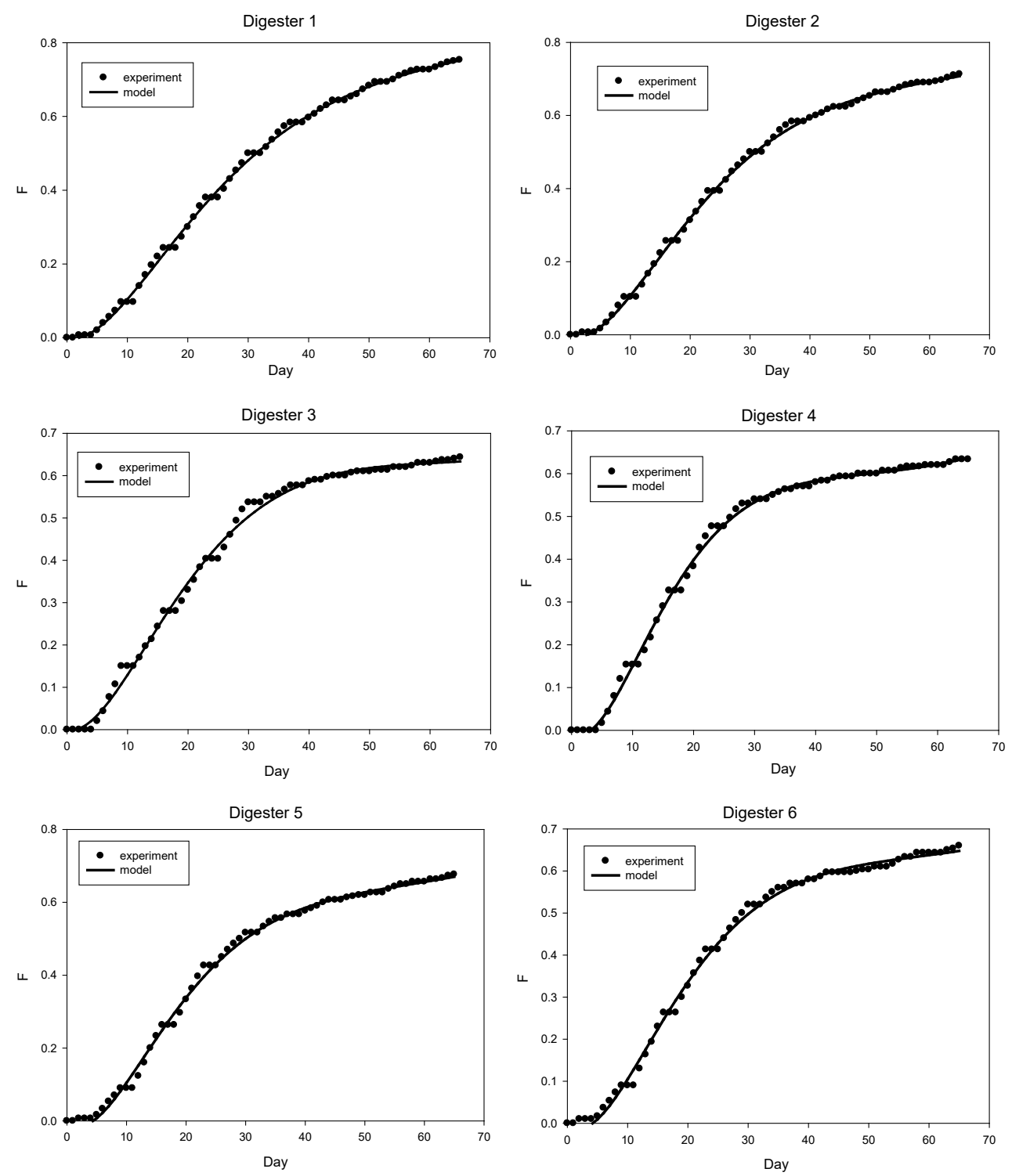

Appendix 4.2. $F$ function with the fitted data for the six reactors against time in days. 

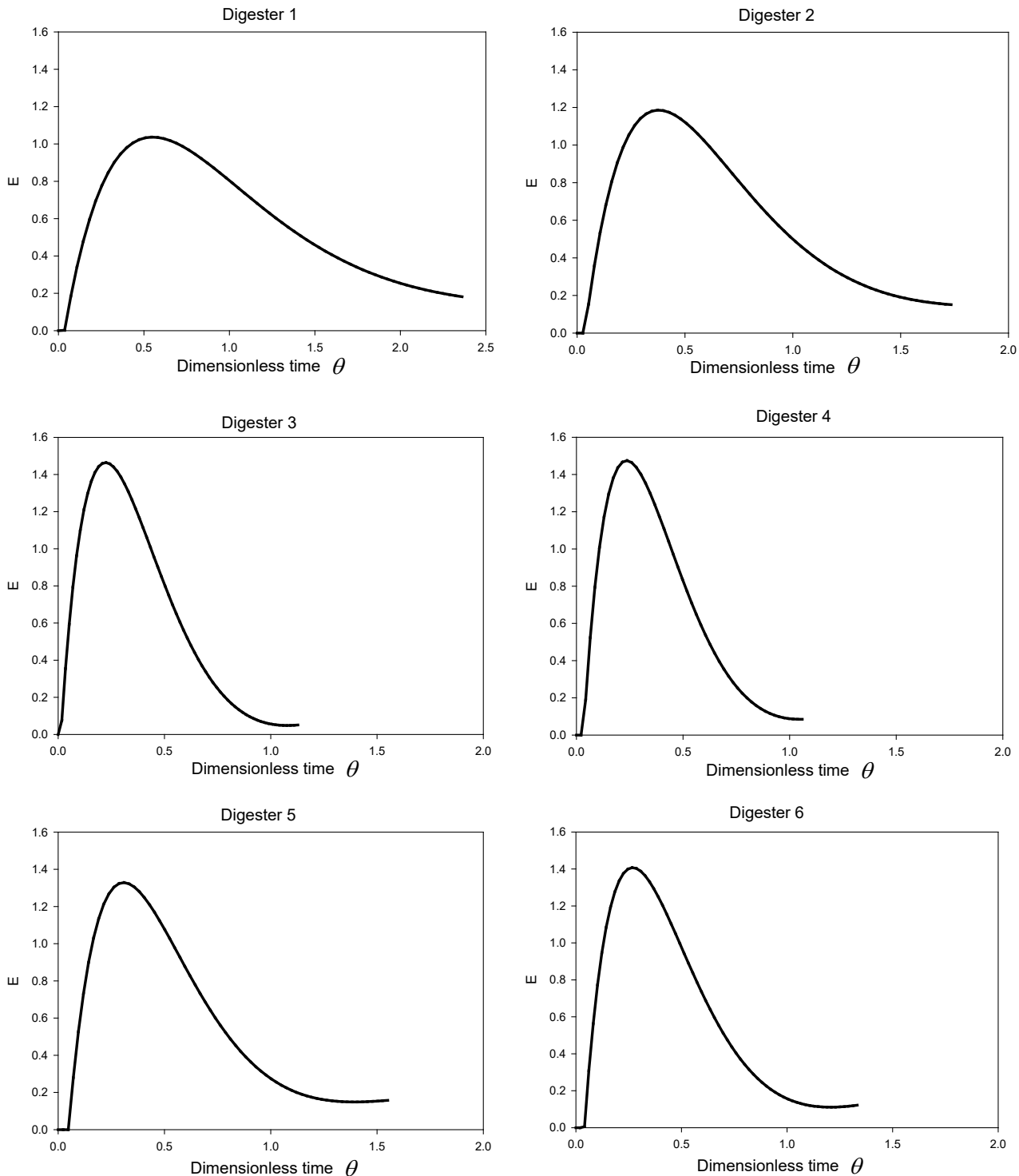

Appendix 4.3. Dimensionless RTD, (E-curves) for the solid phase of all reactors. 


\section{References}

An B.X., Preston, T.R. (1999). Gas production from pig manure fed at different loading rates to polyethylene tubular biodigesters." Livest. Res. Rural Dev., 11. (1) http://www.cipav.org.co/lrrd/lrrd11/1/an111.htm

Arsnow F. George, Vancil A. Michael, Schruber P. Robert, Ramacciotti N. Cristina (2010). Dye trace study: Trid and true method yields surprising results. Proceedings of the annual international conference on soils, sediments, water and energy.15, article 26. http://scholarworks.umass.edu/soilsproceedings/vol15/iss1/26.

Austin G., Blignaut J. (2008). South African national rural domestic biogas feasibility assessment. The Netherlands: Ministry of Development Co-operation.

Battistoni P. (1997). Pre-treatment, measurement execution procedure and waste characteristics in the rheology of sewage sludges and the digested organic fraction of municipal solid wastes. Water Sci. Technol. 36: 33-41.

Battistoni P., Fava G., Stanzini C., Cecchi F., Bassetti A. (1993). Feed characteristics and digester operative conditions as parameters affecting the rheology of digested municipal solid wastes. Water Sci. Technol. 27: 37-45.

Benbelkacem H., Garcia-Bernet D., Bollon J., Loisel D., Bayard R., Steyer J-P., Gourdon R., Buffiere P. (2013). Liquid mixing and solid segregation in high-solid anaerobic digesters.” Bioresour. Technol. 147: 387- 394.

Bridgeman, J. (2012). Computational fluid dynamics modelling of sewage sludge mixing in an anaerobic digester. Advances in Engineering Software. 44:54-62.

Chen Y., Yang G., Sweeney S., Feng Y. (2010). Household biogas use in rural China: a study of opportunities and constraints. Renew Sustain Energy.14: 545-9.

Deublein D. and Steinhauser A. (2008). Biogas from waste and renewable resources.” Weinheim, Germany: Wiley-VCH Verlag GmbH\& Co. KGaA.

El-Mashad H. M., van Loon W. K-P., Zeeman G., Bot G. P. A., Lettinga G. (2004). Design of a solar thermophilic anaerobic reactor for small farms." Biosystem Engineering 87 (3): 345-353

Escudie R., Conte, T., Steyer, J.P., Delgenes J.P. (2005). Hydrodynamic and biokinetic models of an anaerobic fixed-bed reactor. Process Biochem. 40, 2311-2323.

Ferrer I., Garfí M.; Uggetti, E., Ferrer-Martí L., Calderon A.,Velo E. (2011). Biogas production in low-cost household digesters at the Peruvian Andes. Biomass and Bioenergy, 35:1668-1674.

Ferrer I., Cadena E., Perez., Garfi M. (2013). Technical, economic and environmental assessment of household biogas digesters in developing countries. Proceedings of 13th World Congress on Anaerobic Digestion, 25-28 June 2013, Sandiago de Compostela, Spain.

Fulford D. (1988). Running a Biogas Programme: A Handbook. London, Intermediate Technology Publications.

Garcia-Bernet D., Loisel D., Guizard G., Buffiere P., Steyer J.P., Escudie R., (2011). Rapid measurement of the yield stress of anaerobically-digested solid waste using slump tests. Waste Manage. 31:631-635.

Ghimire P. C. (2013). SNV Supported domestic biogas programmes in Asia and Africa. Renewable Energy 49:90-94.

Gomez X., Cuetos M.J., Cara J., Moran A., Garcia A. (2006). Anaerobic co-digestion of primary sludge and the fruit and vegetable fraction of the municipal solid wastes-conditions for mixing and evaluation of the organic loading rate. Renew. Energy 31: 2017-2024.

Grobicki A., Stuckey D. C. (1992). Hydrodynamic characteristics of the anaerobic baffled reactor."Wat. Res. 26 (3):371-378.

Halalsheh M., Kassab G., Yazajeen H., Qumsieh S., Field J. (2011). Effect of increasing the surface area of primary sludge on anaerobic digestion at low temperature. Bioresour. Technol. 102:748-752

Hamad M.A., Abdel Dayem, A.M., E1 Halwagi M. M. (1983). Evaluation of the performance of two rural biogas units of Indian and Chinese design. Energy Agric. 1:235-250.

Ike M., Inoue D., Miyano T., Liu T.T., Sei K., Soda S., Kadoshin S., (2010). Microbial population dynamics during startup of a full-scale anaerobic digester treating industrial food waste in Kyoto eco-energy project. Bioresour. Technol. 101: 3952-3957.

Jegede A. O, Zeeman G., Bruning H. (2018). Effect of mixing regime on anaerobic digestion of cow manure: comparing mechanically mixed, unmixed and Chinese dome digesters. Under review in Sustainable energy technologies and assessments.

Jha A. K., Li, J. Z., Nies, L., Zhang, L. G. (2011). Research advances in dry anaerobic digestion process of solid organic wastes. African J. Biotechnol. 10:14242-14253.

Karthikeyan O. P., Visvanathan C., (2013). Bio-energy recovery from high-solid organic substrates by dry anaerobic bioconversion processes: a review. Rev. Environ. Sci. Biotechnol., 12:257-284.

Kim M., Ahn Y.H., Speece R.E. (2002). Comparative process stability and efficiency ofanaerobic digestion: mesophilic vs. thermophilic. Water Res. 36:4369-4385.

Levenspiel O., (1972). Chemical Reaction Engineering. J. Wiley and Sons, New York. 
Li Y. B., Park S. Y., Zhu J. Y. (2011). “Solid-state anaerobic digestion for methane production from organic waste.” Renew. Sustain. Energ. Rev. 15:821-826.

Lindmark J., Thorin E., Fdhila R. B., Dahlquist E. (2014). Effect of mixing on the result of anaerobic digestion: Review. Renewable and Sustainable Energy Review (40):1030 -1047

Liu X. L., Ren N. Q. Wan C. L. (2007). Hydrodynamic characteristics of a four-compartment periodic anaerobic baffled reactor. J. Environ. Sci. 19: 1159-1165.

Martin A.D. (2000). Interpretation of residence time distribution data. Chem. Eng. Sci. 55:5907-5917.

Noga J. E., Udomkusonsri P. (2002). Fluorescein: A rapid sensitive nonlethal method for detecting skin ulteration in fish. Vet Pathol 39:726 - 731.

Ong H. K., Greenfield P. F., Pullammanappallil P.C. (2002). "Effect of mixing on biometha-nation of cattle-manure slurry." Environ Technol. 23:1081-90.

Rittmann B. E., McCarty, P. L. (2001). Environmental Biotechnology. McGraw-Hill,New York.

Sanchez O., Michaud, S., Escudié, R., Delgenes J.P., Bernet N. (2005). Liquid mixing and gas-liquid mass transfer in a three-phase inverse turbulent bed reactor. Chem. Eng. J. 114: 1-7.

Skiadas I. V., Lyberatos G. (1998). The periodic anaerobic baffled reactor. Wat. Sci. Technol. 38 (9): 401-408.

Sung S., Dague R. R. (1995). “Laboratory studies on the anaerobic sequencing batch reactor.” Water Environ Res. 67:294301.

Terashima M., Goel R., Komatsu K., Yasui H., Takahashi H., Li Y. Y., Noike T., (2009). CFD simulation of mixing in anaerobic digesters. Bioresour. Technol. 100: 2228- 2233.

Tumwesige V., Fulford D., Davidson G.C. (2014). Biogas appliances in Sub-Sahara Africa. Biomass and Bioenergy 70:4050 .

Ward A. J., Hobbs P. J., Holliman P. J., Jones D. L. (2008). Optimisation of the anaerobic digestion of agricultural resources. Bioresour. Technol. 99:7928-7940. 



\title{
Chapter
}

\section{5}

\section{Location of the inlets and outlets of Chinese dome digesters to mitigate biogas emission}

\author{
Abiodun O. Jegede ${ }^{* 1}$, Grietje Zeeman *, Harry Bruning* \\ * Sub-Department of Environmental Technology, Wageningen University, \\ Wageningen, The Netherlands. \\ ${ }^{1}$ Centre for Energy Research and Development, \\ Obafemi Awolowo University, Ile-ife, Nigeria.
}

This chapter is based on:

Jegede A.O., Bruning H., Zeeman G. (2018). Location of inlets and outlets of Chinese dome digesters to mitigate biogas emission. Biosystems Engineering 174:153- 158. 


\begin{abstract}
In this study, three equations were developed and validated for the design of inlet and outlet of the Chinese dome digester (CDD) to prevent biogas emission or leakages. The model was implemented in MATLAB software and validated with results from a pilot study. Biogas and temperature data from the pilot experiment were used to run the model and the model results fit well with the experimental data at lower gas volume ( $<20 \mathrm{~mol}$.) but with some slight deviation at higher gas volume. The model predicted the reactor pressure $\left(P_{G}\right)$ and the slurry displacement in the expansion chamber, inlet pipe $(b)$, and inside the digester $\left(b_{G}\right)$. The relationship between the gas and $b$ is not linear at higher gas volume (> 20 mol.). Lastly, the model approximations can be used to determine the optimal size of the CDD for daily biogas storage before use based on different reactor and expansion chamber sizes, in order to mitigate the emission of surplus biogas from the inlet and outlet pipes.
\end{abstract}




\subsection{Introduction}

Household digesters can serve as a sustainable energy solution to meet the cooking needs of rural households in developing countries. These digesters make use of the anaerobic digestion process to break down organic matter for the production of biogas and nutrient rich effluent or biofertilizer. However, the application of household digester technology in rural areas of developing countries has many challenges such as poor performance of the digester, limited application of feedstock to mono-substrate, and high costs of installation (Yu et al., 2008; Asam et al., 2011). About 45 million domestic biogas or household digesters have been installed in developing countries, mostly in China (Bond \& Templeton, 2011; Mapelli \& Mungwe, 2014). The Chinese dome digester is the most widely applied household digester in developing countries, usually constructed using bricks, concrete, or prefabricated plastic (Jegede et al., 2018a; Perez et al., 2014). The Chinese dome digester operates based on the wet anaerobic digestion concept (influent total solid (TS) concentrations around 7\%) at ambient temperature - mesophilic $20-45^{\circ} \mathrm{C}$ (Mungwe et al., 2016).

Monitoring and evaluating the performance of household digesters is important to evaluate the impact and the overall benefits of the system as a cooking source. The performance of household digester could be evaluated using economic, social, and environmental indicators. The economic indicators are investment cost, net present value and payback time. Social indicators include clean cooking environment, elimination of time to collect firewood, and local job creation while the indicators for the environment are reduction of indoor emission and greenhouse gases, and elimination of the use of firewood (Mungwe et al., 2016), which helps in the mitigation of deforestation. Because of these benefits, household digesters have been strongly supported and promoted by governments and international organizations in Asia and Africa (Feng et al., 2012).

A major reason why various governments and international donors support this system, if managed well, is that it a cost-effective way of mitigating methane $\left(\mathrm{CH}_{4}\right)$ emissions from animal dung or manure (Sommer et al., 2004). Although the combustion of biogas does release a GHG $\left(\mathrm{CO}_{2}\right)$, it reduces the amount of $\mathrm{CH}_{4}$ (a much more potent $\mathrm{GHG}$ ) that would be released if the manure were not subject to anaerobic digestion. Different studies have calculated these savings in India (Bhattacharya et al., 1997), South America (Garfi et al., 2012), and China (Yu et al., 2008). However, the benefits that the household digesters present may not be as they portray because domestic biogas plants often release methane via leaks from the inlets and outlets (Khoiyangbam et al., 2004; Nazir, 1991). In addition, surplus biogas is released intentionally in many cases into the atmosphere, and this could be very significant (Thien et al., 2012). Biogas production in household digesters depends on the type of feedstock, ambient temperature, and residence time. The Chinese fixed dome digester, operated in China for example, makes use of cow and pig manure and the volume usually ranges between $6-10 \mathrm{~m}^{3}$ (Chen et al., 2010; Jiang et al., 2011). These digesters produce between $0.1-0.3 \mathrm{~m}^{3}$ biogas $/ \mathrm{m}^{3}$ of reactor volume per day (Jiang et al., 2011).

Since methane, a strong greenhouse gas (GHG), is the main component of biogas, emissions from household reactors via leaks, and deliberate release of surplus gas threaten to outweigh the benefits of household biogas plants in mitigating the release of GHG. The known sources of methane loss in the digester are the inlet and outlet pipes, cracks in tubing and walls of digesters, and intentional 
or deliberate release of biogas into the atmosphere whenever gas production is more than demand. The greatest source of the emission is the deliberate release of surplus biogas into the atmosphere (Prapaspongsa et al., 2010; Thien et al., 2012). For instance, about 15\% of biogas produced is released and flared in Thailand yearly (Prapaspongsa et al., 2009). In Vietnam, data from Vu and Dinh, (2012), showed that $65 \%$ of household digesters had surplus biogas, which was released into the atmosphere because it could not be used. The total losses of biogas from all these sources have been estimated to be as high as $40 \%$ of the biogas generated. However, this emission will vary depending on location, weather, and types of materials used in construction (Bruun et al., 2014).

The gas storage capacity of a Chinese dome digester is directly related to the positions of the inlet and outlet pipes, and also to the displacement in the expansion chamber because the gas is stored above the slurry. This deliberate biogas release occurs because little effort has been put into optimizing and improving the CDD. To the best of our knowledge, there is no specific literature or study on the prevention of gas leakage from the inlet and outlets of the Chinese dome digesters as a result of excess or unused biogas. Although, a recent study of (Rupf et al., 2017) described a model for the estimation of the daily methane potential and the gasholder volume in the fixed dome digester. The model was, however not validated and failed to include the pressure component - an important parameter in designing gas storage for the fixed dome digester. The objective of this study was therefore to develop a mathematical model that could be used to design the location of inlet and outlet, height and volume of the extension chamber (indirectly for the estimation of gas storage in the dome). The model will help designers and operators of Chinese dome digesters to plan biogas demand and storage in order to avoid leaking through the inlets and outlets, and also to prevent intentional release of biogas into the atmosphere.

\subsection{Methods}

\subsubsection{Model development}

The model development focuses on the displacement level of slurry in the inlet pipe and the extension chamber as a result of the pressure build-up in the dome from biogas production.

The feeding of the digester is done through the inlet pipe and the slurry level in the extension chamber is usually in equilibrium as shown in Fig. 5.1. The gas produced is accumulated in the upper part of the dome. The slurry level difference in the expansion chamber and the inlet is the result of the pressure build-up shown in Fig.5.2. The stored gas needs space and presses part of the slurry into the effluent chamber and inlet pipe because the slurry is an incompressible liquid and their upper ends are at atmospheric pressure. Therefore, Fig. 5.1 and 5.2 illustrate the scheme of the digester before and after biogas production. During gas use for cooking, the slurry flows back into the digester therefore creating a mixing regime (Jegede at. al., 2018a). The flow rate of slurry back into the digester will depend on use of the biogas while the pressure and the height difference will depend on the density of the slurry or digester content, which is directly proportional to the percentage of total solid (TS). 
When the biogas produced in the Chinese dome digester exceeds the daily demand, the pressure will continue to increase and more slurry will be pushed into the expansion chamber and the inlet pipe. If the location of the inlet and the outlet pipes connecting the main reactor to the expansion chamber is not well designed, biogas will escape through these points.

The pressure in the digester is related to the displacement in the inlet pipe and extension or expansion chamber with Equation (5.1).

$\mathrm{P}_{\mathrm{G}}-\mathrm{P}_{\mathrm{a}}=\rho \mathrm{g}\left(h+h_{G}\right)$

where,

where,

$\mathrm{P}_{\mathrm{G}}=$ is the pressure of the gas in the reactor dome and depends on biogas production and usage $\mathrm{Nm}^{-2}$.

$\mathrm{P}_{\mathrm{a}}=$ is the atmospheric pressure in $\mathrm{N} \mathrm{m}^{-2}$

$\rho=$ density of slurry in $\mathrm{kg} \mathrm{m}^{-3}$

$\mathrm{h}=$ slurry displacement in the inlet pipe and extension chamber in $\mathrm{m}$

$\mathrm{h}_{\mathrm{G}}=$ displacement in the digester in $\mathrm{m}$

To relate the biogas production to the pressure in the digester, we make use of the ideal gas law with a gas volume of

$\mathrm{V}=A h_{G}$

where,

$A=$ surface area of slurry in the digester $\mathrm{m}^{2}$

$\mathrm{P}_{\mathrm{G}} A_{G} h_{G}=n R T$

where,

$\mathrm{P}_{\mathrm{G}}=$ pressure of gas in dome of the digester in $\mathrm{N} \mathrm{m}^{-2}$

$A_{G}=$ area of the slurry in the digester in $\mathrm{m}^{2}$

$\mathrm{n}$ = biogas generated in mol.

Since the total slurry volume does not change during gas production the following balance holds:

$\mathrm{V}=A h_{G}$

where,

$A_{1}=$ surface area of the inlet pipe $m^{2}$

$A_{2}=$ surface area of the expansion chamber $\mathrm{m}^{2}$ 
Equations 5.1, 5.3 and 5.4 were solved simultaneously using MATLAB to determine $P_{G}, h, h_{G}$ The MATLAB code and parameters used are given in Appendix 5.1

In case $P_{G}$ is close to $P_{a}$ Equation (5.3) can be well approximated by:

$$
\mathrm{P}_{a} A_{G} h_{G}=n R T
$$

Solving the set $\left(5.1,5.3 \mathrm{a}\right.$ and 5.4) of equations using this approximation and eliminating $h_{G}$ yields:

$$
\begin{aligned}
& P_{G}=P_{a}+\frac{\rho g R T}{P_{a}}\left(\frac{1}{A_{1}+A_{2}}+\frac{1}{A_{G}}\right) \mathrm{n} \\
& h=\frac{R T}{P_{a}\left(A_{1}+A_{2}\right)} \mathrm{n}
\end{aligned}
$$

So, a linear increase of the pressure $P_{G}$ and displacement $h$ with the gas production $n$ can be expected.

\subsubsection{Model validation}

The model was validated using results of pilot study executed by (Jegede et al., $2018 \mathrm{~b}$ ). The model was used to determine the approximate height of the inlet pipe and expansion chamber. In addition, it was used to determine the location of the outlet pipe that connects the reactor and the expansion chamber. The pilot digester was constructed from PVC (Fig. 5.1). The reactor volume is $500 \mathrm{~L}$, with an extension chamber of $250 \mathrm{~L}$ for effluent variation and outlet Measured biogas and temperature data were used as variable parameters to run the code.

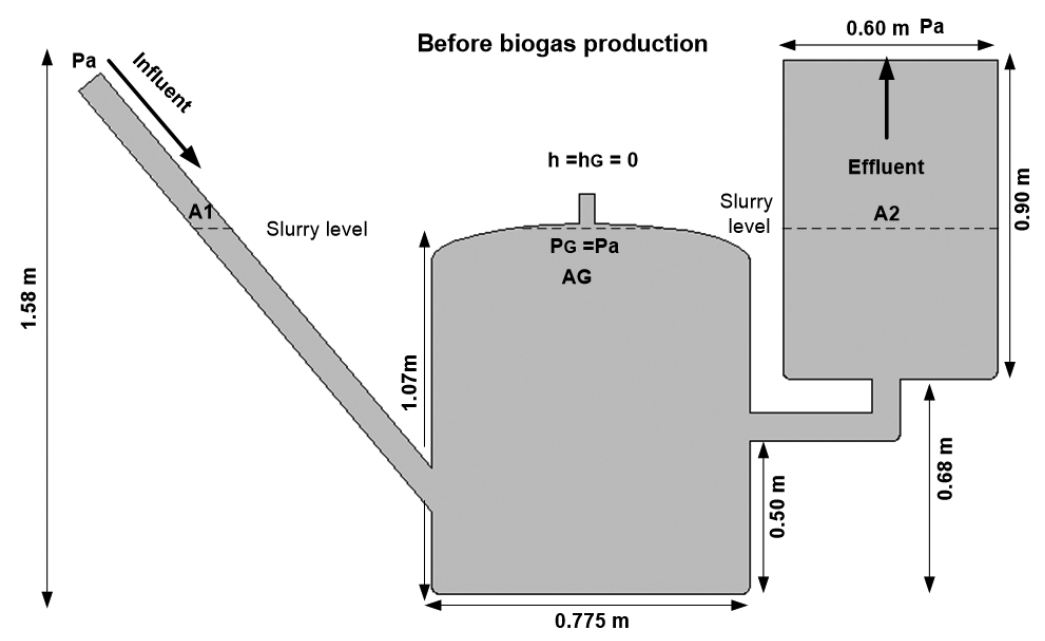

Figure 5.1 | Scheme before biogas production. 


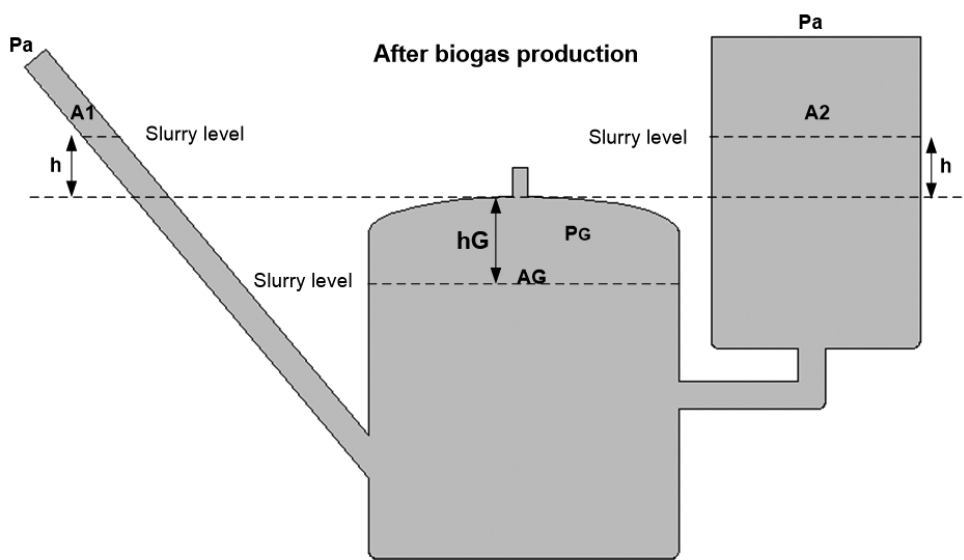

After biogas production

Figure 5.2 $\mid$ Scheme after biogas production.

The reactor was fed with cow manure with a high influent total solid concentration (15\% TS) and operated at a hydraulic retention time of 30 days. Biogas volume was collected in a gas bag and measured using an Ultrasonic biogas meter BF-2000, Longgang, Schenzhen, China. Daily gas volume was converted to moles at standard temperature and pressure (STP). The displacement in the expansion chamber $(\mathrm{h})$ was measured using a calibrated meter rule. The pressure $\left(\mathrm{P}_{\mathrm{G}}\right)$ was measured using a pressure meter. It was not possible to determine the displacement $\left(h_{G}\right)$ in the reactor. Sixty-four data points (gas volume, pressure and displacement (h)) were recorded. Gas collection, pressure measurement and displacement measurements were done three times daily, representing daily cooking times. When gas production exceeded the design limit, collection and measurements were done four times per day. 


\subsection{Results and discussion}

The displacement $(b)$ in the expansion chamber was plotted against the daily biogas production as shown in Fig.5.3. The digester pressure was plotted against the biogas production (Fig.5.4).

The model data fits well with the experimental data for the pressure $\left(P_{\mathrm{G}}\right)$-volume data, but slight deviation exits at higher volume ( $>20 \mathrm{~mol}$. in displacement $(b)$ - volume data. Statistical analysis shows that the R squared values are 75 and $88 \%$ for the displacement in the expansion chamber and digester pressure, respectively. The model results of the slurry displacement $\left(h_{G}\right)$ inside the reactor are presented in Fig. 5.5 as it was not possible to measure this value during the experiment.

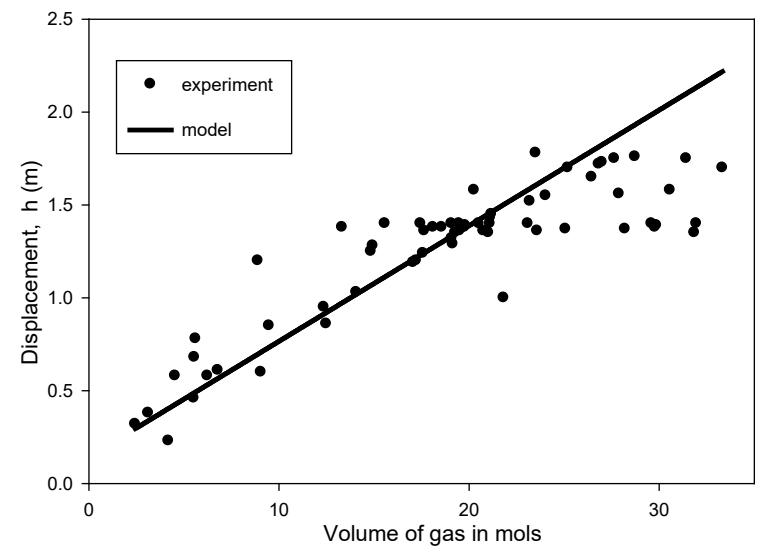

Figure 5.3 $\mid$ The displacement in the expansion chamber plotted against the biogas volume.

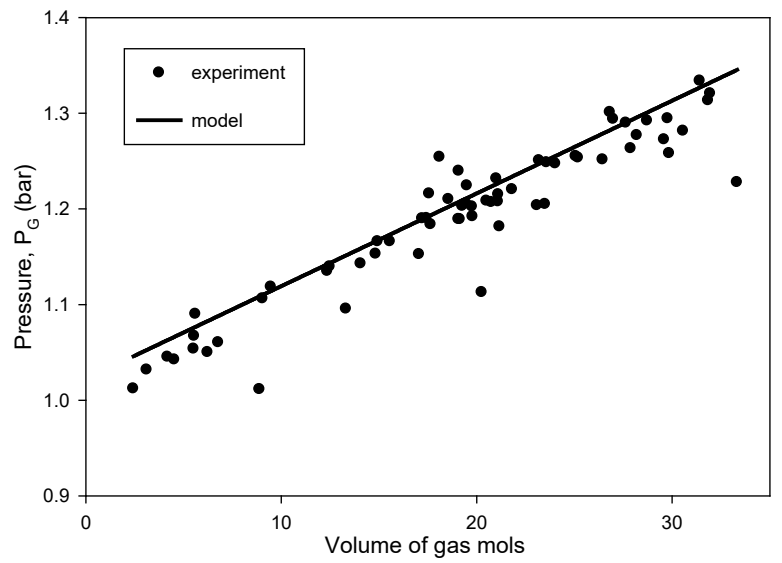

Figure 5.4 $\mid$ The pressure (experimental and model) plotted against the biogas volume. 


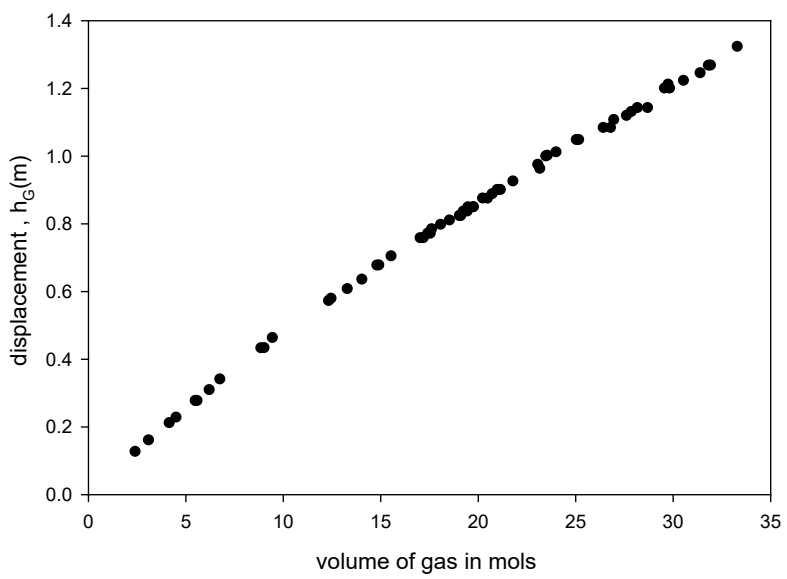

Figure 5.5 | The model displacement in the reactor plotted against the biogas volume.

The results show a linear relationship between the volume of gas produced and the displacement in the expansion chamber at lower volume, but not liner at higher volume with some deviation. In addition, the relationship between the volume of the produced gas and the pressure in the reactor is linear without an exception. This is consistent with the principle of operation of the CDD; when the reactor produces biogas, the pressure increases and the effluent level in the expansion chamber and inlet pipe increases. The deviations in the experimental data points (biogas and pressure) from the model, especially in Fig. 5.3 could be as a result of the pressure variation during the opening of the gas pipe and gas measurements because gas collection was done via gravity without the use of a pump.

The relationship between the volume of gas produced and the slurry displacement $h_{G}$ is also linear but with small deviation at higher gas volume. The slurry level in the reactor is an important factor to designing the location of the inlet pipe and the expansion chamber, and possibly to help in the optimization of the Chinese dome digester. The slurry level is directly determined by the slurry displacement. The maximum value of $h_{G}$ obtained in a day in the pilot study is $1.3 \mathrm{~m}$ at 33.3 moles of biogas produced. The specific gas produced in the digester on the given day is $0.32 \mathrm{~L} \mathrm{CH}_{4} / \mathrm{g} \mathrm{VS}$ (Jegede et al., 2018b), which is based on the Biochemical Methane Potential (BMP), the expected theoretical maximum gas production from the reactor. This implies that the maximum expected gas production from the reactor will not exceed 33.3 moles per day. Since biogas use or collection is done three times a day (representing the number cooking times), the displacement $\left(b_{G}\right)$ in the reactor will not exceed $0.43 \mathrm{~m}$, which is below $0.47 \mathrm{~m}$, the location of the outlet pipe shown in Fig.5.1. The inlet pipe is also connected to the digester at a lower position than the outlet pipe. This means the reactor should be able to store the produced biogas, which is expected to be consumed at least three times a day for cooking. The biogas will not escape through the outlet if operated three times a day according to the operating conditions described earlier. It will indeed prevent fugitive methane emission from the outlet and inlet pipes of the reactor before use or during the zero-consumption period. However, if the biogas is consumed less than three times a day, the 
remaining biogas will leak through the outlet and inlet pipes. In that case, the design should be changed based on new model calculations.

Biogas consumption and reactor loading can be planned by builders and technicians that construct Chinese dome digesters as well as households that make use of them for cooking by applying the approximations (Equations 5.3a, 5.5 and 5.6) of the model developed in this study. These equations can be solved using Microsoft excel software to determine the reactor pressure $\left(P_{G}\right)$, slurry displacement in the expansion chamber $(b)$, and the slurry displacement $\left(b_{G}\right)$ in the reactor, which serve as a guide to determine the location of the outlet and inlet pipe from the dome or top of the reactors. The variation in atmospheric pressure $\left(P_{a}\right)$ because of different locations would have minimum influence on the application of the models; however, local atmospheric pressure should be noted and use for the calculations. The application of this model and the consequent modification of the CDD design will prevent biogas emissions to the atmosphere and thereby substantially reduce GHG emissions of CDD systems.

\subsection{Conclusion}

A model for the prevention of biogas emission from its reactor has been developed for designers and builders of Chinese dome digesters and also validated in an experimental pilot study. The model developed consists of three sets of equations to estimate the displacement of slurry in the expansion chamber and in the reactor, as well as to determine the maximum pressure expected daily. A better decision on the location and heights of the outlet, expansion chamber and inlet pipes could be made using the approximation model and will therefore prevent emissions during the zero consumption periods.

\section{Acknowledgements}

This work was funded by the Netherlands Fellowship Programme (NFP), the Netherlands. Special thanks to the analytic/laboratory support team at Environmental Technology department, Wageningen University, The Netherlands. Special appreciation goes to the management and staff of Biochemical Engineering laboratory, Centre for Energy Research and Development, Obafemi Awolowo University, Ile-ife Nigeria for their support. 


\section{References}

Asam Z., Poulsen T.G., Nizami A.S., Rafique R., Kiely G., Murphy J.D. (2011). How can we improve biomethane production per unit of feedstock in biogas plants? Appl. Energy; 88:2013-8.

Bhattacharya S.C., Thomas J.M., Abdul Salam P. (1997). Greenhouse gas emissions and the mitigation potential of using animal wastes in Asia." Energy 22:1079-85.

Bond T., Templeton M.R. (2011). History and future of domestic biogas plants in the developing world. Energy sustain. Dev. 15 347e354, http://dx.doi.org/10.1016/j.esd.2011.09.003.

Bruun S., Jasen L. S., Vu V.T. K., Sommer S. (2014). Small-scale household biogas digesters: An option for global warming mitigation or a potential climate bomb? Renewable and Sustainable Energy Reviews 33:736-741.

Chen Y., Yang G., Sweeney S., Feng Y. (2010). Household biogas use in rural China: a study of opportunities and constraints. Renew Sustain Energy Rev: 14:545-9.

Feng Y., Guo Y., Yang G., Qin X., Song Z. (2012). Household biogas development in rural China: on policy support and other macro sustainable conditions. Renew Sustain Energy Rev. 16:5617-24.

Garfí M., Gelman P., Comas J., Carrasco W., Ferrer I. (2012). Agricultural reuse of the digestate from low-cost tubular digesters in rural Andean communities. Waste Manag. (Oxf.) 31:2584-2589.

Jegede A., Bruning H., Zeeman G. (2018a). Mixing in anaerobic digester with a specific emphasis on Household digesters: A Review. Under review in Critical reviews in environmental science and technology.

Jegede A., Bruning H., Zeeman G. (2018b). Optimization of mixing in a Chinese dome digester. PhD Thesis, Wageningen University, The Netherlands.

Jiang X., Sommer S.G., Christensen K. V. (2011). A review of the biogas industry in China. Energy Policy, 39:6073-81.

Khoiyangbam R. S., Kumar S., Jain M. C. (2004). Methane losses from floating gasholder type biogas plants in relation to global warming. J Sci Ind Res; 63:344-7.

Mungwe J.N., Mapelli F. (2014). Modern energy services for cooking from improve cookstove to domestic and community based biogas systems.pdf. In: Columbo E., Bologna S., Masera D. (Eds.) Renewable Energy for Unleashing Sustainable Development. Springer International Publishing Switzerland, http://dx.doi.org/10.1007/978-3-31900284-2_1.

Mungwe J. N., Colombo E., Adani F., Schievano A. (2016). The fixed dome digester: An appropriate design for the context of Sub-Sahara Africa. Biomass and Bioenergy. 95: 35-44.

Nazir M. (1991). “Biogas plants construction technology for rural areas.” Bioresour. Technol; 35:283-289.

Perez I, Garfí M, Cadena E., Ferrer I. (2014). Technical, economic and environmental assessment of household biogas digesters for rural communities. Renewable Energy 62: 313- 318

Prapaspongsa T., Pholchan P., Hansen J. A., Poulsen T.G., Christensen P. (2009). Improved energy recovery efficiencies from piggery waste biogas plants in Thailand using Danish experiences. In: Proceedings of the world renewable energy congress, the 3rd international conference on sustainable energy and environment (SE2099, 18-23 May 2009, Bangkok, Thailand.

Prapaspongsa T., Christensen P., Schmidt J. H., Thrane M. (2010). Life cycle assessment of comprehensive pig manure management incorporating integrated technology systems. J Clean Prod.18:1413-22.

Rupf G. V., Arabzadeh B. P., De Boer K., McHenry M. P. (2017). Development of an optimal biogas system design model for Sub-saharan Africa with case studies from Kenya and Cameroon. Renewable Energy 109:586 -601.

Sommer S. G., Petersen S. O., Møller H. B. (2004). Algorithms for calculating methane and nitrous oxide emissions from manure management. Nutr. Cycl. Agroecosyst. 69:143-54.

Thien Thu C.T., Cuong P.H., Hang L.T., Chao N.V., Anh L. X., Trach N.X. (2012). Manure management practices on biogas and non-biogas pig farms in developing countries - using livestock farms in Vietnam as an example. J Clean Prod; 27:64-71.

Vu T. K. V., Dinh X. T. (2012). Survey on impact assessment of climate change on livestock production. Ministry of Agriculture and Rural Development; Hanoi, Vietnam.

Yu L., Yaoqiu K., Ningsheng H., Zhifeng W., Lianzhong X. (2008). Popularizing householdscale biogas digesters for rural sustainable energy development and greenhouse gas mitigation. Renew Energ.33:2027-35. 


\section{Appendices}

Appendix 5.1 | MATLAB code used for solving the model.

clear all

syms pG h hG

$\mathrm{n}=[29.60,31.42,30.57,27.00,26.45,27.65,23.20,27.89,19.09,26.83,28.21,21.18,28.73,29.86$, $17.58,19.08,19.80,21.10,19.15,19.77,21.11,21.83,21.02,14.07,18.57,20.51,19.48,20.76$, 17.23 , 24.03, 31.96, 29.78, 25.20, 25.08, 31.85, 19.27, 19.51, 12.49, 3.12, 5.62, 4.54, 17.06, 23.09, $6.24,6.79,2.44,9.48,5.53,15.57,12.37,23.59,14.94,17.45,18.11,17.65,20.27,9.06,13.32$, $33.33,23.51,8.89,4.19,14.85,5.55] ; \% \mathrm{~mol}$

$\mathrm{dG}=0.775 ; \% \mathrm{~m}$

$\mathrm{AG}=3.14^{*} \mathrm{dG}^{*} \mathrm{dG} / 4 ; \% \mathrm{~m}^{-2}$

$\mathrm{pa}=101325 ; \% \mathrm{~N} \mathrm{~m}^{-2}$

$\mathrm{d} 1=0.075 ; \% \mathrm{~m}$

$\mathrm{A} 1=3.14^{*} \mathrm{~d} 1 * \mathrm{~d} 1 / 4 ; \% \mathrm{~m}^{-2}$

$\mathrm{d} 2=0.60 ; \% \mathrm{~m}$

$\mathrm{A} 2=3.14 * \mathrm{~d} 2 * \mathrm{~d} 2 / 4 ; \% \mathrm{~m}^{-2}$

$\mathrm{rho}=1000 ; \% \mathrm{~kg} \mathrm{~m}^{-3}$

$\mathrm{g}=9.81 ; \% \mathrm{~m} \mathrm{~s}^{-2}$

$\mathrm{R}=8.31 ; \% \mathrm{~J} \mathrm{~mol}^{-\mathrm{K}}$

$\mathrm{T}=[304.1,299.9,301.35,302,300.2,298.75,296.65,299.95,299.5,296,300.3,300,294.8,301.4$, $301.15,299.75,299.5,301.05,298.6,299.9,300.9,300.8,302.3,301,302.2,299.4,299,301,301.2$, $304,301.5,305.8,302.55,304,302.5$, 302.15, 303.9, 305.15, 305.2, 301.5, 303.15, 304.05, 302.6, 305.55, 311.9, 303.7, 312.7, 306.4, 306, 304, 306, 305, 303.4, 304, 306, 303, 304, 302, 305, 306.3, $309.6,303.3,306.7,305.5] ; \% \mathrm{~K}$

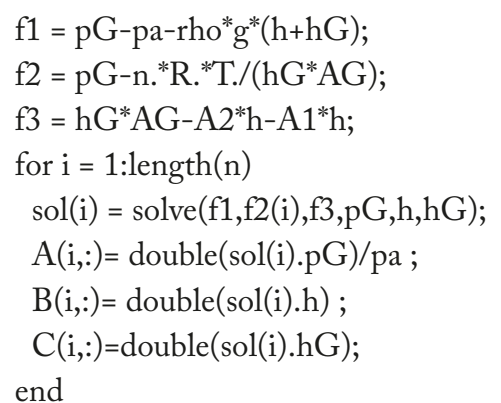




\title{
Chapter
}

\section{Development of an improved Chinese dome digester enables smaller reactor volumes; pilot scale performance}

\author{
Abiodun O. Jegede ${ }^{* 1}$, Grietje Zeeman *, Harry Bruning* \\ * Sub-Department of Environmental Technology, Wageningen University, \\ Wageningen, The Netherlands. \\ ${ }^{1}$ Centre for Energy Research and Development, \\ Obafemi Awolowo University, Ile-ife, Nigeria.
}

This chapter is based on:

Jegede A.O., Bruning H., Zeeman G. (2018). Development of an improved Chinese dome digester enables smaller reactor volumes: pilot scale performance. Under review in Biomass and Bioenergy. 


\begin{abstract}
The Chinese dome digesters are usually operated at a long hydraulic retention time at low influent total solids concentration because of limited mixing. In this study, a newly optimized Chinese dome digester with a self-agitating mechanism was investigated at a pilot scale (digester volume = $500 \mathrm{~L}$ ) and compared with the traditional digester (as blank) at $15 \%$ influent TS concentration at two retention times (30 and 40 days). The reactors were operated at ambient temperature, $27-33^{\circ}$ C. The optimized digester showed better digestion efficiency and process stability, while the blank was unstable throughout the study period. The average specific methane production, volatile fatty acids and percentage of volatile solids (VS) reduction are $0.16 \pm 0.13 \& 0.25 \pm 0.05 \mathrm{~L} \mathrm{CH}_{4} / \mathrm{g}$ VS; $1 \pm 0.5 \& 0.7 \pm 0.3 \mathrm{~g} / \mathrm{L}$ and $51 \pm 14 \& 57 \pm 10 \%$ at 40 days HRT (day 52-136) for the blank and optimized digester, respectively. At 30 days HRT (day 137-309) the results are $0.19 \pm 0.12 \& 0.23$ $\pm 0.04 \mathrm{~L} \mathrm{CH}_{4} / \mathrm{g} \mathrm{VS} ; 1.2 \pm 0.6 \& 0.7 \pm 0.3 \mathrm{~g} / \mathrm{L}$ and $51 \pm 9 \& 58 \pm 11.6 \%$.
\end{abstract}




\subsection{Introduction}

Energy is a vital component needed to improve quality of life, reduce poverty and for the promotion of socio-economic activities. However, till now there is still a global uncertainty in the energy sector because of the declining quantity of fossil fuel reserves coupled with crude oil price instability. This global energy situation requires alternative or renewable sources of energy and review of current technologies. It is vital to focus not only on sustained economic usage of current finite resource but also to identify and develop renewable technologies and resources that possess the potential to provide for the increasing energy demand. These resources and technologies should also be sustainable, clean, globally available and easy to exploit and operate, while contributing towards the materialization of the United Nation MDGs (Nzila et al., 2010).

The growing demand of energy because of population growth, lack of clean energy and inadequate availability of natural resources has led to the growing demand of anaerobic digestion technologies in rural areas of developing countries. Anaerobic digestion is a biochemical process that is applied for the efficient transformation of, for example, manure and other agricultural residues into biogas, a renewable energy source and biofertilizer. Biogas is rich in methane $(50-70 \%)$, and $\mathrm{CO}_{2}(30-$ $50 \%$ ) with traces of water vapor (1-6\%) and $\mathrm{H}_{2} \mathrm{~S}$. Biogas is a renewable, clean and efficient source of alternative energy which can be used as a substitute for fuels such as firewood, charcoal and cattle dung, usually used by rural dwellers (Sasse, 1988; Yu et al., 2008; Bond and Templeton, 2011).

The household or domestic digester is an example of an anaerobic digester usually applied in a single decentralized system mostly in rural areas of developing countries. It serves as an energy producer and sometimes, when coupled to the toilets, as a sanitation system. Household digesters are nonmechanically mixed and non-heated reactors (Qi et al., 2013). Domestic biogas plants can serve as energy solution to meet the cooking needs of rural households. Various governments and international funders support this system and if managed well (Jegede et al., 2018a) it is a cost-effective way of mitigating greenhouse gas emissions from animal dung (Sommer et al., 2004). This is accomplished by replacing fossil fuels with biogas and reducing methane emissions during manure management, starting from its production to the final application on agricultural lands (Bruun et al., 2014).

Among all household digesters, the Chinese dome digester (CDD) is the most popular and most implemented reactor because of its reliability, requirement of low maintenance and long lifespan (Ghimire, 2012; Cheng et al., 2013). The CDD is a basis for the development of recent household digester designs, for example the Puxin digester an example of a prefabricated digester (Cheng et al., 2013).

In CDDs gas pressure is created at the top of the reactor as a result of the biogas produced. The stored biogas pushes part of the slurry into an extension chamber. During gas use, pressure is released and the slurry flows back into the main reactor, creating a mixing regime or cycle (Fig. 6.2 a \& b). Therefore, CDD depends on the hydraulic variation i.e. the change of slurry level in the digester and extension chamber during gas use and could be regarded as intermittent natural mixing (Jegede et al.,2018a). Mixing is an important process in anaerobic digestion for establishing contact between micro-organisms and feed, for homogenization of temperature throughout the digester, and prevention of settling and floating layers. (Deublein and Steinhauser, 2008). 
The effect of mixing on the anaerobic digestion process has been studied by different authors. The requirement for digesters to be adequately and sufficiently mixed has been supported by many authors (Gerardi, 2003; Conklin et al., 2008; Halalsheh et al., 2011; Bridgeman, 2012;) while challenged by many other authors (Gomez et al., 2006, Kim et al., 2002, Ward et al., 2008, Ike et al., 2010). Lindmark et al., (2014) concluded in a review that an intermittent mixing mode looks better compared to continuous mixing, and shorter mixing durations are preferred for higher biogas production and from an energy point of view. Intermittent mixing can result in similar quantity of gas as compared to continuous mixing. In addition, Chinese dome digesters are generally operated at long hydraulic retention times (> 70 days) and low influent total solid (TS) concentrations $(\leq 7 \%)$ when compared to mixed reactors (intermittently or continuously). Mixing is limited, leading to a large reactor volume and higher cost (Jegede et al., 2018a).

Operating anaerobic digesters at high TS content $(>10 \%)$ could present a better alternative to AD systems operating at lower TS content $(<7 \%)$ because of the reduced reactor volume while applying the same HRT (Jha et al., 2011; Karthikeyan and Visvanathan, 2012). A major advantage of this approach is a smaller digester and eventually reduction in reactor cost. Applying this approach to CDD could help in the reduction of both water required for dilution and reactor size, however mixing in CDDs, achieved during feeding, biogas production and use is limited (Jegede et al., 2018a). In addition, Jegede et al., (2018b) investigated the impact of different influent TS (3-15\%) concentrations and the related volumetric biogas production on mixing in lab scale CDDs. Their results revealed that mixing in CDDs, due to biogas production and reactor feeding, is not sufficient at high (>10\%) TS concentration. Indeed, the rheological properties of manure are affected by water content or percentage of TS (Battistoni, 1997; Benbelkacem et al., 2013). The lower the water content, the higher the yield stress, because manure becomes viscoelastic material at high TS. The yield stress is directly proportional to the required force to make manure flow. Because of this property, the increased volumetric biogas production at high (>10\%) influent TS is not sufficient for mixing CDDs.

Therefore, to reduce the digester volume viz. reduction of HRT and operation at higher influent concentration rate (ca. 15\% TS) the Chinese dome digester has been modified to improve mixing via self-agitating mechanism, using the produced gas, while still being simple, cheap, easy to build and maintained at low cost. The objective of this research was to evaluate the performance of this improved self-agitating CDD at a pilot scale in continuous operation in comparison to a regular Chinese dome digester at higher organic loading rates (15\% TS, corresponding to $2.6-4 \mathrm{~g}$ VS/ $\mathrm{m}^{3} / \mathrm{d}$ ) at HRTs of 40 and 30 days. To visualize the mechanism of the self-agitating process, a demo was done using a $19 \mathrm{~L}$ transparent plastic bottle containing water and biogas production was simulated with the injection of air. 


\subsection{Material and methods}

\subsubsection{Reactors design and setup}

In this study two pilot Chinese dome digesters, optimized and blank were operated at a relatively high loading rate. The reactor volume is $500 \mathrm{~L}$, with an extension or expansion chamber of $250 \mathrm{~L}$ for effluent variation and outlet. A scheme of the two pilot reactors is shown in Figs. 6.2 \& 6.3. The difference between the blank and the optimized digester is the inclusion of two baffles at the top and bottom of the optimized digester as seen in (Fig. 6.3). The upper baffle, the main baffle divides the headspace of the reactor into two compartments A and B, (Fig. 6.3). The length of the baffle which should not reach the same level as the effluent outlet pipe of the digester was calculated based on our previous work (Jegede et al., 2018c). The gas outlet is located in compartment B, while compartment A has no gas outlet. Biogas produced is stored in both compartments before gas collection while the slurry level in the extension increases due to the pressure build up as a result of the produced biogas. After gas collection or gas use, the pressure in compartment B reduces to atmospheric pressure while the slurry flows back into the reactor and the level of slurry increases in compartment $\mathrm{B}$, however the pressure in compartment $\mathrm{A}$ remains rather stable with some slight variations when the level reaches the tip of the baffle. The lower baffle helps to prevent short circuiting of influent by creating mild hold-up and help to improve mixing of the influent with the reactor content.

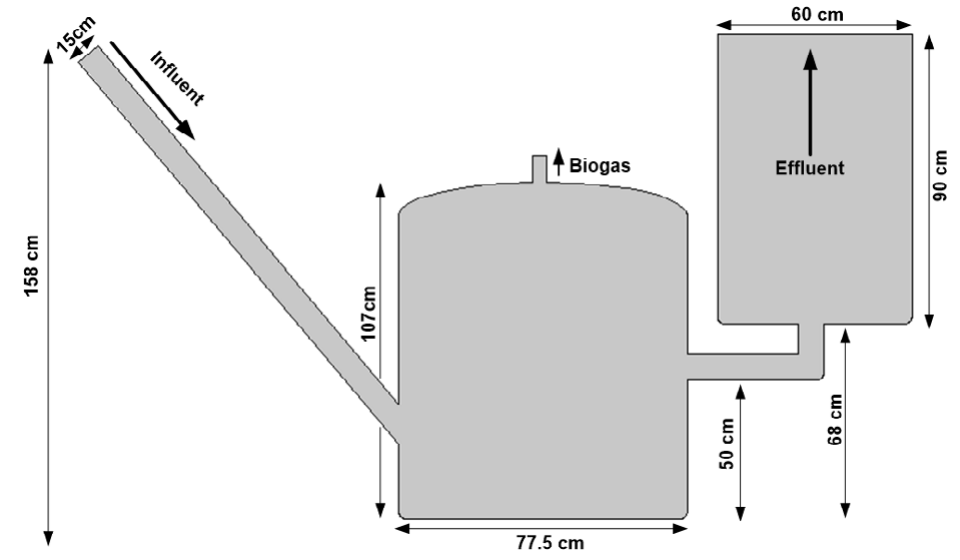

Figure 6.1 | Schematic of the blank digester with dimension (based on Jegede et al. 2018c).

Further production and release of biogas into compartment $\mathrm{A}$ will increase the pressure in the compartment and pushes the slurry below the baffle. This will make some biogas to be transported below the baffle into compartment $\mathrm{B}$, immediately afterwards the slurry level in compartment $\mathrm{A}$ will return to the initial level before the gas flows into $\mathrm{B}$. This process creates a self-agitation cycle. Septums were incorporated on top of the reactors to take pressure measurements. 


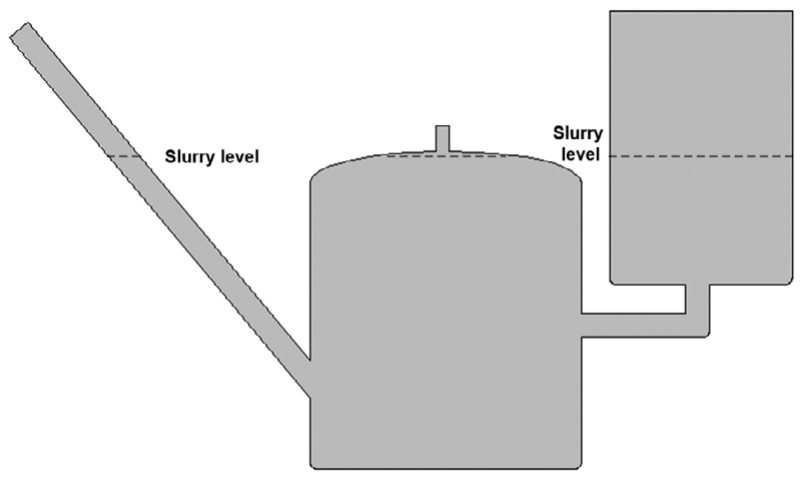

Before biogas production

(a)

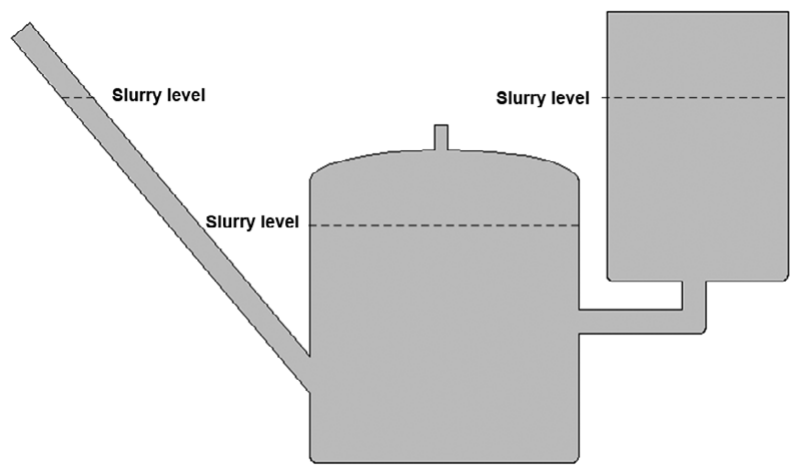

After biogas production

(b)

Figure 6.2 | Schematics of the blank digester (a) before (b) after gas production (based on Jegede et al. 2018c). 


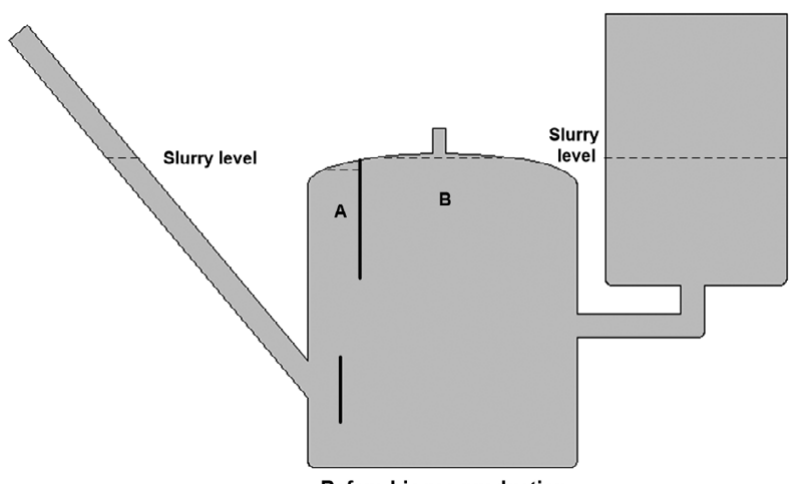

Before biogas production

(a)

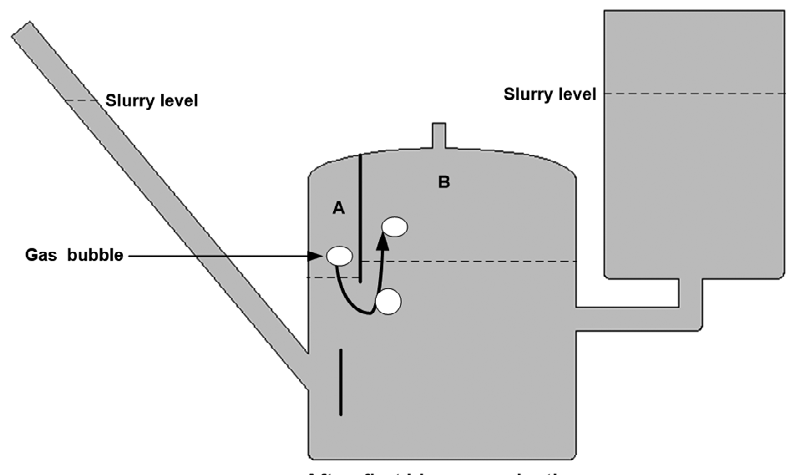

After first biogas production

(b)

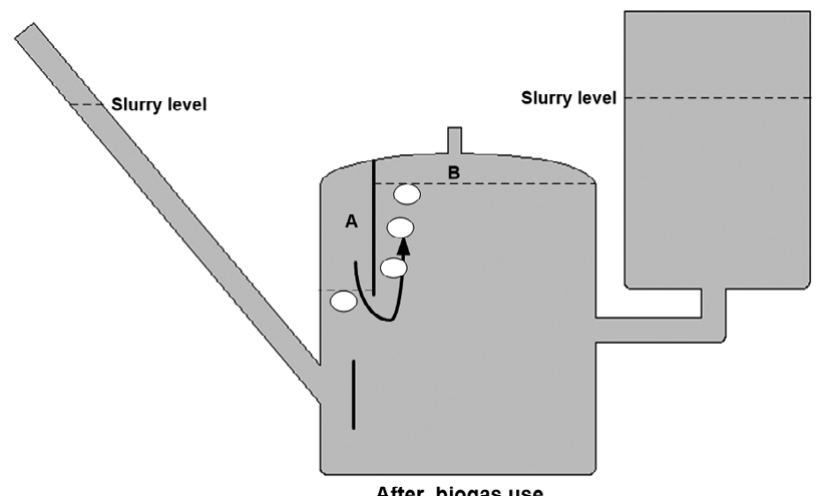

After biogas use

(c)

Figure 6.3 | Scheme of the biogas production in the optimized digester (a) before biogas production (b) biogas production and flow of gas into compartment B. (c) biogas production continues, gas flows to compartment B after gas used. 


\subsubsection{Manure collection and preparation}

The inoculum used for the digesters seeding was collected from a $10 \mathrm{~m}^{3}$ Chinese dome digester treating cow manure with a TS concentration of $8 \%$ operated at an average ambient temperature of $30^{\circ} \mathrm{C}$, at 40 days HRT. The inoculum was collected on the same day the reactors were started and $300 \mathrm{~L}$ each were added into reactors as seed. The cow manure used as feed in this study was collected freshly at the agricultural farm, Obafemi Awolowo University, Ile ife, Osun, Nigeria. Each batch collected was refrigerated at $3{ }^{\circ} \mathrm{C}$ prior to use and later diluted up to $15 \%$ TS prior to feeding. The mean characteristics of the feed are given in Table 6.1.

\subsubsection{Operation}

The reactors were operated throughout at the same conditions except for the HRT. After seeding with $300 \mathrm{~L}$ the reactors were fed at a TS of ca. 15\% corresponding to approximately an OLR of $2.6-3 \mathrm{~g} \mathrm{VS} / \mathrm{L} / \mathrm{d}$, daily without wasting or effluent withdrawal till the digesters were filled up. Effluent withdrawal from the expansion chamber/outlet started on day 32 and HRT was 40 days from day 32 to 136, and 30 days (HRT) from day 137-319. The digesters were operated at ambient temperature, $26-33^{\circ} \mathrm{C}$.

\subsubsection{Monitoring and analytical methods}

The ambient temperature of the shed where the reactors are located was monitored using an EL- USB digital temperature logger. $\mathrm{pH}$ of effluents was measured using a table top $\mathrm{pH}$ meter with a probe, Ohaus Starter 2100, The total solids (TS) and volatile solids (VS), ammonium nitrogen $\left(\mathrm{NH}_{4}^{+}-\mathrm{N}\right)$ of influents and effluents were determined according to standard methods as described by APHA, (2006). Daily biogas volume and methane content were measured using an Ultrasonic biogas flow meter BF-2000 Puxin Biogas meter. Concentration of volatile fatty acids (VFA) in effluent samples were determined in triplicate using a $7890 \mathrm{~B}$ gas chromatograph (Agilent Technologies) equipped with an HP-5 column $(30 \mathrm{~m} \times 0.32 \mathrm{~mm} \times 0.25 \mu \mathrm{m}$, Agilent Technologies) and a flame ionization detector (FID). The carrier gas was nitrogen with a flow rate of $6.5 \mathrm{~mL} \mathrm{~min}{ }^{-1}$. The operating conditions were as follows: injector temperature, $120{ }^{\circ} \mathrm{C}$ (split-splitless); detector temperature, $250{ }^{\circ} \mathrm{C}$; an oven temperature program initiating at $40{ }^{\circ} \mathrm{C}$, followed by three sequenced temperature increases (i) at a rate of $60 \mathrm{~K} \cdot \mathrm{min}^{-1}$ up to $100{ }^{\circ} \mathrm{C}$, (ii) at a rate of $50 \mathrm{~K} \cdot \mathrm{min}^{-1}$ up to $150{ }^{\circ} \mathrm{C}$ and, finally, (iii) at a rate of $90 \mathrm{~K} \cdot \mathrm{min}^{-1}$ until $240{ }^{\circ} \mathrm{C}$ was reached. Calibration stock solution and sample preparation where done according to Standard Methods for the examination of Water and Wastewater (APHA, 2005). The continuous online pressure measurement was done with a Greisinger GMH 3151 digital pressure meter with logger and was done after feeding the reactors. The specific biogas and methane yields were calculated as daily biogas methane produced, divided by the amount of VS fed to the reactors, were used to monitor the digestion efficiency of the digesters.

Biogas production rates were calculated as volume of gas produced per liter of digester volume per day. Methane yields were calculated as the volume of methane produced per unit mass of VS added. Steady state condition is considered when methane production is within $15 \%$ variation (Karim et al., 2005) 
Table 6.1 | Feed characteristics and operating parameters; average values of input feed.

\begin{tabular}{|c|c|}
\hline Parameter & Both Reactors \\
\hline Total solids influent (TS) (\% after dilution) & 15 \\
\hline Volatile solids influent (VS) ( $\%$ after dilution) & $73 \pm 0.04$ \\
\hline Hydraulic retention time (HRT), (days) & 40,30 \\
\hline Organic loading rates (OLRs), (g VS/m $/ \mathrm{d}$ ) (40 days) & $2.6-3$ \\
\hline Organic loading rates (OLRs), (g VS/m $3 /$ ) (30 days) & $3.5-4$ \\
\hline $\mathrm{NH}_{4}^{+}-\mathrm{N}(\mathrm{g} / \mathrm{L})$ (average in influent) & $2.1 \pm 0.6$ \\
\hline
\end{tabular}

\subsection{Results and discussion}

\subsubsection{Reactor performance in time}

The specific gas production, VFA concentration and VS reduction in time for both the optimised and blank reactors are presented in Fig. 6.4, showing a start-up period, with relatively low gas production for both reactors up till ca. 80 days of operation. VFA concentrations were relatively low for the whole period in the optimised reactor, while the blank reactor showed much higher VFA concentrations, up till $1 \mathrm{~g} / \mathrm{L}$.

Steady state at an HRT of 40 days could be achieved for the optimised reactor in the period between 82 to 137 days, characterised by an average specific methane production of $0.32 \pm 0.05$ $\mathrm{L} \mathrm{CH}_{4} / \mathrm{g}$ VS, a VFA concentration of $0.7 \pm 0.2 \mathrm{~g} / \mathrm{L}$ and a VS reduction of $63 \pm 4 \%$. Even at a relatively long HRT of 40 days gas production and VFA concentration in the blank reactor fluctuated considerably, characterised by an average specific methane production of $0.19 \pm 0.14 \mathrm{~L}$ $\mathrm{CH}_{4} / \mathrm{g}$ VS, VFA concentration of $1 \pm 0.3 \mathrm{~g} / \mathrm{L}$ and a VS reduction of $54 \pm 17 \%$ during the period that the optimized operated rather stable.

The decrease in HRT from 40 to 30 days on day 137 to 309 (end of experiment), resulted in the decline of gas production in both reactors.

In the blank, methane dropped rapidly to approx. $0.01 \mathrm{~L} \mathrm{CH}_{4} / \mathrm{g} \mathrm{VS}$ while the average VFA concentration increased to about $2.3 \mathrm{~g} / \mathrm{L}$, but VS reduction remains high at an average of 56 $\pm 3 \%$. Gas production increased once again and peaked at $0.51 \mathrm{~L} \mathrm{CH}_{4} / \mathrm{g}$ VS on day 182 with VFA dropping to $0.5 \mathrm{~g} / \mathrm{L}$ before becoming a bit stable again from day 183-270. Apart from the instability caused by the change in HRT from 40 to 30 days, the blank digester experienced instability for most of the time except for the period from day 183 to 270 . The accumulation of VFA, mainly acetate, was due to the change in HRT indicating system overloading. The high gas production recorded during short periods, viz. day 80- 85, 176-195, 253-258, might be attributed to the degradation of accumulated VFA. The VFA concentration observed in the effluents are shown in Fig. 6.4.

Similarly, a rapid decrease in methane production from 0.35 to $0.10 \mathrm{~L} \mathrm{CH}_{4} / \mathrm{g}$ VS and increase in VFA concentration from 0.7 to approx. $2 \mathrm{~g} / \mathrm{L}$, was noticed in the optimized reactor when decreasing the HRT to 30 days (day 138 -158). Afterwards the reactor recovered and remained stable till the end of the study (day 309). 


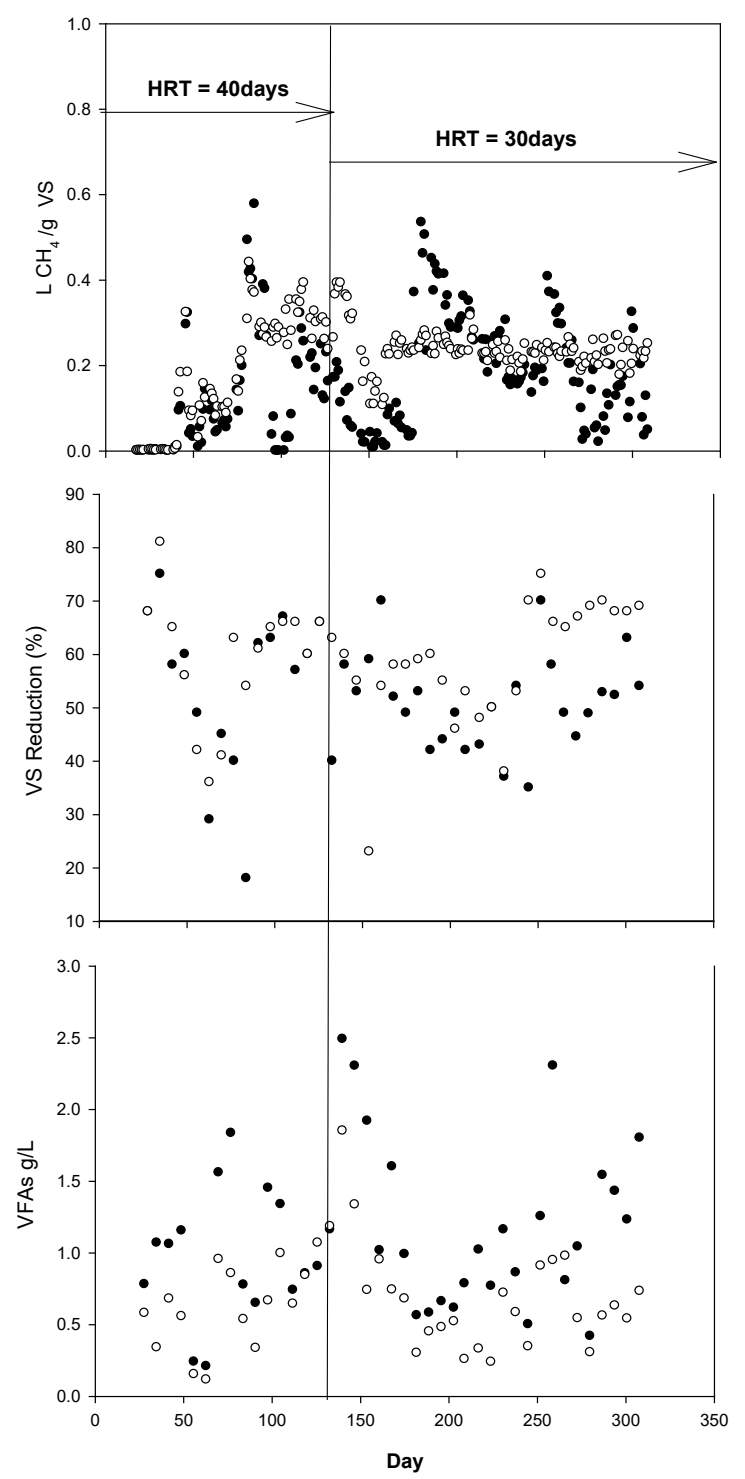

Figure 6.4 | Methane production, Volatile solid reduction, and total volatile fatty acids (acetate, propionate, iso-butyrate, butyrate, iso-valerate valerate), blank digester $(\bullet)$, optimized digester $(\circ)$. 


\subsubsection{Steady state period}

In Table 6.2, the average results of the two reactors are presented over the periods day 82 to 137 (HRT 40 days) and day 160 to 309 (HRT 30 days). Based on the set criteria, 'steady state' could be considered for the modified reactor for both periods but not for the blank reactor. The average methane production for the optimised reactor at an $\mathrm{HRT}$ of 40 days was $0.32 \mathrm{~L} \mathrm{CH}_{4} / \mathrm{g} \mathrm{VS}$, with a small variability $(\mathrm{std}=0.05)$ compared to the blank having an average methane production of $0.19 \mathrm{~L} \mathrm{CH}_{4} / \mathrm{g}$ VS, but with a large variability (std =0.14). Similarly, at an HRT of 30 days (day 160 -309), average methane production was $0.23 \mathrm{~L} \mathrm{CH}_{4} / \mathrm{g} \mathrm{VS}$, with small variability (std $=0.02$ ), compared to $0.21 \mathrm{~L} \mathrm{CH}_{4} / \mathrm{g} \mathrm{VS}$, large variability (std = 0.12) in the blank digester. This trend also holds for VFA, as shown in Table 6.2. In addition to stability, the optimised digester produced 50 $\%$ more methane than the blank at an HRT of 40 days.

As expected some lower gas production was recorded at and HRT of 30 days as compared to 40 days. This is also true for the VS reduction in both reactors. In the optimized digester, the average specific methane production and average percentage of VS reduction during the second steady state period is much lower compared to the first steady state. However, the average VFA concentrations $(0.7 \pm 0.3 \mathrm{~g} / \mathrm{L})$ during the first steady state period is slightly higher than VFA concentrations $(0.6 \pm 0.2 \mathrm{~g} / \mathrm{L})$ during the second. This implies, the change in HRT from 40 to 30 days affected the digester performance. Similar trend was observed by Zeeman, (1991) in a continuously_stirred tank reactor (CSTR). When HRT was changed from 25 to 10 days during anaerobic digestion of cow manure at $30^{\circ} \mathrm{C}$. The methane production observed were 0.13 and 0.10 $\mathrm{L} \mathrm{CH}_{4} / \mathrm{g}$ VS for 25 and 10 days. Also, Ghanimeh et al., (2012) observed reduction in methane production from 0.32 to $0.21 \mathrm{~L} \mathrm{CH}_{4} / \mathrm{g}$ VS when HRT was changed from 67 to 40 days during the thermophilic anaerobic digestion of source-sorted organic fraction of municipal solid waste. Indeed, digesters treating slurries and solid waste, might have their HRT similar but not equal to the solid retention time (SRT) depending on how well the reactor is mixed. During anaerobic digestion process of solid wastes, the hydrolysis stage of particulate matter is usually the ratelimiting step (Sanders, 2001) and therefore long SRT is often required. Long solid retention times are of interest and advantageous because it increases the conversion capacity, give buffering capacity against shock loadings and toxic compounds (Ramassary and Abbasi, 2007; Climenhaga and Banks, 2008; Wang et al., 2010).

The lower and more stable VFA concentration in the optimized reactor indicates a longer SRT in comparison to the blank digester, considering that Monod kinetics prevailed. The higher gas production in the modified as compared to the blank reactor is mainly due to improved hydrolysis, as the VFA concentration is relatively low and acidogenesis is generally not limiting in manure digestion (Zeeman, 1991). However, when first order kinetics are valid, smaller differences in hydrolysis are expected at longer HRTs. The large difference in methane production and therefore hydrolysis at a theoretical HRT of 40 days between the modified and blank CDD digester suggests a very large difference in real SRT. The blank reactor might suffer from extensive dead zones as shown in laboratory experiments by Jegede et al., (2018d). It is not clear why these differences are less distinct when operating the CDDs at a theoretical HRT of 30 days. Nonetheless at both theoretical HRTs, the modified CDD, with inclusion of two baffles, performs better as compared to the blank. Details of the impact of the baffles are discussed in the next paragraph. 
Table 6.2 Average operating conditions, gas production and effluent values of the optimized and blank CDD reactor at 'steady state' conditions in the optimized reactor.

\begin{tabular}{|c|c|c|c|c|c|c|c|c|c|}
\hline Reactor & $\begin{array}{l}\text { HRT } \\
\text { day }\end{array}$ & $\begin{array}{l}\text { Period } \\
\text { day }\end{array}$ & $\begin{array}{l}\text { OLR } \\
\text { gVS/L d }\end{array}$ & $\begin{array}{l}\text { Biogas } \\
\text { prod. rate } \\
\mathrm{L} / \mathrm{L} / \mathrm{d}\end{array}$ & $\begin{array}{l}\text { Sp. Methane } \\
\text { prod. } \\
\mathrm{L} \mathrm{CH}_{4} / \mathrm{g} \mathrm{VS}\end{array}$ & $\begin{array}{l}\text { VFA } \\
(\mathrm{g} / \mathrm{L})\end{array}$ & $\begin{array}{l}\text { VS red. } \\
(\%)\end{array}$ & $\begin{array}{l}\text { Effluent } \\
\mathrm{NH}_{4}^{+}-\mathrm{N} \\
\mathrm{g} / \mathrm{L}\end{array}$ & $\begin{array}{l}\text { Effluent } \\
\text { pH }\end{array}$ \\
\hline Blank & 40 & $82-137$ & $2.6-3$ & $0.91(0.6)$ & $0.19(0.14)$ & $1(0.3)$ & $54(17)$ & $2.5(0.10)$ & $7.5(0.2)$ \\
\hline Blank & 30 & 160-309 & $3.5-4$ & $1.16(0.6)$ & $0.221(0.12)$ & $1(0.47)$ & $50(9)$ & $2.1(0.4)$ & $7.8(0.1)$ \\
\hline Optimized & 40 & $82-137$ & $2.6-3$ & $1.40(0.2)$ & $0.32(0.05)$ & $0.7(0.2)$ & $63(4)$ & $2.05(0.16)$ & $7.6(0.12)$ \\
\hline Optimized & 30 & $160-309$ & $3.5-4$ & $1.30(0.12)$ & $0.23(0.02)$ & $0.58(0.23)$ & $60(10)$ & $2.1(0.5)$ & $7.8(0.07)$ \\
\hline
\end{tabular}

* standard deviation values are in parenthesis

\subsubsection{Effect of baffles on mixing}

\subsubsection{Self mixing cycle}

The results of in-situ pressure measurement to confirm and evaluate the self-agitating mixing cycles are presented in Figs.6.5 for the baffled, and unbaffled sides of the optimized and blank digesters. The pressure me asurements were done after the optimized reactor achieved a steady biogas production, however the gas production in the blank digester didn't stabilize throughout the period of study. The aim of the pressure measurement was to determine the frequency of the pressure variation in the reactors.

Fig. 6.5a presents pressure measurements of the baffle side of the optimized reactor at five different days. The pattern for each measurement is almost the same. The patterns show pressure fluctuations at an average of two mins interval for all measurements indicating a self-agitating mixing cycle when gas flows from compartment A to B. Whereas, in Fig. 6.1b and 6.1c showing measurements for the unbaffled side of the optimized and blank digesters respectively, gradual step-wise increase of the pressure is noticed. This means a gradual pressure build-up due to the production of biogas. 

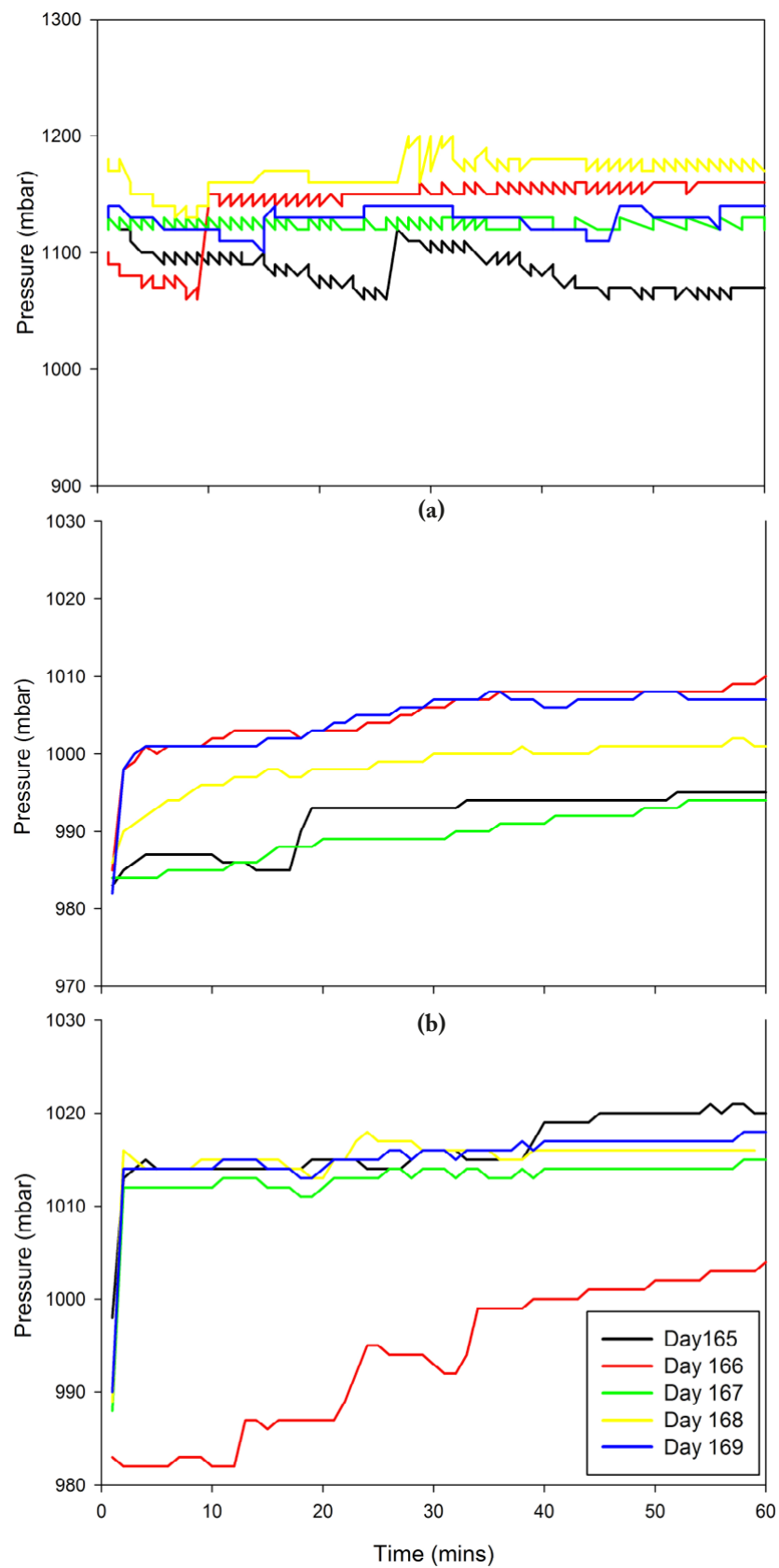

(c)

Figure 6.5 | Pressure reading on different days (a) baffled sided of the optimized compartment A (b) compartment B. (c) blank digester. The colours represent different days of measurement. 


\subsubsection{Effect of baffles on mixing and reactor performance}

Since the upper baffle of the optimized digester results in self-mixing of the top layer of the reactor, latter might have improved the overall performance of the digester despite high applied loading rates. In addition, improved mixing was also achieved by prevention of short circuiting of the incoming substrate to the outlet/expansion chamber by the lower baffle. Short circuiting of incoming substrate will lead to the reduction of the real HRT (=SRT) and eventually low digestion performance. The lower baffle helps incoming substrate to mix with the reactor content and therefore prevent stratification and eventually mitigating the dead zones at the bottom of the reactor. Dead zones impact negatively on overall digestion performance because the active volume in anaerobic digesters is reduced. For example, in previous studies Jegede et al., (2018d) showed that laboratory scale, conventional CDD systems have dead zones, resulting in shorter real HRT as compared to the theoretical HRT at 15\% influent TS. 23\% dead zone was estimated based on residence time distribution (RTD) technique which impacted negatively on the amount of methane generated and digestion efficiency. Furthermore, the improved mixing in the optimized digester prevented the accumulation of scum or floating layers on top of the reactor compared to the blank digester. This might be another reason for the large fluctuations of the biogas production in the blank digester, because produced gas might be trapped in these floating layers. Chinese dome digesters have a cylinder shape with a large surface area to allow large storage volume of biogas. The large surface area will aid the build-up of suspended solids or scum if mixing is limited (Tchobanoglous et al., 2003). Moreover, mixing is important to (i) provide even temperature distribution and proper diffusion or spread of metabolic intermediates (Gerardi, 2003) (ii) enables sufficient contacts between micro-organism and nutrients (Ward et al., 2008) (iii) improve hydrolysis and increase substrate surface area (Halalsheh et al., 2011).

Jegede et al., (2018e), modelled a conventional CDD system in comparison to a modified CDD system, including the two baffles (see Fig. 6.2) with respect to mixing. They clearly showed that the improved system has less dead zones and the actual HRT is similar to the theoretical HRT.

The pilot reactors could unfortunately not be tested for mixing behaviour using tracers, but the reactor performance results clearly show a better stability, higher gas yield and lower effluent VFA concentration for the modified in comparison to the conventional CDD reactor. Latter indicates that the real HRT in the modified CDD approaches the theoretical HRT as predicted in the model study. Latter should be tested in practice in future research.

Lastly, the results of this study have shown that intermittent mixing cycle in the improved CDD is important compared to the normal CDD with limited intermittent mixing cycles. 


\subsection{Conclusion}

The optimized Chinese dome digester has been investigated and has a self-mixing or agitation cycle of the top layer of the CDD of two minutes, using the produced gas without a mechanical device. The optimized digester showed superior digestion treatment efficiency and is more stable in terms of VFA (mainly acetate) concentration than the conventional or blank reactor. The improved Chinese dome digester with baffles showed a better performance than the conventionally designed reactor and can be operated at high influent TS (15\%) concentration.

\section{Acknowledgements}

This work was funded by the Netherlands Fellowship Programme (NFP), the Netherlands. Special thanks to the analytic/lab support team at Environmental Technology department, Wageningen University, The Netherlands. Special appreciations to the management and support staff of Biochemical Engineering laboratory, Centre for Energy Research and Development, Obafemi Awolowo University, Ile-ife Nigeria for their support. 


\section{References}

APHA (2006). Standard methods for the examination of water and waste water, 22nd edn. American Public Health Association, Washington, DC.

APHA (2005). Standard methods for the examination of water and waste water, 21st edn. American Public Health Association, Washington, DC.

Battistoni P., (1997). Pre-treatment, measurement execution procedure and waste characteristics in the rheology of sewage sludges and the digested organic fraction of municipal solid wastes. Water Sci. Technol. 36: 33-41.

Benbelkacem H, Garcia-Bernet D, Bollon J, Loisel D., Bayard R, Steyer J-P., Gourdon R, Buffière P., Escudié R. (2013). Liquid mixing and solid segregation in high-solid anaerobic digesters Bioresour. Technol.147:387-394

Bond T., Templeton M.R., (2011). History and future of domestic biogas plants in the developing world, Energy sustain. Dev.15:347-354.

Bridgeman J. (2012). Computational fluid dynamics modeling of sewage sludge mixing in an anaerobic digester. Advances in Engineering Software. 44:54-62.

Bruun S., Jensen L. S., Vu K V T., Sommer S. (2014). Small Scale household biogas digesters: An option for global warming mitigation or a potential climate bomb. Renewable and sustainanle energy rev. 33: 736-741.

Cheng S., Li Z., Mang H. P., Huba E. M., (2013). A review of prefabricated biogas digesters in China. Renewable and Sustainable Energy Reviews 28:738 -748.

Climenhaga M.A., Banks C. J. (2008). Anaerobic digestion of catering wastes: effect of micronutrients and retention time. Waste Sci. Technol. 57(5): 687-692.

Conklin A. S., Chapman T., Zahller J.D., Stensel H.D., Ferguson J.F. (2008). Monitoring the role of aceticlasts in anaerobic digestion: activity and capacity. Water Research. 42, 4895-4904

Deublein D., Steinhauser A. (2008). Biogas from waste and renewable resources. Weinheim, Germany: Wiley-VCH Verlag $\mathrm{GmbH} \& \mathrm{Co} . \mathrm{KGaA}$.

Gerardi, M. (2003). The Microbiology of Anaerobic Digesters. John Wiley and Sons, Inc., Pennsylvania.

Ghanimeh S., Fadel M. E., Saikaly P. (2012). Mixing effect on thermophilic anaerobic digestion of source-sorted organic fraction of municipal solid waste. Bioresource Technology 117:63-71.

Ghimire P. C. (2013). SNV Supported domestic biogas programmes in Asia and Africa. Renewable Energy 49:90-94.

Gomez X., Cuetos M.J., Cara J., Moran A., Garcia A. (2006). Anaerobic co-digestion of primary sludge and the fruit and vegetable fraction of the municipal solid wastes-conditions for mixing and evaluation of the organic loading rate. Renew. Energy 31:2017-2024.

Halalsheh M., Kassab G., Yazajeen H., Qumsieh S., Field J. (2011). Effect of increasing the surface area of primary sludge on anaerobic digestion at low temperature. Bioresour. Technol. 102:748-752.

Ike M., Inoue D., Miyano T., Liu T.T., Sei K., Soda S., Kadoshin S. (2010). Microbial population dynamics during startup of a full-scale anaerobic digester treating industrial food waste in Kyoto eco-energy project. Bioresour. Technol. 101:3952-3957.

Jegede A., Bruning H., Zeeman G. (2018a). Mixing in anaerobic digester with a specific emphasis on Household digesters: A Review. Under review in Critical Reviews in Environmental Science and Technology.

Jegede A., Bruning H., Zeeman G. (2018b). Effect of mixing regime on anaerobic digestion of cow manure: comparing mechanically mixed, unmixed and Chinese dome digesters. Under review in Sustainable Energy Technologies and Assessment.

Jegede A., Bruning H., Zeeman G. (2018c). Design considerations for inlet and outlet of Chinese dome digesters to mitigate methane loss. Revised edition summited to Biosystems Engineering.

Jegede A., Bruning H., Zeeman G. (2018d). Evaluation of liquid and solid phase mixing in Chinese dome digesters using Residence Time Distribution (RTD) technique. Under review in Renewable Energy.

Jegede A., Gualtieri C., Zeeman G., Bruning H. (2018e). Simulation of the hydraulic characteristics of an improved high loaded Chinese dome digester using COMSOL Multiphysics. In preparation.

Jha A.K., Li J.Z., Nies L., Zhang L.G. (2011). Research advances in dry anaerobic digestion process of solid organic wastes. African J. Biotechnol. 10:14242-14253.

Karim K., Hoffmann R., Klasson K. T., Al-Dahhan M. H. (2005). Anaerobic digestion of animal waste: effect of mode of mixing. Water Research 39:3597-3606.

Karthikeyan O. P., Visvanathan C. (2012). Bio-energy recovery from high-solid organic substrates by dry anaerobic bioconversion processes: a review. Rev. Environ. Sci. Biotechnol. 12: 257-284.

Kim M., Ahn Y.H., Speece R.E. (2002). Comparative process stability and efficiency of anaerobic digestion: mesophilic vs. thermophilic. Water Res. 36:4369-4385. 
Lindmark J., Thorin E., Fdhila R. B., Dahlquist E. (2014). Effect of mixing on the result of anaerobic digestion: Review. Renewable and Sustainable Energy Review 40:1030 -1047.

Tchobanoglous G., Burton F.L., Stensel H.D. (2003). Wastewater Engineering: Treatment and Reuse (4th ed.) Metcalf and Eddy Inc, New York, NY., McGraw-Hill.

Nzila C., https://www.sciencedirect.com/science/article/pii/S0960148110001837 - ! Dewulf J., Spanjers H., Kiriamiti H., Langenhove H. (2010). Biowaste energy potential in Kenya. Renewable Energy, 35:2698-2704.

Qi W-K, Toshimasa H., Li Yu-You. (2013). Hydraulic Characteristics of an innovative self-agitation anaerobic baffled reactor (SA-ABR). Bioreource Tech 136:94-101.

Sanders W. T. M. (2001). Anaerobic hydrolysis during digestion of complex substrates. PhD Thesis, sub-Department of Environmental Technology, Wageningen University, Wageningen.

Sasse L. (1988) Biogas Plan, GTZ publication. (http://www.susana.org/en/knowledge-hub/resources-and-publications/ library/details/1799) [Accessed February, 2016]

Sommer S G., Petersen S.O., Møller H. B. (2004). Algorithms for calculating methane and nitrous oxide emissions from manure management. Nutr. Cycl. Agroecosyst. 69:143-54.

Wang Z W, Ma J, Chen S. (2010). Bipolar effects of settling time on active biomass retention in anaerobic sequencing batch reactors digesting flushed dairy manure. Bioresource Technol 102:697-702.

Ward A.J., Hobbs P.J., Holliman P.J., Jones D.L. (2008). Optimization of the anaerobic digestion of agricultural resources. Bioresour. Technol. 99:7928-7940.

Yu L, Yaoqiu K, Ningsheng H, Zhifeng W, Lianzhong X. (2008). Popularizing householdscale biogas digesters for rural sustainable energy development and greenhouse gas mitigation. Renew Energ.33:2027-35

Zeeman G. (1991). Mesophilic and psychrophilic digestion of liquid cow manure. PhD thesis. Sub-Department of Environmental Technology, Wageningen University, Wageningen. 



\title{
Chapter
}

\section{7}

\section{Simulation of the hydraulic characteristics of an improved high loaded Chinese dome digester using COMSOL Multiphysics}

\author{
Abiodun O. Jegede ${ }^{* 1}$, Carlo Gualtieri**, \\ Grietje Zeeman *, Harry Bruning* \\ * sub-Department of Environmental Technology, Wageningen University, \\ Wageningen, The Netherlands \\ ** Civil, Architectural and Environmental Engineering Dept. (DICEA), \\ University of Napoli Federico II, Napoli, Italy \\ ${ }^{1}$ Centre for Energy Research and Development, \\ Obafemi Awolowo University, Ile-ife, Nigeria.
}

Jegede A.O., Gualtieri C., Zeeman G., Bruning H. (2018). Simulation of hydraulic characteristics of an improved high loaded Chinese dome digester using COMSOL Multiphysics. (to be submitted). 


\begin{abstract}
Domestic (household) biogas plants constitute a growing sub-sector of the anaerobic digestion industry worldwide but have received low interest for improvements. The Chinese dome digester (CDD), a major type of domestic biogas plant is a naturally mixed, unheated and low technology reactor mainly applied in rural and pre-urban areas for treatment of animal manure. In this study, a multiphase computational fluid dynamics (CFD) model was applied to evaluate an improved CDD design. Outcomes were compared with results of pilot scale experiments. The optimized digester under goes self-agitating cycles created by the pressure variation from the produced biogas with the aid of a baffle, whereas the blank does not self-agitate. The optimized digester has two pressure zones which helped to improve mixing viz. the self-agitation cycles. The optimized digester is characterized by better, stable and improved hydraulic characteristics and mixing.
\end{abstract}




\subsection{Introduction}

Sufficient research effort has been made on mixing of large-scale systems in the anaerobic digestion industry (Lindmark et al., 2014), but little effort has been put into studying household digesters especially the Chinese dome digester (CDD). Household digesters are non-mechanically (naturally) mixed and non-heated systems used mainly in rural areas (Qi et al.,2013) of developing countries. Millions of these systems have been built around the world (Khan \& Martin, 2016) but they lack proper evaluation for optimization and standardization, especially with respect to mixing. The performance of biogas plants is influenced by the extent of contact between microbes and substrate, homogenization of temperature and prevention of occurrence of dead zones which are promoted by mixing (Deubien and Steinhanuser, 2008). The role of mixing in conversion of substrate to biogas is well known, however the optimal mixing range still remains a topic for debate (Karim et al., 2005; Jegede et al., 2018a).

Biogas produced in household digesters could serve as a sustainable energy source to meet the cooking needs of millions of rural households in developing countries and mitigate greenhouse gas emissions from animal manure (Sommer et al., 2004). Among the household digesters, the Chinese dome digester (CDD) is the most popular and most widely implemented because of its reliability, low maintenance and long lifespan (Ghimire, 2012; Cheng et al., 2013). The CDD has become a basis for the development of twenty-first century household digester designs, such as the Puxin digester, an example of a prefabricated digester (Cheng et al., 2013).

In CDDs, as biogas is produced, gas pressure is created at the top of the reactor. The stored biogas pushes part of the slurry into an extension chamber. When the biogas is used for cooking, pressure is released and the slurry flows back into the main reactor; this creates a mixing regime. These systems are operated at low total solid (TS) influent concentrations $(\leq 7 \%)$ and long hydraulic retention times (HRT) (i.e. $\geq 40$ days) compared to forced mixed reactors which are generally operated at high influent total solids (TS) concentration $(\geq 10 \%$ TS) and HRTs of 30 days or shorter (Mungwe et al., 2016; Jegede et al., 2018a). These characteristics make household digesters large and therefore too expensive for millions of households in developing countries, when no governmental subsidy is provided. To improve and optimize the design of the Chinese dome digester, advanced modeling and simulation techniques could be employed.

Computational fluid dynamics (CFD) models has been used to model and study mixing in anaerobic bioreactors since the early 2000s. CFD is an important tool for studying velocity contours, particle trajectories and dead zones in anaerobic digesters. CFD studies usually focus on fluid dynamics and is not connected to the kinetics of the anaerobic digestion process. A major advantage of CFD modelling of anaerobic digesters is the presentation of visual results which aids system analysis, for example, visualization of velocity flow fields and directions. (Lindmark et al., 2014; Lopez-Jimenez et al., 2015).

Vesvikar \& Al-Dahhan, (2005) and Karim et al., (2007) investigated gas-lift mixing in an anaerobic digester with gas lifting configuration. The results showed that positioning, gas flow rate and the length of the tube in the reactor had minor effect on mixing and percentage of dead zone in the reactor. The use of four and six-blades impellers with angles of $30^{\circ}$ and $45^{\circ}$ was 
studied by Manea and Robescu, (2012). Their results demonstrated the minor effect of number of blades on the generated flow, but the impeller with a larger angle generated a higher flow rate in the draft tube. Different biogas plant designs with different number and configuration of the draft tubes were evaluated by Maroney and Colorado, (2009). The found mixing features with less short circuiting and dead zones for all tank configurations considered. Wu, (2012a) linked mixing models and biochemical kinetics of the AD process to bridge the gap between kinetic and CFD models. The model therefore has the capacity to track the production and spread of various components such as $\mathrm{CH}_{4}, \mathrm{CO}_{2}, \mathrm{VFA}$, and the distribution of HRT, $\mathrm{pH}$ and temperature. Yu et al., (2013) evaluated the physical biomass retention time using the CFD model and the anaerobic digestion No.1 (ADM1) model for the biochemical process and biomass retention time. Settling and suspension was described using a multi-fluid model coupled with kinetic theory of granular flow (KTGF). The results showed that the coupling of KTGF with the multi-fluid model gives better understanding of the effect of settling and suspension of biomass particles in reactors such as the Upflow Anaerobic Sludge Bed (UASB) and Anaerobic Sequencing Batch Reactor (ASBR).

A number of other researchers (Hoffmann et al., 2009; Lindmark et al., 2008; Lindmark et al., 2011; Wu, 2012b and Jimenez et al., 2015) have also studied the different aspects of mixing in anaerobic digesters but no studies on the evaluation of mixing in the Chinese dome digester are available in literature.

The objective of the present research was to study the flow pattern and hydraulic characteristics of the CDD. Furthermore, the study was carried out to obtain detailed knowledge of the self-mixing behaviour of an improved CDD through the study of the flow behaviour and other hydraulic characteristics. Computation fluid dynamics (CFD) was used to study the hydraulic characteristics of both reactors. Since mixing in the CDD is natural (self-mixing) and intermittent, the laminar flow conditions were assumed in the digester. Pressure data were used for validation and biogas production data were used to evaluate the impact of the mixing from pilot experiments reported by Jegede et al., (2018).

\subsection{Model development}

\subsubsection{Geometry and operating principle}

The modeling and simulations reported were performed on the CDD and the improved CDD. The pilot biogas plants were constructed from PVC materials, with a reactor volume of $500 \mathrm{~L}$ and an expansion chamber of $250 \mathrm{~L}$ for liquid displacement and outlet (Jegede et al., 2018c). One is the optimized design and the other the normal reactor design which serves as a blank shown in Figs. 7.1 and 7.2. The geometries were developed using COMSOL Multiphysics software (COSMOL, 2015)

In the normal or blank Chinese dome digester, the biogas produced is accumulated and stored in the upper part of the reactor i.e. above the slurry level. Pressure is created by biogas production and results in the slurry level difference. The stored biogas needs space as biogas is produced and pushes part of the slurry into the expansion chamber and inlet pipe. During biogas use the 
slurry flows back into the reactor, therefore creating a mixing regime. The difference between the blank and the optimized digester is the inclusion of two baffles at the top and bottom of the optimized digester as shown in Fig. 7.2. The upper baffle $(0.43 \mathrm{~m})$ which is the main baffle and the main focus of this article, divides the headspace of the reactor into two compartments A and B. The length is determined based on a model reported by Jegede et al., (2018b). The gas outlet is located in top compartment $\mathrm{B}$, while compartment $\mathrm{A}$ has no outlet. Biogas produced is stored in both compartments before gas collection while the slurry level in the extension chamber increases due to the pressure build up as a result of the gas production. After gas collection or gas use, the pressure in compartment $B$ reduces while the slurry flows back into the reactor and the level of slurry increases in compartment B, however the pressure in compartment A remains high when the slurry level reaches the tip of the baffle. Further biogas production and release of biogas in compartment $\mathrm{A}$ will increase the pressure in the compartment and pushes the slurry below the baffle. As a result, some biogas flows below the baffle into compartment $B$, immediately afterwards the slurry level in compartment $\mathrm{A}$ will return to the initial level. This process creates a self-agitating cycle.

For the feeding process, the lower baffle in the optimized digester should help to mix incoming influent and prevent short circuiting of incoming feeds.

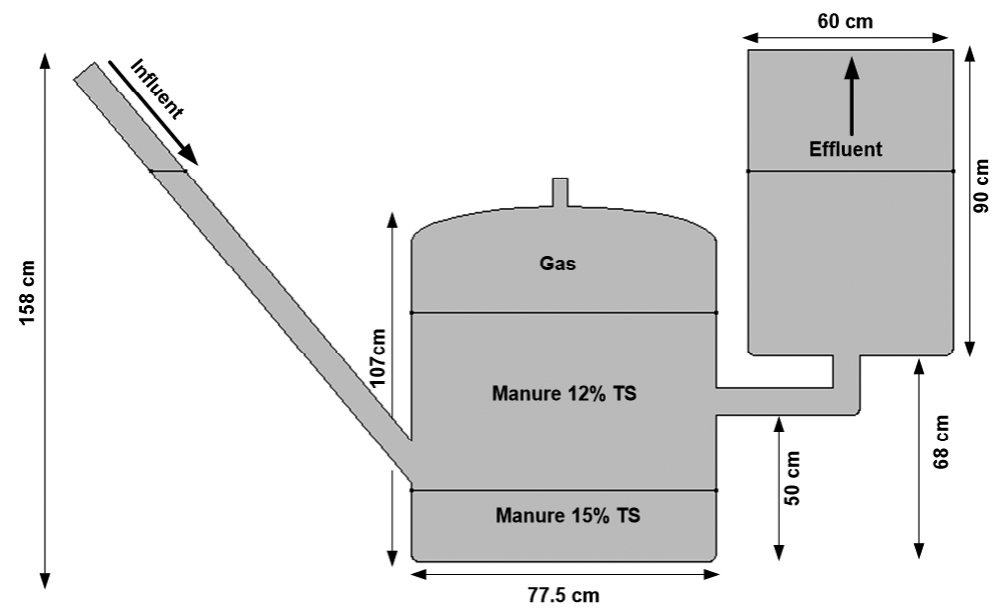

Figure 7.1 | Geometry of the blank Chinese dome digester showing the three phases (based on Jegede et al., 2018c). 


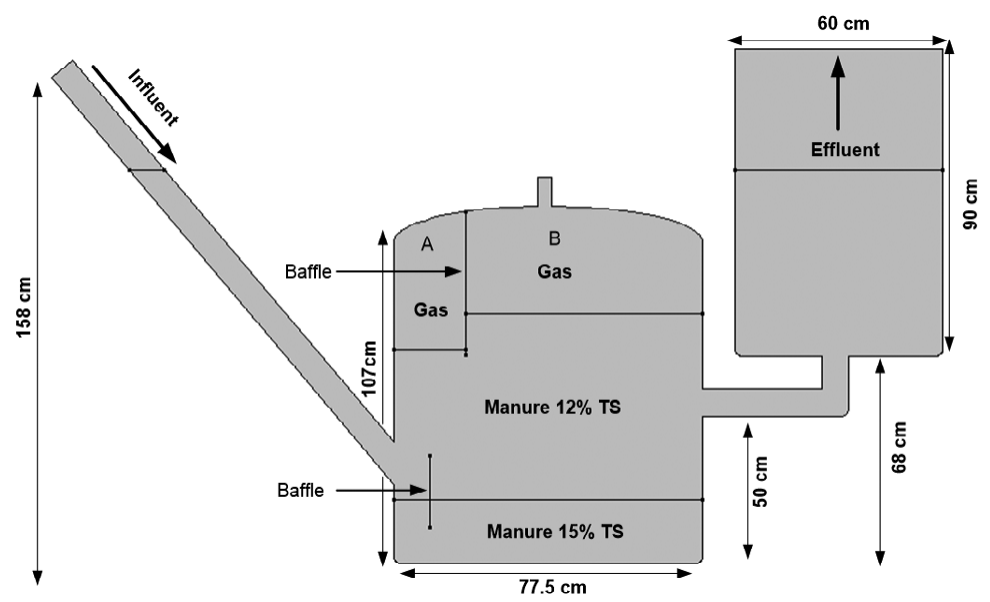

Figure 7.2 | Geometry of the optimized Chinese dome digester showing the three phases (based on Jegede et al., 2018c).

\subsubsection{CFD Equations}

The numerical simulations of the digesters were performed using COMSOL Multiphysics software. These CFD codes are based on the conservation laws for mass and momentum. Two groups of simulations were carried out, related feeding and biogas production, because mixing in the reactors is induced by these two activities in the reactors. The laminar three-phase field model was used to solve for the velocity and pressure profile for the two categories.

Laminar flow equations: The 3-Phase flow, phase field interface was used to study the evolution of three fluid phases denoted by fluid $A$, fluid $B$, and fluid $C$. The phases are manure with $15 \%$ TS, manure with $12 \%$ TS and gas respectively. The code solves the Navier-Stokes equations governing the conservation of momentum and mass. The momentum equation is

$\rho \frac{\partial \mathrm{u}}{\partial \mathrm{t}}+\rho(\mathrm{u} \cdot \nabla) \mathrm{u}=\nabla \cdot\left[-\mathrm{pI}+\mu\left(\nabla \mathrm{u}+\nabla \mathrm{u}^{\mathrm{T}}\right)-\frac{2}{3} \mu(\nabla \cdot \mathrm{u}) \mathrm{I}\right]+\mathrm{F}_{\mathrm{st}}+\mathrm{F}$

where; $\boldsymbol{F}_{\mathrm{st}}$ is the surface tension force $(\mathrm{N} / \mathrm{m})^{3}, \rho=\operatorname{density}\left(\mathrm{kg} / \mathrm{m}^{3}\right) ; \mathrm{u}=$ velocity $(\mathrm{m} / \mathrm{s}) ; \mathrm{p}=$ pressure in $(\mathrm{Pa}) ; \mathrm{I}=$ incompressible term; = dynamic viscosity $(\mathrm{Pa} . \mathrm{s}) ; \mathrm{t}=$ time $(\mathrm{s}) ; \mathrm{T}=$ temperature $(\mathrm{K}) ;=$ volume force $\left(\mathrm{N} / \mathrm{m}^{3}\right)$. The density of each phase is assumed to be constant. To accurately solve the systems, because the densities of the phases are different, the following compressible continuity equation was solved at the interface:

$\frac{\partial \log \rho}{\partial t}+\nabla \cdot \mathrm{u}+\mathrm{u} \cdot \nabla \log \rho=0$

Ternary phase field equations: To track the interfaces between the three phases, a ternary phase field model based on (Boyer et al., 2010) was used. The model solves the following Cahn-Hilliard equations: 


$$
\begin{aligned}
& \frac{\partial \phi_{i}}{\partial t}+\nabla \cdot\left(\mathrm{u} \phi_{i}\right)=\nabla \cdot\left(\frac{M_{o}}{\Sigma_{i}} \nabla \eta_{i}\right) \\
& \eta_{i}=\frac{4 \Sigma_{T}}{\varepsilon} \sum_{j \neq i}\left(\frac{1}{\Sigma_{j}}\left(\frac{\partial F}{\partial \phi_{i}}-\frac{\partial F}{\partial \phi_{j}}\right)\right)-\frac{3}{4} \varepsilon \Sigma_{j} \nabla^{2} \phi_{i}
\end{aligned}
$$

governing the phase field variable, $\phi_{i}$, and a chemical potential, $\eta_{i}$, for each phase $i=A, B, C$.

The phase field variables vary between 0 and 1 . At each point the phase field variables satisfied the following condition:

$$
\sum_{i=A, B, C} \phi_{i}=1
$$

The density of each phase is assumed to be constant which means that the phase field variable is equivalent to the volume fraction of the phase being considered. To satisfy (7.5), equations (7.3, and 7.4) were solved, namely for phase $A$ and phase $B$. The phase field variable, and mass fraction for phase $C$ is calculated from (7.5). The density and viscosity of the fluid mixture applied in (7.1) and (7.2) are defined as:

$$
\begin{aligned}
& \rho=\rho_{A} \phi_{A}+\rho_{B} \phi_{B}+\rho_{C} \phi_{C} \\
& \mu=\mu_{A} \phi_{A}+\mu_{B} \phi_{B}+\mu_{C} \phi_{C}
\end{aligned}
$$

The free energy of the 3-phase system was defined as a function of the phase field variables as:

$$
F=\sigma_{A B} \phi_{A}^{2} \phi_{B}^{2}+\sigma_{A C} \phi_{A}^{2} \phi_{C}^{2}+\sigma_{B C} \phi_{B}^{2} \phi_{C}^{2}+\phi_{A} \phi_{B} \phi_{C}\left(\Sigma_{A} \phi_{A}+\Sigma_{B} \phi_{B}+\Sigma_{C} \phi_{C}\right)+\Lambda \phi_{A}^{2} \phi_{B}^{2} \phi_{C}^{2}
$$

where $\sigma_{i j}$ means the surface tension coefficient $(\mathrm{N} / \mathrm{m})$ of the interface, separating phase $i$ and $j ; \Lambda$ is the parameter specifying the additional free bulk energy. The capillary parameters $\Sigma_{i}$ were defined for each phase as follows:

$$
\begin{aligned}
& \Sigma_{A}=\sigma_{A B}+\sigma_{A C}-\sigma_{B C} \\
& \Sigma_{B}=\sigma_{A B}+\sigma_{B C}-\sigma_{A C} \\
& \Sigma_{A}=\sigma_{B C}+\sigma_{A C}-\sigma_{A B}
\end{aligned}
$$

In (7.3 and 7.4), $\varepsilon(1 / \mathrm{m})$ is a parameter determining the thickness of the interface; $M_{0}\left(\mathrm{~m}^{3} / \mathrm{s}\right)$ is a molecular mobility parameter, and $\Sigma_{\mathrm{T}}$ was defined as

$$
\frac{3}{\Sigma_{T}}=\frac{1}{\Sigma_{A}}+\frac{1}{\Sigma_{B}}+\frac{1}{\Sigma_{C}}
$$


The surface tension force, applied as a body force, was calculated from the chemical potentials:

$$
F_{s t}=\sum_{i=A, B, C} \eta_{i} \nabla \phi_{i}
$$

\subsubsection{Physical parameters}

The CFD simulations were performed on the Chinese dome digesters for gas production process and reactor feeding. The digesters were divided into three phases as shown in Fig. 7.1 \& 7.2. The bottom phase contains digested manure at $15 \%$ total solid (TS) concentration, the middle layer contains digested manure at $12 \%$ TS and the upper phase contain biogas. The properties of the manure at $35{ }^{\circ} \mathrm{C}$ are given in Table 7.1 (Wu, 2013a). The gas density and viscosity were $1 \mathrm{Kg} / \mathrm{m}^{3}$ and $1.9 \times 10^{-5} \mathrm{~Pa} . \mathrm{s}$.

Table 7.1 | Rheological properties of manure (Wu, 2013a).

\begin{tabular}{lllll}
\hline $\mathbf{T S}(\mathbf{\%})$ & $\mathbf{K}\left(\mathbf{P a ~ s}^{\mathrm{n}}\right)$ & $\mathbf{n}$ & $\dot{\boldsymbol{y}}\left(\mathrm{s}^{-1}\right)$ & $\boldsymbol{P}\left(\mathbf{k g} / \mathbf{m}^{3}\right)$ \\
\hline 12 & 5.885 & 0.367 & $3-149$ & 1001.73 \\
\hline 15 & 31.3 & 0.3 & $0.64-24.14$ & 973 \\
\hline
\end{tabular}

Manure behaves as a non-Newtonian fluid at TS concentrations $>5 \%$ and obeys the power law (El-Mashad et al., 2004), In Table 7.1, $\dot{y}$ is the shear rate, $K$ is the consistency index and $n$ indicate the flow behaviour index.

A multiphase approach was applied in the simulations as described in the CFD equation section. During reactor feeding, the influents enter the reactor through the inlet pipe and come out by gravity through the extension chamber after an average hydraulic retention time (HRT) of 30 days. The gas produced, exerts pressure on the middle phase, this pressure on the digested manure pushes the slurry towards the inlet pipe and extension chambers, simultaneously. The focus of the flow modeling in the digesters were the movement of the manure during the gas production and feeding.

\subsubsection{Boundary conditions}

For the feeding process simulation, an inlet velocity boundary condition of $0.01 \mathrm{~m} \mathrm{~s}^{-1}$ was applied to the top of the inlet pipe and an outlet pressure of $98100 \mathrm{~Pa}$ on the top of the extension chamber. In the case of biogas production, the daily biogas production rate is assumed constant over time. The whole top of the blank digester was considered at a pressure of $101000 \mathrm{~Pa}$ while the top of the inlet pipe and the top of the extension chamber are at atmospheric pressure of $98100 \mathrm{~Pa}$. The baffles were defined as interior walls. The remaining part of the geometry was defined as standing walls. In the optimized digester, after bubble formation, a pressure constraint of $110000 \mathrm{~Pa}$ was applied to the tip of the baffle. The pressure values applied represents the approximate values estimated in relation to the level of the slurry in the reactors by the model developed by Jegede et al., (2018b). It was not possible to model and estimate the actual residence time distribution in 
both reactors, however it was possible to introduce tracer particles into the model and estimate the number of particles at the outlet after a certain time. The density and the diameter of the specified particle is $1000.78 \mathrm{~kg} \mathrm{~m}^{-3}$ similar to the manure and $0.0001 \mathrm{~m}$ respectively and the total number of particles introduced was 3000 . The inlet velocity was $0.01 \mathrm{~m} \mathrm{~s}^{-1}$ and the run time was $8000 \mathrm{~s}$.

Furthermore, particles settling was evaluated as a factor contributing to the formation of dead zones in the reactors. The settling theory in anaerobic digester described by Lopez-Jimenez et al., (2015) using stokes law was used to estimate the velocities in this study.

$V_{s}=\left(\frac{2}{9}\right) r^{2} g\left(\rho_{p}-\rho_{f}\right) / v$

In equation (7.14), $V s$, is the settling velocity, $r$, is the radius of particle, $\rho_{p}$ and $\rho_{f}$ are the densities of the particle and water, while $V$, is the kinematic velocity $\left(1 \mathrm{e}-6 \mathrm{~m}^{2} \mathrm{~s}^{-1}\right)$. Threshold velocities were specified for semi-dead zones as velocities $<0.004251 \mathrm{~m} \mathrm{~s}^{-1}$ and mixing regions as velocities > $0.004251 \mathrm{~m} \mathrm{~s}^{-1}$.

\subsubsection{Mesh}

Mesh independence analysis was performed on the blank and optimized reactors. The user defined mesh used was predominantly triangular with minimal skewness, which has surface quality independence and aligns with the user coordinate system. The total number of elements are 10890 and 13158 , the maximum growth rates are 2.483 and 2.534 , while the average element qualities are 0.9738 and 0.9748 for the blank and optimized reactors respectively.

\subsubsection{Solver parameters and data post-processing}

COMSOL time dependent solver configuration was used to solve pressure, velocity field and all the phase variables. Convergence was attained for each simulation when scaled residuals were less than $10^{-3}$ for continuity, momentum and transport equations. The study was applied to two pilot digesters and the outcomes of the simulations were analyzed using the following:

- surface: to observe the phases, pressure and velocity profiles.

- stream lines: to study and show the flow direction

- 1D line plots were used to give further details of the velocity profile and vorticity around the baffles regions.

\subsubsection{Runs}

The simulation focused on reactor feeding and the biogas production process in the digesters. One run each was done for both reactors for the feeding process. However, for the biogas production process, one run was done for the blank digester and two runs for the optimized. The first run in the optimized reactor shows biogas production before the creation of the bubble from the baffled side, while the second run shows flow of the bubble through the slurry into the head space of the second compartment. The first simulation was done for both digesters using the same parameters, properties and time. In the blank digester the whole top of the digester was assumed as a single 
pressure inlet whereas in the, optimized digester the pressure inlet was applied into parts, on the compartment on A and B but with the same pressure value. A scheme for the second modeling run of the optimized digester is presented in Fig. 7.3.

The simulation duration for biogas production in both digesters was $0.25 \mathrm{~s}$, while the duration for the second run for the optimized digester for the migration of the biogas from compartment $\mathrm{A}$ to $\mathrm{B}$ was $0.75 \mathrm{~s}$. These choices were based on finding the appropriate duration for the convergence of the simulations at the applied initial conditions.

Table 7.2 | Simulations runs.

\begin{tabular}{ll}
\hline Model & Simulation \\
\hline Blank & biogas production, feeding \\
\hdashline Optimized & biogas production, feeding \\
\hdashline Optimized after bubble formation & bubble migration \\
\hline
\end{tabular}

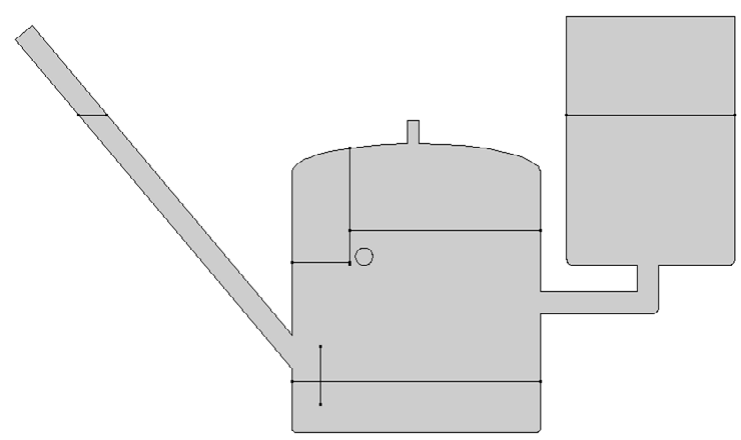

Figure 7.3 | Optimized digester after bubble formation. The diameter of the bubble was assumed to be equivalent to one third of the distance between the baffle and the wall (left) of the reactor.

The major steps for the simulation were:

a) Define the solver as two dimensional (2D), time dependent implicit and pressure based. This approach was applied to reduce computational demand and to achieve simplicity during results evaluations.

b) Activate the three-phase field model and laminar flow for the feeding and gas production process simulations;

c) Define the material properties of cow manure and biogas;

d) Configure phase properties and interaction;

e) Configure boundary conditions for the three phases;

f) Define the under-relaxation parameters and convergence criteria and then solve. 


\subsection{Results and discussion}

\subsubsection{Model validation}

The model is validated with pressure results from literature. The pressure measurements were performed in-situ and reported by Jegede et al., (2018c). The online pressure measurements of pilot scale reactors at steady state conditions were used. The pressure profile presented in Fig. 7.4 of the baffled section compartment $\mathrm{A}$, of the optimized pilot reactor is different from the profile of compartment $\mathrm{B}$. From the simulation results, the maximum pressure values are 112000,110000 and $101000 \mathrm{~Pa}$ for the optimized (compartment $\mathrm{A}$ and B) and blank digester respectively. The values of optimized (compartment $\mathrm{A}$ ) and blank reactors are well within the range reported in literature, whereas the value of the pressure in optimized (compartment B) was $5 \%$ higher than the measured experimental value. The pressure characteristics reported by Jegede et al., (2018c) in compartment $\mathrm{A}$ indicate pressure fluctuation which occurs at an average of 2 minutes over the 60 minutes measurement. The profile for compartment B and the blank indicates a gradual pressure increase which represents the production and accumulation of biogas in the head space before gas use. The pressure fluctuation in compartment A means biogas is transported below the baffle into compartment $B$ leading to a self-mixing cycle in the reactor. This is further supported by the velocity vector results of the optimized reactor with gas bubble, shown in Fig. 7.12. The figure illustrates the change in the direction of the arrows to sideways and downwards in Fig. 7.12 compared to Fig. 7.9. The direction of arrows especially in the inlet pipe region, around the upper baffle and the expansion chamber is the effect of gravity on the slurry or reactor content during the self-mixing process. When the pressure increases and the manure is pushed below the tip of the upper baffle then a big gas bubble is formed. There is a sudden pressure drop in compartment $\mathrm{A}$, (the baffled side) and the gas (bubble) diffuses through the slurry into the headspace of compartment $\mathrm{B}$. The change of the velocity vector direction sideways and downwards (chaotic movement) is a result of the sudden pressure drop in compartment A and recorded during the pressure measurement described by Jegede et al., (2018c). 

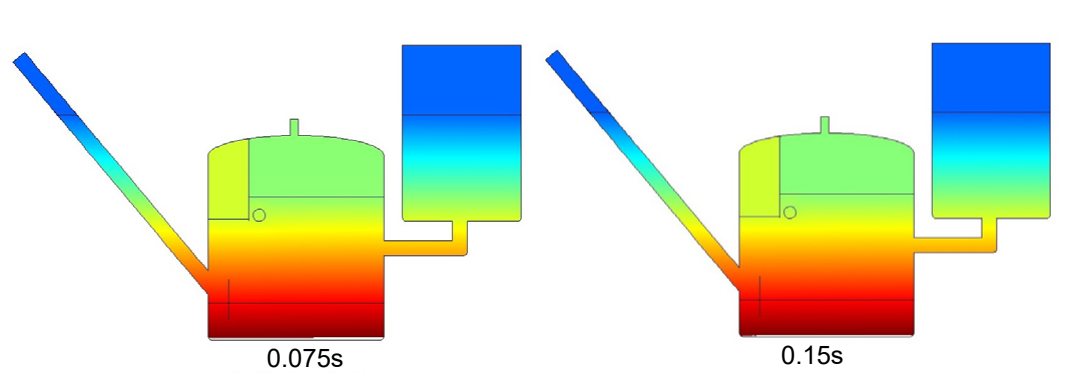

Pa.
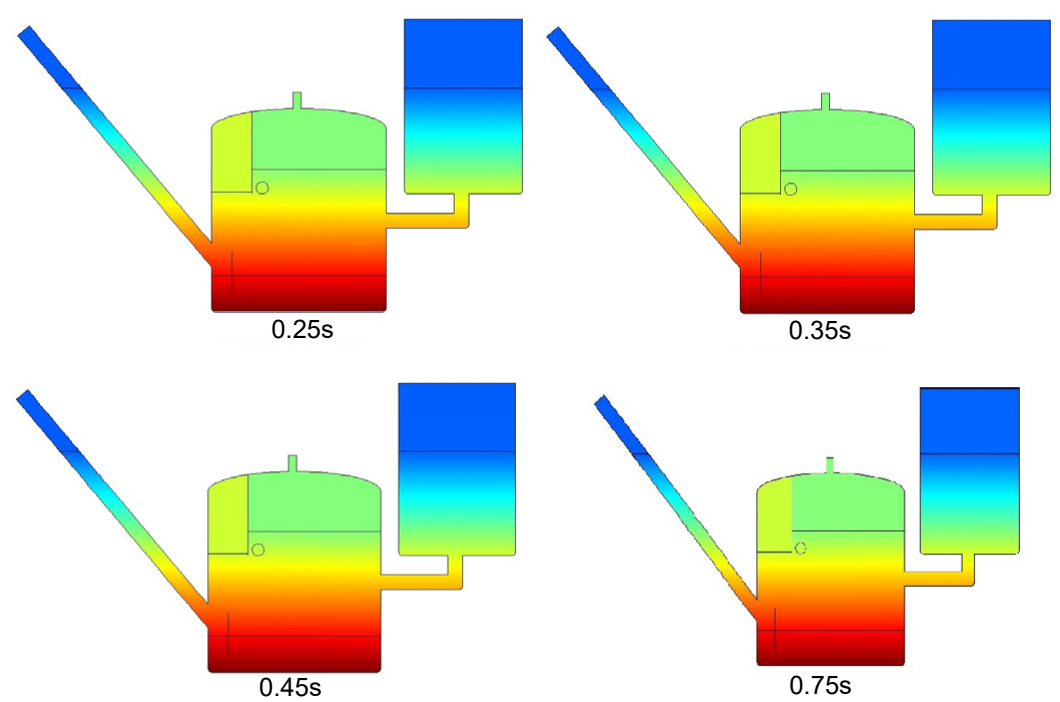

Figure 7.4| Pressure profile of the optimized digester after bubble formation at different times during biogas production.

\subsubsection{Self-mixing process: blank vs optimized}

The process of mixing during the biogas production in the blank reactor is illustrated in Fig.5. There is no self-agitation regime in the blank reactor and only one major stage in the mixing cycle i.e. during biogas production and use. The headspace in the blank reactor is closed and biogas produced is stored in this chamber. This is consistent with the pressure measurement reported by Jegede et al., (2018c). The simulation duration (0.25s) represents approximated one hour of continuous gas production resulting to a displacement of approximately $0.053 \mathrm{~m}$ inside the reactor. When biogas production continues during the cause of the day before it is used, the gas pushes the slurry into the inlet pipe and into the expansion chamber. The bottom phase indicates stratification with higher influent density since this reactor is not a completely mixed reactor. The slight color change seen in the two slurry phases at each stage is an indication of mixing between the phases as the pressure pushes the slurry into the inlet pipe and expansion chambers. The middle phase (12\% TS) with deep blue color changed to light blue, while the bottom phase (15\% TS), changed 
from light green to yellow. The fluid vectors are shown in Fig. 7.6. illustrating the direction of flow of the slurry in the digester. As shown in the diagrams, the arrows represent the direction of the flow from the headspace to the inlet pipe and to the outlet pipe and to the expansion chamber. Figs. 7.6 presents velocity vectors and correspond to all the stages illustrated in the Fig.7.5. Biogas production is a slow process and the force applied by the pressure build up makes the slurry in the reactor to mix with the slurry in the inlet pipe and expansion chamber. This is how the conventional Chinese dome digester works, however this mixing regime has been described as insufficient (Jegede et al., 2018a).

The direction of the vector did not change throughout the process of gas production, which is consistent with the constant increase pressure measurement (Jegede et al., 2018c).
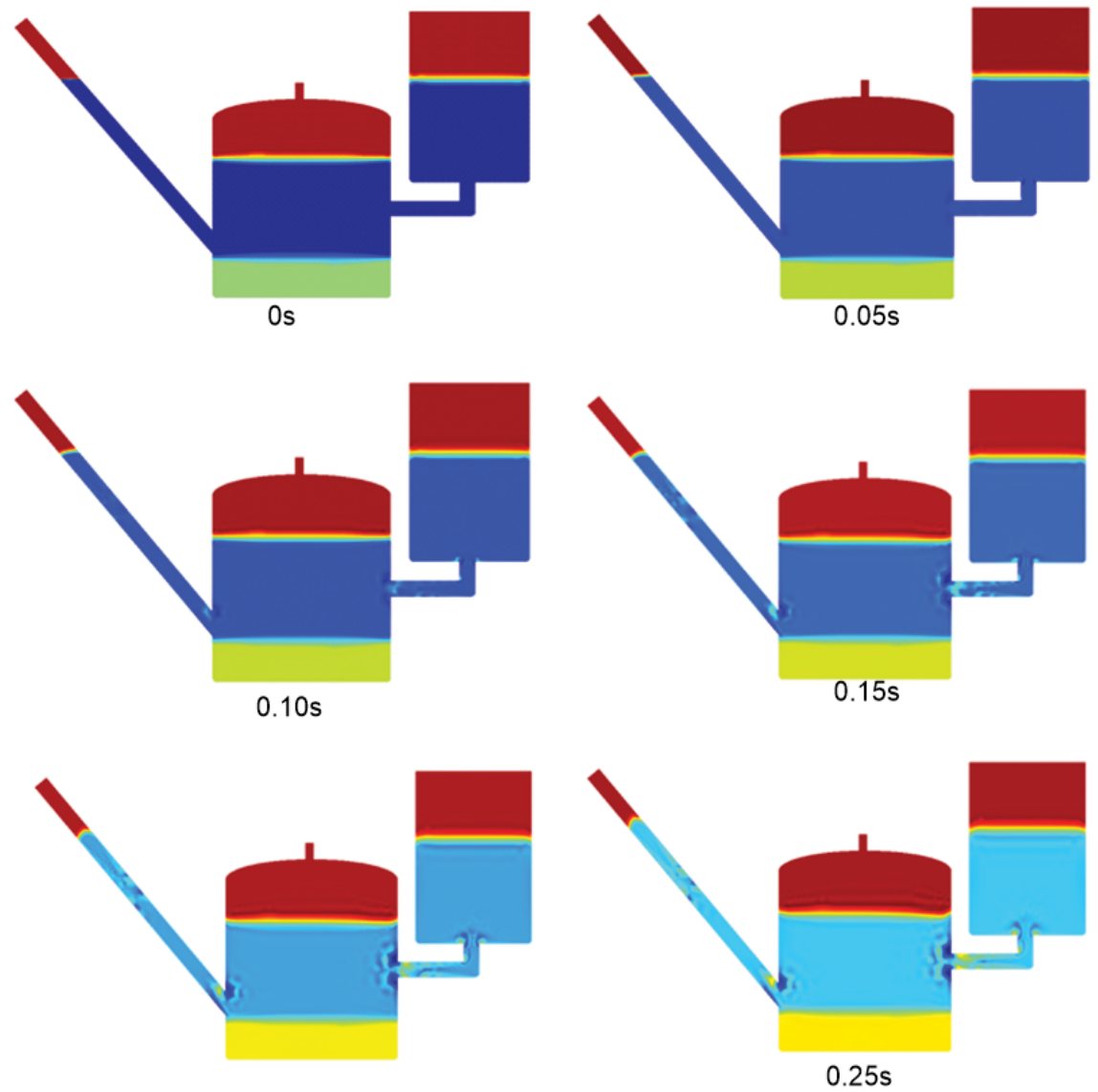

$0.20 \mathrm{~s}$

Figure 7.5 | Representation of the mixing of the blank digester at different times during gas production simulation. Red-gas phase, deep to light blue-liquid phase (12\% TS), green to yellow phase- liquid phase (15\% TS). 

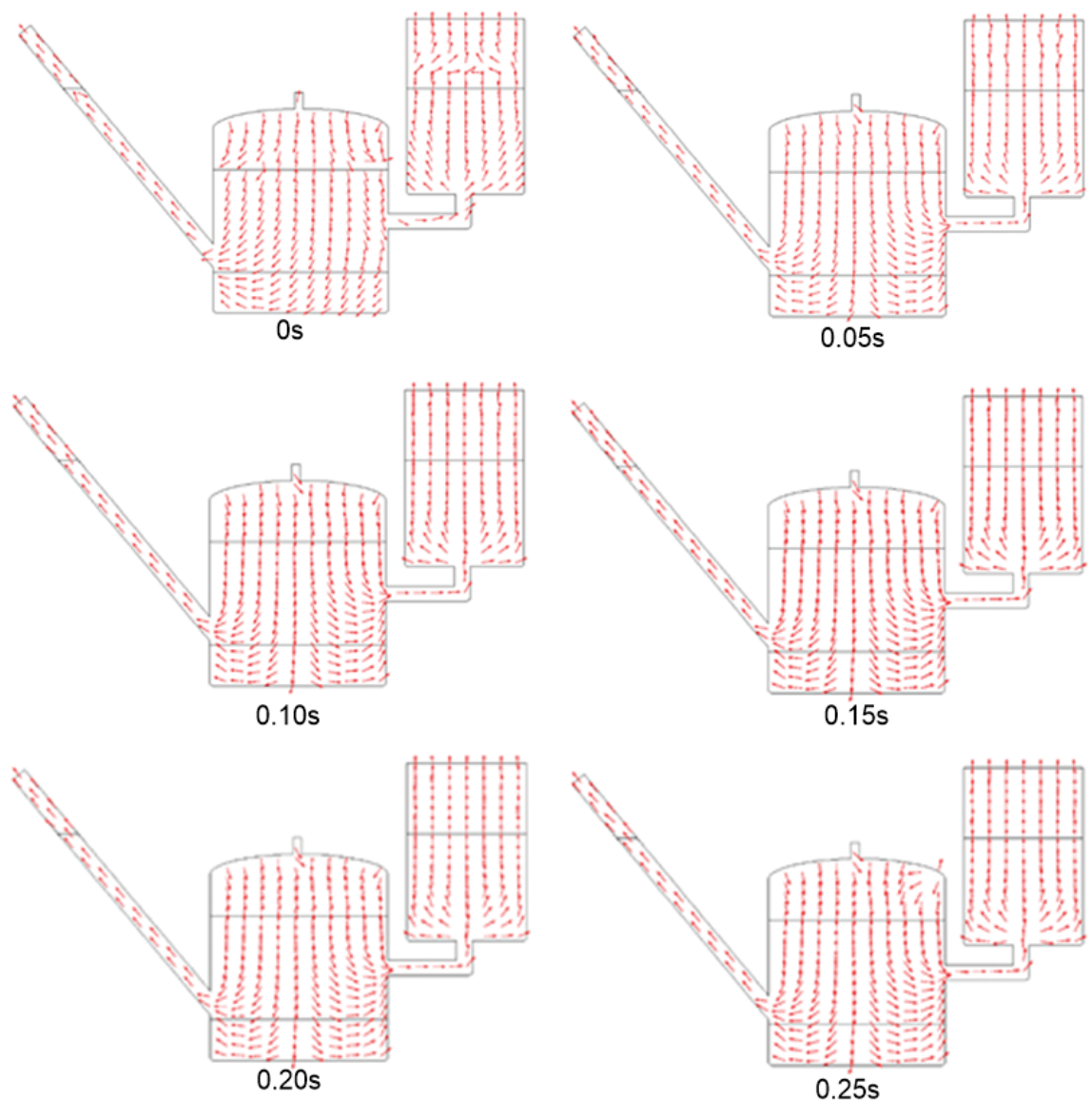

Figure 7.6 | Velocity vectors of blank digester at different times during gas production simulation.

Mixing in the optimized reactors during gas production is illustrated in Fig. 7.8 and 7.9. Fig. 7.8 shows that the slurry level in the baffled side (compartment $A$ ) is lower compared to that in compartment $\mathrm{B}$ and always remains lower. When the digester was started, the liquid level in both compartments were at the same level (data not shown). At $t=0$, the scheme (Fig.7.7) show that some biogas has been produced and occupies some space as shown in Fig.2. Biogas accumulated in both compartments pushes the slurry downwards almost at the same rate, assuming biogas production rate is constant. When biogas is collected or used from the gas phase of compartment $\mathrm{B}$, the slurry from the extension chamber and the inlet pipe flows back into the reactor and the slurry level in compartment B increases depending on the volume of gas used, while the slurry level in compartment A remains almost the same. Further biogas production will push the slurry in compartment $\mathrm{A}$ to the tip of the baffle, at this time the slurry level in compartment $\mathrm{B}$ is already higher than the slurry level in compartment A. As biogas production continues the pressure in compartment A increases, the slurry level will move below the bottom of the baffle. Some of the biogas produced will form a big bubble and flow into the head space of compartment $B$ 
and the slurry level in compartment A returns to approximately its original level, i.e. the tip of the baffle before the gas phase exceeded the length of the baffle. This process is the self-mixing process. As biogas is collected or used through the gas outlet on compartment $\mathrm{B}$, the slurry level in compartment $\mathrm{B}$ will always be higher than compartment $\mathrm{A}$ because the pressure will remain relatively higher and consistent with the pressure measurement in the optimized reactor.

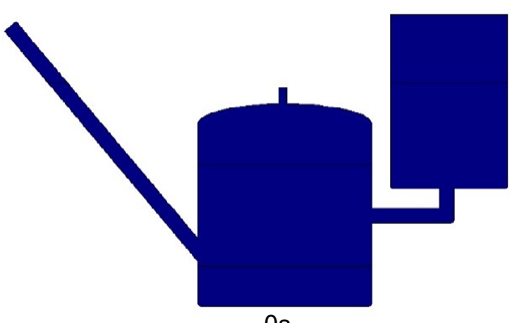

0s

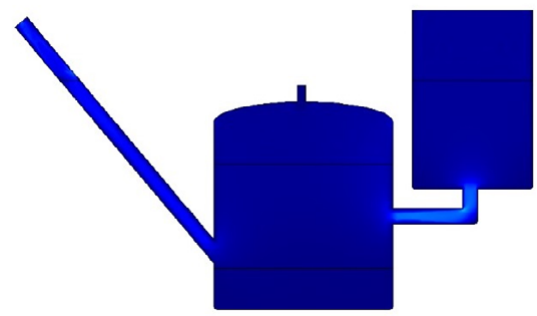

$0.10 \mathrm{~s}$

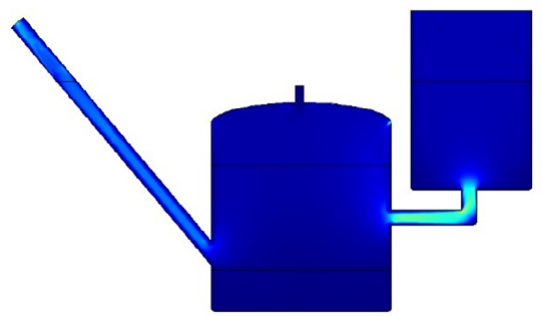

$0.20 \mathrm{~s}$

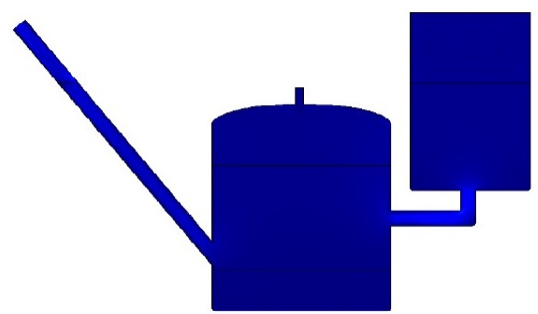

$0.05 \mathrm{~s}$

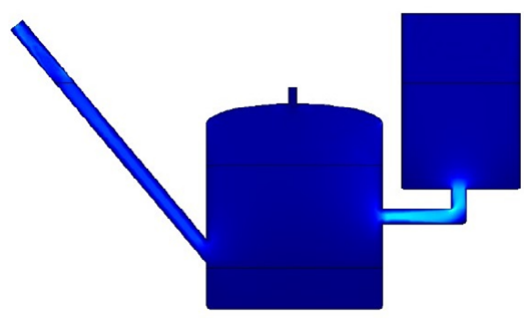

$0.15 \mathrm{~s}$

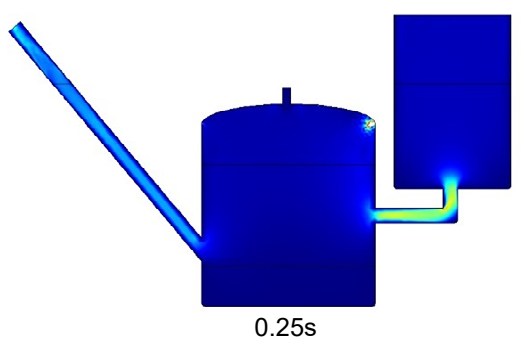

$\mathrm{m} \mathrm{s}^{-1}$

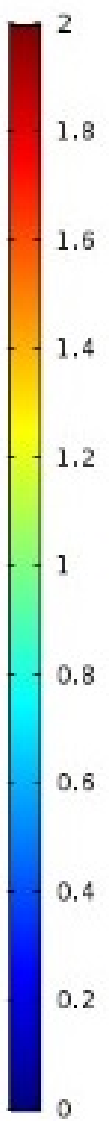

Figure 7.7| Velocity profile of blank digester at different times during gas production simulation. 


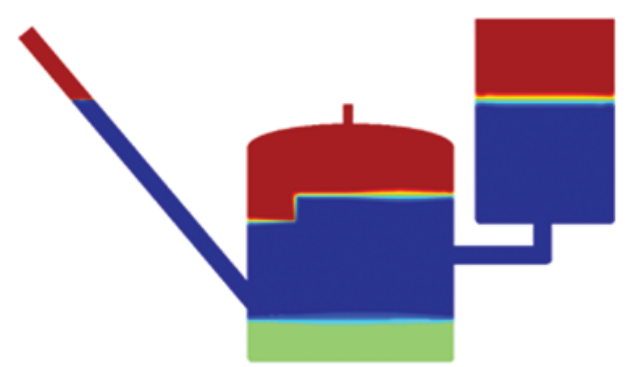

Os
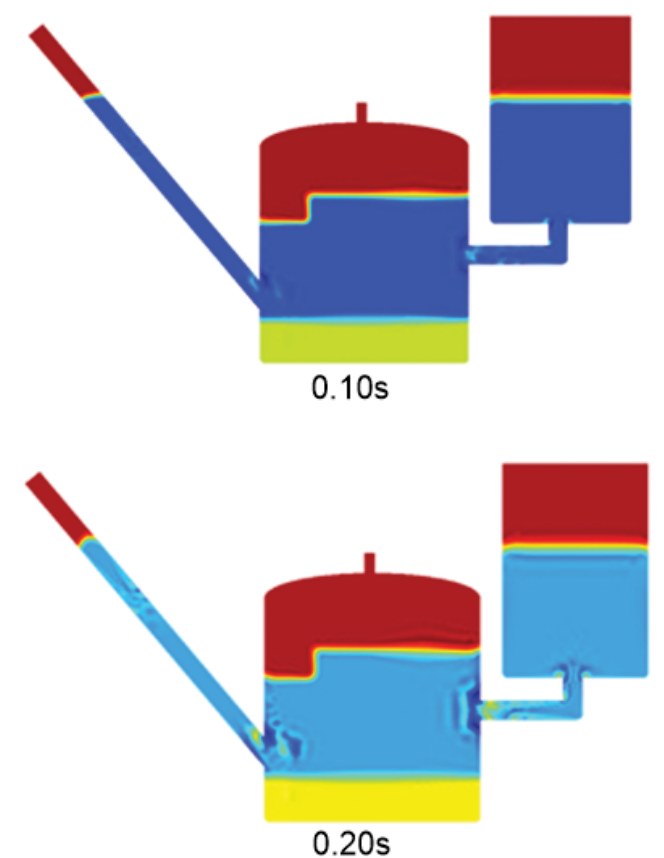
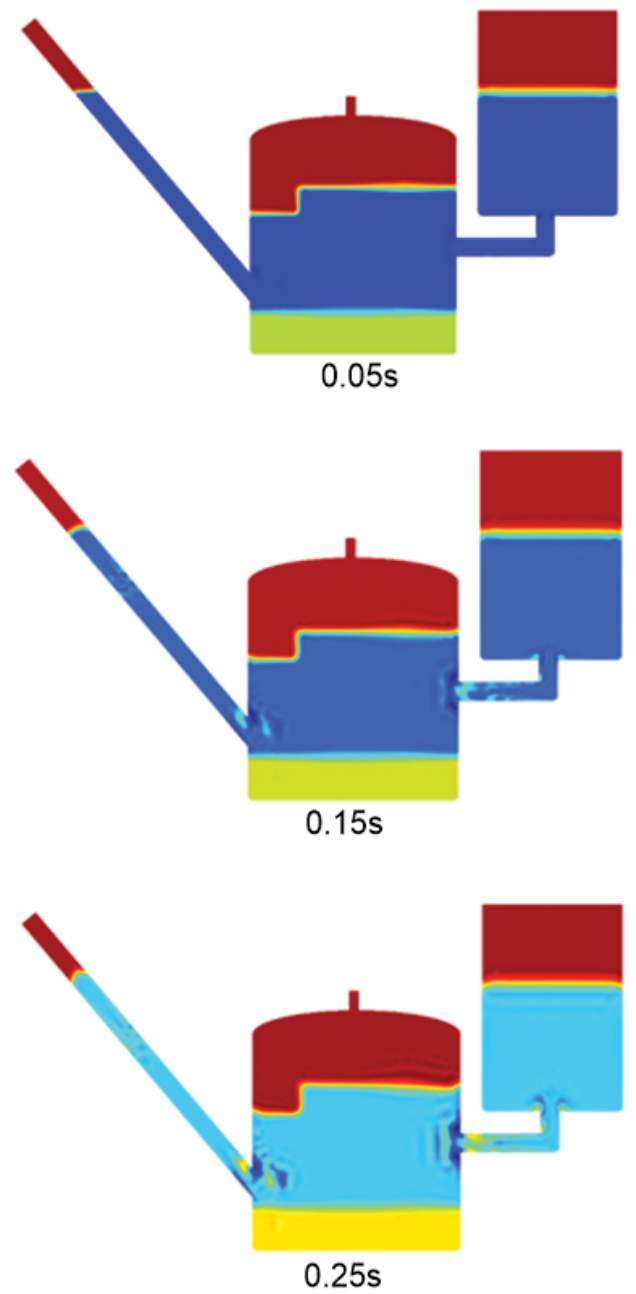

Figure 7.8 | Phases of the optimized digester before bubble formation at different times during biogas production Red-gas phase, deep to light blue-liquid phase (12\% TS), green to yellow phase- liquid phase (15\% TS). 

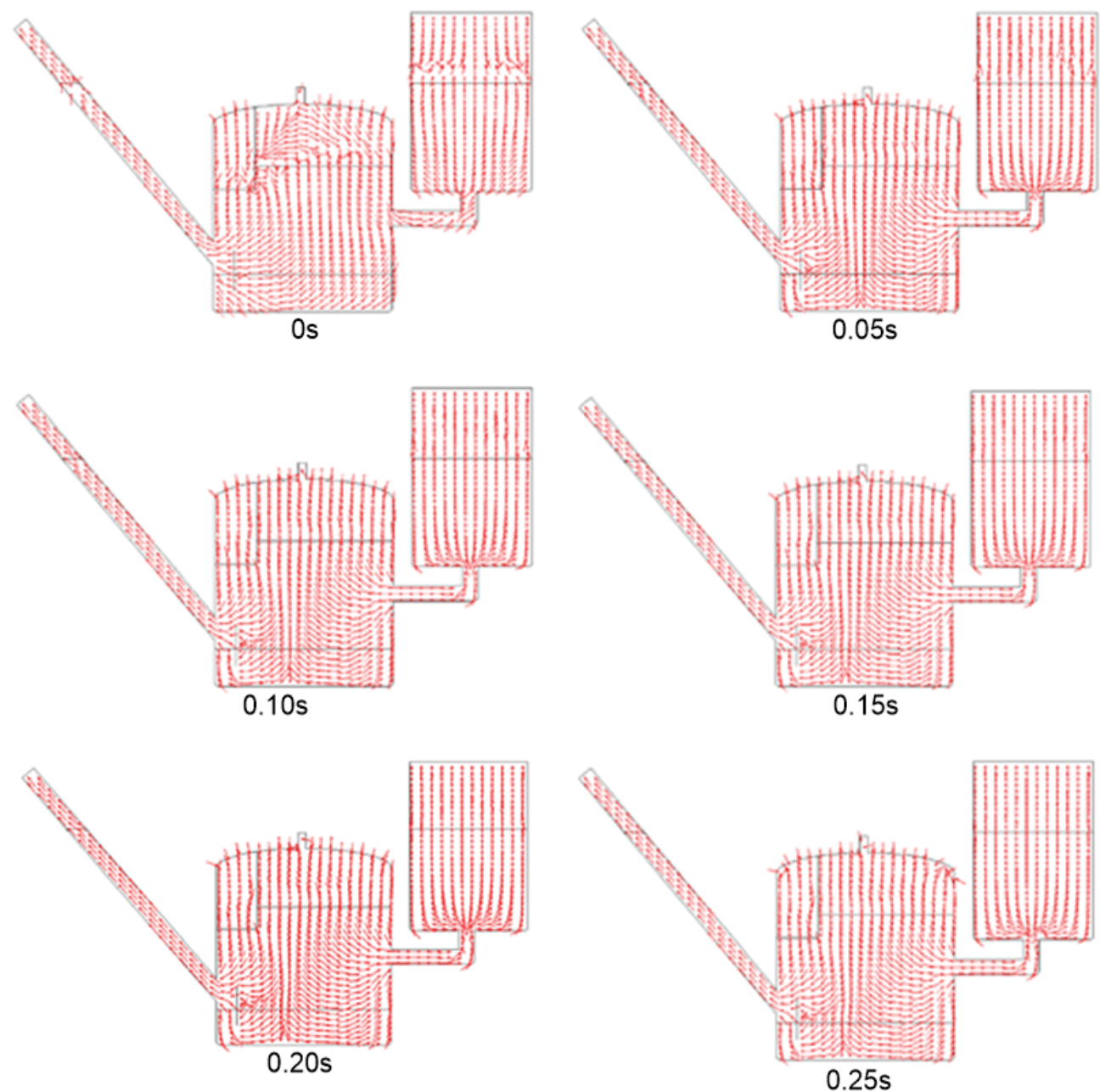

Figure 7.9| Velocity vectors of the optimized digester before bubble formation at different times during biogas production. 


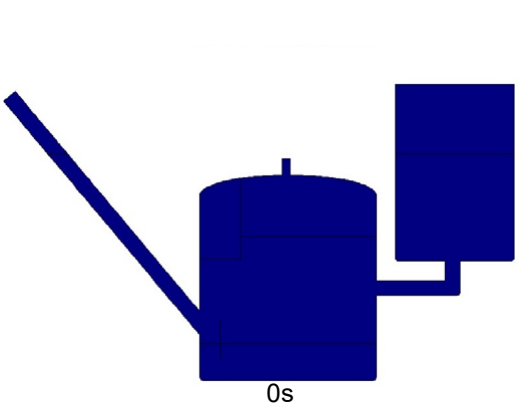

0s

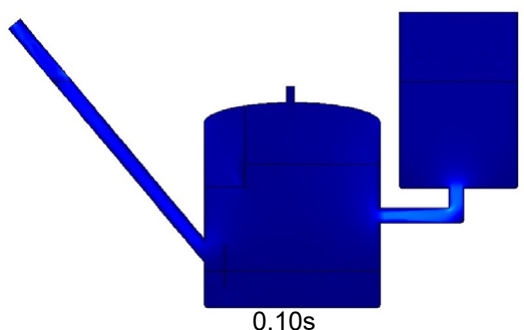

$0.10 \mathrm{~s}$

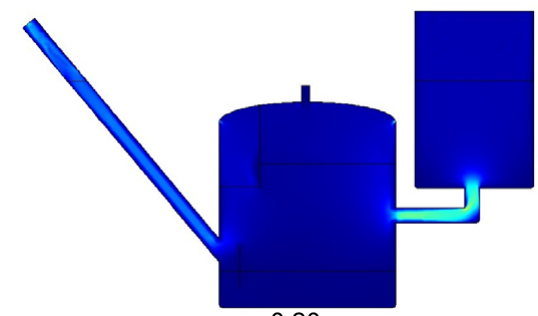

$0.20 \mathrm{~s}$

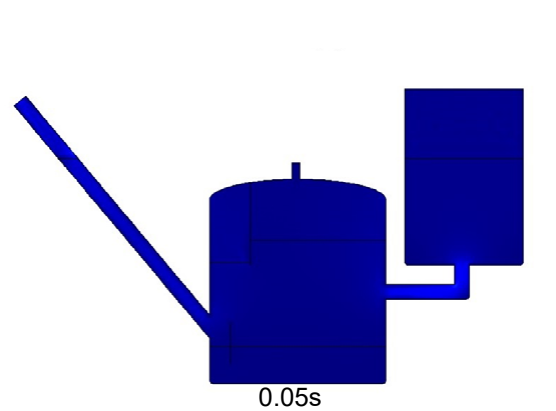

$0.05 \mathrm{~s}$

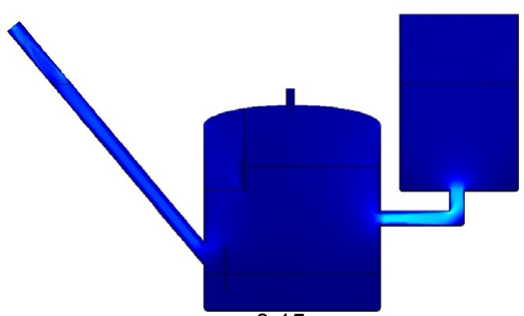

$0.15 \mathrm{~s}$

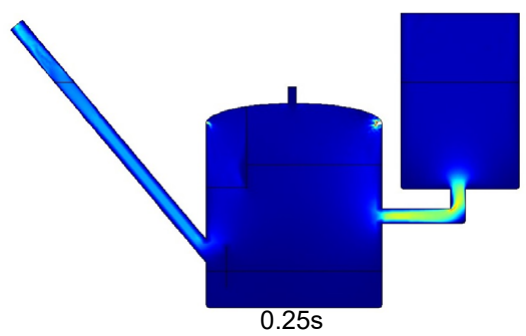

$\mathrm{m} \mathrm{s}^{-1}$

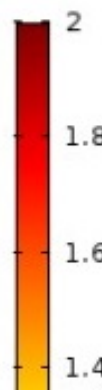

1.2

1

0.8

0.6

0.4

0.2

Figure 7.10 | Velocity profile of the optimized digester before bubble formation at different times during biogas production.

The velocity profiles in both blank and the optimized digesters before bubble formation are shown in Fig. 7.7 and 7.10 are similar with maximum velocity reaching $2 \mathrm{~m} \mathrm{~s}^{-1}$ in both reactors at the outlet pipe connecting the main reactor with the expansion chamber. Fig. 7.15 (a-d) give more specific information at two cross sections in the reactors, the upper and the lower cross sections between the walls of the reactors. In the optimized digester, velocity reached $1.5 \mathrm{~m} \mathrm{~s}^{-1}$ around the upper baffle region (compartment $\mathrm{A}$ ), whereas maximum velocity was below $0.3 \mathrm{~m} \mathrm{~s}^{-1}$ in the same region in the blank digester (Fig. 7.15a). In additions, Fig. 7.15 b shows the vorticity (flow circulation) around the same regions for both reactors. The circulation is more prominent in the baffled region of the optimized reactors with several peak, whereas almost flat in the blank. This suggests the positive impact of the upper baffle during the self-agitation process. This increased velocity and several peaks for the circulation (vorticity) in the modified reactor is the result of the energy stored in the pressurized gas. 
Furthermore, the lower baffle also played an important role to aid mixing at the bottom of the optimized digester during the biogas production process before and after bubble formation. As illustrated by the direction of the velocity vectors in Fig. 7.9 and 7.12, recirculation of slurry could be observed with the change in the direction of the during this process. The pressure exerted by the slurry on the baffles creates a mild mixing zones during the biogas production which was not the case in the blank digester. This could also be supported by the vorticity profiles presented in Fig. $7.15 \mathrm{c}$ for the lower region. The plot shows about three peaks around the lower baffle region for the optimized reactor representing circulation of slurry.
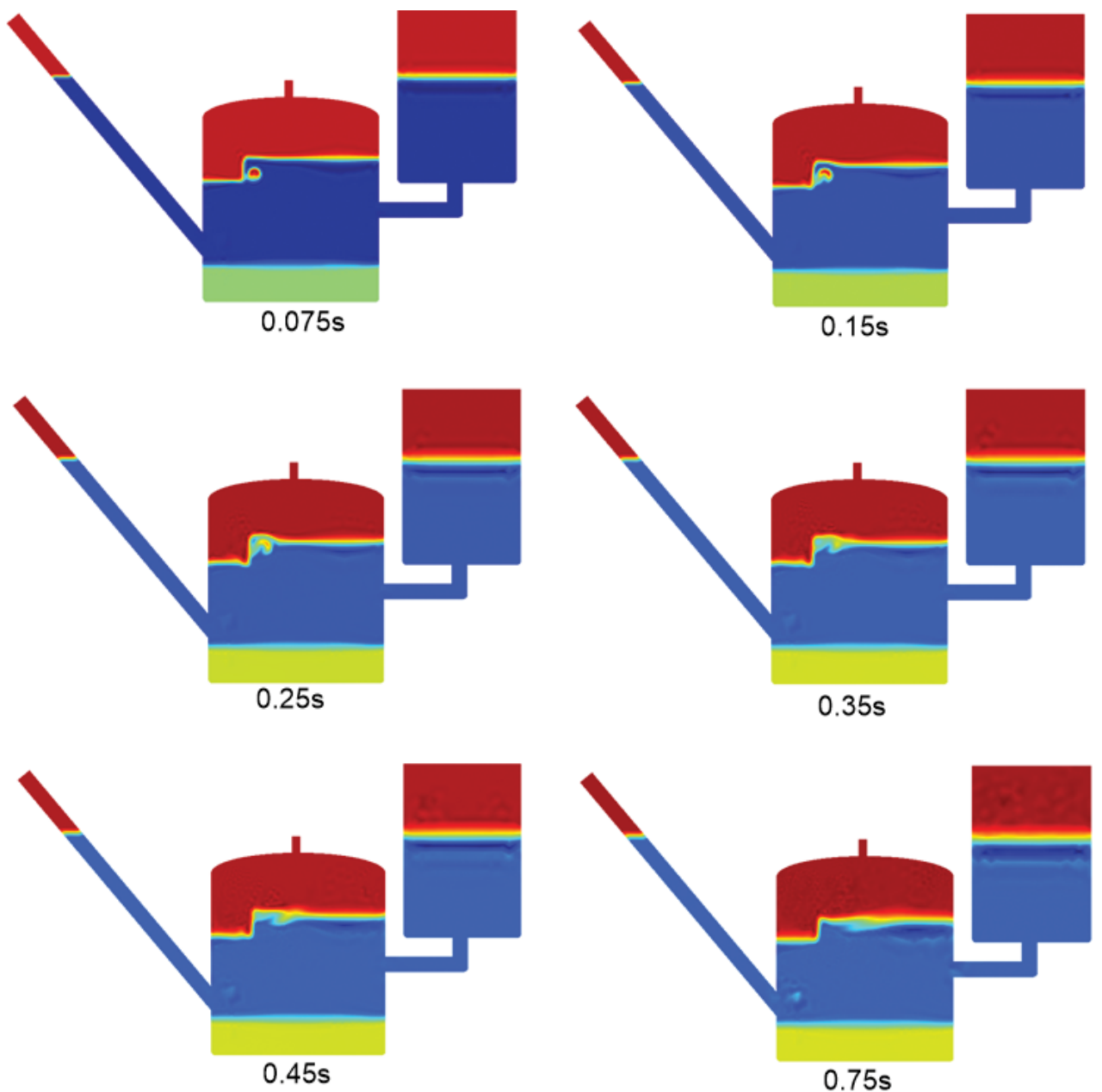

Figure 7.11 | Phases of the optimized digester after bubble formation at different times during biogas production. Red-gas phase, deep to light blue-liquid phase (12\% TS), green to yellow phase- liquid phase (15\% TS). 

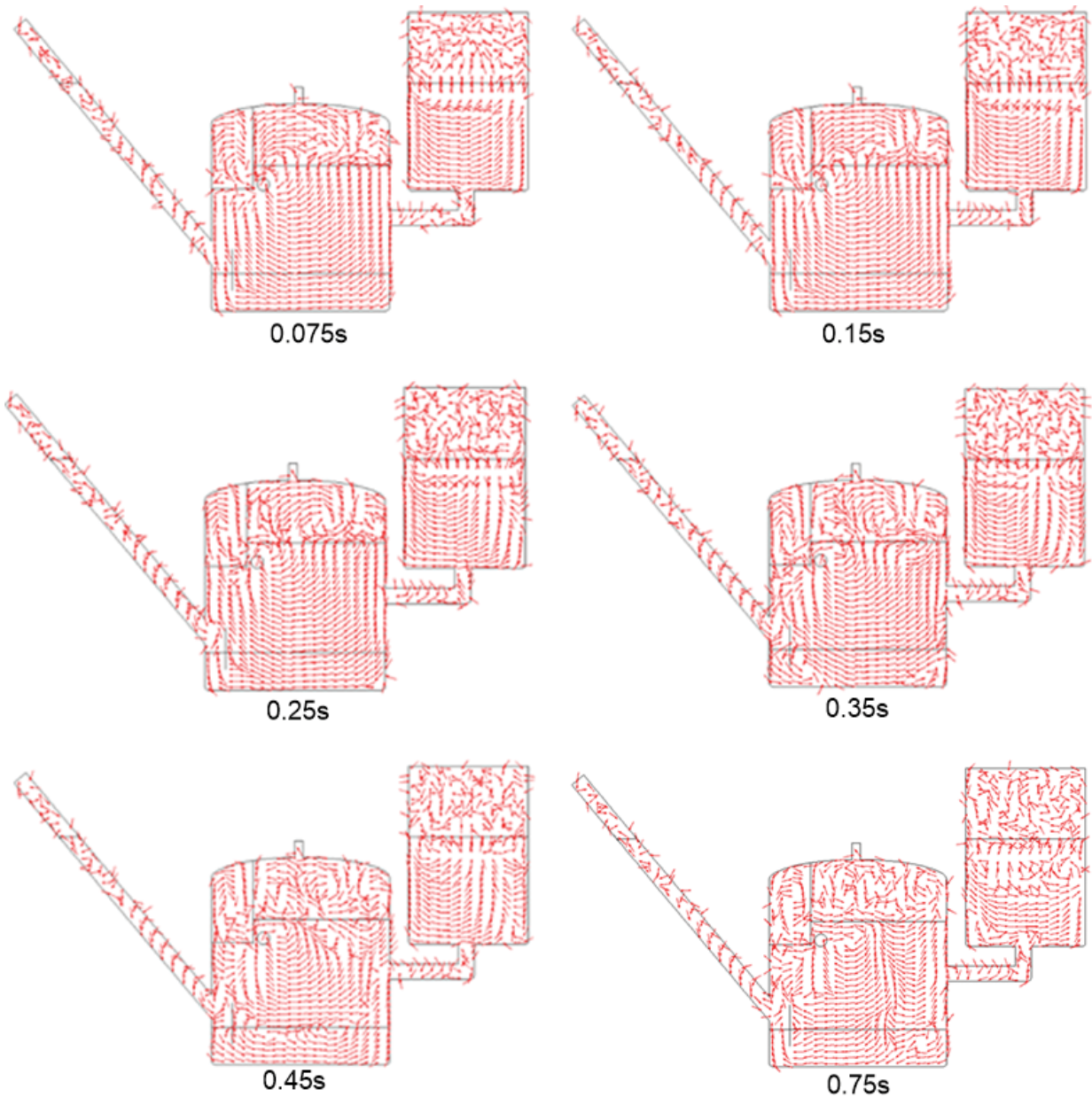

Figure 7.12 | Velocity vector of the optimized digester after bubble formation at different times during biogas production.

\subsubsection{Analysis of hydraulic characteristics and impact on digestion efficiency}

The numerical results demonstrated that the optimized reactor have an energy storage and release process in compartment A. Experimental results have shown that the duration of this cycle is 2 minutes (Jegede et al., 2018c). The self-mixing cycle might prevent scum formation and accumulation of suspended solids on the top of the slurry in the digester as shown during pilot scale experiments. The modified pilot reactor had higher specific biogas production as compared to the blank highly probably as a result of the improved mixing (Jegede et al., 2018c). Scums and accumulated suspended solids on top layer of reactor contents might hinder the release or liberation of gas from the liquid phase into the gas phase. The intermittent transport of gas from compartment A through the slurry to B would mitigate formation of floating layer in the reactor. In addition, as illustrated in Fig. 7.12, the velocity vectors in the optimized digester show better 
recirculation of reactor content compared to the blank digester. The circulation can also be seen in the inlet pipe and the expansion chamber of the optimized digester as indicated by the vector direction. This means the reactor content is better mixed during the self-mixing process compared to the blank digester.

The theoretical hydraulic retention time $(t=1129 s)$ of the model was estimated by dividing the total surface area of the model by the product of inlet velocity and the diameter of the inlet pipe. The inlet velocity $\left(0.01 \mathrm{~m} \mathrm{~s}^{-1}\right)$ represents the flow speed of manure during the reactor feeding. The velocity profile in the reactors during the feeding regime simulation were used for the particle tracing paths, with the same inlet velocity used in both reactors. During simulations, after $8000 \mathrm{~s}$, $82 \%$ percent of tracer particles left the optimized reactor, while only $60 \%$ for the blank digester. This means that $40 \%$ of the particles introduced in the blank are trapped while only $18 \%$ were trapped in the optimized reactor. This is an indication that the semi-dead zone in the blank is larger than the one in the optimized digester.

The settling velocity $\left(V_{s}\right)$ was used to estimate semi-dead zones as $18.5 \%$ and $14 \%$ for the blank and optimized reactors as described in the methods. The existence of large semi-dead zones in the blank reactor implies mixing is limited in some regions compared with the optimized reactor and eventually led to under performance of the blank digester as reported by Jegede et al., (2018c). The improved hydraulic performance in the optimized reactor could be associated with the inclusion of the two baffles at the top and bottom. The bottom baffle in the optimized digester helped in reducing circuiting of influent from the inlet to the outlet, while helping to mix the incoming influent with the reactor content during feeding and biogas production as illustrated with the velocity vectors presented in Fig. 7.13 and 7.14. In addition, the lower baffle also aids mixing at the bottom of the reactor during gas production. Recirculation of reactor content could be noticed by the direction of the velocity vectors in Fig. 7.9 around the lower baffle region. To support this claim, Fig. $7.15 \mathrm{~d}$ presents vorticity results around the lower baffle regions for both reactors. Two distinct peaks are visible in the optimized reactor whereas only one for the blank reactor. This contributes to the improved hydraulic characteristics of the system make it to approach a gently mixed (low intensity) continuously mixed CDD. Therefore, the modelling results suggest that the mixing in the optimized is better compared to the blank digester.

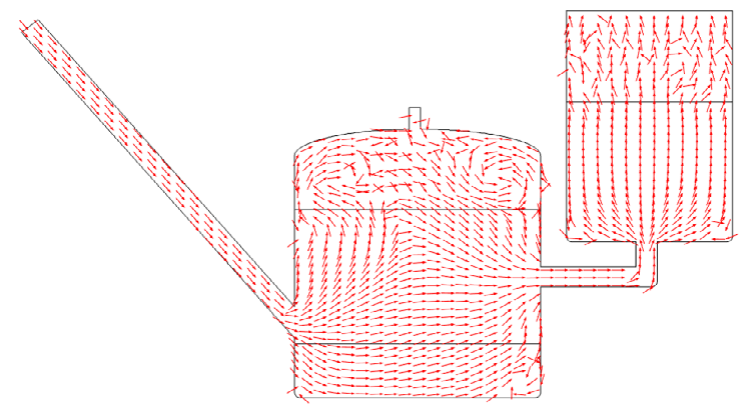

Figure 7.13 | Velocity vectors of blank digester during feeding simulations. 


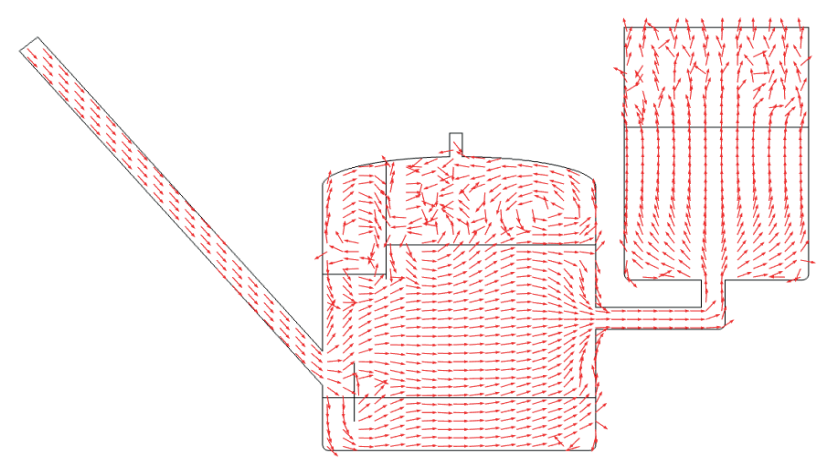

Figure 7.14 | Velocity vectors of optimized digester during feeding simulation.
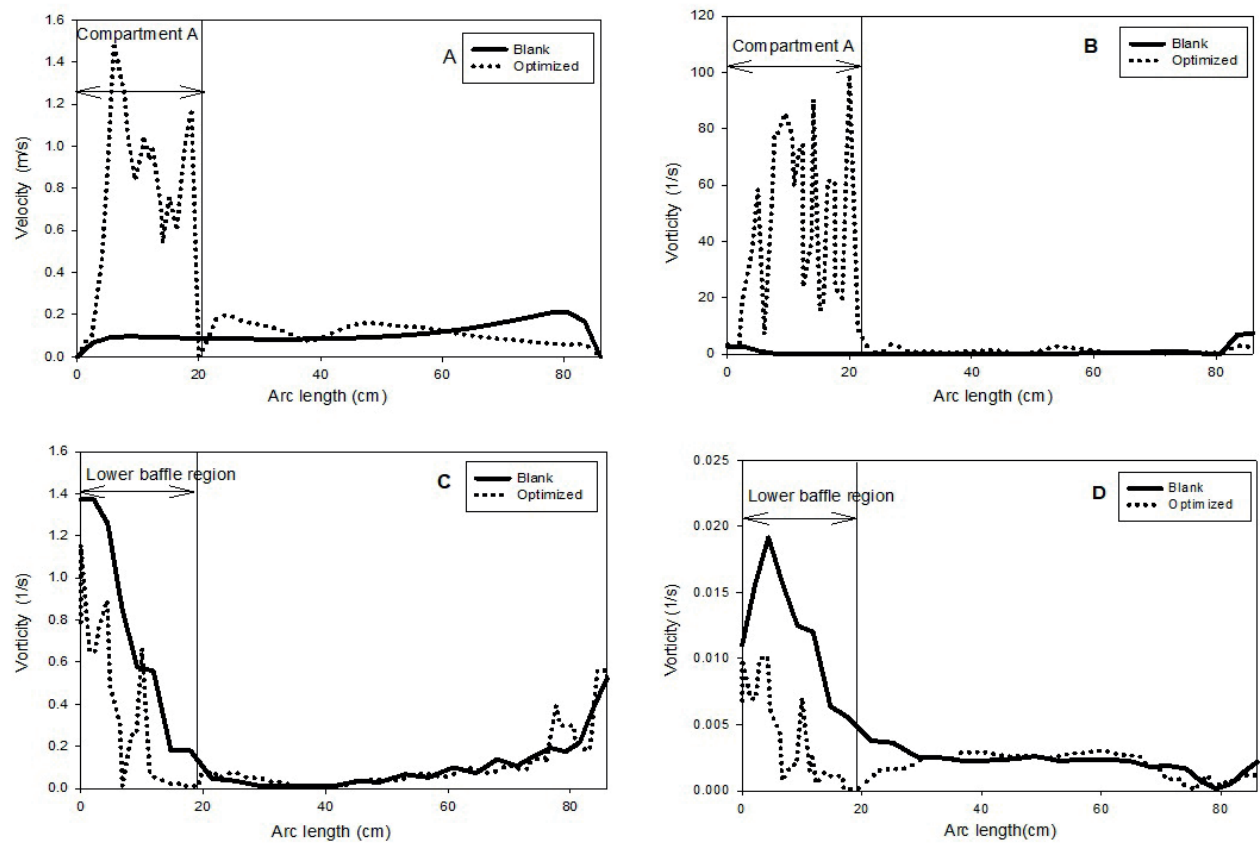

Figure 7.15 | Presents velocity and vorticity profiles of cross section of the reactors from the left wall $(0 \mathrm{~cm})$ to the right wall $(86 \mathrm{~cm}$ ), at heights $70 \mathrm{~cm}$ (upper section) and $20 \mathrm{~cm}$ (lower section) from the bottom of the reactors. (A) Velocity profiles of both reactors at the upper cross section during gas production (B) Vorticity profiles of both reactors at the upper cross section during gas production. (C) Vorticity profiles of both reactors at lower cross section during gas production (D) Vorticity profiles of both reactors at lower cross section during reactor feeding.

Furthermore, since the reactors were operated at $15 \%$ influent TS concentration (higher influent TS concentration) higher volumetric biogas production would be achieved and would be beneficial to improving mixing only in the optimized digester. In a past study by Jegede et al., (2018d), higher volumetric biogas production at higher influent TS (15\%) concentration did not improve 
mixing in anaerobic digester mainly because of the rheological properties of the manure at higher TS concentration. However, in the case of optimized digester higher volumetric biogas production would have contributed to the overall performance of the reactor viz. improved mixing with the aid of the baffle in the gas phase. As seen in Fig. 7.3, about $20 \%$ of the produced biogas in the optimized digester goes to compartment $\mathrm{A}$, since this compartment is closed, meaning pressure will always be high in this compartment and a higher agitating frequency, and a shorter energy storage process would be experienced as reported in this study due to more biogas production.

Some authors reported that gentle, intermittent mixing is preferred above continuous vigorous mixing (McMahon et al., 2001; Stroot et al., 2001; Kim et al., 2002). Continuous, vigorous mixing might disrupt symbiotic relationships between different types of microorganisms. In conventional CDDs, mixing is intermittent and gentle, but not sufficient making the system to be operated at long retention time and high-water dilution. In this study, improved mixing was achieved because of the improved design of the Chinese dome digester. The improved mixing might have favoured the syntrophic relationships between microorganisms (Zeeman, 1991). Lastly, it also favors the stability in the gas production and avoidance of VFA accumulation in the improved reactor as reported by Jegede et al., (2018c).

\subsection{Conclusion}

This study presents a computational fluid dynamic study of an optimized pilot Chinese dome digester in comparison to a blank. The simulations results produced higher velocity profile and recirculation regions viz. velocity vectors directions in the improved digester. The CFD model was validated using the pressure data and impact of mixing evaluated with biogas results from a pilot study. The phases and flow fields were analyzed in relation to mixing. The installed baffles in the optimized digester improved the hydraulic characteristics of the optimized digester and the mixing. The lift force created when the produced biogas flow below the upper baffle from the compartment A to B resulted to an increase in velocity, the change of flow characteristics of the slurry in the digester, inlet pipe and expansion chamber resulted in the improved mixing of the reactor content.

\section{Acknowledgements}

This work was funded by the Netherlands Fellowship Programme (NFP), the Netherlands. Special thanks to the analytic/lab support team at Environmental Technology department, Wageningen University, The Netherlands. Special appreciations to the management and support staff of Biochemical Engineering Laboratory, Centre for Energy Research and Development, Obafemi Awolowo University, Ile-ife Nigeria for their support. 


\section{References}

Boyer F., Lapuerta C., Minjeaud S., Piar B., Quintard M., (2010) Cahn-hilliard/Navier-Stokes model for the simulation of three-phase flows. Transport in Porous Media, COMSOL manual 28:463-484.

Cheng S., Li Z., Mang H. P., Huba E. M. (2013). A review of prefabricated biogas digesters in China. Renewable and Sustainable Energy Reviews 28:738 -748.

Comsol (2015). Comsol Multiphysics user's guide version 5.2, Comsol AB, Stockholm, Sweden

Deublein D., Steinhauser A. (2008). Biogas from waste and renewable resources. Weinheim, Germany: Wiley-VCH Verlag $\mathrm{GmbH} \& \mathrm{Co} . \mathrm{KGaA}$.

Ghimire P. C. (20120. SNV Supported domestic biogas programmes in Asia and Africa. Renewable Energy 49: 90-94.

Hoffmann RA., Garcia M L, Veskivar M., Karim K., Al-Dahhan M. H., Angenent L.T.. (2008). Effect of shear on performance and microbial ecology of continuously stirred anaerobic digesters treating animal manure. Biotechnol Bioeng.100: 38-48.

Jegede A.O., Bruning H., Zeeman G. (2018a). Mixing in Anaerobic Digesters with a specific emphasis on Household Digesters. Under review in Critical Reviews in Environmental science and Technology.

Jegede A.O., Bruning H., Zeeman G. (2018b). Design considerations for inlet and outlet of Chinese dome digester to mitigate biogas emission. Revised version submitted to Biosystems Engineering.

Jegede A.O., Zeeman G., Bruning H., (2018c). Performance evaluation of an optimized Chinese dome digester in a pilot study. In preparation for submission.

Jegede A.O., Bruning H., Zeeman G. (2018d). Effect of mixing regime on anaerobic digestion of cow manure: comparing mechanically mixed, unmixed and Chinese dome digesters. Under review in Sustainable Energy Technologies and Assessment.

Karim K., Hoffmann R., Klasson K. T., A1-Dahhan M. H. (2005). Anaerobic digestion of animal waste: effect of mode of mixing. Water Research 39:3597-3606.

Karim K., Thoma G.J., Al-Dahhan M. H. (2007). Gas-lift digester configuration effects on mixing effectiveness. Water Res. 41:3051-60.

Keanoi N., Hussaro K., Teekasap S. (2014). Effect of with/without agitation of agricultural waste on biogas production from anaerobic co-digestion- A small scale. Am J Environ Sci 10(1): 74 -85.

Khan E. U., Martin A. R, (2016). Review of biogas technology in rural Bangladesh Renewable and sustainable energy reviews. 62: 247- 259

Lindmark J., Bel Fdhila R., Thorin E. (2009). On modelling the mixing in a digester for biogas production. In: Proceedings of mathmod, 6th international conference on mathematical modelling, Vienna, Austria.

Lindmark J., Bel Fdhila R., Thorin E. (2011). Retention time and nutrient tracking inside a digester for biogas production. In: Proceedings of scanSIMS, Västerås, Sweden.

Lindmark J., Thorin E., Fdhila R. B., Dahlquist E. (2014). Effect of mixing on the result of anaerobic digestion: Review. Renewable and Sustainable Energy Review (40):1030 -1047

Lopez-Jimenez P.A., Escudero-Gonzalez J., Martinez T. M., Montanana V. F., Gualtieri C., (2015). Application of CFD methods to an anaerobic digester: The case of Ontinyent WWTP, Valencia, Spain. Jour.of water process Engineering 7:131-140.

Manea E., Robescu D. (2012). Simulation of mechanical mixing in anaerobic digesters. UPB Sci Bull Ser D: Mech Eng. $74: 235-42$.

Maroney R.N., Colorado P. E. (2009). CFD simulation of mechanical draft tube mixing in anaerobic digester tanks. Water Res. 43:1040-50.

Mungwe J N., Colombo E., Adani F., Schievano A. (2016) The fixed dome digester: An appropriate design for the context of sub-Sahara Africa? Biomass and Bioenergy 95: 35-44.

Qi W-K, Toshimasa H., Li Yu-You. (2013). Hydraulic Characteristics of an innovative self-agitation anaerobic baffled reactor (SA-ABR). Bioreource Tech 136:94-101.

Sommer S.G., Peterson S.O., Moller H.B. (2004). Algorithms for calculating methane and nitrous oxide emissions from manure management. Nutr Cyl Agoecosyst; 69: 143 -54.

Vesvikar M.S., Al-Dahhan M. (2005). Flow pattern visualization in a mimic anaerobic digester using CFD. Biotechnol Bioeng 89:719-32.

$\mathrm{Wu}$ B. (2012). Integration of mixing, heat transfer, and biochemical reaction kinetics in anaerobic methane fermentation. Biotechnol Bioeng. 109:2864-74.

Wu B. (2012). CFD simulation of mixing for high-solids anaerobic digestion. Biotechnol Bioeng. 109:2116-26 
Yu L., Ma J., Frear C., Zhao Q., Dillon R., Li X., Chen S. (2013) Multiphase modelling of settling and suspension in anaerobic digester. Applied Energy 111: 28 -39.

Zeeman G. (1991). Mesophilic and psychrophilic digestion of liquid cow manure. PhD Thesis. Sub-Department of Environmental Technology, Wageningen University, Wageningen. 


\section{Appendices}

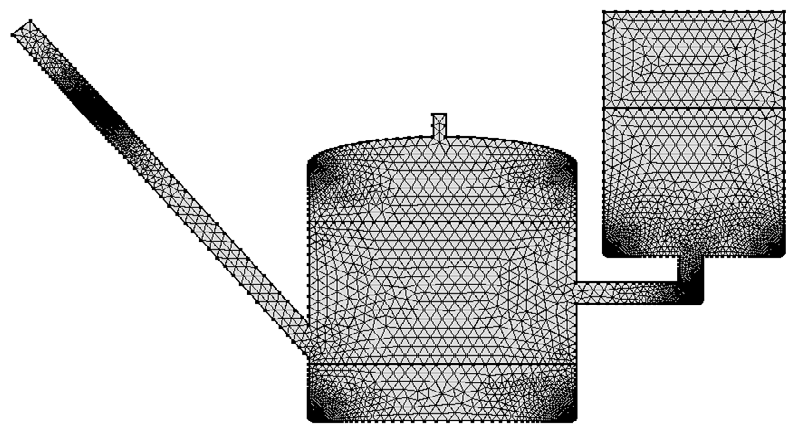

Appendix 7.1 | Mesh diagram of the blank reactor.

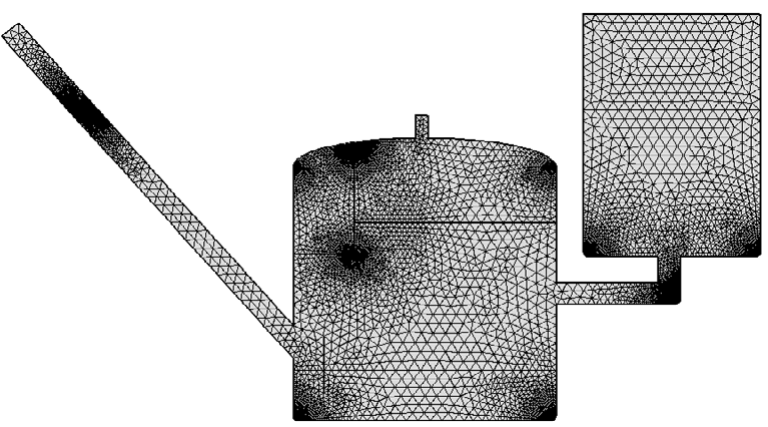

Appendix 7.2 | Mesh diagram of the improved reactor. 


\section{Chapter}

8

General discussion and further research 


\subsection{Introduction}

Modern energy access is a necessity for human development, protection of health and the environment. In addition, modern energy access is pivotal to the achievement of the 2030 United Nations Sustainable Development goals. The ability to access modern sources of energy is of eminent importance to over 2.6 billion people who make use of traditional biomass (wood) as a source of cooking and lighting (Okello et al., 2013; Stefano et al., 2014; Avery et al., 2014)

Biogas has been identified as an important modern and clean source of energy, while biogas technology also provides an organic fertilizer to be used in agriculture for food security for rural dwellers in developing countries, especially Sub-Saharan Africa (Rupf et al., 2017). When toilets are connected to the biogas installation also sanitation is considerably improved. Biogas technology moreover enables indoor cooking and provides waste management (Garfi et al., 2012; Kranert et al., 2012). Domestic or household digesters as such help to improve livelihoods and replace the use of traditional biomass such as firewood. However, the uptake and diffusion of domestic biogas plant in tropical regions, especially in Sub-Saharan Africa, is still hindered by factors like installation cost, poor designs and availability of water in arid regions. Since water is required to mix and dilute the substrate (usually cow manure) digester feeding, lack of sufficient water will reduce the uptake of domestic biogas plants in arid regions. In China and other Asian countries, where the domestic biogas plant has greater uptake, the success is based on government programs through provision of supports in form of subsidies and loans (Rupf et al., 2017). An important drawback of Chinese Dome digesters in operation, is the emission of part of the biogas due to poor design (Chapter 5). In many cases significant amounts of surplus biogas are intentionally released to the atmosphere (Thien et al.,2012). Biogas emission from household reactors as a result of leakages and deliberate release of surplus biogas threatens to reverse the benefits of household biogas plants in mitigating GHG (Chapter 5).

The Chinese fixed dome digester is a type of household digester and usually constructed underground with a hemispherical dome top serving as a gas holder (Gunnerson and Stuckey, 1986). The reactor is operated in a semi-continuous mode i.e. feeding is done once a day. To meet the daily biogas requirement for a family of about five people, a reactor size between $6 \&$ $10 \mathrm{~m}^{3}$ is required when using cow manure as the feedstock, applying mesophilic conditions at a long HRT of 40 - 90 days and a loading rate of $1.5 \mathrm{~kg} \mathrm{VS} / \mathrm{m}^{3}$ day (Kalia, 1998; An \& Preston, 1999; Ferrer et al., 2011). The Chinese fixed dome biogas plant is most popular in developing countries in terms of number (Fulford, 1988; Chen et al., 2010; Ghimire, 2013; Ferrer et al., 2013) and largely supported by SNV (a Dutch non-for-profit organization). It is the design of choice for most of their programmes in rural areas in developing countries because of reliability, low maintenance and long lifespan (Ghimire, 2013). Mixing is achieved in the digester via hydraulic variation during feeding, effluent discharge and gas use (Tamkin et al., 2014). Chapter 2 of this thesis reviews the operation of household biogas plants for manure treatment focusing on mixing in Chinese dome digesters (CDD) in relation to applied dilution, HRT and organic loading rates (OLRs). Household digesters are unheated and non-forced mixed digesters, making them simple to operate with little or no monitoring needed (Qi et al., 2013). In Chapter 2 of this thesis, domestic digesters were compared with forced mixed digesters, based on data from literature. 
This chapter illustrates that forced mixed (mechanically, slurry recirculation, gas recirculation) digesters are generally operated at relatively low HRT ( $\leq 20$ days) for a wide range of influent total solids (TS) (5-15\%) concentrations compared to domestic digesters with long HRT $(\geq 40$ days) at low influent TS $(\leq 7 \%)$ concentration. The result of the review suggests, that household digesters need to be operated at low organic loading rates as a result of the limited mixing. Since domestic digesters are designed for low income earners, especially in the rural areas of developing countries, a strategy to reduce the reactor volume and the amount of water for substrate dilution, while maintaining a simple design and limiting maintenance requirement, can result in reduction of costs. A bottom-up approach was therefore applied to improve mixing in the digester, with the intention of reducing the amount water required for substrate dilution, reactor volume and eventually the cost for digester installation.

The first strategy was executed and evaluated in_Chapters 3 and 4. The focus was to study the impact of higher volumetric biogas production rates on mixing at different OLRs in different anaerobic digester designs (impeller mixed, hydraulically mixed and unmixed), including the Chinese dome digester, at laboratory scale. The results showed that natural mixing induced by biogas production did not produce sufficient mixing. The hydraulic variation or mixing cycle in the CDDs does not suffice for the treatment of cow manure at an influent TS concentration of $10 \%$ and above (Chapter 3). The residence time distribution (RTD) technique was used to evaluate mixing in both liquid and solid phases of the three types of reactors using appropriate tracers at 2.5 times the theoretical HRT. The tracer results were used to calculate the actual residence time and then subsequently the dead zones in the reactors. The percentage of dead zones in the CDDs was higher compared to the impeller mixed reactors, because of the limited natural mixing in the Chinese dome digester (Chapter 4). Chapter 5 describes a set of equations developed to model the hydraulic variation in the Chinese dome digester and to prevent gas emission from the inlet and outlet of the digester, and also to help in gas storage design. The model results were in agreement with experimental results presented in $\underline{\text { Chapter } 6}$

Since, the volumetric biogas production rates, coupled with the hydraulic variation in the Chinese dome digester did not impact positively on mixing at higher influent TS, a creative modification approach was applied to the CDD by adding two baffles at two strategic positions to improve mixing also at higher TS concentration (Chapter 6). The hydraulic characteristics of the modified digester were studied in Chapter 7, using computational fluid dynamics (CFD) and the anaerobic digestion performance of the modified CDD was evaluated at $15 \%$ influent TS in a pilot study. The modified reactor resulted in a better hydraulic and digestion performance compared to the blank (conventional CDD). The research strategy is presented in Table 8.1. 
Table 8.1 | Overview of the contents of the successive thesis chapters.

Thesis progression
$\begin{aligned} & \text { Review of mixing in Chinese dome digester } \\ & \text { Evaluation of impact of volumetric biogas } \\ & \text { production and hydraulic variation }\end{aligned}$
$\begin{aligned} & \text { Optimization of storage capacity to prevent } \\ & \text { methane emission }\end{aligned}$
Performance evaluation of improved CDD

\subsection{Effect of mixing in forced mixed reactors and Chinese dome digesters}

The effect of the mixing regime on the digestion efficiency of forced mixed reactors is frequently reported in literature, but little effort has gone into optimizing domestic biogas reactors, especially the Chinese dome digester, which could serve a major energy solution to meeting the cooking needs of rural households in developing countries (Chapter 2).

The anaerobic digestion process depends on mixing for the dispersal of nutrients and microbes, inoculation of substrates, removal of metabolic waste and homogenization of reactor content and temperature (Deublein and Steinhauser, 2008). Forced mixed reactors are mixed via mechanical mixing (impeller), pneumatic mixing (pumping of gas in the reactor) or hydraulic mixing (slurry recirculation). Apart from the mixing methods or equipment applied, intensity and alternate mixing modes could be applied to further influence the anaerobic process (Lindmark et al., 2014). In domestic digesters (e.g. Chinese dome digester) mixing is achieved naturally via volumetric biogas production and hydraulic variation between the reactor and expansion chamber during gas production and gas use (Chapter 2 and 3). In CDDs, the degree of mixing will depend on the reactor geometry, type of feed, OLR and frequency of gas use. When considering the optimization of domestic digesters without energy input for forced mixing, the challenge was quantifying the natural mixing in relation to above mentioned parameters. The interest in optimizing mixing in Chinese dome digesters is to generate as much biogas (yield $-\mathrm{m}^{3} / \mathrm{kg}$ feed) as possible while applying a higher loading rate.

After comparing the performance of several forced mixed reactors with domestic biogas digesters based on a literature review (Chapter 2), it was concluded that the performance of domestic biogas digesters could be improved when mixing is improved. While HRTs and OLRs applied in forced mixed reactors varies between 10 and 20 days and 0.6 and $6.9 \mathrm{~kg} \mathrm{VS} / \mathrm{m}^{3} /$ day, respectively, these vary between $23-170$ days at $0.04-4.45 \mathrm{~kg} \mathrm{VS} / \mathrm{m}^{3} /$ day respectively, for household digesters. The average volumetric biogas production rate of $1.3 \mathrm{~m}^{3} / \mathrm{m}^{3} /$ day in reactors with forced mixing is higher compared to the average of $0.5 \mathrm{~m}^{3} / \mathrm{m}^{3}$ day in household digesters. Similarly, the average specific biogas production is $30 \%$ higher in forced mixed reactors compared to household systems. 


\subsection{Impact of organic loading rate and volumetric gas production on mixing}

Since a household digester could be regarded as an intermittently mixed reactor, it was hypothesized in Chapter 3 that mixing in a Chinese dome digester could be positively affected by a higher volumetric gas production. This was the first strategy for the optimization of the reactor. Higher volumetric biogas rate can be achieved by increased loading rate, applying less dilution of the influent and/or shorter HRT, both leading to smaller reactor volumes. Significant difference in reactor performance was seen between an impeller mixed, unmixed and Chinese dome digester, studied at laboratory scale at single and double influent TS (3-7.3\%, 6-15\%) concentration (Chapter 3). The impeller mixed digesters exhibited better biogas production and treatment efficiency, followed by the CDDs and the unmixed digesters. The impeller mixed reactor operated between 3-7.3 \% TS concentration, produced 20\% more methane than the CDD and 37\% more methane than the unmixed digesters at steady state conditions. At applying double influent TS concentrations to achieve higher volumetric biogas production, all reactor configurations showed lower specific biogas production and higher VFA concentrations with a few exceptions. The VFA accumulation was more pronounced in the unstirred digesters and CDDs. Double TS concentration does not result in a better reactor performance (based on specific methane production and VFA concentrations) in the CDDs despite the higher volumetric biogas production rate. This indicates that the natural mixing induced by the biogas production did not yield sufficient mixing. The hydraulic variation or mixing cycle in the CDDs may not suffice for the treatment of cow manure at TS concentration of $10 \%$ and above (Chapter 3).

This was further confirmed by evaluation of the hydraulic characteristics of the laboratory digesters (Chapter 4). The Residence Time Distribution (RTD) technique was applied to three type of digesters, when operating at steady state at an input concentration of 7.5 and $15 \%$ TS. The mode of mixing strongly affected the effective or actual residence time $\left(t_{\mathrm{a}}\right)$ and directly influenced the percentage of dead zones. The CDDs had more dead volume than the impeller mixed reactors and less than the unmixed reactors.

A possible reason why higher volumetric gas production did not improve mixing and hence, digestion efficiency at high influent TS could be the behavior (rheological properties) of manure. It was shown by El-Mashad et al., (2004) and Karim et al., (2005) that shear rates increase with total solid concentration. Manure behaves like a non-Newtonian and real plastic material and the higher the TS concentration the higher the viscosity.

The mixing intensity in the impeller mixed reactors is higher than that in the CDDs because the spatial coverage of mixing and duration is more than the hydraulic mixing in the CDDs. The hydraulic variation in the CDDs occurred once a day in the lab scale study (Chapter 3). The hydraulic mixing in fully operational household digesters occurs three times a day, representing the frequency of cooking a day (Chapter 7). Biogas production was some higher in the mechanically stirred reactors than in the CDDs, but the difference in biogas production was not much when considering the vast difference in (calculated) energy utilization (Chapter 4). Both lab reactors were intermittently mixed but applying different types and duration of mixing. The duration between each cycle in the mechanically stirred reactor was 50 minutes while it lasted 24 hours for the CDD (Chapter 3). 


\subsection{The concept of mixing optimization and emission in Chinese dome digester}

Another approach was hypothesized to improve the mixing in the CDD, since higher volumetric gas production would not suffice. The pathway to the optimization of mixing in the CDD moreover provided an opportunity for the mitigation of emission of surplus biogas (Chapter 5).

Firstly, since methane, a strong greenhouse gas (GHG), is the main component of biogas, emissions from CDDs via leaks and deliberate release of surplus gas could threaten to cancel the benefits of CDDs in mitigating the release of GHG. The known sources of methane loss in the digester are the inlet and outlet pipes, cracks in tubing and walls of digesters, and intentional or deliberate release of biogas into the atmosphere whenever gas production is more than demand. The greatest source of the emission is the deliberate release of surplus biogas into the atmosphere (Prapaspongsa et al., 2010; Thien et al., 2012). The gas storage capacity of a Chinese dome digester is directly related to the position of the inlet and outlet pipes, and also to the displacement in the expansion chamber because the gas is stored above the slurry. This deliberate release of biogas occurs because little effort has been put into optimizing and improving the CDD. A relevant simulation model was developed and validated with experimental results for the location of inlet and outlet pipes and height and volume of the extension chamber. The model would help designers and operators of CDDs to plan biogas demand and storage and avoid leakages through the inlet and outlet pipes, and also prevent intentional release of biogas into the atmosphere (Chapter 5).

Secondly, it was hypothesized based on the results of Chapter 3 and 4 , that the inclusion of two baffles at two strategic locations could improve the hydraulic characteristics of the reactor and eventual the digestion efficiency at lower influent dilution. The first baffle, inserted at the upper side inside of the digester (Chapter 6 and 7) created intermittent mixing periods next to the mixing during gas use. This upper baffle divides the headspace of the reactor into two compartments $\mathrm{A}$ and B. The length of the upper baffle was estimated based of the model developed in Chapter 5, assuming that produced biogas is used or collected three times daily, representing the cooking times of a household. The lower baffle, was inserted to prevent short circuiting of incoming substrate based on result of the RTD analysis (Chapter 4) and to aid mixing around the inlet pipe and base of the digester during gas production and use. The length of the lower baffle, for a designed pilot reactor of 500 liters, was determined to be $20 \mathrm{~cm}$, a bit longer than the diameter of the inlet pipe.

The hydraulic characteristics of the digester with the inclusion of the two baffles was evaluated and compared with a digester without baffles, using computational fluid dynamic module in COMSOL Multiphysics in two dimensions (2D). The frequency (2 minutes) of this self-mixing process was experimentally determined using a pressure meter attached to the top of the 500 liter pilot reactor (Chapter 6). The self-mixing or self-agitation process, induced by the upper baffle, was not vigorous but sufficient to improve mixing in the digester as well as in the expansion chamber. This was so, because when gas flows from compartment $\mathrm{A}$ to compartment $\mathrm{B}$, a sudden but short back flow of slurry from the expansion chamber and inlet pipe into the main reactor was experienced. Velocity reached $0.6 \mathrm{~m} / \mathrm{s}$ at the upper part of the optimized reactor, the baffled section, whereas maximum velocity was lower at $0.3 \mathrm{~m} / \mathrm{s}$ in the same region in the blank pilot 
CDD. This suggests a positive impact of the upper baffle during the self-agitation process. The increase in velocity in this region was the result of the increase in the kinetic energy of the slurry during the movement below the baffle caused by the stored potential energy in the gas.

The optimized reactor possessed an energy storage process with a duration of 2 minutes, the period between two self-agitation cycles. The self-mixing cycle prevented scum formation and accumulation of suspended solids on the top of the slurry in the digester which resulted in a stable biogas production over time (Chapter 6). Scum and accumulated suspended solids, as observed in the upper part of the non-modified CDD, might hinder the release of gas from the liquid phase into the gas phase, resulting in a strongly varying gas production (Chapter 6). A CDD is a cylinder shape digester with a large surface area to allow for a large biogas storage. The large surface area will however aid the build-up of suspended solids or scum if mixing is limited (Tchobanoglous et al., 2003).

In addition, as illustrated in Chapter 7, the velocity vectors in the optimized digester show recirculation of reactor content that does not occur in the blank digester. The circulation can also be seen in the inlet pipe and the expansion chamber of the optimized digester as indicated by the vector direction. This means the reactor content is better mixed as compared to the blank digester because of the self-mixing process.

The evaluation of the hydraulic characteristics in both reactors revealed existence of large dead zones in the blank reactor which implied that mixing was limited in some regions compared to the optimized reactor and eventually led to the under performance of the blank digester when operated on a pilot scale for approximately a year. The improved hydraulic performance in the optimized reactor was associated with the inclusion of the two baffles at the top and bottom. The bottom baffle in the optimized digester helped in reducing circuiting of influent from the inlet to the outlet. It also aided the mixing of the incoming influent with the reactor content during feeding and biogas production.

Furthermore, since the reactors were operated at a high influent TS concentration of 15\%, a relatively high volumetric biogas production was achieved. In Chapter 3, higher volumetric biogas production at higher influent TS (15\%) concentration did not improve mixing in anaerobic digester mainly because of the rheological properties of the manure at higher TS concentration. But, in the case of optimized household digester, higher volumetric biogas production contributed to the overall performance of the reactor viz. improved mixing with the aid of the baffle in the gas phase. About $20 \%$ of the produced biogas in the digester goes to compartment A (Chapter 6) during the first biogas production. Since the compartment is closed continuous biogas release into the compartment will increase the agitating frequency and create short energy storage process as reported in this thesis (Chapter 6). 


\subsection{Performance of the Improved Chinese dome digester (ICDD)}

The improved Chinese dome digester with the two baffles was evaluated in a pilot study and compared with the conventional digester, in continuous operation at higher organic loading rates (ca. 15\% TS, corresponding to $2.6-4 \mathrm{~kg} \mathrm{VS} / \mathrm{m}^{3} / \mathrm{d}$ ) at HRTs of 40 and 30 days. Since the optimized digester is self-mixed with the aid of baffles, the overall performance of the digester did improve, despite the applied high loading rates (Chapter 7).

Volatile fatty acid (VFA) concentrations were relatively low for the whole period in the optimised reactor, while the blank reactor showed much higher VFA concentrations, up till $2.5 \mathrm{~g} / \mathrm{L}$. An average specific methane production of $0.32 \pm 0.05 \mathrm{~L} \mathrm{CH}_{4} / \mathrm{g}$ VS, an effluent VFA concentration of $0.7 \pm 0.2 \mathrm{~g} / \mathrm{L}$ and a VS reduction of $63 \pm 4 \%$, were achieved when operating the optimized reactor at an HRT of 40 days, at steady state. However, at a relatively long HRT of 40 days, the gas production and VFA concentration in the blank reactor fluctuated considerably in this same operational period, with an average specific methane production of $0.19 \pm 0.14 \mathrm{~L} \mathrm{CH}_{4} / \mathrm{g} \mathrm{VS}$, VFA concentration of $1 \pm 0.3 \mathrm{~g} / 1$ and a VS reduction of $54 \pm 17 \%$. Reduction in HRT, from 40 to 30 days, resulted in a decline of the gas production in both reactors. At an HRT of 30 days, the average specific methane production at steady state, in the optimized CDD, is $0.23 \pm 0.02 \mathrm{~L} \mathrm{CH}_{4} / \mathrm{g}$ VS, while the average VS reduction and VFA concentration are $60 \pm 9 \%$ and $0.5 \pm 0.3 \mathrm{~g} / \mathrm{L}$ respectively. As expected some lower gas production was recorded at an HRT of 30 days as compared to 40 days (Chapter 7).

The pilot reactors were not tested for mixing behavior using tracers, but the reactor performance results clearly show a better stability, higher gas yield and lower effluent VFA concentration for the modified system in comparison to the conventional CDD reactor.

\subsection{Implication of optimization on reactor size and cost}

The impact of the improved mixing in the optimized Chinese dome digester on size, cost and water reduction is evaluated in this section. The improved Chinese dome digester design parameters and output were compared with the optimal design of a conventional Chinese dome digester for rural Kenyan and Cameroonian households (Rupf et al., 2017). The main parameters are presented in Table 8.2. Both digesters presented, for Kenya and Cameroon (Rupf et al., 2017) have similar characteristics, except that, the Kenya's digester was operated at a lower OLR. The estimated size for the improved system in this study is based on the reduced HRT (30 days) and increased influent TS. The cost of the improved CDD, using 50\% of the Cameroonian reactor volume, was estimated, after consulting W. van Nes of SNV, to be $\$ 450$ plus $7.5 \%$ for the added baffles.

The two digesters (Kenya and Cameroon) were made from cheap stabilized interlocking soil blocks constructed by the organization SNV. From the table it is obvious that the improved mixing created by the addition of baffles made a positive impact on the problems highlighted in the review at the beginning of the thesis in Chapter 2- long hydraulic retention time, high water dilution, reactor size and capital cost of the system. 
Table 8.2 Optimal digester design for rural Kenya and Cameroonian households, and optimized digester in this thesis.

\begin{tabular}{|c|c|c|c|}
\hline Digester design details & $\begin{array}{l}\text { Kenya } \\
\text { (Rupf et al., 2017) }\end{array}$ & $\begin{array}{l}\text { Cameroon } \\
\text { (Rupf et al., 2017) }\end{array}$ & $\begin{array}{l}\text { Improved design } \\
\text { (This Thesis) }\end{array}$ \\
\hline Digester size $\left(\mathrm{m}^{3}\right)$ & 6 & 6 & 3 \\
\hline Material & $\begin{array}{l}\text { Stabilized soil block } \\
\text { digester }\end{array}$ & $\begin{array}{l}\text { Stabilized soil block } \\
\text { digester }\end{array}$ & $\begin{array}{l}\text { Stabilized soil block } \\
\text { digester }\end{array}$ \\
\hline Hydraulic retention time (d) & 62 & 49 & 30 \\
\hline Organic loading rate (OLR) (g VS/L/d) & 0.81 & 1.8 & 3.6 \\
\hline Estimated daily biogas production $\left(\mathrm{m}^{3}\right)$ & 1.48 & 1.43 & $3.9^{\mathrm{a}}$ \\
\hline Estimated capital cost (USD) & 684 & 628 & $484^{b}$ \\
\hline Estimated annual running cost (USD) & 2.85 & 2.75 & $2.85^{\mathrm{c}}$ \\
\hline Supplier contact details & $\begin{array}{l}\text { Uganda Domestic } \\
\text { Biogas Programme/ } \\
\text { SNV (the Netherlands } \\
\text { Development } \\
\text { Organization }\end{array}$ & $\begin{array}{l}\text { Uganda Domestic } \\
\text { Biogas Programme/ } \\
\text { SNV (the Netherlands } \\
\text { Development } \\
\text { Organization }\end{array}$ & \\
\hline
\end{tabular}

a based on volumetric biogas gas production in this thesis Chapter 6, Table 6.2

b based on exchange rate of 1 USD $=361$ Naira (May, 2018); capital cost estimated $450 \$+7.5 \%$ for baffles (pers. communication W. van Nes)

${ }^{\mathrm{c}}$ assumed same as Kenya

The size of the improved baffled CDD is half that of the Kenyan and Cameroonian digesters while the volumetric biogas production is far more. The major differences between the improved and conventional (Rupf et al., 2017) CDD are the higher OLR, higher biogas production (more than two-fold) and the improved mixing conditions. In addition, the requirement for water is reduced by half. The applied influent VS concentration for the Cameroonian is calculated to be $88.2 \mathrm{~g}$ VS/L, while it was 108g VS/L for the improved CDD. Assuming the manure was 25\% TS and $18 \%$ VS (73\% of the TS; chapter 6 of this thesis) before water dilution, 1.1 and 0.7 liter dilution water per liter manure is needed for the Cameroonian and improved CDD, respectively. The lower water requirement will impact positively on the application of the improved system because of limited water availability in arid regions.

Parameters of the three Chinese dome digesters presented in Table 8.2 confirm the hypothesis presented in the critical review in Chapter 2. In fact, the similar biogas production at a quite different organic loading rate, applied at the Kenyan and Cameroonian systems indicates that mixing is limited in the conventional CDD. The results of this thesis have shown that the established intermittent mixing cycle in the improved CDD considerably improves the conversion efficiency as compared to that in the conventional CDD. Indeed, in anaerobic digesters, mixing is important to (i) provide even temperature distribution and proper diffusion of metabolic intermediates (Gerardi, 2003); (ii) enable sufficient contacts and interaction between microorganism and nutrients (Ward et al., 2008); (iii) eventually improve hydrolysis (Halalsheh et al., 2011). 


\subsection{Recommendation for further research}

This study showed that the improved Chinese dome digester provided improved mixing, lower dilution requirement and eventually reduction in reactor volume. However, the improved reactor requires further rigorous field trials and should be evaluated for hydraulic characteristics using appropriate tracers.

Improved sanitation could be achieved in rural households by combining toilets with the improved CDD, but two issues may arise from this strategy. Firstly, reduction of flush water applied in such toilets is needed as low concentrated toilet water would dilute the animal manure to a too high extent. Secondly, the concentration of (human) pathogens in the effluent of the digester will increase as a result of the addition of toilet waste. Zeeman, (2012) recommends the application of hyper-thermophilic anaerobic digestion $\left(70^{\circ} \mathrm{C}\right)$ of concentrated toilet waste for combined biogas production and disinfection. Future research should focus on possible pathogen mitigation methods, applicable in rural developing areas.

Lastly, the anaerobic digestion model (ADM1) should be coupled with the CFD model for the improved CDD in future studies, to couple mixing and bio-conversions. Full 3D simulations of the digester should be studied to investigate other positions and sizes of the baffles for achieving further mixing optimization. 


\section{References}

An B.X., Preston T.R. (1999). Gas production from pig manure fed at different loading rates to polyethylene tubular biodigesters. Livest. Res. Rural Dev., 11(1). http://www.lrrd.org/lrrd11/1/an111.htm.

Avery L M, Yongabi K, Tumwesige V., Strachan N, Goude P. J. (2014). Potential for pathogen reduction in anaerobic digestion and biogas generation in Sub-Saharan Africa. Biomass and Bioenergy 70: 112-124.

Chen Y., Yang G., Sweeney S., Feng Y. (2010). Household biogas use in rural China: a study of opportunities and constraints. Renewable and Sustainable Energy Reviews 14 (1):545-9.

Deublein D, Steinhauser A. (2008). Biogas from waste and renewable resources. Weinheim, Germany: Wiley-VCH Verlag $\mathrm{GmbH} \& \mathrm{Co}$ KGaA;

El-Mashad H. M., van Loon W. K-P., Zeeman G., Bot G. P. A, Lettinga G. (2004). Design of A Solar Thermophilic Anaerobic Reactor for Small Farms. Biosystems Engineering 87 (3): 345-353.

Ferrer I., Garfí, M., Uggetti, E., Ferrer-Martí L., Calderon A., Velo, E. (2011). Biogas production in low-cost household digesters at the Peruvian Andes. Biomass and Bioenergy, 35:1668-1674.

Ferrer I., Cadena E., Perez B. Garfi M. (2013). Technical, economic and environmental assessment of household biogas digesters in developing countries. Proceedings of 13th World Congress on Anaerobic Digestion, Sandiago de Compostela, Spain.

Fulford D. (1988). Running a Biogas Programme: A Handbook. London, Intermediate Technology Publications.

Garfí M., Gelman, P., Comas J., Carrasco W., Ferrer I. (2012). Agricultural reuse of the digestate from low-cost tubular digesters in rural Andean communities. Waste Manag. (Oxf.) 31:2584-2589.

Gerardi M., (2003). The Microbiology of Anaerobic Digesters. John Wiley and Sons, Inc., Pennsylvania.

Ghimire P. C. (2013). SNV Supported domestic biogas programmes in Asia and Africa. Renewable Energy 49: 90-94.

Gunnerson C., G. and D. Stuckey C. (1986). Anaerobic Digestion - Principles and Practices for Biogas systems. Washington DC., The World Bank \& UNDP: http://documents.worldbank.org/curated/en/980401468740176249/pdf/multipage.pdf.

Halalsheh M., Kassab G., Yazajeen H., Qumsieh S., Field J. (2011). Effect of increasing the surface area of primary sludge on anaerobic digestion at low temperature. Bioresour. Technol. 102:748-752.

Kalia A. K. (1988). Development and evaluation of a fixed dome plug flow anaerobic digester. Biomass, 16: 225-235.

Karim K., Hoffmann R., Klasson K. T., Al-Dahhan M. H. (2005). Anaerobic digestion of animal waste: effect of mode of mixing. Water Research 39:3597-3606.

Mandelli S., Barbieri J., Mattarolo L., Colombo E. (2014). Sustainable energy in Africa: A comprehensive data and policies review. Renewable and sustainable energy reviews 37:256-286.

Lindmark J., Thorin E., Fdhila R. B., Dahlquist E. (2014). Effect of mixing on the result of anaerobic digestion: Review. Renewable and Sustainable Energy Review (40):1030 -1047.

Okello C., Pindozzi S., Faugno S., Boccia L. (2013). Development of bioenergy technologies in Uganda: A review of progress. Renewable and Sustainable Energy Reviews, 18: 55-63.

Prapaspongsa T., Christensen P., Schmidt J. H, Thrane M. (2010). Life cycle assessment of comprehensive pig manure management incorporating integrated technology systems. J Clean Prod.18:1413-22.

Qi W-K, Toshimasa H., Li Yu-You. (2013). Hydraulic Characteristics of an innovative self-agitation anaerobic baffled reactor (SA-ABR). Bioreource Tech 136: 94-101.

Rupf G. V., Arabzadeh B. P., De Boer K., McHenry M. P., (2017). Development of an optimal biogas system design model for Sub-saharan Africa with case studies from Kenya and Cameroon, Renewable Energy 109:586 -601.

Tamkin A., Martin J., CastanoJ., Ciotola R., Rosenblum J., Bisesi M. (2014). Impact of organic loading rates on the $\mathrm{p}$ erformance of variable temperature biodigesters. Ecological Engineering. 78; 87-94.

Tchobanoglous G., Burton F.L., Stensel H.D. (2003). Wastewater Engineering: Treatment and Reuse (4th ed.). Metcalf and Eddy Inc, New York, NY: McGraw-Hill.

Thien Thu CT., Cuong PH, Hang L.T., Chao NV, Anh L.X., Trach N.X . (2012). Manure management practices on biogas and non-biogas pig farms in developing countries - using livestock farms in Vietnam as an example. J Clean Prod; 27:64-71.

Ward A.J., Hobbs P.J., Holliman P.J., Jones D.L. (2008). Optimisation of the anaerobic digestion of agricultural resources. Bioresour. Technol. 99: 7928-7940.

Zeeman G (2012). New Sanitation; Bridging Cities and Agriculture. Inaugural lecture upon taking up the post of Personal Professor of New Sanitation at Wageningen University on 13 September 2012. Wageningen University. 



\section{Summary}

The growing demand for energy because of population growth, lack of clean energy and inadequate availability of natural resources have led to the growing demand of anaerobic digestion technologies in rural areas of many developing countries. Biogas a renewable, clean and efficient source of alternative energy which can be used as a substitute for fuels such as firewood, charcoal and cattle dung, used by rural dwellers. The domestic digester is an example of an anaerobic digester usually applied in a single decentralized system mostly in rural areas of developing countries and can serve as energy solution to meet their cooking needs. Among all household digesters, the Chinese dome digester (CDD) is the most popular and most implemented reactor because of its reliability, requirement of low maintenance and long lifespan (Chapter 2).

Mixing in the Chinese dome digester (CDD) depends on the change of slurry level in the digester and extension chamber during gas use and could be regarded as intermittent natural mixing. Mixing is an important process in anaerobic digestion for establishing contact between microorganisms and feed, for homogenization of temperature throughout the digester, and preventing settling and floating layers. However, mixing is limited in the CDD and are therefore operated at long hydraulic retention times (> 40 days) and low influent total solid (TS) concentrations $(\leq 7 \%)$ when compared to forced mixed reactors (intermittently or continuously), leading to a large reactor volume and higher cost (Chapter 2). In this thesis, mixing was optimized in the Chinese dome digester without the inclusion of moveable parts with lower water dilutions (high influent TS, 15\%) at reduced hydraulic retention times 40 and 30 days.

First, Chapter 3 examined the effect of higher volumetric gas production on mixing during the anaerobic digestion of cow manure in Chinese dome digesters (CDD) at ambient temperature $\left(27-32^{\circ} \mathrm{C}\right)$ in comparison with mechanically mixed and unmixed digesters at laboratory scale. Six digesters (two of each type) were operated at two different influent total solids (TS) concentration ranges, viz. $3-7.3 \%$ and $6-15 \%$, at a hydraulic retention time (HRT) of 30 days for 319 days. The impeller mixed reactors were mixed at $55 \mathrm{rpm}, 10 \mathrm{mins} /$ hour, the unmixed digesters were not mixed and the Chinese dome digesters were mixed once a day releasing the build-up gas pressure. Significant differences were observed among the three types of digesters at both influent TS concentration applied in this study. The impeller mixed digesters exhibited better biogas production and treatment efficiency, followed by the Chinese dome digesters (hydraulic mixed) and the unmixed digesters. The stirred reactor operated between 3-7.3\% TS concentration produced 20\% more methane than the Chinese dome and 37\% more methane than the unstirred digesters respectively at steady state conditions. At applying double influent TS concentrations, the reactors showed lower specific biogas production and higher VFA concentrations with few exceptions. The VFA accumulation was more pronounced in the unstirred digesters and Chinese dome digesters. It could also be seen from the results that double TS concentration did not produce better reactor performance (based on specific methane production and VFA concentrations) in the CDDs despite higher volumetric biogas production rate. The natural mixing induced by biogas production did not yield sufficient mixing. In addition, the hydraulic variation or mixing cycle in Chinese dome digesters may not suffice for the treatment of cow manure at TS concentration of $10 \%$ and above. 
In Chapter 4, the Residence Time Distribution (RTD) technique was applied to evaluate mixing of liquid and solid phases in laboratory scale Chinese dome digesters. Appropriate tracers were studied over a theoretical hydraulic retention time (HRT) of 30 days in the three different digesters (impeller mixed, unmixed and CDDs) each at influent concentration of ca. 7.5 and $15 \%$ TS concentrations. The impeller mixed reactors had the lowest dead zones followed by the CDDS and lastly the unmixed. The reactor performance in terms of methane production was consistent with the evaluation of the RTD results. The reactor type and mixing modes had direct impact on reactor hydrodynamic and eventually reactor performance. At both TS concentrations, the hydraulic reactors had considerable dead zones because the mixing viz. hydraulic variation is inadequate. The CDD (hydraulic) digester therefore needed optimization for improved hydraulic variation to achieve optimized mixing cycles without use of moveable parts or external energy.

A model for prevention of biogas emission from inlet and outlet of the Chinese dome digester was developed and validated with pilot experimental data in Chapter 5. The model predicted well the reactor pressure $\left(\mathrm{P}_{\mathrm{G}}\right)$ and the slurry displacement in the expansion chamber, inlet pipe $(\mathrm{h})$ and inside the digester $\left(\mathrm{h}_{\mathrm{G}}\right)$. A better decision on the location and heights of the outlet, expansion chamber and inlet pipes can be made using the approximation model and will therefore prevent emissions during the zero biogas consumption periods.

In chapter 6 the optimized CDD with self-agitating mechanism with the inclusion of two baffles was investigated at a pilot scale (digester volume $=500 \mathrm{~L}$ ) and compared with the conventional CDD (as blank) at 15\% influent TS concentration at two HRTs (30 and 40 days). The reactors were operated at ambient temperature, $27-33^{\circ} \mathrm{C}$. The optimized digester showed better digestion efficiency and process stability, while the blank was unstable throughout the study period. The optimized Chinese dome digester has a self-mixing or agitation cycle of two minutes using the produced gas without a moving part. The optimized digester showed superior digestion treatment efficiency, and more stable in terms of VFA (mainly acetate) concentrations than the conventional reactor. The improved Chinese dome digester with baffles showed better performance than conventional design and the reactor can be operated at high influent TS (15\%) concentration. Therefore, this implies a smaller reactor volume could be achieved at high loading rate at reduced HRT (< 40 days), and eventually reduction in reactor cost.

Lastly, a multiphase computational fluid dynamics (CFD) was applied to evaluate the improved mixing in the Chinese dome digester at a pilot scale in Chapter 7. The digesters studied in Chapter 6, are one conventional CDD and the other, improved (baffled) CDD. The optimized digester under goes self-agitating cycles created by the pressure variation from the produced biogas with the aid of a baffle, whereas the blank does not self-agitate. The length of the baffle in the optimized digester was estimated using the model developed in Chapter 5.

The CFD models were validated using the pressure and biogas experimental data from the pilot study of same digesters. The phases and flow fields were analyzed in relation to mixing and then digestion performance in both reactors. The necessary intermittent mixing performed by the produced gas in the optimized digester achieved without moving parts, improved mixing and the hydraulic characteristics of the optimized digester. The lift force created when the produced 
biogas flow below the baffle from the compartment $\mathrm{A}$ to $\mathrm{B}$ and the change of flow direction of the slurry in the digester, inlet pipe and expansion chamber resulted in improved mixing of the of reactor content sufficient to improve digestion performance. 



\section{Acknowledgements}

The journey to achieving a $\mathrm{PhD}$ degree at Wageningen University has been quite challenging but I am full of joy to grace its end. The successful completion of the programme would not have been possible without the input and support of so many people.

I thank the Dutch government immensely for providing the funding for my $\mathrm{PhD}$ programme through the Netherlands Fellowship Programme (NFP). This great privilege has helped me to achieve my academic dream.

Grietje Zeeman, my promotor, is the main pillar of the project and I want to appreciate her for giving me the opportunity to be her $\mathrm{PhD}$ student. With her, the process was thorough but rewarding. I am really grateful to her for the unlimited accesses and wise counsels.

I equally want to appreciate Harry Bruning for accepting to be part of the project and to be my co-supervisor. He brought balance into the project and his contributions were very critical. I am thankful for your time and advice.

I appreciate Tim Hendrickx for his contribution and support at the beginning of the project as my co-supervisor. My sincere gratitude goes to Carlo Gualtieri (Prof. at Civil, Architectural and Environmental Engineering department, University of Napoli Federico II, Naples, Italy), for contributing greatly to the modelling part of the project. Thank you for coaching me on computational fluids dynamics (CFD).

Special thanks to all the analytical staff of sub-Department Environmental Technology for providing the technical support for setting up the laboratory in Nigeria. I am grateful to Katja for tutoring and helping with the methods design. I appreciate Hans, Livio, Vinnie, Isle, Pieter for assisting with the setting up the Gas chromatography system. I appreciate Jean and Bert for their support with ammonium nitrogen measurements and providing technical inputs respectively.

Thank you Huub for the encouragement and administrative support you offered throughout my programme. Liesbeth, Gea, Marjolein and others were awesome at arranging all administrative activities and finance. Thank you so much for making life easy. Thank you Shokouch for being so helpful with my settling down in Wageningen and showing me around. Delaram and James, I thank you for giving me aids with the MATLAB codes when it became challenging. I appreciate Yvonne and Elackiya for their kind support towards putting my thesis together and words of encouragements. I am so grateful to all my office mates and colleagues at ETE and LeAF.

I acknowledge the support of the management and staff of Centre for Energy Research and Development (CERD), Obafemi Awolowo University throughout the programme. I am grateful to all the CERD directors from 2013 till date viz. Prof. A. Osinkolu, Prof. D. A Pelemo and Prof.E. I. Obiajuwan. I want to specially appreciate Prof. J-FK Akinbami, HOD of Energy Management and Technology department, CERD, for his enormous support and contribution throughout my $\mathrm{PhD}$ programme. Thank you Atilade, Seun, Seun (Sleem), Efosa and all the interns that worked so hard to keep the reactors and Biochemical Engineering laboratory running in CERD. The technical support provided by Mr. Agbaje and Mr. Siji (CERD) is highly appreciated. 
At CERD, I extend my sincere appreciation to the drivers who moved my equipment and other materials to the laboratory, especially the transportation of manure from the Agricultural farm; the cleaners who assisted with cleaning of the laboratory; the gardeners who cleared the site for the pilot reactors and all other colleagues at CERD I cannot mention.

I want to specially appreciate my love and wife, Olufunmilayo, for the love, commitment and moral support. Thank you for proofreading my articles. I sincerely appreciate your words of encouragement and constant prayers.

I really appreciate my parents, Mr. and Mrs. Jegede for their undying love and support. Thank you for investing in me. I promise to always make you proud parents. I am grateful to my siblings: Yetunde \& Babatunde Odedairo and Odunayo \& Dolapo Jegede for their encouragements and moral support. I also acknowledge the support of my uncles, aunts and cousins.

Special gratitude goes to my in-laws: Mummy Ajayi, Dele Ajayi, Sola \& Damilola Ajayi, Segun \& Tina Ajayi, Tolu and Tunji Fulani, and Amarachi Wosu for their prayers and encouragements. I appreciate my friends for their unflinching support throughout the programme: Babatunde Showemimo, Lekan Abiola, Olawale Abiye, Aremo Bolaji, Elackiya and many others cannot list.

I thank my paranymphs, Bingman and Esther, for their support during the preparation of the defence and graduation ceremony.

\section{OPE NI FO OLUWA!!}




\section{SENSE Diploma}

\section{SENSE}

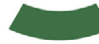

Netherlands Research School for the

Socio-Economic and Natural Sciences of the Environment

\section{I P L O M A}

For specialised PhD training

The Netherlands Research School for the Socio-Economic and Natural Sciences of the Environment (SENSE) declares that

\section{Abiodun Jegede}

born on 29 November 1980 in Lagos, Nigeria

has successfully fulfilled all requirements of the Educational Programme of SENSE.

Wageningen, 15 October 2018

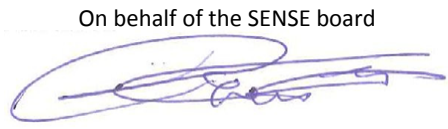

Prof. dr. Huub Rijnaarts

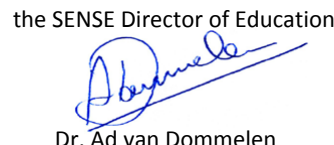

Dr. Ad van Dommelen

The SENSE Research School has been accredited by the Royal Netherlands Academy of Arts and Sciences (KNAW)

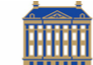

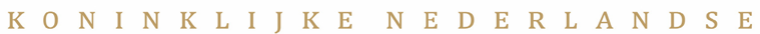

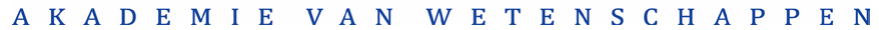




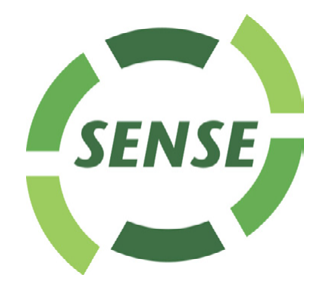

The SENSE Research School declares that Abiodun Jegede has successfully fulfilled all requirements of the Educational PhD Programme of SENSE with a work load of $41.1 \mathrm{EC}$, including the following activities:

\section{$\underline{\text { SENSE PhD Courses }}$}

- Environmental research in context (2013)

- Research in context activity: 'Contributing to short documentary on $\mathrm{PhD}$ research and communicating accessible synopsis of documentary, aired a.o. at Channels TV"

\section{Other PhD and Advanced MSc Courses}

- School on Hands-on Research in complex systems, International Centre for Theoretical Physics (ICTP), Trieste, Italy (2013)

- Instrumentation, modelling and control in Anaerobic Digesters (AD), University of Santiago de Compostela, Spain (2013)

- Scientific writing, Wageningen Graduate Schools, The Netherlands (2016)

- Advanced course in Environmental Biotechnology, Biotech Delft, Technical University Delft, The Netherlands (2016)

\section{Management and Didactic Skills Training}

- Established the Biochemical Laboratory at the Centre for Energy Research and Development, Obafemi Awolowo University, Ile-ife, Nigeria (2014)

- Managing the Biochemical Laboratory at the Centre for Energy Research and Development, Obafemi Awolowo University, Ile-ife, Nigeria (2014-2017)

- Supervised $>30$ BSc internship students

\section{Oral Presentations}

- Performance of an innovative pressure-mixed Chinese dome digester. The $15^{\text {th }}$ International Water Association (IWA) International conference on Anaerobic Digestion, 17-20 October 2017, Beijing, China

- Optimization of the Chinese dome digester for developing countries. The 15th IWA Leading Edge Conference on Water and Wastewater Technologies, 27-31 May 2018 Nanjing, China

\section{SENSE Coordinator PhD Education}

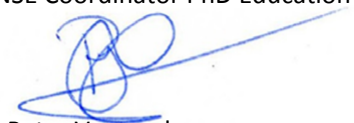

Dr. Peter Vermeulen 

This research was funded by the grant from the Netherlands Fellowship programme - NUFFIC (Grant number \#CF8770, NFP-PhD.12/426).

Financial support from sub-Department, Environmental Technology, Wageningen University for printing the thesis and transportation of analytical equipment to Nigeria is gratefully acknowledged.

The provision of space for the Biochemical Engineering Laboratory and pilot reactors by Centre for Energy Research and Development (CERD), Obafemi Awolowo University, Ile-ife, Nigeria is also greatly appreciated and acknowledged.

Cover design \& Layout : AgileColor | AgileColor.com

Printing: GVO drukkers \& vormgevers B.V. | gvo.nl 


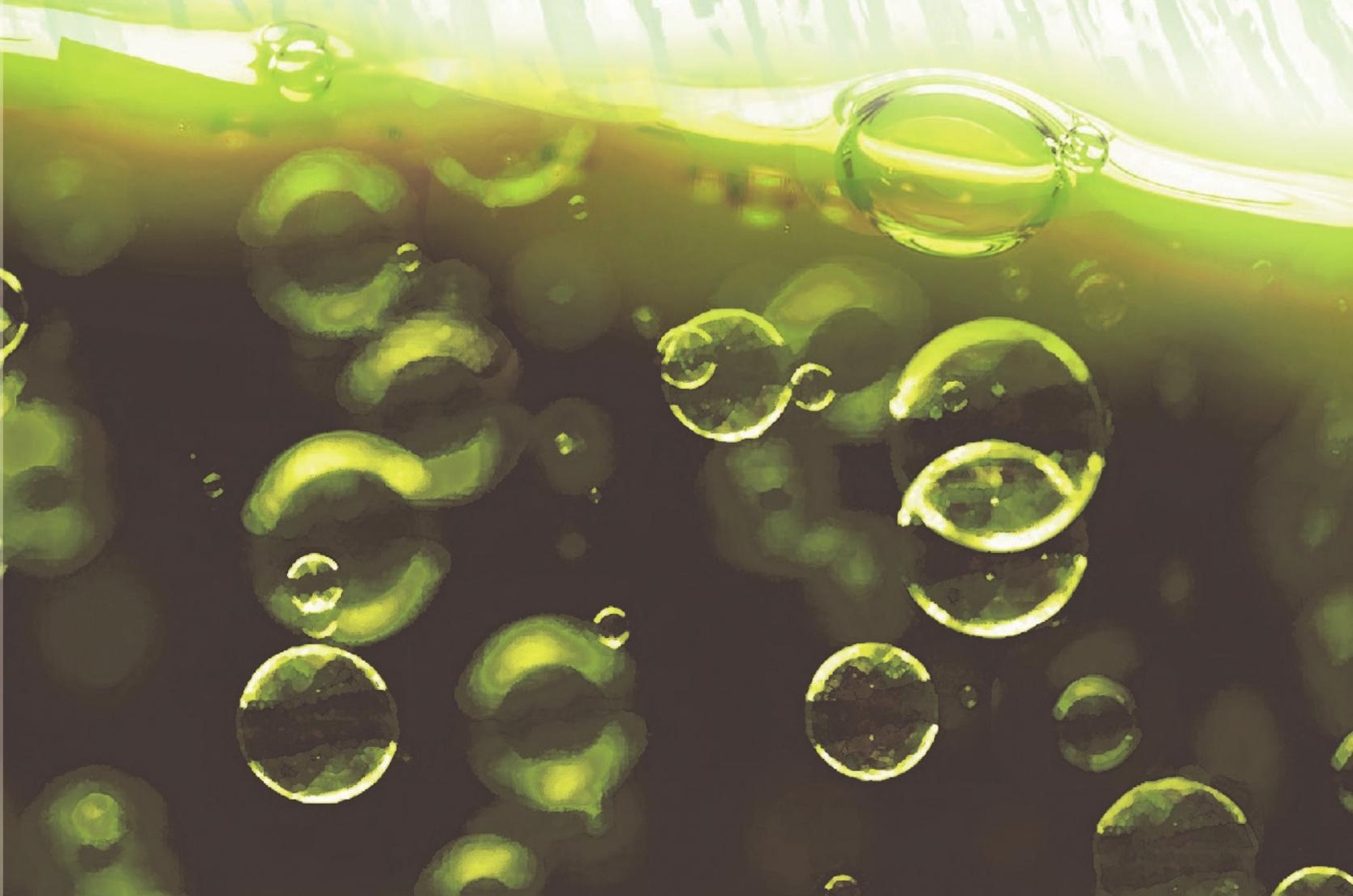

